WSRC-RP.92.222

\title{
EXAMINATION OF CADMIUM SAFETY ROD THERMAL TEST SPECIMENS AND FAILURE MECHANISM EVALUATION (U)
}

by

J. K. Thomas, H. B. Peacock, and N. E. Iyer

Westinghouse Savannah River Company

Savannah River Site

Aiken, South Carolina 29808

This report was prepared in connection with work done under Contract No. DE-AC09-89SR18035 with the U.S. Department of Energy. By acceptance of this report, the publisher and/or recipient acknowledges the U.S. Government's right to retain a nonexclusive, royalty-free license in and to any copyright covering this report, along with the right to reproduce and to authorize others to reproduce all or part of the copyrighted report. 


\section{NRTSC}

NUCLEAR REACTOR TECHNOLOGY

AND SCIENTIFIC COMPUTATIONS

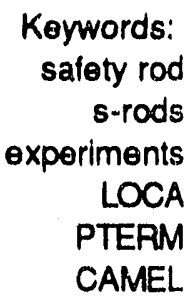

Retention - Permanent

\section{EXAMINATION OF CADMIUM SAFETY ROD THERMAL TEST SPECIMENS AND FAILURE MECHANISM EVALUATION (U)}

ISSUED: January 1992

$$
\frac{\text { G.C. Kae } 3-19-92}{\text { Derivative Classifier }}
$$

SRL SAVANNAH RIVER LABORATORY, AIKEN, SC 29808 Westinghouse Savannah River Company Prepared for the U. S. Department of Energy under Contract DE-AC09.76SR00001 Presently under Contract DE-AC09-88SR18035 
PROJECT: REACTOR COMPONENTS RESPONSE TO GAMMA HEATING ACCIDENT

DOCUMENT：WSRC-RP-92-222

TITLE: EXAMINATION OF CADMIUM SAFETY ROD THERMAL TEST SPECIMENS AND FAILURE MECHANISM EVALUATION (U)

TASK: $\quad 91-001-1$

APPROVALS

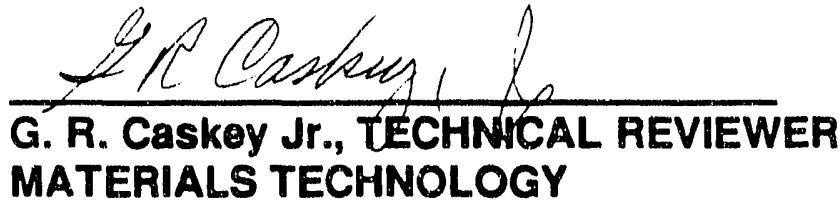
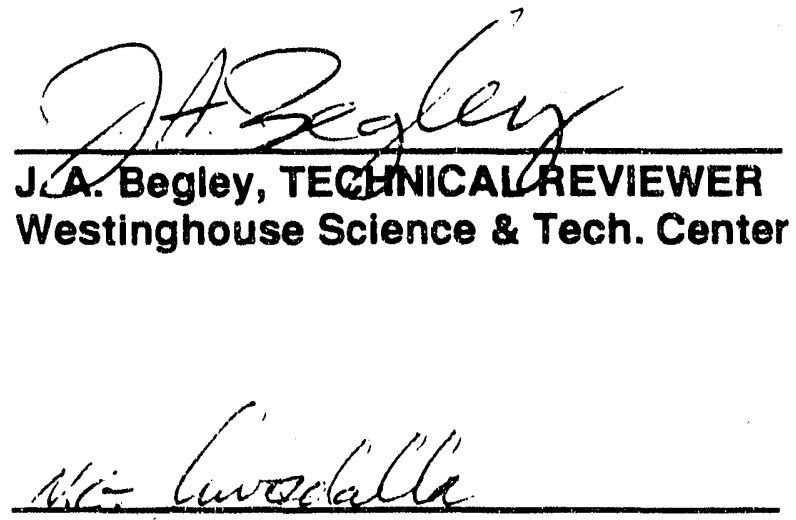

N. G. Awadalla, MANAGER MATERIALS TECHNOLOGY
DATE: $3 / 20 / 92$ DATE: $2 / 24 / 92$ DATE: $3 / 26 / 92$ . DATE: $3 / 20 / 92$ 


\section{EXECUTIVE SUMMARY}

The reactor safety rods may be subjected to high temperatures due to gamma heating after the core coolant level has dropped during the ECS phase of a hypothetical LOCA event. Accordingly, an experimental cadmium safety rod testing subtask was established as part of a task to address the response of reactor core components to this accident. Companion reports describe the experiments and a structural evaluation (finite element analysis) of the safety rod. This report deals primarily with the examination of the test specimens, evaluation of possible failure mechanisms, and confirmatory separate effects experiments.

Based on the data presented in this report, it is concluded that the failures observed in the cadmium safety rod thermal tests which occurred at low temperature $\left(\mathrm{T}<600^{\circ} \mathrm{C}\right)$ with slow thermal I $\lrcorner$ mp rates (slow cladding strain rates) resulted from localized dissolution of the stainless steel cladding by the cadmium/aluminum solution and subsequent ductility exhaustion and rupture. The slow thermal ramp rate is believed to be the root cause for the failures; specifically, the slow ramp rate led to localized cladding shear deformation which ruptured the protective oxide film on the cladding inner surface and allowed dissolution to initiate. It is recognized that differences among the safety rods from which the specimens were taken may have also played a role. The test results and proposed failure mechanism support the conclusion that the rods would not fail below $500^{\circ} \mathrm{C}$ even at slow ramp rates. The safety rod thermal test specimen failures which occurred at high temperature $(\mathrm{T}>$ $800^{\circ} \mathrm{C}$ ) with fast thermal ramp rates are concluded to be mechanical in nature without significant environmental degradation.

Based on the results of these tests, tasks were initiated to design and manufacture $\mathrm{B}_{4} \mathrm{C}$ safety rods to replace the cadmium safety rods (SRL Tasks 91-003-1 and 91-047-1). The $\mathrm{B}_{4} \mathrm{C}$ safety rods have been manufactured at this time and it is currently planned to charge them to the reactor in the near future. 


\section{TABLE OF CONTENTS}

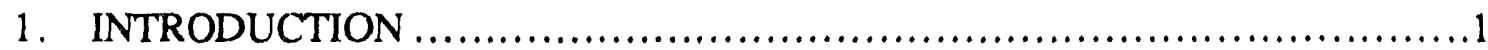

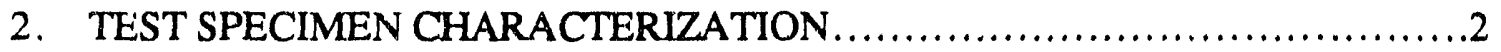

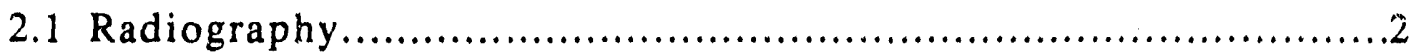

2.2 Dimensional Characterization ...............................................

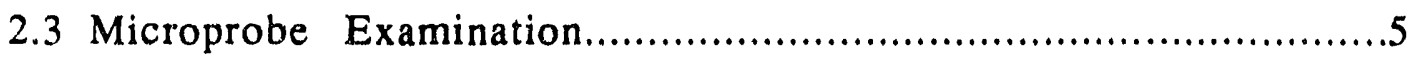

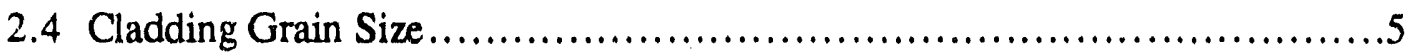

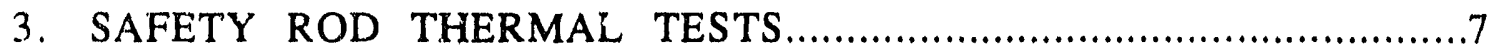

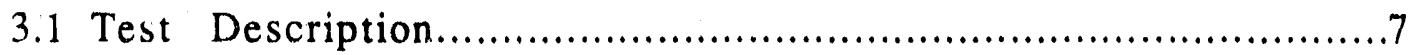

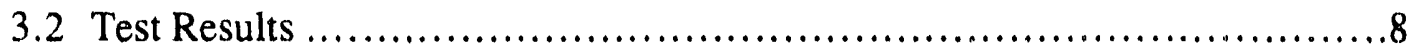

4. POST-TEST NON DESTRUCTIVE EXAMINATION...............................10

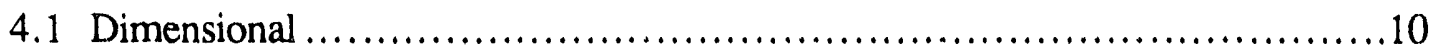

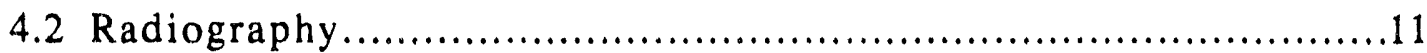

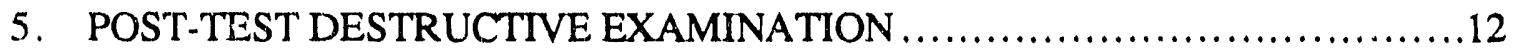

5.1 Optical and Scanning Electron Microscopy........................................12

5.1.1 First Failed Specimen (no.9) .................................12

5.1 .2 Unfailed Specimen (no. 10) .................................. 18

5.1 .3 Other Failed Specimens (nos. $11 \& 12$ ) ...........................20

5.2 Microprobe Examination of First Failed Specimen (no.9) .........................23

6. CANDIDATE FAILURE MECHANISMS ...............................26

6.1 Pure Mechanical (Ductility Exhaustion, Creep Rupture).............................26

6.1.1 Effect of Temperature and Strain Rate for Annealed SS304.............28

6.1.2 Effect of Cold Work on SS304 Ductility ............................29

6.1.3 Effect of Multiaxial Loading................................................30

6.1.4 Predicted Failure Strains and Comparison with Experimental Data .....31

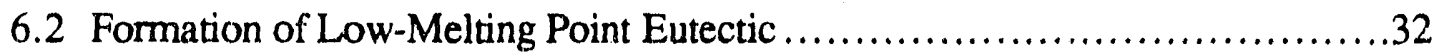

6.2.1 Phase Diagrams..................................................

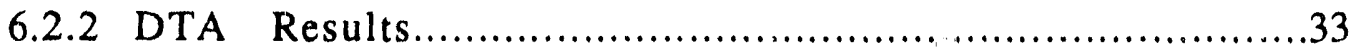

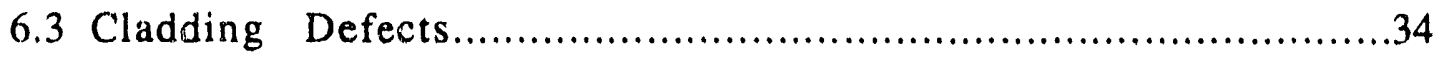

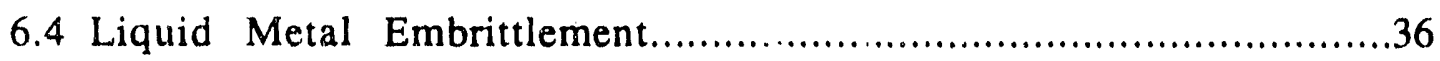

6.4.1 Characteristics of "Classic" LME .......................................36

6.4.2 Relevant LME Test Variables ......................................38

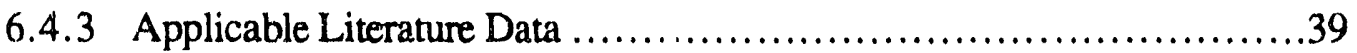

6.4.4 Evidence from Destructive Examinations .............................40

6.4 .5 U-Bend Tests ...............................................41 
6.4.6 Tensile Tests ...............................................4 42

6.4 .7 Conclusions ...................................................43

6.5 Liquid Metal Dissolution..............................................43

6.5.1 Expected Behavior Based on Phase Diagrams and Literature Data .....43

6.5.2 Evidence From Destructive Examinations ..........................

6.5.3 Structural Analysis .............................................46

6.5 .4 Conclusions ................................................46

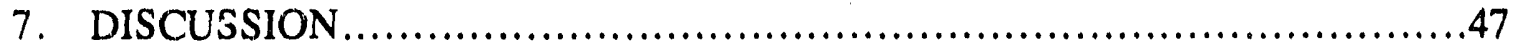

8. CONCL.USIONS .........................................................53

9. ACKNOWLEDGEMIENTS ................................................ 55

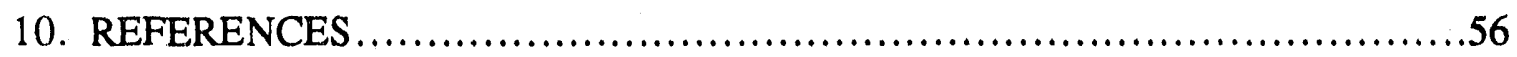




\section{LIST OF TABLES}

2-1 Cladding Thickness and Gap Size Based on Radiographs ........................61

2-2 Cladding Thickness Measurements Based on Photomicrographs .................62

2-3 Gap Size Measurements Based on Photomicrographs..........................62

2-4 Composition Data From Electron Microprobe Examination..........................63

2-5 Safety Rod Cladding Grain Size Data........................................63

3-1 Summary of Safety Rod Thermal Test Conditions and Results ..................64

4-1 Measured Hoop Strains for Unfailed Specimens................................65

6-1 Summary of Predicted Safety Rod Cladding Hoop Strain at Failure..................65

6-2 Tensile Test Conditions and Results ....................................66 


\section{LIST OF FIGURES}

2-1 Safety Rod Cross Section...................................................67

2-2 Safety Rod Cladding Thickness Circumferential Variation .......................68

2-3a SEM Micrograph of Safety Rod 1 Characterization Specimen (BSE, 15x).......69

$2-3 \mathrm{~b}$ SEM Micrograph of Safety Rod 1 Characterization Specimen (BSE, 500x) .....69

2-4a Optical Micrograph of Safety Rod 1 Characterization Specimen (50x)..............70

2-4b Optical Micrograph of Safety Rod 1 Characterization Specimen (50x)..............70

3-1 Experimental Apparatus....................................................71

3-2 Histogram of Test Data........................................................

3-3 Simplified Schematic of Thermal Histories for the "Slow Ramp" Tests ..........73

3-4 Simplified Schematic of Thermal Histories for the "Fast Ramp" Tests ............73

3-5 Thermal History for Typical "Slow Ramp" Test ..................................74

3-6 Thermal History for Typical "Fast Ramp" Test ................................75

3-7a Specimen 9, Just Prior to Rupture ...................................... 76

3-7b Specimen 9, 1 Frame (1/30 sec.) After Rupture ..............................76

3-7c Specimen 9, 2 Frames (2/30 sec.) After Rupture ...............................77

3-7d Specimen 9, 3 Frames (3/30 sec.) After Rupture ...........................77

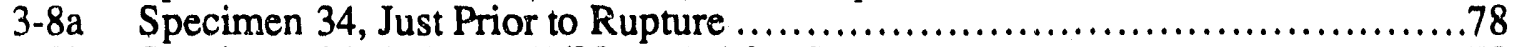

3-8b Specimen 34, 1 Frame (1/30 sec.) After Rupture.............................78

3-9a Specimen 43, Just Prior to Rupture ........................................79

3-9b Specimen 43, 1 Frame (1/30 sec.) After Rupture...............................79

4-1 Hoop Strain Data for Unfailed Specimens and Model Predictions...................80

4-2a Hoop Strains for Specimens from Rods 1 and 4 "Fast Ramped" to $600^{\circ} \mathrm{C} \ldots \ldots . .81$

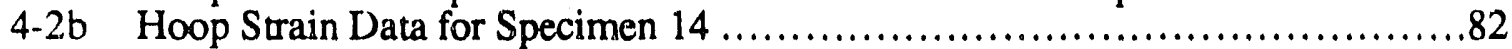

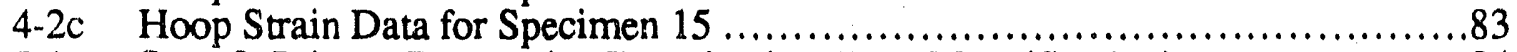

5-1a Spec.9, Prior to Destructive Examination (Low Magnification) ...................84

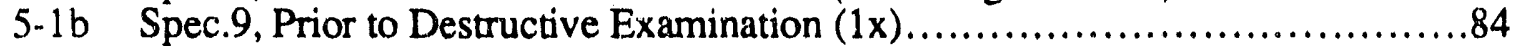

5-1c Spec.9, Prior to Destructive Examination (High Magnification)................85

5-2 Spec.9, After Transverse Sectioning ......................................85

5-3 Spec.9, Inner Surface of Cladding and Outer Surface of Aluminum Core ........86

$5-4 a \quad$ Spec.9, Montage of Outer Surface Near Fracture (BSE) . ......................87

5-4b Spec.9, Montage of Outer Surface Near Fracture (SE) .......................88

5-5a Spec.9, Outside of Cladding Surface Near Top of Fracture (BSE, 15.1x) .......89

$5-5 \mathrm{~b}$ Spec.9, Oxide Layer on Outside of Cladding Surface (BSE, 157x)................89

$5-5 \mathrm{c}$ Spec.9, High-Magnification Micrograph of Oxide Layer (BSE, 750x) ..........90

5-6a Spec.9, EDS Spectrum for Spot "C" on Figure 5-5c.................................90

5-6b Spec.9, EDS Spectrum for Spot "D" on Figure 5-5c................................

5-7a Spec.9, Cladding Inner Surface Near Top of Fracture (BSE, 11x) .............91

5-7b Spec.9, Cladding Inner Surface Near Top of Fracture (SE, 55x) . ............92

5-7c Spec.9, Cladding Inner Surface Near Bottom of Fracture (SE, 219x) ..........92

5-8 Sectioning and Examination Schematic for Specimen 9............................93

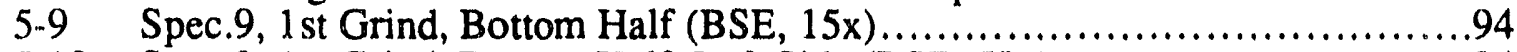

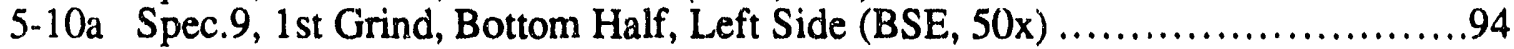

5-10b Spec.9, 1st Grind, Bottom Half, Right Side (BSE, 39.3x) .................95

5-1 1a Spec.9, 1 st Grind, Bottom Half, Montage of Left Side (BSE) ................96

5-11b Spec.9, 1st Grind, Bottom Half, Montage of Right Side (BSE)...................97

5-11c Spec.9, 1st Grind, Bottom Half, Montage of Cladding Inner Surface to the

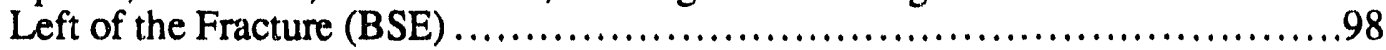

5-11d Spec.9, 1st Grind, Bottom Half, Montage of Cladding Inner Surface to the Right of the Fracture (BSE) ...........................................99

5-12 Spec.9, 1 st Grind, Bottom Half, Left Side Near Cladding Midpoint (BSE,

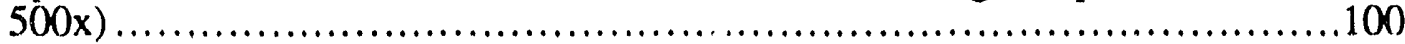


5-13a Spec.9, 1 st Grind, Bottom Half, EDS Spectrum for Spot "A" on Figure 5-

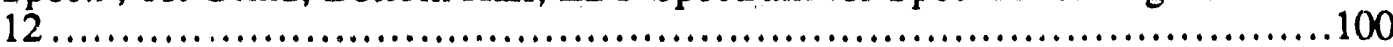

5-13b Spec.9, 1st Grind, Bottom Half, EDS Spectrum for Spot "B" on Figure 5-

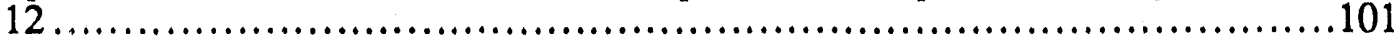

5-13c Spec.9, 1st Grind, Bottom Half, EDS Spectrum for Spot "C" on Figure 5-

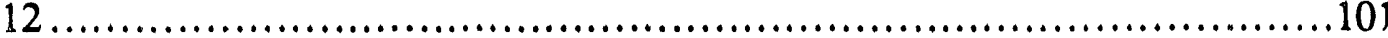

5-14 Spec.9, 1st Grini, Bottom Half, Right Side on Cladding Outer Surface (BSE, 1000x) ........................................................ 102

5-15 Spec.9, 1st Grind, Bottom Half, Right Side on Cladding Inner Surface (BSE, 296x) ......................................................102

5-16 Spec.9, 2nd Grind, Bottom Half, Low-Magnification SEM Micrograph

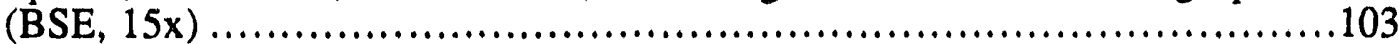

5-17a Spec.9, 2nd Grind, Bottom Half, Left Side (BSE, 50x) ....................103

5-17b Spec.9, 2nd Grind, Bottom Half, Right Side (BSE, 75x)..........................104

5-18 Spec.9. 2nd Grind, Bottom Half, Montage of Right Side (BSE)...................105

5-19a Spec.9, 2nd Grind, Bottom Half, Left Side at Cladding O.D. (BSE, 200x).....106

5-19b Spec.9, 2nd Grind, Bottom Half, Left Side Near Cladding Midpoint (BSE,

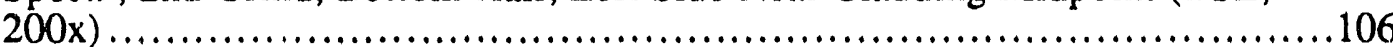

5-20 Spec.9, 2nd Grind, Bottom Half, Left Side on Cladding Inner Surface

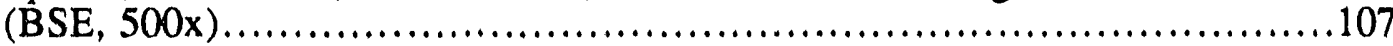

5-21a Spec.9, 2nd Grind, Bottom Half, EDS Spectrum for Spot "A" on Figure 5-

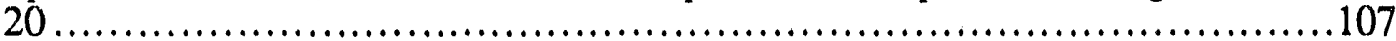

5-21b Spec.9, 2nd Grind, Bottom Half, EDS Spectrum for Spot "B" on Figure 5-

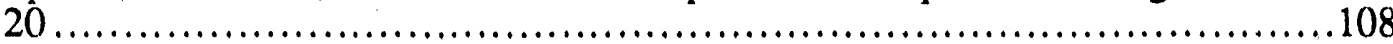

5-21c Spec.9, 2nd Grind, Botiom Half, EDS Spectrum for Spot "C" on Figure 5-

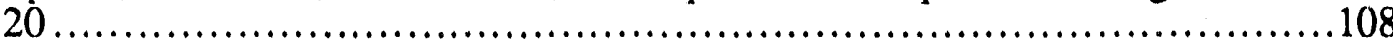

5-22a Spec.9, 3rd Grind, Bottom Half, Left Side (SE, 50x) ...........................109

5-22b Spec.9, 3rd Grind, Bottom Half, Right Side (BSE, 50x) ......................109

5-23a Spec.9, 3rd Grind, Bottom Half, Left Side at Cladding O.D. (BSE, 297x) .....110

5-23b Spec.9, 3rd Grind, Bottom Half, Right Side at Cladding O.D. (BSE,

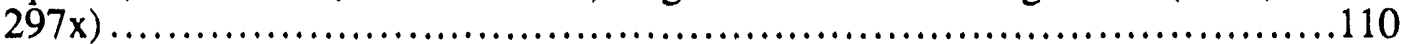

5-24a Spec.9, 3rd Grind, Bottom Half, Left Side Near Cladding Midpoint (BSE,

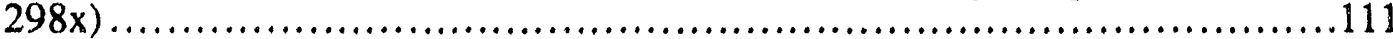

5-24b Spec.9, 3rd Grind, Bottom Half, Right Side Near Cladding Midpoint (SE,

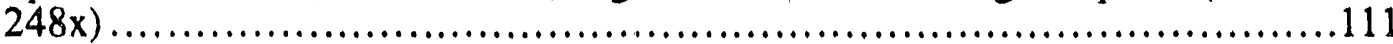

5-25 Spec.9, 3rd Grind, Bottom Half, Left Side on Inner Surface (SE, 298x) .......112

5-26a Spec.9, 4th Grind, Bottom Half, Left Side (BSE, 50x) ....................112

5-26b Spec.9, 4th Grind, Bottom Half, Right Side (BSE, 50x) .....................113

5-27 Spec.9, 4th Grind, Bottom Half, Left Side at Cladding O.D. (BSE, 295x).......113

5-28 Spec.9, 4th Grind, Bottom Half, Cladding Outer Surface to the Right of the Fracture (BSE, 392x) .................................................114

5-29a Spec.9, 21st Grind, Top Half, Optical Micrograph of Fracture (100x) ..........114

5-29b Spec.9, 22nd Grind, Top Half, Optical Micrograph of Fracture (100x)..........11s,

5-29c Spec.9, 23rd Grind, Top Half, Optical Micrograph of Fracture (100x) ..........115

5-30a Spec.9, 21 st Grind, Top Half, Optical Micrograph of Fracture Tip (500x) ......116

5-30b Spec.9, 22nd Grind, Top Half, Optical Micrograph of Fracture Tip (500x) .....115

5-30c Spec.9, 23rd Grind, Top Half, Optical Micrograph of Fracture Tip (500x).......117

5-31 Spec.9, 24th Grind, Top Half, Optical Micrograph of Fracture (100x).............117

5-32 Spec.9, 25th Grind, Top Half, Optical Micrograph of Fracture (100x),............118

5-33a Spec.9, 26th Grind, Top Half, Left Side, Optical Micrograph of Fracture

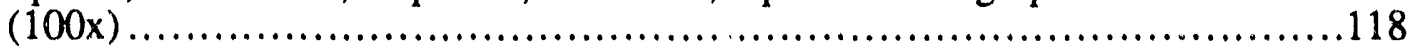

5-33b Spec.9, 26th Grind, Top Half, Right Side, Optical Micrograph of Fracture $(100 \mathrm{x})$ 
5-34a Spec.9, 27th Grind, Top Half, Left Side, Optical Micrograph of Fracture

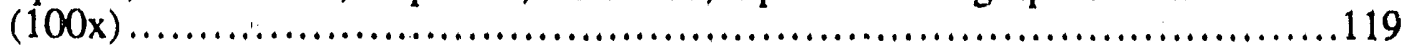

5-34b Spec.9, 27th Grind, Top Half, Right Side, Optical Micrograph of Fracture

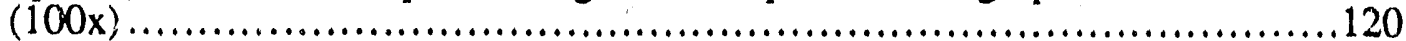

5-35a Spec.9, 25th Grind, Top Half, Low-Magnification SEM Micrograph (BSE,

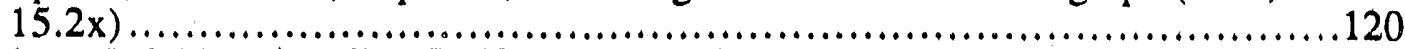

5-35b Spec.9, 26th Grind, Top Half, Low-Magnification SEM Micrograph (BSE,

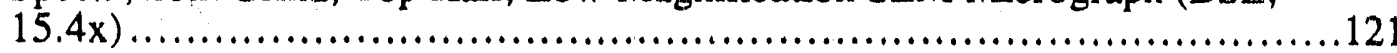

5-35c Spec.9, 27th Grind, Top Half, Low-Magnification SEM Micrograph (BSE,

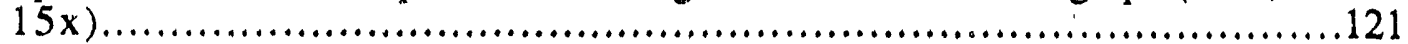

5-35d Spec.9, 29th Grind, Top Half, Low-Magnification SEM Micrograph (BSE,

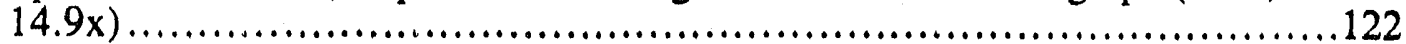

5-36a Spec.9, 25th Grind, Top Half, Fracture Surface Near I.D. (BSE, 398x) ........122

5-36b Spec.9, 26th Grind, Top Half, Fracture Surface Near I.D. (BSE, 398x) ........123

5-36c Spec.9, 27th Grind, Top Half, Fracture Surface Near I.D. (BSE, 200x) ........123

5-37a Spec.9, 28th Grind, Top Half, Inner Cladding Surface (BSE, 990x) ............124

5-37b Spec.9, 28th Grind, Top Half, EDS Spectrum for Spot "A" on Figure 5-

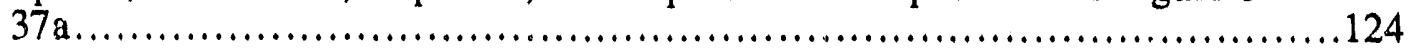

5-38 Spec.9, 27th Grind, Top Half, Low-Magnification SEM Micrograph (BSE,

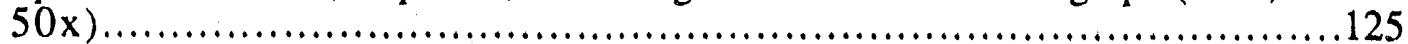

5-39 Spec.9, 29th Grind, Top Half, Outer Cladding Surface (BSE, 394x) ...........125

5-40a Spec.9, 30th Grind, Top Half, Left Side, (BSE, 75x) ..............................126

5-40b Spec.9, 30th Grind, Top Half, Right Side (BSE, 75x) .......................126

5-4la Spec.9, 30th Grind, Top Half, Left Side, Fracture Surface Near I.D. (BSE,

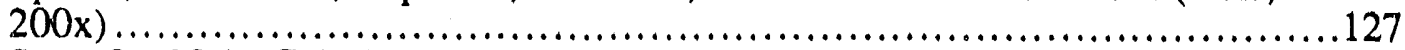

5-41b Spec.9, 30th Grind, Top Half, Left Side, Fracture Surface $\approx 1 / 3$ throughwall (BSE, 200x) .............................................. 127

5-41c Spec.9, 30th Grind, Top Half, Left Side, Fracture Surface $\approx 3 / 4$ throughwall (BSE, 298x) ............................................... 128

5-41d Spec.9, 30th Grind, Top Half, Left Side, Fracture Surface at O.D. (BSE,

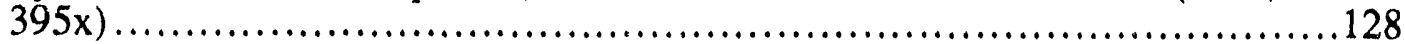

5-42a Spec.9, 30th Grind, Top Half, Right Side, Fracture Surface Near I.D.

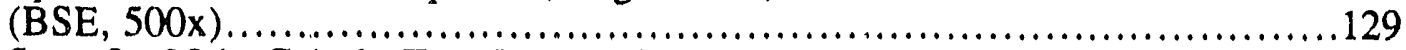

5-42b Spec.9, 30th Grind, Top Half, Right Side, Fracture Surface $\approx 1 / 3$ throughwall (BSE, 394x) .............................................129

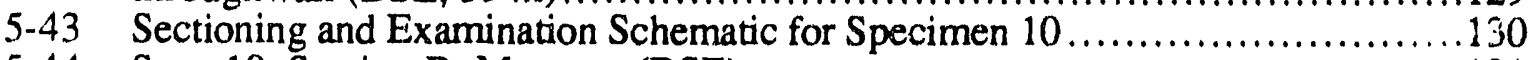

5-44 Spec.10, Section B, Montage (BSE) ......................................131

5-45a Spec.10, Section B, Area Identified as Possible Cladding Attack on Radiograph (BSE, 100x) ...........................................132

5-45b Spec.10, Section B, Area Identified as Possible Cladding Attack on Radiograph (BSE, 500x) ...............................................132

5-46a Spec.10, Section B, EDS Spectrum for Spot "A" on Figure 4-45b ................ 133

5-46b Spec. 10, Section B, EDS Spectrum for Spot "B" on Figure 4-45b...............133

5-46c Spec.10, Section B, EDS Spectrum for Spot "C" on Figure 4-45b .................134

5-47a Spec.10, Section B, Particle at Inner Cladding Surface (SE, 199x).................134

5-47b Spec.10, Section B, Particle at Inner Cladding Surface (BSE, 750x)................135

5-47c Spec.10, Section B, EDS Spectrum for A reas Identified on Figure 5-47b .......135

5-48a Spec.10, Section A, Low-Magnification Optical Micrograph (50x) ..............136

5-48b Spec.10, Section A, Low-Magnification Optical Micrograph (50x) ................136

5-48c Spec.10, Section A, Low-Magnification Optical Micrograph (50x) ...............137

5-48d Spec.10, Section A, Low-Magnification Optical Micrograph (50x) ...............137

5-49a Spec.10, Section A, Optical Micrograph of Al-Cd Interface (250x)................138

5-49b Spec.10, Section A, Optical Micrograph of Al-Cd Interface (250x)................138

5-50 Spec. 10, Section A, Low-Magnification SEM Micrograph (BSE, 50x)..........139 


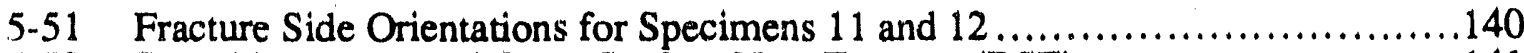

5-52a Spec.11, Montage of Outer Surface Near Fracture (BSE) .......................141

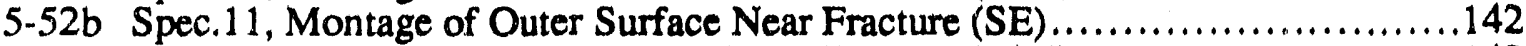

5-53 Spec.11, Montage of Inner Surface Near Fracture (BSE) ....................143

5-54 Spec.11, 1st Grind, Top Half, Low-Magnification SEM Micrograph (BSE,

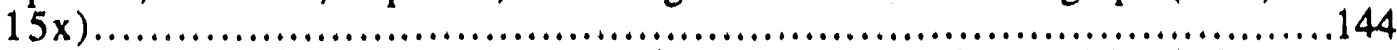

5-55a Spec.11, 1st Grind, Top Half, Left Side, Fracture Surface at I.D. (BSE,

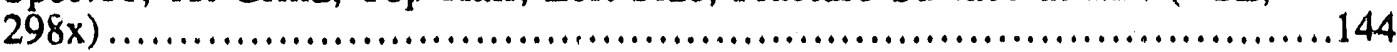

5-55b Spec.11, 1st Grind, Top Half, Left Side, Near Cladding Midpoint (BSE,

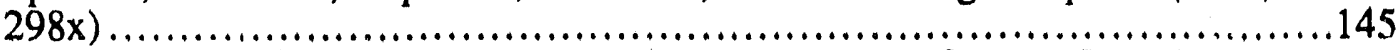

5-55c Spec.11, 1st Grind, Top Half, Left Side, Fracture Surface at O.D. (BSE,

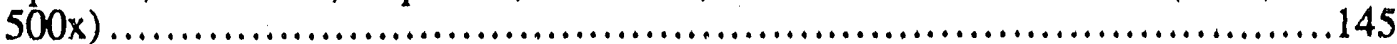

5-56a Spec.11, 2nd Grind, Top Half, Left Side, Fracture Surface at I.D. (SE, 297x) ................................................................ 146

5-56b Spec.11, 2nd Grind, Top Half, EDS Spectrum for Spot "J" on Figure 5-

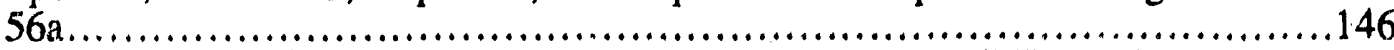

5-56c Spec.11, 2nd Grind, Top Half, EDS Spectrum for Spot "K" on Figure 556 ................................................................ 147

5-57a Spec.11, 2nd Grind, Bottom Half, Right Side, Fracture Surface $\approx 3 / 4$

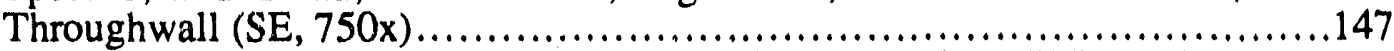

5-57b Spec.11, 2nd Grind, Bottom Half, EDS Spectrum for Spot "L" on Figure

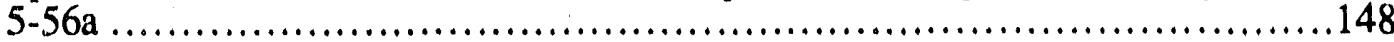

5-58a Spec.12, Montage of Outer Surface Near Fracture (BSE) ......................149

5-58b Spec.12, Montage of Outer Surface Near Fracture (SE) ....................... 150

5-59a Spec.12, Montage of Inner Surface Near Fracture (BSE) .................... 151

5-59b Spec.12, Montage of Inner Surface Near Fracture (SE) .......................152

5-60 Spec.12, 1st Grind, Bottom Half, Low-Magnification SEM Micrograph (BSE, 15x) ...........................................................153

5-61a Spec. 12, 1st Grind, Bottom Half, Left Side (BSE, 75x) ....................... 153

5-61b Spec.12, 1st Grind, Bottom Half, Right Side (BSE, 75x) ....................154

5-62a Spec.12, 1st Grind, Bottom Half, Left Side, Fracture Surface at I.D. (BSE,

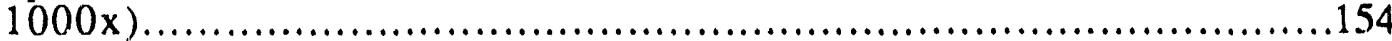

5-62b Spec.12, 1st Grind, Bottom Half, EDS Spectrum for Spot "H" on Figure 5-

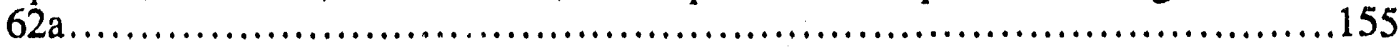

5-63 Spec.12, 1st Grind, Bottom Half, Right Side, Fracture Surface Near Cladding Midpoint (BSE, 1500x) ....................................... 155

5-64a Spec.12, 1st Grind, Bottom Half, Right Side, Fracture Surface at O.D.

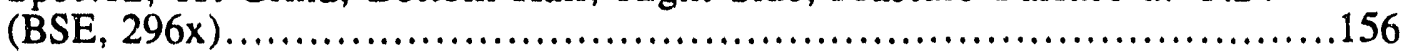

5-64b Spec.12, 1st Grind, Bottom Half, Right Side, Fracture Surface at O.D.

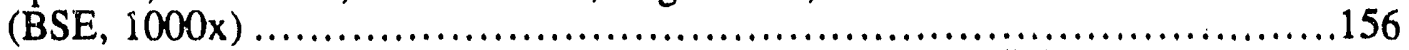

5-64c Spec.12, 1st Grind, Bottom Half, EDS Spectrum for Spot "I" on Figure 5.

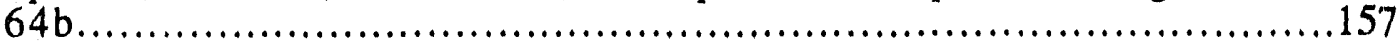

5-64d Spec.12, 1 st Grind, Bottom Half, EDS Spectrum for Spot "J" on Figure 5-

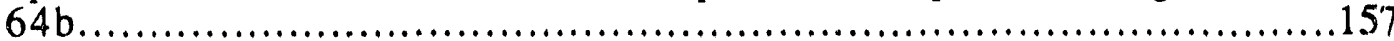

5-65a Spec.12, 1st Grind, Top Half, Left Side (SE, 75x) .......................158

5-65b Spec.12, 1st Grind, Top Half, Right Side (SE, 50x) ..........................

5-66a Spec.12, 1 st Grind, Top Half, Right Side, Fracture Surface near O.D. (SE,

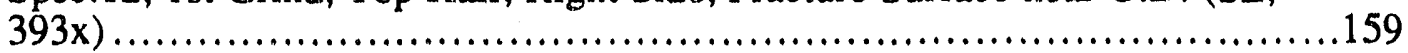

5-66b Spec.12, 1st Grind, Top Half, EDS Spectrum for Spot "A" on Figure 5-

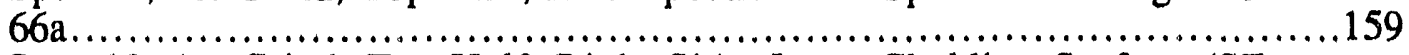

5-67a Spec.12, 1st Grind, Top Half, Right Side, Inner Cladding Surface (SE, 296x) ............................................................ 160

5-67b Spec.12, 1 st Grind, Top Half, EDS Spectrum for Spot "B" on Figure 5$67 a$. 
5-68a Spec.9, 1st Grind, Bottom Half, Left Side, Cladding I.D., Electron Microprobe Micrograph (BSE).

5-68b Spec.9, 1 st Grind, Bottom Half, Left Side, Cladding I.D., Cr x-ray map .........161

5-68c Spec.9, 1st Grind, Bottom Half, Left Side, Cladding I.D., Al x-ray map ........162

5-68d Spec.9, 1st Grind, Bottom Half, Left Side, Cladding I.D., Cd x-ray map .......162

5-69 Spec.9, 1 st Grind, Bottom Half, Left Side, $\approx 1 / 2$ throughwall, SEM Micrograph (BSE, 500x) .............................................. 63

5-70a Spec.9, 1st Grind, Bottom Half, Left Side, $\approx 1 / 2$ throughwall, Electron Microprobe Micrograph (BSE)............................................. 164

5-70b Spec.9, 1st Grind, Bottom Half, Left Side, $\approx 1 / 2$ throughwall, Al x-ray map .......................................................................164

5.70c Spec.9, 1st Grind, Bottom Half, Left Side, $\approx 1 / 2$ throughwall, Cd $x$-ray map ......................................................................165

5-70d Spec.9, 1st Grind, Bottom Half, Left Side, $\approx 1 / 2$ throughwall, Fe $x$-ray

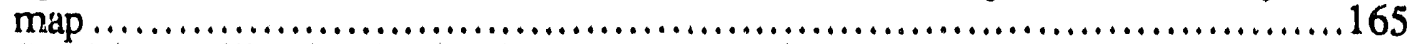

6-1 SS304 Ductility (Reduction in Area) vs. Strain Rate and Temperature..............166

6-2 Al-Cd Phase Diagram .....................................................167

6-3 Cd-Rich End of Al-Cd Phase Diagram........................................ 168

6-4 Cd-Ni Phase Diagram ........................................................169

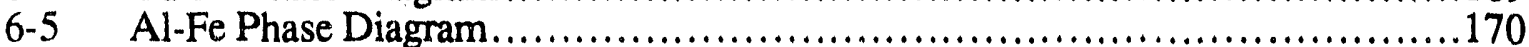

6-6 Al-Cr Phase Diagram.............................................................. 171

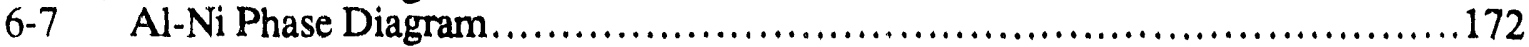

6-8a SEM Micrograph of Al/SS304/Cd DTA Specimen (SE, 1000x).................173

6-8b Al/SS304/Cd DTA Spec., EDS Spectrum for Spot "A" on Figure 6-8a ..........173

6-8c Al/SS304/Cd DTA Spec., EDS Spectrum for Spot "B" on Figure 6-8a ..........174

6-8d Al/SS304/Cd DTA Spec., EDS Spectrum for Spot "C" on Figure 6-8a ..........174

6.9a SEM Micrograph of Al/Cd DTA Specimen (SE, 500x) .....................

6-9b Al/Cd DTA Spec., EDS Spectrum for Spot "A" on Figure 6-9a..................175

6-10a SEM Micrograph of SS304/Cd DTA Specimen (BSE, 760x) ......................176

6-10b SS304/Cd DTA Spec., EDS Spectrum for Spot "D" on Figure 6-10a ............ 176

6-10c SS304/Cd DTA Spec., EDS Spectrum for Spot "E" on Figure 6-10a .............177

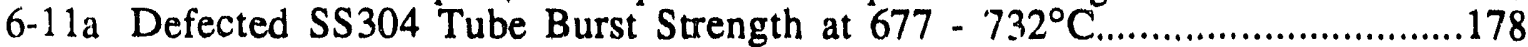

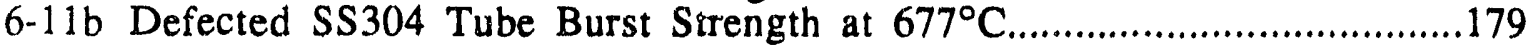

6-12a Optical Micrograph of U-Bend Specimen No. $5(100 \mathrm{x}) \ldots \ldots \ldots \ldots \ldots \ldots \ldots \ldots \ldots \ldots$

6-12b Optical Micrograph of U-Bend Specimen No. $6(100 x) \ldots \ldots \ldots \ldots \ldots \ldots \ldots \ldots \ldots \ldots$

7-1a Load Displacement Curve for SS304 Tensile Test at $500^{\circ} \mathrm{C}$ and $3 \times 10^{-3} \mathrm{~min}^{-1} \ldots . .181$

7-1b Load Displacement Curve for SS304 Tensile Test at $550^{\circ} \mathrm{C}$ and $3 \times 10^{-3} \mathrm{~min}^{-1} \ldots . .182$

7-1c Load Displacement Curve for SS304 Tensile Test at $6100^{\circ} \mathrm{C}$ and $3 \times 10^{-3} \mathrm{~min}^{-1} \ldots . .183$ 


\section{INTRODUCTION}

The reactor safety rods may be subjected to high temperatures due to gamma heating after the core coolant level has dropped during the ECS phase of a hypothetical LOCA event. Accordingly, an experimental safety rod testing subtask was established as part of a task to address the response of reactor core components to this accident (Thomas 1991). The experimental subtask compliments the structural evaluation (finite element analysis) of the safety rod (Gupta 1991). A companion report discusses the experiments conducted to determine safety rod failure threshold (Thomas et al. 1991); this report deals primarily with the examination of the test specimens, evaluation of possible failure mechanisms, and confirmatory separate effects experiments.

The characterization of the safety rods employed in these experiments and the test specimens is discussed in Section 2. Test specimen characterization included tangential xray radiography, dimensional measurements, cladding grain size measurements, and an electron microprobe examination of a safety rod characterization sample. An overview of the cadmium safety rod thermal tests is given in Section 3; this is based primarily on the information given in Thomas et al. (1991). Section 4 discusses the post-test nondestructive examination, which included tangential $x$-ray radiogr', phy and dimensional measurements. The post-test destructive examination consisted of optical and scanning electron microscopy for 4 of the test specimens and an electron microprobe examination of 1 of the test specimens, as discussed in Section 5 . Section 6 discusses the candidate failure mechanisms considered in this evaluation (mechanical failure, formation of low-melting point eutectics, material defects, liquid metal embritulement, and liquid metal dissolution) in terms of the test results, nondestructive and destructive examinations, and literature data. Section 6 also presents the results from confirmatory separate effects experiments (U-bend, tensile, pressurized tube burst, and differential thermal analysis) performed to support the evaluation. A discussion of the main findings is given in Section 7, and conclusions are given in Section 8. 


\section{TEST SPECIMEN CHARACTERIZATION}

The safety rods employed in these experiments were obtained from the SRS Reactor Operations Department. The rods were part of the essential materials inventory of reactor components (Dyer 1991) and had not previously been placed in-service. A cross section of the safety rod is shown in iigure 2-1. The active, or cadmium (Cd) bearing, portion of the safety rod consists of a 0.756 " diameter aluminum alloy (Al-6061) core, a 0.05" thick Cd layer, and a 0.042" thick Type 304 stainless steel cladding (SR.S 1982 and Iyer 1991). As part of the manufacturing process, a thin $(\approx 1$ mil) nickel $(\mathrm{Ni})$ flash coating was applied to the Al-6061 core to aid in Cd application, and the stainless steel cladding was swaged from 1 " to 0.94 " outer diameter so as to contact the $\mathrm{Cd}$ layer. The active portion of the safety rod is approximately 168" in length (SRS 1952).

The test specimens were manufactured by cutting an 18-20" segment from the safety rod and removing the $\mathrm{Al}$ and $\mathrm{Cd}$ from the ends of the specimen to a depth of approximately $1 / 8^{\prime \prime}$. Specimen end caps were welded into place to seal the specimen. Tangential $x$-ray radiography and dimensional measurements were performed on the test specimens both before and after testing. Small characterization sections $\left(\approx 1 / 2^{\prime \prime}\right)$ were taken from the bottom end of each of the 4 safety rods employed in these experiments; a second characterization specimen (no.53) was taken from the top end of the safety rod from which the failed specimens were taken. Additionally, small characterization sections were taken from the cold ends of the first failed specimen (no.9).

The pre-test characterization and testing procedures are given in NRTSC Technical Procedures TP-91-007 (rev.1); post-test characterization procedures are given in NRTSC Technical Procedures TP-91-017 (rev.0) and TP-91-018 (rev.0).

\subsection{Radiography}

Tangential $x$-ray radiography was performed on the test specimens before and after testing. The main goal of the radiography was to identify cladding areas which contained defects or local thin spots (pre-test), and to locate areas where the cladding had been attacked by liquid metal (post-test). The radiographs also provided an estimate of cladding thickness and were used to detect the presence and estimate the size of radial gaps between the cladding and $\mathrm{Cd}$ layer and axial gaps in the Cd layer. Radiogl phs were made at incremental locations spaced 10 to $30^{\circ}$ around the circumference of the test specimens in 
order to obtain a sufficient level of characterization. The $10^{\circ}$ spacing was initially employed, later specimens were examined with a $30^{\circ}$ spacing since no information relating to the failure mechanism was apparent in the radiographs. None of the pre-test radiographs indicated the presence of localized thin spcts or geometric irregularities in the cladding.

Table 2-1 gives the cladding thickness and gap size values based on measurements taken from the pre-test radiographs. These measurements were taken at 6 different circumferential locations at an axial position corresponding approximately to the center of the hot zone. The reported cladding thickness values were rounded to the nearest 5 mils; a specific uncertainty was not assigned to the gap size measurements, but they are judged to be accurate within a few mils. Based on the radiographs, safety rods 1,2 and 4 all have 50 mil thick cladding, while the safety rod 3 cladding is only 40 mils thick. The gap between the cladding and cadmium layer based upon the radiographs was a few mils or less for specimens taken from safety rods 1,2 and 4; the gap size for specimens taken from safety rod 3 ranged from a few mils up to 20 mils. In addition, a small axial gap (10 - 20 mils) in the cadmium layer was noticeable in the radiograph for pecimen 11 (from safety rod 1). During manufacture, the stainless steel cladding was swaged down upon the core and all the safety rods examined would therefore be expected to have at least a small gap. The swaging process reduced the cladding outer diameter from 1 " to 0.954 "; a reduced cladding thickness would therefore produce a larger gap between the cladding and $\mathrm{Cd}$ layer, as is the case for safety rod 3.

\subsection{Dimensional Characterization}

Two diameter measurements, spaced $90^{\circ}$ apart, were made at each of several axial locations in the portion of the rod to be heated. These data, along with post-test measurements, were used to calculate plastic hoop strains for the test specimens, as discused in Section 4.1.

The cladding thickness, cladding- $\mathrm{Cd}$ gap size, and $\mathrm{Cd}-\mathrm{Al}$ core gap size were measured for the safety rod characterization samples using a tool makers microscope. A total of 29 measurements were made at approximately $12.5^{\circ}$ increments around the circumference of each of the samples. As discussed above, the characterization samples were taken from the bottom end of each of the 4 safety rods, the top end of safety rod 1 (specimen no. 53), and the cold ends (top and bottom) of thermal test specimen 9 (safety rod 1). 
The mean cladding thickness, minimum and maximum values, and standard deviation of the measurements are given in Table 2-2. The measurements are accurate to within approximately $0.1 \mathrm{mil}$, so that the standard deviations given in Table $2-2$ reflect cladding thickness circumferential variations. The rod 1 characterization sample showed a sizeable cladding thickness circumferential variation (standard deviation of $8.2 \%$ ). The samples taken from the top and bottom of specimen 9 (which was cut from rod 1 just above the characterization sample) do not exhibit the same variability; the characterization sample taken from the top end of rod 1 also has a relatively uniform cladding thickness. The cladding below the bottom end of the safety rod was drawn to a tip and welded during manufacture, and it is possible that this operation distorted the cladding at the bottom end of the rod. It is also possible that the surfaces of the characterization sample from rod 1 were not cut square. The standard deviations for the cladding thickness data from specimen 9 is slightly high relative to the other values given in Table 2-2; it is likely that some distortion was introduced during remcval of the cooling coils from the test specimen (see Section 3 ). The cladding thickness data for the characterization samples and for the top and bottom ends of specimen 9 are shown in Figure 2-2. The large variation in the rod 1 characterization sample cladding thickness is clearly evident. It is also apparent that the cladding thickness for all the safety rods does exhibit a small, somewhat periodic, variation. Note that this circumferential variation in cladding thickness will introduce a similar variation in cladding stress during the thermal test. The cladding thickness data taken from the photomicrographs (Table 2-2) are in general agreement with those from the radiographs (Table 2-1), which gave cladding thicknesses of 50 mils for safety rods 1,2 and 4 , and 40 mils for safety rod 3.

The mean cladding-Cd and $\mathrm{Cd}-\mathrm{Al}$ core gap sizes and associated standard deviations are give $n$ in Table 2-3. As mentioned above, the measurements are accurate to within 0.1 mil, so the standard deviations given in Table 2-3 reflect circumferential variations in gap size. The cladding-Cd and $\mathrm{Cd}-\mathrm{Al}$ core gap sizes ior safety rod 4 and the $\mathrm{Cd}-\mathrm{Al}$ core gap size for safety rod 3 were very small and appeared to be uniform; the values given in Table 2-3 are estimates which are probably accurate to within a factor of 2 . The cladding-Cd gap size values given in Table 2-3 are in general agreement with those based upon the radiographs, but are slightly larger. This is expected since the grinding and polishing operations involved in preparing the metallographic specimen can remove material and round the edges of the cladding and cadmium, thus producing a larger apparent gap size. An occasional lack of bonding between the aluminum core and cadmium layer was also noted when the aluminum core was removed from one of the specimens. 


\subsection{Microprobe Examination}

The characterization sample taken from the bottom end of safety rod 1 was examined using an electron microprobe, as described in Tovo (1991). SEM micrographs of this sample in the polished condition are shown in Figures 2-3a and 2-3b; optical micrographs of the sample after a light electrolytic etch in oxalic acid are shown in Figures 2-4a and 2-4b. Compositions were determined using $x$-ray wavelength dispersive spectroscopy (WDS) with an acceleration voltage of $20 \mathrm{keV}$. A sample current of 100 to 110 nanuamps was employed, and the current was held constant to within \pm 0.3 nanoamps during each analysis. The composition of the cladding and core are given in Table 2-4, along with the corresponding SS304 and Al-6061 composition specifications (Harvey 1982 and ASM 1979). The measured compositions fall within the range for the specifications. The core was actually specified to be $\mathrm{Al}-61 \mathrm{~S}$, but the Al-6061 specification is essentially the same as and has superseded that for Al-61S (Reynolds 1954). The composition of the Ni layer is also given in Table 2-4. The Cd layer composition was greater than $99.7 \% \mathrm{Cd}$. The microprobe measurements are essentially point counts and do not necessarily reflect the presence of precipitates and inclusions in the matrix. The standard deviation of these measurements was not rigorously determined, but based on comparison with data taken on available standards, is judged to be less than $10 \%$.

\subsection{Cladding Grain Size}

Grain sizes were measured using the Three Circle (Abrams) technique per ASTM Standard E112-88 (Anderson 1991). As with the cladding thickness measurements, the characterization samples were taken from the bottom ends of all 4 safety rods, from the top of safety rod 1, and from the top and bottom ends of the first failed safety rod specimen (no.9). The samples were electrolytically etched at $6 \mathrm{~V}$ for 20 to 40 seconds in oxalic acid. A single measurement was made per sample. The resulting ASTM grain size numbers and mean linear intercept distances are given in Table 2-5; the grain diameter is proportional to the mean linear intercept distance. Note that the grain size for safety rod 1 cladding is approxirnately a factor of 2 smaller than that for the other three safety rods. The measured grain sizes for the four rod 1 characterization samples are in good agreement; the data for the safety rods 2, 3 and 4 are also consistent. This indicates ihat the tubing used for safety rod 1 may have come from a different lot than that for other safety rods, that the manufacturing process used with safety rod 1 may have been different, or that a different 
manufacturer might have supplied safety rod 1 . No other differences were detected in the appearance, dimensions, or composition of safety rod 1 as compared to the others employed in these tests. 


\section{SAFETY ROD THERMAL TESTS}

The relevant features of the safety rod thermal tests and results are discussed in this section. The tests were previously described in Thomas et al. (1991), which gives slightly more detail.

\subsection{Test Description}

The experimental apparatus is shown in Figure 3-1. The specimens were placed in a muffle furnace such that approximately 2 to 3 " in the center of the rod was exposed to the furnace hot zone. Insulating surfaces built up at the top and bottom of the furnace protected the remaining length of the rod inside the furnace. Water flowing through the copper coils fitted over the ends of the specimens provided cooling to prevent end cap weld failure due to overpressurization. The ends of the specimens were kept below $275^{\circ} \mathrm{C}$; the melting point of cadmium is $321^{\circ} \mathrm{C}$, so this level of cooling was sufficient to prevent end cap failure. After the initial tests, quartz or ceramic cylindrical tubes were placed around the portion of the specimen in the furnace hot zone to contain $\mathrm{Cd}$ in the event of a failure. The furnace was equipped with two viewing ports fitted into the top section; selected tests were recorded using cameras placed at these locations (the video tapes are retained in the task record files).

Type $\mathrm{K}$ chromel-alumel thermocouples were employed fur temperature measurement. The initial tests were conducted using thermocouple wires twisted together to form a junction and spot welded to the surface of the specimens; ceramic insulators were employed to protect the thermocouple wires inside the furnace. The first test employed wire wrapping to hold the junction in place due to concerns about spot weld failure; wire wrapping was not employed with any of the other specimens. Some of the spot welds did occasionally fail during the tests and to prevent this, later tests employed stainless steel sheathed thermocouples ( $1 / 16^{\prime \prime}$ sheath diameter) which were held in place by tack welding a thin $(\approx 5$ mil) stainless steel strip over the sheath end. Most of the tests employed seven thermocouples; three in the heated zone, one on either side of the heated zone, and one on either end on the rod just below the end caps. The first test only employed a single thermocouple in the hot zone.

The temperature history for the tests consisted of a ramp to the test temperature, a holding period, and a ramp down period. The rate of temperature increase, or thermal ramp rate, 
employed for the tests can be characterized as "slow" $\left(<10^{\circ} \mathrm{C} / \mathrm{min}\right)$ or "fast" $\left(>25^{\circ} \mathrm{C} / \mathrm{min}\right)$. The fast ramp rate is more prototypic of the conditions expected in the gamma heating accident (Cooper and Taylor 1991). Both 1 and 4 hour holding period durations were employed; the 1 hour hold time bounds the conditions expected in the gamma heating accident (Cooper and Taylor 1991), and the 4 hour hold time was used in 3 of the tests to examine the effect of extended high-temperature exposure. The ramp down was at $50^{\circ} \mathrm{C}$ /hour for a three hour period (e.g. $150^{\circ} \mathrm{C}$ over 3 hours) and is representative of that expected in the gamma heating accident (Cooper and Taylor 1991).

\subsection{Test Results}

Table 3-1 summarizes the test conditions and results. 'Twenty five tests were conducted using specimens taken from 4 different safety rods at maximum test temperatures between 500 and $900^{\circ} \mathrm{C}$. Five failures occurred via rupture of the stainless steel cladding. Three of the failures occurred at maximum temperatures between 521 and $590^{\circ} \mathrm{C}$; these failures occurred with specimens taken from a single safety rod (no. 1) in tests using a slow ramp rate $\left(\approx 4^{\circ} \mathrm{C} / \mathrm{min}\right)$. The other two failures occurred above $830^{\circ} \mathrm{C}$; these failures occurred with specimens taken from two separate safety rods (nos. 2 and 4 ) using a fast ramp rate (> $\left.100^{\circ} \mathrm{C} / \mathrm{min}\right)$ in tests intended to determine the fast ramp failure threshold. No failures occurred below $521^{\circ} \mathrm{C}$. Two of the fast ramp tests listed in Table 3-1 were conducted using specimens from safety rod 1 (specimens 13 and 14) which had previously been tested under slow ramp conditions to $500^{\circ} \mathrm{C}$; neither of these specimens failed. A histogram of the test results is given in Figure 3-2. The maximum uncertainty associated with the thermocouples used in these experiments was $5^{\circ} \mathrm{C}$ and the data acquisition system introduces less than $1^{\circ} \mathrm{C}$ uncertainty; thermocouple placement introduces addition al uncertainty. Based on these considerations, the failure temperatures reported here are judged to have a total uncertainty of $\pm 10^{\circ} \mathrm{C}$. The cladding temperature in the fast ramp tests increases much faster than that of the aluminum and cadmium, however the cladding will not experience significant strain until these materials reach elevated temperatures. The fast ramp rate values given in Table 3-1 are representative of the rate of temperature increase experienced by the aluminum and cadmiurn.

Simplified schematics of the test temperature histories are given in Figures 3-3 and 3-4. The "slow" and "fast" thermal ramp rates are shown in these figures as being the same for all tests; this is done only for illustrative purposes and the actual ramp rates are given in 
Table 3-1. Figures 3-5 and 3-6 show actual temperature histories for representative slow and fast ramp tests.

As mentioned above, the furnace was equipped with two viewing ports fitted into the top section and the tests were recorded using cameras placed at these locations. The initial tests were conducted with only one camera. The camera speed was set to give 30 frames per second, so consecutive frames are spaced by $1 / 30$ of a second apart. The cladding rupture for first failure (specimen no. 9) occurred on the side of the rod being filmed. Figures 3-7a through 3-7d are still shots, taken from the video tape, just before the rupture occurred and for 3 consecutive frames after rupture (Figures 3-7a through 3-7d span $0.1 \mathrm{sec}$.). The wire wrapping used to attach the thermocouple, as discussed in Section 3.1, is visible towards the bottom of the figures. The light colored material at the top and bottom are the insulating surfaces built up within the oven to restrict the hot zone. Oxidation of the liquid metal upon contact with the furnace elements and walls generated a "smoke cloud" which is evident in Figure 3-7d and completely obscured the specimen in the next frame. As can be seen in Figure 3-7a, very little cladding deformation is evident prior to the rupture. The liquid metal ejected from the rupture appears as a very fine spray in Figure 3-7b; this "spray" becomes a "stream" in Figures $3.7 \mathrm{c}$ and $3-7 \mathrm{~d}$ as the rupture extends axially and the rupture opening area rapidly increases. The other two low-temperature failures (nos. 11 and 12) ruptured on the side of the test specimen away from the camera. Later tests were recorded using two cameras to insure that any additional ruptures would be recorded. Figures 3-8a and $3-8 \mathrm{~b}$ show consecutive frames for the first high-temperature failure (no, 34) just prior to and after the rupture; Figures $3-9 \mathrm{a}$ and $3-9 \mathrm{~b}$ are the corresponding still shots for the second high-temperature failure (no. 43). The thin straps employed to attach the sheathed thermocouples are evident in this figures. Note that the cladding for these test specimen has clearly undergone significant deformation prior to rupture, and that the rupture opening area increases much faster than was the case with the low-temperature failure (no. 9) shown in Figures 3-7a through 3-7d. 


\section{POST-TEST NONDESTRUCTIVE EXAMINATION}

\subsection{Dimensional}

Table 4-1 gives the hoop strain, based upon the measured cladding diameter at the axial position corresponding to the center of the hot zone, as a function of the maximum test temperature for the unfailed specimens; these values are illustrated in Figure 4-1. Cladding hoop strain is primarily a function of test temperature and cladding-Cd gap size, as discussed below. The diameter measurements have an uncertainty of $1 \mathrm{mil}$; the corresponding absolute uncertainty in the calculated hoop strain is less than $0.2 \%$. Also shown in the figure are the hoop strains calculated using an axisymmetric finite element model assuming a zero gap size and uniform temperature (Gupta 1991). Specimens with large gaps will have smaller strains than predicted by this model since the gap will accommodate expansion. For specimens with small gaps, the experimental hoop strain should be larger than the predicted values since the hottest cladding will preferentially accommodate expansion from colder regions; this trend was verified with a finite element model, but convergence difficulties prevented a quantitative analysis of the experiments. The scatter in the experimental data reflects variations in gap size and, to a lesser extent, cladding thickness. The gap size for safety rod 3 provided sufficient void space such that the volume increase from the thermal expansion of $\mathrm{Cd}$ and Al-6061 and the volume increase upon $\mathrm{Cd}$ melting did not mechanically load the cladding; the measured strains for specimens from this safety rod are very close to zero. Some specimens with large gaps actually showed a very small reduction in diameter $(0.1 \%)$ due to the axial load exerted by the weight of the specimen in the absence of any significant radial loading. Similarly, the radiograph for specimen 44 taken from rod 2 showed a gap size of 3 mils and this was sufficient to limit the strain to almost zero.

The measured hoop strains were generally symmetric about the middle of the hot zone. Some asymmetry was evident and is probably due to slight errors in positioning the specimens in the test rig (e.g. the location intended to be in the center of the hot zone was actually placed sightly above or below it); slight asymmetries were also evident in the axial temperature profiles. Hoop strain axial profiles are given in Figures 4-2a for the specimens from safety rods 2 and 4 "fast ramped" to $600^{\circ} \mathrm{C}$. Figures $4-2 \mathrm{~b}$ and $4-2 \mathrm{c}$ are hoop strain surface plots for specimens 14 and 15 based on post-test diameter data taken with a laser micrometer. The laser micrometer was not a category 1 instrument; however, the diameter values agreed with the hand-held micrometer data for these specimens to within $1.5 \%$ with 
an average difference of $0.37 \%$. The hand-held micrometer data showed greater scatter and, in general, gave larger diameter values; this is expected since any cocking of the handheld micrometer will increase the measured diameter and introduce scatter. Figures 4-2b and 4-2c clearly illustrate that both the axial and circumferential hoop strain profiles have a limited amount of asymmetry. In some locations, the asymmetry is significant; for example, the hoop strain increases by nearly a factor of 2 from the 157.7 to $180^{\circ}$ orientations just above the middle of the hot zone for specimen 14 .

The hoop strain for specimens which failed between 521 and $590^{\circ} \mathrm{C}(9,11$ and 12) was visually observed to be very low prior to failure and are estimated be less than $3 \%$. Conversely, the specimens which failed above $800^{\circ} \mathrm{C}$ (34 and 43) were observed to undergo extensive deformation prior to failure; the hoop strains for specimens 34 and 43 , based on post-failure circumference measurements, were 14 and $13 \%$, respectively. The difference in cladding deformation for the low- and high-temperature failures is clearly evident in the still shots taken from the test video tapes (see Section 3.2 and Figures 3-7 through 3-9).

\subsection{Radiography}

Potential cladding aitack in 2 specimens was identified on the basis $\therefore$ the post-test radiographs. 'The inner cladding surface of specimen 10 appeared to have been attacked (e.g. dissolved). However, as discussed in Section 5.1.3, the apparent cladding attack was actually foreign material partially embedded in the inner cladding surface. Specimen 28 appeared to have an axial crack in the cladding just below the heated zone; however, a destructive examination of this specimen showed that the crack was actually in the $\mathrm{Cd}$ layer. The post-test radiographs did not indicate any attack of the cladding in any of the other test specimens. 


\section{POST-TEST DESTRUCTIVE EXAMINATION}

Post-test destructive examinations were performed on specimens 9 through 12. Optical and scanning electron microscopy were carried out for all of these specimens, and an electron microprobe examination was performed on specimen 9.

\subsection{Optical and Scanning Electron Microscopy}

This section presents the optical and scanning electron microscopy that was performed on the specimens which failed at temperatures between 521 and $590^{\circ} \mathrm{C}(9,11$ and 12) and the first unfailed specimen (10). The examination of specimen 9 was much more extensive than that for the other specimens, and it is discussed in greater detail. Note that some of the features observed in the examination of specimen 9 were not identified in the limited examinations performed for specimens 11 and 12; this is discussed in Section 7. The metallographic specimens were electrolytically etched in oxalic acid (6V, 20 to $60 \mathrm{sec}$.). Compositions were examined using electron dispersive spectroscopy (EDS); a light element detector was installed late in the course of these examinations, but the majority of the EDS measurements were performed without it and could not detect light elements such as oxygen. An accelerating voltage of $20 \mathrm{keV}$ was employed for the SEM examinations.

In some cases, SEM micrographs were obtained both prior to and after etching, and there are some differcnces in the appearance of micrographs taken of the same location pre- and post-etch; these differences are not explicitly called out in the discussions below. The preetch micrographs were made to insure that any microstructural or compositional data which might be destroyed by etching was preserved.

Destructive examinations of specimens 34 and 43 , which failed above $800^{\circ} \mathrm{C}$, were not performed since the failure strains were very close to those predicted for a purely mechanical failure (see Section 6.1). The destructive examination of the low-temperature failures was deemed to be a better utilization of the time and resources available.

\subsubsection{First Failed Specimen (no.9)}

The appearance of the safety rod thermal test specimen and fracture prior to destructive examination is shown in Figures 5-1a through 5-1c. The discolored area in the center of the test specimen is the portion of the rod which was heated to elevated temperatures. The 
brown discoloration results from deposition of cadmium oxide after the failure and, to a much lesser degree, oxidation of the stainless steel cladding; the unfailed specimens had only a very light discoloration. The marks around the circumference of the specimen just below the bottom of the failure, evident in Figure 5-1b, are from wire wrapping used to attach the hot zone thermocouple (as discussed in Section 3.1 and shown in Figure 3-7a). A slight bulge at the rupture location can be seen in Figure 5-1c; this bulge is not evident in still shots taken from the video tape of the test just prior to rupture, and is therefore thought to have been produced as a result of the liquid metal ejecting from the tube. The video tapes of the other failed specimens also showed this effect.

The specimen was sectioned approximately 1 " on either side of the fracture tips, as shown in Figure 5-2. The peak temperature for this test, $591^{\circ} \mathrm{C}$, was just above the solidus point of the Al-6061 core material $\left(582^{\circ} \mathrm{C}\right)$; as a result, the core did not melt and can be seen through the fracture in Figure 5-2. The sectioned portion of the specimen was then cut longitudinally. Figure 5-3 shows the inside of the cladding and outer surface of the core, some solidified molten metal adhering to these surfaces is evident. The cladding segment shown in Figure 5-3 was examined using the SEM in both the backscattered electron (BSE) and secondary electron (SE) modes. Figure 5-4a and 5-4b are montages showing the outer surface of the cladding in the vicinity of the fracture. Figure 5-5a shows the cladding outer surface near the top of the fracture. The surface deposit, which appears light grey in the SEM micrographs, was examined via EDS and found to be cadmium rich; based on the color and texture of the material, this deposit is probably cadmium oxide. Cadmium ejected from the test specimen during the test was oxidized in the furnace and some of this oxidized $\mathrm{Cd}$ was deposited on the cladding surface. The small sphere-like deposits near the bottom of the fracture shown in Figure 5-4a and 5-4b were formed as a result of liquid metal solidification after the fracture had occurred. There appear to be secondary cracks near the top and bottom of the fracture, as can be seen in the montages (Figs. 5-4a and 5-4b) and the high magnification SEM micrograph (Fig. 5-5a); however, as discussed below, these cracks are only in the cadmium oxide layer and do not extend to the base metal. The cracks were apparently formed during cooldown due to differential thermal expansion between the cadmium oxide layer and SS304 cladding. The cladding surface beneath this layer can be seen in Figure 5-5b, where a small portion of the oxide layer has spalled off. Figure 5-5c is a high-magnification SEM micrograph typical of this layer. The light material is cadmium oxide and the dark particle is primarily aluminum; the EDS spectra for the points denoted as " $C$ " and "D" in Figure 5-5c are shown in Figures 5-6a and 5-6b, respectively. Fig:ıres 5-7a and 5-7b show the inside surface of the cladding near the top of the fracture; 
Figure 5-7c shows the inside surface near the bottom of the fracture. As mentioned above, the light grey deposit is thought to be cadmium oxide and the cracks present on the surface do not extend into the cladding.

After examining the cladding surface near the fracture, the specimen was cut in half at approximately the fracture midplane. The top half was mounted so as to allow examination from the top of the fracture towards the center, while the bottom half was mounted so as to facilitate examination from the center of the fracture towards the bottom. This is illustrated in Figure 5-8. The metallographic specimens ${ }^{\prime}$ 'ere successively ground and exanined, und the layers examined in this manner are referred to below as "1st grind", "2nd grind", etc. to indicate that the examinations were performed after the first grinding and polishing step, second grinding and polishing step etc. This notation is also illustrated in Figure 5-8.

Figure 5-9 is a low-magnification SEM micrograph of the 1st grind on the bottom half (e.g. just below the midplane of the fracture). Figures 5-10a and 5-10b are higher magnification SEM micrographs of the left and right sides of the fracture, respectively ("left" and "right" are as viewed from inside the safety rod). Figures 5-11a and 5-11b are montages of the left and right sides of the fracture, and 5-11c and 5-11d show the inner surface of the cladding just to the left and right of the fracture. The white deposits present on the inner and outer cladding surfaces and the fracture face are cadmium rich, a mix of cadmium oxide and/or solidified cadmium-rich liquid metal solution. A grey deposit is also present on the inner surface of the cladding adjacent to the fracture, and on the fracture surface up to approximately $1 / 2$ to $3 / 4$ through the cladding wall thickness. Note that this deposit does not extend around the entire inner cladding surface and is primarily limited to the area immediately adjacent to the fracture. EDS analysis, discussed below, shows this deposit to be an $\mathrm{Al} / \mathrm{Fe} / \mathrm{Cr} / \mathrm{Ni}$ alloy; microprobe analysis, discussed in Section 5.2, shows the $\mathrm{Al}$ is the major component. The grain structure of the cladding in the vicinity of the fracture is also evident in the montages of the etched specimens (Figures 5-11a and 5-11b). The fracture is intergranular near the outer surface of the cladding and the grains have undergone little deformation. Grain boundary decohesion is also evident near the outer surface. Conversely, the grains near the inner diameter show evidence of highly localized and extensive shear deformation. Very little deformation is apparent more than a few grains away from the fracture surface. Two locations on the inner cladding surface just to the left of the fracture appear to have been attacked, as noted in Figure 5-11a; these locations are also evident in later grinds on the bottom half on specimen 9. 
Figure 5-12 shows the appearance of the left side of the fracture at approximately the midpoint of the cladding. The grey and white deposits discussed above are readily apparent. EDS analysis was performed at the locations marked A, B, and C in Figure 512; the corresponding spectra are given in Figures $\mathrm{S}-13 \mathrm{a}, 5-13 \mathrm{~b}$, and 5-13c, respectively. As mentioned above, the dark grey deposit adhering the cladding surface is an $\mathrm{Al} / \mathrm{Fe} / \mathrm{Cr} / \mathrm{Ni}$ alloy. The light grey deposit is primarily cadmium. As shown in Figure 5-12, the deposit away from the cladding contains both the cadmium-rich material and small inclusions of the $\mathrm{Al} / \mathrm{Fe} / \mathrm{Cr} / \mathrm{Ni}$ alloy. In most locations examined, these two deposits are distinct, with very little of the "mixing" shown in Figure 5-12. Figure 5-14 shows the outer cladding surface just to the right of the fracture. A small crack $(\approx 20 \mu \mathrm{m})$ is present on the cladding outer surface; other similar cracks were observed near the midplane of the fracture. As discussed above, the cladding deformed markediy in the vicinity of the fracture as a result of the rupture, and these cracks may have been formed during rupture as a result of this deformation. Figure 5-15 shows the inner cladding surface just to the right of the fracture. small deposits of the $\mathrm{Al} / \mathrm{Fe} / \mathrm{Cr} / \mathrm{Ni}$ alloy can be seen adhering to the inner cladding surface along with an adherent region of cadmium.

The main features observed on the 1 st grind on the bottom half specimen 9 were:

- a grey $\mathrm{Al} / \mathrm{Fe} / \mathrm{Cr} / \mathrm{Ni}$ deposit along the fracture surface up to approximately the cladding midpoint,

- a Cd-rich deposit along the cladding inner and outer surfaces and fracture surface,

- localized shear deformation on the inner portion of fracture,

- intergranular nature of the outer portion of fracture, and

- additional areas of apparent attack on cladding inner surface to the left of the fracture.

Approximately 6 mils was removed between the 1 st and 2 nd grinds on the bottom half of specimen 9. A low-magnification SEM micrograph of the 2 nd grind is shown in Figure 516. Figures 5-17a and 5-17b are higher magnification SEM micrographs of the left and right sides of the fracture, respectively. Figure 5-18 is a montage of the right side of the fracture. The microstructural features observed on the first grind on the bottom haif, and listed above, are also evident in these figures. Figure 5-19a shows the left side of the fracture at the outer surface of the cladding; the intergranular nature of the fracture and evidence of grain boundary decnhesion can both be seen in this figure. Figure 5-19b shows the left side of the fracture at approximately the cladding midpoint. The location shown in the figure is approximately the same as that for Figure 5-12 on the 1st grind. 
Figure 5-20 is a high magnification SEM micrograph of one of the areas where the cladding appears to have been attacked on the inside cladding surface just to the left of the fracture. The composition of the deposits is the same as on the fracture inner surface; the EDS spectra are given in Figures 5-21a through 5-21c.

Approximately 5 mils was removed between the 2 nd and $3 \mathrm{rd}$ grinds on the bottom half of specimen 9. Figures 5-22a and 5-22b show the left and right sides of the fracture, respectively. Figures 5-23a and 5-23b show the left and right sides of the fracture at the cladding outer surface. The left side of the fracture surface at the midpoint is shown in Figure 5-24a; this area is similar to that shown in Figures 5-12 and 5-19b for the 1st and 2nd grinds, respectively. A similar region for the right side of the fracture is shown in Figure 5-24b. The apparent area of attack shown in Figure 5-20 for the 2nd grind is shown in Figure 5-25 for the 3rd grind; the EDS spectra for the dark grey layer is the same $(\mathrm{Al} / \mathrm{Fe} / \mathrm{Cr} / \mathrm{Ni})$. The features discussed above for the 1 st and 2 nd grinds can also be observed on the 3rd grind. A crack extending approximately 5 mils in from the outer cladding surface can be seen to the right of the fracture in Figure 5-22b; this is also evident in the 2nd grind (Figure 5-17b), but it is much larger in the 3rd grind.

The left and right sides of the fracture on the 4th grind are shown in Figures 5-26a and 5$26 \mathrm{~b}$, respectively. Figures 5-27 shows the left side of the fracture at the cladding outer surface. Figure 5-28 shows the crack on the outer surface of the cladding to the right of the fracture; this is the same feature illustrated in Figures 5-22b (3rd grind) and 5-17b (2nd grind), but it is much more open at the 4 th grind. This crack lies on, or very close to, the line of shear extending from the inner cladding surface. The other features discussed for the 1st through 3rd grinds are also evident in these Figures. However, the apparent areas of attack on the cladding inner surface are much smaller and the $\mathrm{Al} / \mathrm{Fe} / \mathrm{Cr} / \mathrm{Ni}$ layer is reduced relative to the earlier grinds. This indicates that the fracture initiation site is above the 4th grind. No other examinations were carried out on the bottom half of specimen 9 .

As indicated in Figure 5-8, the top half of the fracture sample was mounted and ground starting above the fracture tip. The samples were sequentially ground and polished (approximately 10 to 20 mils per grind) and examined at each stage with both optical and scanning electron microscopy. The fracture was not observed until the 19 th grind, after approximately 0.32 " had been removed (approximately 0.45 " from the midplane of the fracture). Optical micrographs of the fracture for the 21st through 23rd grinds are shown in Figure 5-29a through 5-29c, respectively. The fracture extends from the cladding outer 
surface towards the inner surtace. High magnification optical micrographs of the fracture tip for these same grinds are shown in Figures 5-30a through 5-30c. In these micrographs, the fracture is transgranular. Microvoid coalescence appears to have been the fracture mode, indicative of a dictile failure. Shear bands in front of the fracture tip are also evident in some of the micrographs. This portion of the fracture resulted from extension after rupture had occurred, and thus the appearance of the failure at this level is quite different from that near the midplane. The fracture extends through the cladding on the 24th grind. Optical micrographs of the fracture for the 24th, 25th, 26th, and 27th grinds are shown in Figures 5-31, 5-32, 5-33a and 5-33b, and 5-34a and 5-34b, respectively. Low magnification $(\approx 15 \mathrm{x})$ SEM micrographs for the 25th, 26th, 27th, and 29th grinds are shown in Figures 5-35a through 5-35d. The fracture appears to have extended through this region from the initiation site along a shear line. There is no evidence of the $\mathrm{Al} / \mathrm{Fe} / \mathrm{Cr} / \mathrm{Ni}$ layer or intergranular fracture near the outer portion of the cladding, as were evident near the fracture midplane. The appearance of the cladding at the edge of the fracture is shown in Figures 5-36a through 5-36c for grinds 25 through 27. Several locations on the I.D. of the cladding show evidence of limited attack. Figure 5-37a shows one such area (28th grind), the layer coating the cladding is $\mathrm{Cd}$, and the corresponding EDS spectra is shown in Figure 5-37b. Figure 5-38 is an SEM micrograph of the 27th grind showing both sides of the fracture (this is similar to Figure 5-35c, but at a higher magnification). Cracks on the outer surface of the cladding just to the right and left of the fracture are evident; these are similar to those shown in Figure 5-28 for the 4th grind on the bottom half of this specimen. Small cracks on the outer surface, similar to those seen on the bottom half, were also observed, as shown in Figure 5-39.

The 30th grind on the top half of specimen 9 revealed some of the same features and structure seen for the bottom half near the fracture midplane; the 30th grind is approximately 0.3 " above the midplane. Figures 5-40a and 5-40b are SEM micrographs of the left and right sides of the fracture. The dark grey $\mathrm{Al} / \mathrm{Fe} / \mathrm{Cr} / \mathrm{Ni}$ layer adhering to the fracture surface can be seen in these figures; it extends approximatzly $3 / 4$ through-wall on the left side, and 1/2 through-wall on the right side of the fracture. Comparing the left and right fracture surfaces in Figures 5-40a and 5-40b, it appears that a piece of the cladding has been ripped or sheared away from the outer surface. This is probably the piece of cladding that can be seen jutting out from the left side (as seen from the inside of the rod) of the fracture in Figures 5-4a and 5-4b. The midplane cut that was made to separate the specimen into bottom and top halves probably tore this cladding fragment loose. Figures 5-41 a, 5-41b, 5-41c and 5-41d show the left side of the fracture at the cladding inner 
surface, $\approx 1 / 3$ throughivall, $\approx 3 / 4$ throughwall, and at the cladding outer surface. The features discussed for the examination of the bottom half of the specimen are evident in these figures (sheared grains towards the inside of the cladding, $\mathrm{Al} / \mathrm{Fe} / \mathrm{Cr} / \mathrm{Ni}$ layer along the fracture surface, intergranular appearance near the outer cladding surface). Figures 5-42a and $5-42 \mathrm{~b}$ show the right half of the fracture surface at the I.D. and approximately $1 / 3$ throughwall.

Summarizing the observations discussed above, the 1st through 29th grinds on the top of half of specimen 9 show evidence of ductile failure with little, if any, interaction with the liquid metal solution; these grinds cover an axial segment approximately $1 / 2$ " in length. Conversely, the 30 th (last) grind on the top half and the 4 bottom half grinds all show:

- a grey $\mathrm{Al} / \mathrm{Fe} / \mathrm{Cr} / \mathrm{Ni}$ deposit along the fracture surface up to approximately $1 / 2$ to $3 / 4$ through the cladding thickness,

- a Cd-rich deposit along the cladding inner and outer surfaces and fracture surface,

- localized shear deformation on the inner portion of fracture,

- intergranular nature of the outer portion of fracture, and

- additional areas of apparent attack on cladding inner surface near the fracture.

The 30th grind on the top half and 4th grind on the bottom half are approximately $0.35^{\prime \prime}$ apart.

\subsubsection{Unfailed Specimen (no. 10)}

The post-test radiography for specimen 10 indicated localized cladding attack might have occurred in the heated section (see Section 4.2). The specimen was sectioned for destructive examination in the vicinity of the suspected attack as illustrated in figure 5-43. Section A was mounted so as to allow a transverse cross section, while sections $B$ and $C$ were mounted so as to allow an examination of the longitudinal cross section. Sections B and $\mathrm{C}$ were cut at the circumferential position corresponding to the radiograph indication and just above the midplane of the specimen. Section $B$ contained the portion of the cladding corresponding to the radiograph indication.

It is evident from the montage of one side of section $\mathrm{B}$, figure 5-44, that the inner cladding surface has not been attacked to any significant degree. The small precipitates distributed in the solidified $\mathrm{Cd}$ are primarily $\mathrm{Al}$. There are also some Al-Ni deposits present. These precipitates are preferentially located towards the cladding inner surface. The ends of the 
safety rod test specimen ends were cooled in the thermal tests; since the Al core represents the most favorable conduction path from the heated zone, heat would primarily flow into and then axially along the Al core. Therefore, when a test was stopped and the furnace shut down, the liquid metal solution would hegin to solidify next to the aluminum core first and the solidification front would progress towards the cladding. This would tend to move precipitates and solid impurities towards the cladding, in a fashion analogous to zone refining. Thus, the preferential location of precipitates near the cladding inner surface after an unfailed thermal test specimen has cooled is not surprising. An area where $\mathrm{Cd}$ solidification has left a void is also evident in the montage shown in Figure 5-44.

The area identified on the radiographs as possible cladding attack is located at the top of the montage shown in Figure 5-44. Higher magnification SEM micrographs of this area are shown in Figures 5-45a and 5-45b. The apparent area of attack is actually a particle, composed primarily of sodium (Na), partially embedded in the cladding inner surface. Adjacent to this, a compound composed primarily of $\mathrm{Na}, \mathrm{Al}, \mathrm{Si}$ and sulfur (S) was identified. Slightly further away from the cladding $(\approx 100 \mu \mathrm{m})$, a layer of an Al-Cd mixture can be seen. These regions are identified as $A, B$, and $C$ on Figure 5-45b and the corresponding EDS spectra are given on Figures 5-46a through 5-46c. Since this region was identified via radiography priur to cutting, the $\mathrm{Na}$ and $\mathrm{S}$ particles were not foreign substances introduced as a result of sectioning operations. Figures $5-47 \mathrm{a}$ and $5-47 \mathrm{~b}$ are high magnification SEM micrographs of an area approximately $0.2^{\prime \prime}$ down from that discussed above. The "sphere-like" object, as well as several other smaller particles, is comprised of $\mathrm{Al}, \mathrm{Cd}, \mathrm{Cr}, \mathrm{Fe}$, and $\mathrm{Ni}$. The EDS spectrum for the areas identified in Figure $5-47 \mathrm{~b}$ is given in Figure 5-47c. The Al core, Ni flash coating, and $\mathrm{Cd}$ all contained trace amounts of $\mathrm{Fe}, \mathrm{Cr}$, and $\mathrm{Ni}$, so that it is not possible to say if these particles are the result of cladding attack or, alternatively, resulted from precipitation of impurities in the liquid metal solution. Other precipitates and deposits containing $\mathrm{Na}, \mathrm{S}, \mathrm{Al}, \mathrm{Si}, \mathrm{Fe}, \mathrm{Cr}$, and $\mathrm{Ni}$ were identified on or near the cladding inner surface.

The destructive examination of section $\mathrm{C}$ revealed features similar to that of section $\mathrm{B}$, and is not discussed in this report

Figures 5-48a through 5-48d are optical micrographs of section A. The precipitates in the $\mathrm{Cd}$ layer are primarily $\mathrm{Al}$, as mentioned above. The "line-like" deposit in Figure 5-48c is typical of the $\mathrm{Ni}-\mathrm{Al}$ deposits, which are probably segments of the Ni flash coating which did not fully dissolve in the liquid metal solution. Figures 5-49a and 5-49b are higher 
magnification optical micrographs of the Cd-Al interface. The dissolution of the Al core by the liquid $\mathrm{Cd}$ is evident. Figure $5-50$ is an SEM micrograph which corresponds to the same area as illustrated in Figure 5-48b.

In summary, the possible cladding attack indicated by the post-test radiography was found to be impurities next to and embedded in the cladding inner surface. Deposits of $\mathrm{Al}$ and $\mathrm{Al}$ $\mathrm{Ni}$ were observed in the solidified $\mathrm{Cd}$ and were preferentially located towards the cladding inner surface; this is consistent with the expected temperature gradients in the thermal test specimens and with the partial dissolution of the Ni flash coating and Al core by the liquid $\mathrm{Cd}$. The other elements present in the precipitates ( $\mathrm{Na}, \mathrm{S}, \mathrm{Si}, \mathrm{Fe}, \mathrm{Cr}$ and $\mathrm{Ni}$ ) may have originated from any of the safety rod materials (Al core, Ni flash coating, Cd layer or SS304 cladding).

\subsubsection{Other Failed Specimens (nos. $11 \& 12$ )}

The destructive examination of specimens 11 and 12 was not as extensive as that for specimen 9, and was limited to a small area near the center of the rupture. Safety rod thermal test specimens 11 and 12 were cut above and below the rupture to allow SEM examination of the cladding inner and outer surfaces near the rupture. Both specimens were then sectioned in the vicinity of the rupture midplane and mounted so as to allow examination from the midplane of the rupture towards the ends. This mounting technique makes notation of the 'left' and 'right' fracture sides slightly confusing. As with specimen 9, 'left' and 'right' correspond to the orientation of the fracture as viewed from inside the rod. However, when the top half of the fracture is mounted "upside down" to allow examination of the region immediately above the fracture midplane, the side of the fracture which appears on the 'left' side of the micrograph is actually the 'right' side of the fracture (as viewed from inside the rod prior to sectioning). Furthermore, shear lines will appear to be reflected (about a radial line) in the top half of the fracture as compared to the bottom half. This is illustrated in Figure 5-51 for the sake of clarity.

\section{Specimen 11}

Figures 5-52a and 5-52, b are montages of the outer cladding suriace in the vicinity of the rupture comprised of SEM micrographs taken in the BSE and SE modes, respectively. Figure 5-53 is a montage of the inner cladding surface. The appearance of the fracture is similar to that for specimen 9 (Figures 5-4a and 5-4b). EDS spectra for these surfaces 
show mainly $\mathrm{Cd}$, with some deposits and traces of $\mathrm{Al}, \mathrm{Fe}, \mathrm{Cr}$, and $\mathrm{Ni}$. As with specimen 9, there are numerous areas where the $\mathrm{Cd}$ coating has cracked during coldown of the test spccimen.

Figure 5-54 is a low-magnification SEM micrograph of the 1st grind on the top half of this specimen (e.g. just above the midplane of the rupture). Figures 5-55a through 5-55c show the left side of the fracture for this grind at the cladding inner surface, midwall, and outer surface, respectively. The grains near the fracture show extensive shear deformation up to about $3 / 4$ of the cladding thickness, as was the case with specimen 9. However, the grains along the fracture surface near the outer cladding surface also show some deformation. There is no clear evidence of the grain boundary decohesion and intergranular fracture which were present in specimen 9.

Composition analysis with EDS revealed several locations where the cladding inner surface and fracture surface were coated with an $\mathrm{Al} / \mathrm{Fe} / \mathrm{Cr} / \mathrm{Ni}$ layer. Figure $5-56 \mathrm{a}$ is an SEM micrograph of the left side of the fracture at the inner cladding surface for the 2 nd grind on the top half. Figure 5-56b shows the EDS spectra for the two layers adhering to the cladding surface indicated in Figure 5-56a; the inner layer is comprised on $\mathrm{Al}, \mathrm{Cd}$ and the cladding constituents $(\mathrm{Fe} / \mathrm{Cr} / \mathrm{Ni})$, and the suter layer contains only $\mathrm{Cd}$. Figure $5-57 \mathrm{a}$ shows the left side of the fracture approximately $3 / 4$ throughwall for the 2 nd grind on the bottom half; the composition of the layer indicated in Figure $5-57 \mathrm{a}$ is $\mathrm{Al} / \mathrm{Fe} / \mathrm{Cr} / \mathrm{Ni}$, as shown in the EDS spectrum in Figure 5-57b. Note that the intensity of the Al signal is much lower at the outer surface of the rladding relative to that at the inner surface (Figure 5-57b vs. 5-56b). Although, like specimen 9, some locations on the cladding inner and fracture surfaces are coated with an $\mathrm{Al} / \mathrm{Fe} / \mathrm{Cr} / \mathrm{Ni}$ layer, the layer is much thinner $(\approx 1$ to 2 vs. $\approx 10 \mu \mathrm{m}$ ) and its appearance is different than that which was present in specimen 9 .

\section{Specimen 12}

Figures 5-58a and 5-58b are montages of the outer cladding surface in the vicinity of the rupture comprised of SEM micrographs taken in the BSE and SE modes, respectively. Figures 5-59a and 5-59b show the inner cladding surface. The fracture appears to have a "tear drop" shape, however the bottom part of the fracture is obscured by a mass of oxidized and/or solidified cadmium. The outline of the bottom part of the fracture is faintly visible in Figure 5-58. The cladding surface is visible in the luwer right hand corner of Figure 5-59 where the cadmium has pulled away. 
Figure 5-60 is a low-magnification SEM micrograph of the 1st grind on the bottom half of this specimen (e.g. just below the midplane of the rupture). The cadmium "bridge" between the left and right sides of the iracture, which gave the fracture an apparent tear drop shape, is evident in this figure. Figures 5-61a and 5-61b show the left and right sides of the fracture, respectively. The left side of the fracture at the cladding inner surface is shown in Figure 5-62a; the thin layer between the cadmium and cladding, present on the cladding inner surface and fracture surface, has the $\mathrm{Al} / \mathrm{Fe} / \mathrm{Cr} / \mathrm{Ni}$ composition, as shown by the EDS spectrum on Figure 5-62b. Figure 5-63 shows the right side of the fracture near the cladding midpoint; the $\mathrm{Al} / \mathrm{Fe} / \mathrm{Cr} / \mathrm{Ni}$ layer is evident. Figures $5-64$ a shows the right side of the fracture at the cladding outer surface; Figure 5-64b is a higher magnification SEM micrograph at the cladding outer surface. The Al-bearing layer is present along the fracture almost out to the cladding outer surface; the EDS spectrum for this layer is shown in Figure 5-64c. As with specimens 9 and 11 , the intensity of the Al signal is much lower at the outer surface of the cladding relative to that at the inner surface (Figure 5-64c vs. 5-62b). The white material adhering to this layer is cadmium, as shown by the EDS spectrum in Figure 5-64d.

The cladding grains show some signs of deformation (shear) to very near the cladding outer surface. The fracture appears to have occurred in at least a partially ductile manner. It is clear that the cladding thinned locally at the fracture site prior to rupture, as evidenced by the curvature of the cladding outer surface immediately adjacent to the fracture and deformation of the grains in this region. This was also the case for the portion of the rupture examined in specimen 11, although to a lesser degree; no such highly localized thinning was apparent in specimen 9. As was also the case for specimen 11, the clear evidence of the grain boundary decohesion and intergranular fracture evident in specimen 9 was not seen with specimen 12 .

Figures 5-65a and 5-65b show the left and right sides of the fracture, respectively, for the 1 st grind on the top half of the specimen. Note that the fracture changes direction near the outer surface, leaving a "lip" on the outer surface; this "lip" is also evident in the outer surface montage (Figure 5-58a), just above the top of the "cadmium bridge". A shear line is clearly evident on the left side of the fracture (Figure 5-65a) which coincides with the fracture un to the "lip", at then continues through the cladding to the outer surface. Note the discontinuity in the cladding outer surface where the shear line intersects it. Although is not clearly visible in these figures, an $\mathrm{Al} / \mathrm{Fe} / \mathrm{Cr} / \mathrm{Ni}$ layer is present on the fracture face just 
up to the "lip". As with the bottom half of the fracture, the grains appear to have been deformed even at the outer cladding surface. Figure 5-66a shows the right side of the fracture at the "lip", near the cladding outer surface; the EDS spectrum for the thin $\mathrm{Al} / \mathrm{Fe} / \mathrm{Cr} / \mathrm{Ni}$ layer is given in Figure 5-66b. Figures 5-67a and 5-67b show the cladding inner surface just to the right of the fracture and the EDS spectrum for this same layer. As before, the Al signal in the EDS spectra is stronger at the inner surface than towards the outer surface (Figure $5-67 \mathrm{~b}$ vs. 5-66b). The $\mathrm{Al} / \mathrm{Fe} / \mathrm{Cr} / \mathrm{Ni}$ layer is much thinner and its appearance different than that which is present in specimen 9, as was also the case with specimen 11.

\subsection{Microprobe Examination of First Failed Specimen (no.9)}

The electron microprobe examination of specimen 9 is described in Tovo (1991) and discussed below. X-ray maps were generated for the 1 st grind on the bottom half and the 29th grind on the top half of specimen 9, and quantitative compositional linescans were made on the 3rd grind on the bottom half of specimen 9. The microprobe operating conditions are given in Section 2.3.

$\mathrm{X}$-ray maps were produced for two areas on the 1 st grind of the bottom half of specimen 9 (this is the grind most heavily characterized with the SEM, as discussed in Section 5.1.1), the inner cladding surface just to the left of the fracture and the left side of the fracture near the cladding midpoint. Figure 5-68a is a micrograph obtained with the microprobe of the inner cladding surface just to the left of the fracture (typical of the SEM micrographs shown in Figure 5-11c). The light grey region is the SS304 cladding, the dark grey layer corresponds to the Al-rich layer seen in the SEM examinations, the white (very bright) layer corresponds to the Cd-rich layer seen in the SEM examinations, and the outer layer is the fracture face sloping down and away. Figures 5-68b through 5-68d show the $\mathrm{x}$-ray maps for $\mathrm{Cr}, \mathrm{Al}$ and $\mathrm{Cd}$, respectively. The $\mathrm{x}$-ray maps for $\mathrm{Fe}$ and $\mathrm{Ni}$ are essentially identical to that for $\mathrm{Cr}$, but the $\mathrm{Cr}$ map was acquired as a higher resolution. As can be seen in the figures, $\mathrm{Al}$ is exclusively associated with the dark grey layer and $\mathrm{Cd}$ with the white layer. The $\mathrm{Cr}$ outside of the base metal is associated with the dark grey ( $\mathrm{Al}$ ) layer only. The geometric features associated with these layers (as shown on the micrograph, Figure 568a) can be matched exactly with the composition $x$-ray maps. Note that very few $x$-rays are reflected off the fracture face (e.g. the outer layer in Figure 5-68a). 
Figures 5-69 and 5.70a are SEM and microprobe micrographs, respectively, of the area examined on the left fracture surface near the cladding midpoint; this is the location where the dark grey, Al-rich layer on the fracture surface ends, and the remainder of the fracture surface out to the cladding outer diameter is either coated with the $\mathrm{Cd}-\mathrm{Cd}$ oxide layer or is bare. Note that the image obtained with the microprobe is inverted and rotated $180^{\circ}$ with respect to that from the SEM. As with the inner cladding surface, the outermost layer in Figure 5-70a is the fracture face sloping down and away. Figures 5-70b through 5-70d show the $\mathrm{x}$-ray maps for $\mathrm{Fe}, \mathrm{Al}$ and $\mathrm{Cd}$, respectively. Iron is detected only in the dark grey (Al) layer, as was the case for the $\mathrm{x}$-ray map for the inner cladding surface. No $\mathrm{Cd}$ is detected in the dark grey (Al) region, and $\mathrm{Al}$ is not detected beyond the point along the fracture surface where the dark grey layer stops. The Al extends somewhat into the white layer, unlike the $\mathrm{x}$-ray map for the inner cladding surface, indicating some degree of mixing with the Cd-rich material; this mixing is also apparent on the SEM micrograph (Figure 569). The $x$-ray intensity for this mixed zone appears to be very weak, indicating either that the material is very porous, or that the surface is not in the same orientation as the cladding and is not normal to the electron beam. As discussed in Section 7, the mixing between these layers and the porosity of the layer is thought to be the result of the local cladding temperature exceeding that required for $\mathrm{Al}$ melting and partial decomposition of $\mathrm{Al}$ $\mathrm{Fe}, \mathrm{Cr}, \mathrm{Ni}$ compounds after rupture had occurred.

$\mathrm{X}$-ray maps were produced for 3 areas on the 29th grind of the top half of specimen 9 , the left and right side of the fracture adjacent to the cladding outer surface and the left side of the fracture surface approximately $1 / 3$ through the cladding thickness. The SEM examination showed little or no $\mathrm{Al}$ on this grind, and all $3 \mathrm{x}$-ray maps confirmed this.

Compositional linescans were made for the 3rd grind on the bottom half of specimen 9 . Four linescans were performed on the left side on the fracture at approximately the cladding midpoint. This corresponds to the location where the $\mathrm{Al} / \mathrm{Fe} / \mathrm{Cr} / \mathrm{Ni}$ layer coating the fracture surface stops; an SEM micrograph of this area is given as Figure 5-24a. There is very little material adhering to the grey $\mathrm{Al} / \mathrm{Fe} / \mathrm{Cr} / \mathrm{Ni}$ layer, and the fracture face appears to slope down and away at a steep angle. Since this surface is very far off normal to the electron beam, the line scan data beyond the $\mathrm{Al} / \mathrm{Fe} / \mathrm{Cr} / \mathrm{Ni}$ layer has no relevance. Further difficulties with the line scan measurements resulted from electron beam channelling between the $\mathrm{A} / \mathrm{Fe} / \mathrm{Cr} / \mathrm{Ni}$ layer and the cladding, from porosity entrained in this layer, and possibly from differences in orientation between the cladding and $\mathrm{Al} / \mathrm{Fe} / \mathrm{Cr} / \mathrm{Ni}$ layer (the sample was etched prior to the line scans). The data from the linescans is very erratic and it is difficult, 
if not impossible, to estimate the error associated with the data. Based on the total amount of material measured relative to the pure element standards, the error could be as high as an order of magnitude for some of the data points. Furthermore, the error will vary significantly from point to point depending on the severity of channeling, porosity, and surface orientation effects. The only information from the linescans which was consistent, and thus judged to be reliable, is that the $\mathrm{Al} / \mathrm{Fe} / \mathrm{Cr} / \mathrm{Ni}$ layer is predominantly $\mathrm{Al}$, on the order of 40 to 80 weight per cent. This was also approximately the range of values obtained using standardless semi-quantitative analysis on the SEM, and expected based on the intensity of the Al signal relative to those of the SS304 constituents in the $\mathrm{x}$-ray maps generated for this layer.

In summary, the microprobe examinations confirmed the general composition of the $\mathrm{Al} / \mathrm{Fe} / \mathrm{Cr} / \mathrm{Ni}$ layer. Quantitative analysis of the layer composition was not possible with the specimens examined. 


\section{CANDIDATE FAILURE MECHANISMS}

This section discusses mechanisms which wer : considered as possible causes for the fuilures observed in the cadmium safety rod thermal tests. The mechanisms considered were: pure mechanical (e.g. ductility exhaustion [creep rupture] or overpressure), formation of low-melting point eutectics, material defects, liquid metal embrittlement, and liquid metal dissolution. The characteristics of and evidence for each of these mechanisms are discussed below.

\subsection{Pure Mechanical (Ductility Exhaustion, Creep Rupture)}

The safety rod cladding deformation during the thermal tests can be conceptualized as a two-step process; the first being displacement controlled and due to thermal expansion and phase changes of the Cd layer and Al-6061 core, and the second being load controlled and due to internal pressure exerted by air, water vapor and/or gases trapped within the cladding.

During the deformation controlled load step, the pressure exerted on the cladding and the resulting cladding stresses are determined by its strength; if the cladding were very weak, then the pressure and cladding stress would be small, conversely the pressure and stress would be comparatively large for a high strength cladding. The cladding strain would be the same in either case and is determined directly by the magnitude of the volume increase for the Cd layer and Al-6061 core. The results obtained from the finite element model developed to model the cadmium safety rod test specimens show that the internal pressure, and hence cladding stress, can decrease as temperature is increased due to the decrease in cladding strength (Gupta 1991). In addition, any creep deformation of the safety rod cladding would decrease the applied load. To the extent that the safety rod cladding loading is deformation controlled, it is fundamentally different than a pressurized tube test; cladding deformation in a pressurized tube does not relieve the applied load and strain continues to accumulate until rupture occurs. The presence of air, water vapor and/or gases trapped within the cladding introduces another load component on the cladding which is load controlled rather than deformation controlled. For a temperature of $550^{\circ} \mathrm{C}$ and an internal pressure of $3000 \mathrm{psi}$, which is in the range predicted for the safety rod thermal tests (Gupta 1991), calculations based on the ideal gas law show that the volume of the air trapped in the safety rod would be reduced to $1.4 \%$ of its pre-test value (it is recognized that this is only an estimate since the ideal gas law is not accurate at elevated pressures and air is a gas 
mixture). The maximun predicted hoop stress for the test condicions was calculated to be $40 \mathrm{ksi}$ due to the expansion of the Cd and Al-6061 relative to the cladding (Gupta 1991); if the corresponding elastic component of the cladding hoop strain were relieved (which would eliminate this portion of the applied load), then for a 2 mil Cd-cladding gap the air would still exert a pressure of approximately 100 psi. Unless the safety rods were fabricated in an inert environment, there will also be some amount of water and water vapor trapped inside the rod; this will act to increase the internal pressure at elevated temperatures. It is also reasonable to expect that oxidation of $\mathrm{Cd}$ and $\mathrm{Al}$ will occur during the test, so that hydrogen may be generated and act to increase the internal pressure. Therefore, the safety rod loading is not purely deformation controlled and the rod will be pressure loaded even if significant cladding deformation occurs at a fixed temperature. The internal pressure due to the volume increase of $\mathrm{Cd}$ and Al-6061 is augmented by these other terms, although their contribution is not expected to be large.

Cladding hoop strain at failure was selected as a failure criterion, rather than the cladding tensile or creep rupture strength, due to the uncertainties in calculating the cladding hoop stress. Since failure strain is employed, the evaluation is independent of both the magnitude of the loads placed on the cladding and the loading mechanisms. The conclusions reached are therefore valid even if large amounts of water were present inside the safety rod prior to the tests, large amounts of hydrogen were generated during the tests, or if other loading mechanisms not discussed above were operative. In the absence of any cladding flaws or environmental degradation (e.g. interaction between the cladding and liquid metal solution), the cladding will fail when its hoop strain exceeds the failure strain (e.g. ductility exhaustion).

The cladding temperature, strain rate, cold work and loading geometry must all be considered in evaluating the failures observed in the safety rod thermal tests. The lowtemperature safety rod test specimen failures occurred at peak cladding temperatures ranging from 521 to $590^{\circ} \mathrm{C}$, and the high-temperature failures occurred with peak cladding temperatures of 830 and $870^{\circ} \mathrm{C}$. The cladding strain rate actually varies somewhat throughout a test since the rate of temperature increase is not a fixed constant. In addition, the relationship between cladding strain and temperature is nonlinear, although between the melting point of $\mathrm{Cd}\left(321^{\circ} \mathrm{C}\right)$ and the solidus of $\mathrm{Al}-6061\left(528^{\circ} \mathrm{C}\right)$ a linear relationship is a reasonable approximation. Based upon the failure strain and time above $321^{\circ} \mathrm{C}$, the average cladding strain rates for the low-temperature failures were on the order of $2 \times 10^{-4}$ to $7 \times 10^{-4}$ inin $^{-1}$, and those for the high-temperature failures were approximately $0.02 \mathrm{~min}^{-1}$. A 
pressurized tube burst test with a sample of safety rod cladding, discussed later in this section, was conducted at $550^{\circ} \mathrm{C}$ with an average strain rate of $0.03 \mathrm{~min}^{-1}$. The safety rod cladding was swaged down from 1 " to 0.94 " outer diameter during fabrication, introducing approximately $6 \%$ cold work. The load placed on the safety rod cladding during both the thermal and burst tests is multiaxial, unlike a standard tensile test where the applied load is uniaxial. The effects of temperature and strain rate, cold work, and multiaxial loading on failure strain are discussed separately below in order to predict the cladding hoop strain at failure for the safety rod test specimens and pressurized tube burst test specimen.

\subsubsection{Effect of Temperature and Strain Rate for Annealed SS304}

A number of evaluations have been reported in the literature for the tensile properties of annealed SS304 at elevated temperatures. The total elongation values reported in these evaluations are in fairly good agreement for temperatures less than $500^{\circ} \mathrm{C}$. Total elongation decreases from room temperature to approximately $300^{\circ} \mathrm{C}$ and is nearly constant to about $500^{\circ} \mathrm{C}$; the total elongation at $500^{\circ} \mathrm{C}$ is approximately 40 to $45 \%$. Tensile tests with SS304 conducted as part of this task (Thomas 1992) gave similar values (see Section 6.4.6). Above this temperature, strain rate and metallurgical variables (e.g. grain size, impurity levels) appear to play a much greater role and there is considerable scatter in the ductility data and disagreement among different evaluations.

Stainless steel tensile property data from the U.S. were collected and reported by Simmons and Cross (1952) and Simmons and Van Echo (1965); these data indicate that the total elongation of SS304 is relatively insensitive to temperature above $500^{\circ} \mathrm{C}$, although the data does exhibit some scatter. Sikka and Booker (1977) correlated the available annealed SS304 tensile data from U.S., U.K., and Japanese data bases separately. They report that total elongation above $500^{\circ} \mathrm{C}$ decreases slightly for the U.S. data (reaching $30 \%$ at $750^{\circ} \mathrm{C}$ ), increases slightly for the U.K. data (reaching $45 \%$ at $750^{\circ} \mathrm{C}$ ), and increases greatly for the Japanese data (reaching $80 \%$ at $750^{\circ} \mathrm{C}$ ). The difference in the ductility trend above $500^{\circ} \mathrm{C}$ for these data bases is probably due to differences in specimen composition and metallurgical condition. Some of the difference may also be due to specimen geometry; a comparatively short gauge length will accentuate the effect of necking and increase the measured failure strain. Brinkman et al. (1977) evaluated and correlated the combined U.S.-U.K.-Japanese annealed SS304 tensile properties data base and concluded that total elongation increases with temperature after approximately $500^{\circ} \mathrm{C}$ (reaching $57 \%$ at $750^{\circ} \mathrm{C}$ ); 
the evaluation of Brinkman et al. (1977) has been adopted in a number of more recent reviews on the properties of austenitic stainless steels (Marshall 1984).

Standard tensile tests are typically run at strain rates between $5 \times 10^{-3}$ and $5 \times 10^{-2} \mathrm{~min}^{-1}$ (ASTM Standards E21-79 and E8-88), and the data given above corresponds to this range. Sikka (1978) tested the tensile properties of SS304 up to $800^{\circ} \mathrm{C}$ for strain rates from $2.6 \times 10^{-6}$ up to $5 \mathrm{~min}^{-1}$. Total elongation remained fairly constant above $500^{\circ} \mathrm{C}$ for strain rates above $1 \times 10^{-2} \mathrm{~min}^{-1}$. Below this strain rate, the ductility dropped off at elevated temperatures. The decrease in total elongation was more severe and occurred at lower temperatures for lower strain rates; a limited recovery of ductility occurred in the range from 700 to $8 \mathrm{~W}^{\circ} \mathrm{C}$. These effects are more apparent in the reduction of area (RA) data; the data from Sikka (1978) are shown in Figure 6-1 (Swindeman and Brinkman 1982). As can be seen, ductility drops sharply above $500^{\circ} \mathrm{C}$ at low strain rates and recovers slightly at higher temperature $\left(\approx 700^{\circ} \mathrm{C}\right)$. The decrease in ductility is generally associated with the onset of intergranular failure due to grain boundary decohesion. The strain rate temperature regime where intergranular failure dominates is denoted in Figure 6-1. The total elongation data is not as sensitive, since grain boundary separation normal to the tensile axis provides elongation with little or no reduction in area. The susceptibility of austenitic stainless steels to intergranular fracture in this strain rate - temperature regime has been observed in a number of experiments (Myers 1962, Wray 1969, Ahlblom and Sandström 1982, Marshall 1984).

The U.S. SS304 tensile property data bases are the most relevant to the safety rod cladding. The low temperature failures occurred at a sufficiently slow strain rate that the ductility of annealed SS304 in the range from 500 to $600^{\circ} \mathrm{C}$ would be decreased relative to that for a standard tensile test; a total elongation of approximately $30 \%$ would appear applicable based on the data of Sikka (1978). The strain rate for the high temperature failures was consistent with that for standard tensile tests and a total elongation of approximately $35 \%$ would be expected in the range of 800 to $900^{\circ} \mathrm{C}$. Similarly, the safety rod cladding burst tests were conducted at a high strain rate and a $40 \%$ total elongation at the test temperature $\left(550^{\circ} \mathrm{C}\right)$ would be expected.

\subsubsection{Effect of Cold Work on SS304 Ductility}

Cold work increases strength and decreases ductility, with the effect of cold work generally decreasing with increasing temperature. Swaging during manufacture introduced 
approximately $6 \%$ cold work to the safety rod cladding. For $6 \%$ cold work, the total elongation on SS304 decreases by approximately $25 \%$ at $550^{\circ} \mathrm{C}$ and $10 \%$ at $850^{\circ} \mathrm{C}$ relative to annealed material (Gold et al. 1975, Moen and Smith 1975, and Moen and Duncan 1976).

\subsubsection{Effect of Multiaxial Loading}

The total elongation values discussed above are applicable to uniaxial loading. Multiaxial loading, as is the case for the safety rod thermal tests, reduces the magnitude of the principal strain at failure. The maximum principal strain at failure for a multiaxial loading can be approximated as the uniaxial failure strain divided by the triaxiality factor (Manjoine 1975 and Wei and Nelson 1982). The triaxiality factor (TF) is defined as:

$$
\begin{aligned}
& \mathrm{TF}=\frac{\sigma_{1}+\sigma_{2}+\sigma_{3}}{\sqrt{\frac{1}{2}\left(\left(\sigma_{1}-\sigma_{3}\right)^{2}+\left(\sigma_{3}-\sigma_{2}\right)^{2}+\left(\sigma_{2}-\sigma_{1}\right)^{2}\right)}} \\
& \text { where: } \quad \mathrm{TF}=\text { Triaxiality factor, } \\
& \sigma_{\mathrm{j}}=\text { Principal stresses, and } \\
& \sigma_{\mathrm{e}}=\text { Equivalent (von Mises) stress. }
\end{aligned}
$$

The hoop, radial, and axial stresses correspond to the three principal stresses for a pressurized tube. The safety rod can be treated as a thin-walled pressurized tube under the thermal test conditions; therefore the hoop stress is approximately twice the axial stress and, under the safety rod thermal test conditions, the radial stress is negligible in comparison (Rust 1979). This gives a TF of 1.73 and a predicted multiaxial to uniaxial failure strain ratio of 0.58 . Of course, the formulation given above is very simple and does not account for differences in metallurgical condition. Wei and Nelson (1982) give experimental data for multiaxial to uniaxial failure strain ratio as a function of the TF for a number of different alloys. According to their data, the multiaxial to uniaxial failure strain ratio varies between 0.75 and 0.25 for a TF of 1.73 (e.g. for pressurized tubes).

Deformation of the safety rod cladding due to expansion of the $\mathrm{Cd}$ and Al-6061 is analogous to biaxial stretching in metalworking processes. Forming limit diagrams developed for these processes can therefore be used to predict ductility limits based on the major to minor in-plane strain ratio. This ratio is approximately 2 for a uniaxial tensile test on a ductile material. The minor (axial) strain is essentially zero for the safety rod cladding. 
Based on typical forming limit diagrams, the ratio between the major strain at failure for these two cases is approximately a factor of 2 (Hecker 1975, Dieter 1976, Newby 1979, Embury and Duncan 1981).

The multiaxial ductility limits based upon the triaxiality factor and forming limit diagrams are in reasonable agreement. A multiaxial to uniaxial failure strain ratio of 0.5 was adopted in this evaluation.

\subsubsection{Predicted Failure Strains and Comparison with Experimental Data}

The predicted safety rod cladding hoop strain at failure under the conditions applicable to the low-temperature failures, high-temperature failures, and pressurized tube burst test are given in Table 6-1; the effects of temperature and strain rate, cold work, and multiaxial loading are illustrated separately. The predicted cladding hoop strains at failure for these three conditions are 12,16 , and $15 \%$. Considering the uncertainties in deriving these values, it is reasonable to assume that the predicted failure strains are good to within $\pm 25 \%$ (e.g. $12 \pm 3 \%$ for the low-temperature failures).

In order to verify the high-temperature multiaxial ductility of the safety rod cladding and demonstrate the nature of an overpressure failure with this material, a set of pressurized tube burst tests were conducted using safety rod cladding samples (Thomas 1992). These tests, conducted at the Westinghouse Science and Technology Center, were considered scoping in nature and were not carried out under an NRTSC technical procedure. However, the guidance given in the NRTSC experimental QA procedures was employed where possible and, since the data do not form the only basis for the ductility estimates (e.g. they are confirmatory), they do not require qualification for critical applicaitons per NRTSC QAP III-2. One of the cladding specimens was pressurized rapidly to failure at $550^{\circ} \mathrm{C}$. The pressure was increased in an approximately linear fashion and failure occurred at a pressure of $4200 \mathrm{psi}$ with a test time of 330 seconds. The hoop strain at failure was $15.4 \%$, which gives an average strain rate of $0.03 \mathrm{~min}^{-1}$. This failure strain is in good agreement with the predicted value given in Table 6-1 (15\%).

The measured hoop strains for unfailed safety rod specimens tested at 500 to $600^{\circ} \mathrm{C}$ ranged from approximately 0 to $5.5 \%$, with the variation in experimental values attributed to variations in cladding thickness and gap size (see Section 4.1). The specimens which failed in this temperature range were also observed to have very low hoop strains $(<3 \%)$. 
These hoop strain values are well below the predicted failure strain given in Table 6-1 $(12 \%)$. The specimens which failed at high temperatures had measured hoop strains of 13 $-14 \%$, which is in good agreement with the predicted value given in Table 6-1 (16\%). It is therefore concluded that the low-temperature failures were not purely mechanical in nature (e.g. as the result of ductility exhaustion or overpressure). Furthermore, it is concluded that the high-temperature failures were primarily mechanical in nature with little, if any, contribution from the other failure mechanisms considered in this evaluation.

\subsection{Formation of Low-Melting Point Eutectic}

This mechanism refers to the possibility that elements in the liquid metal solution might have combined with $\mathrm{Fe}, \mathrm{Cr}$, or $\mathrm{Ni}$ in the stainless stee! to produce a compound which would subsequently melt as test temperature was increased; based on the temperatures at which failures occurred, the melting point of such a compound would have to be at or below approximately $500^{\circ} \mathrm{C}$. This would lead to thinning of the cladding and, once a sufficient fraction of the wall thickness had been consumed by the reaction, rupture. This mechanism was evaluated by examining the relevant phase diagrams and by conducting differential thermal analysis (DTA) experiments with material samples taken from a safety rod.

\subsubsection{Phase Diagrams}

The phase diagram for the Cd-Al system is shown in Figure 6-2 (ASM 1990); Figure 6-3 shows the $\mathrm{Cd}$ end of the diagram (McAlister 1982). In the temperature range where the low-temperature failures occurred $\left(500-600^{\circ} \mathrm{C}\right)$, liquid $\mathrm{Cd}$ can dissolve $1 / 2$ to $1 \mathrm{wt} . \%$ of Al. Evidence of appreciable dissolution of the Al-6061 core by the liquid $\mathrm{Cd}$ solution was observed in the destructive examination of the unfailed specimen (Section 5.1.2). The phase diagram for the Cd-Ni system is shown in Figure 6-4 (ASM 1990). Liquid Cd can dissolve approximately 6 to $7 \mathrm{wt} . \% \mathrm{Ni}$ in the temperature range of interest; the $\mathrm{Ni}$ flash coating on the Al-6061 was observed to be partially dissolved in the destructive examination of the unfailed specimen. Therefore, the liquid metal solution would be expected to contain $\mathrm{Al}, \mathrm{Ni}$, and the minor alloying elements and impurities associated with the Al-6061 core and Ni flash coating.

The phase diagrams for the $\mathrm{Al}-\mathrm{Fe}, \mathrm{Al}-\mathrm{Cr}$ and $\mathrm{Al}-\mathrm{Ni}$ systems are shown in Figures 6-5 through 6-7 (ASM 1990). Intermetallic compounds of $\mathrm{Al}$ and the stainless steel 
constitutive elements form, but have melting points above $640^{\circ} \mathrm{C}$. The phase diagram for the Cd-Ni system was given in Figure 6-3. A low melting point compound does exist in this system $\left(\mathrm{Cd}_{5} \mathrm{Ni}, \mathrm{T}_{\mathrm{m}}=495^{\circ} \mathrm{C}\right.$ ); however, since $\mathrm{Ni}$ is a minor constituent in SS304 (8 to $10 \mathrm{wt} . \%)$, it is not likely that this reaction could consume significant quantities of cladding even if the reaction were very rapid. No compounds are known to form in the Cd-Fe and Cd-Cr systems. The available ternary phase diagrams for the stainless steel constituents, $\mathrm{Al}$, and major alloying elements in $\mathrm{Al}-6061(\mathrm{Mg}, \mathrm{Si}, \mathrm{Cu})$ were also examined (Phillips 1959, Rivlin and Raynor 1981); no low-melting point eutectic compounds were identified.

Thus, based upon examination of the relevant phase diagrams, it appears that a low-melting point eutectic would not be formed as a result of reactions between any of the constituents present in the safety rod.

\subsubsection{DTA Results}

Differential Thermal Analysis (DTA) tests were conducted with shavings of Cd, Al, and SS taken from a safety rod in order to confirm this conclusion (NRTSC Technical Procedure TP-90-022 Rev.0). The DTA tests, conducted in both air and nitrogen environments at temperatures up to $700^{\circ} \mathrm{C}$, did not indicate any reactions (Marra 1991). Since it is known that $\mathrm{Al}$ will form intermetallics with $\mathrm{Fe}, \mathrm{Cr}$ and $\mathrm{Ni}$, the lack of reported reactions must be interpreted as evidence that the reactions which did occur were neither extensive or rapid. This is partly due to the formation of oxides and/or nitrides, particularly with $\mathrm{Cd}$, interfering with the DTA trace such that other reactions taking place are difficult to detect. Samples fror the tests were examined using the SEM/EDS. Limited interaction (dissolution) of SS by $\mathrm{Al}$ was observed in a number of tests. Figure 6-8a is representative of this reaction; the EDS spectra for the points indicated in Figure 6-8a are given in Figures $6-8 \mathrm{~b}$ through $6-8 \mathrm{~d}$. The shaving shown in the Figure 6-8a is Al. The light gray areas correspond to dissolved SS and the dark grey particle in the lower right of figure is an agglomeration of $\mathrm{Al}, \mathrm{Mg}$ and $\mathrm{Cd}$. Most of the $\mathrm{Cd}$ present on the $\mathrm{Al}$ and $\mathrm{SS}$ shavings was in the form of spherical beads, indicating a lack of wetting due to protective oxide films; however limited areas where good wetting took place were observed. Figure 6-9a illustrates very good wetting of $\mathrm{Al}$ by $\mathrm{Cd}$ and limited interaction between $\mathrm{Al}$ and $\mathrm{Cd}$. The $\mathrm{Cd}$ is present in sheets on the surface, as shown by the EDS spectra in Figure 6-9b. Similarly, Figure 6-10a shows limited wetting of the SS by Cd. Most of the Cd is present as small spherical particles, however some of the $\mathrm{Cd}$ appears to have wetted the surface, 
such as the spot " $\mathrm{D}$ " denoted in the figure. The EDS spectra for these areas denoted in Figure 6-10a are given in Figures 6-10b and 6-10c.

The SEM/EDS observations on the DTA test specimens are consisteni with other observations made in the safety rod destructive examinations, with the behavior expected based on the phase diagrams, and with other investigations reported in the literature. Dissolution of stainless steels by molten $\mathrm{Al}$ has been documented in a number of studies (Webb and Pohlman 1980, Nazarchuk et al. 1985, Dybkov 1990), and the dissolution of $\mathrm{Al}$ by $\mathrm{Cd}$ was clearly seen in the examination of specimen 10 (Section 3.3) and has been reported elsewhere (Ondrejcin 1967). The general lack of wetting of the inside surface of the safety rod cladding by molten $\mathrm{Cd}$ (e.g. Cd present as small spherical particles attached to the surface) was observed in the examinations of the failed rods. Dissolution is discussed in more detail in Section 4.5.

\subsection{Cladding Defects}

This candidate failure mechanism refers to thin spots, pre-existing cladding cracks or flaws, or any deleterious microstructural features which would lead to low cladding strains and/or stresses. This mechanism was considered since the low temperature $\left(<600^{\circ} \mathrm{C}\right)$ failures occurred at relatively sinall global strains and were highly localized. A local thin spot, cladding flaw or geometric irregularity in the cladding therefore appeared to be a plausible failure mechanism. Such flaws might have been present while the cladding was in the drawn condition, or could have been generated during swaging operations. However, as discussed in Section 2.1, none of the pre-test radiographs indicated the presence of localized thin spots or dimensional irregularities in the cladding. Any flaws present in the cladding would therefore have to be fairly small, on the order of $20 \%$ of the wall thickness or less.

Gupta (1991) developed a 3D finite element model of the safety rod cladding to examine the response of the cladding to semi-elliptical cracks. It was concluded that, for the predicted loading conditions, cracks would be stable for depths up to at least $62 \%$ of the cladding wall thickness. Thus, small cracks present in the cladding prior to thermal testing would not be expected to propagate rapidly and lead to failure.

Analyses presented in Gupta (1991) also demonstrated that, for the predicted loading conditions, hemispherical pits located on the inner cladding surface would not increase the 
stress-strain field in front of the pit sufficiently to cause failure until the pit depth was greater than $1 / 2$ the wall thickness. This result is supported by a pressurized burst tests conducted with defected SS304 tubing (Kirby 1962). In Kirby's experiments, artificial defects similar in shape and orientation to those normally present as the result of drawing and swaging operations were generated on the outside of SS304 tubes using spark machining; the defects produced were approximately $0.125^{\prime \prime}$ in length and 3 mils wide. The tubes had an $0.875^{\prime \prime}$ outer diameter and a wall thickness of 16 mils, and were tested in both the annealed and 1/8 hard temper condition. The tubes were subsequently pressurized to failure. The hoop stress at failure as a function of the defect depth is shown in Figure 6$11 \mathrm{a}$ for temperatures ranging from 677 to $732^{\circ} \mathrm{C}\left(1250-1350^{\circ} \mathrm{F}\right)$ and defect depths up to $20 \%$ of wall thickness, and in Figure $6-11 \mathrm{~b}$ for $677^{\circ} \mathrm{C}\left(1250^{\circ} \mathrm{F}\right)$ for defect depths up to $50 \%$. The scatter evident in these figures represents tube to tube variations, as evidenced in Figure $6-11 \mathrm{~b}$ by the scatter for a $0 \%$ defect depth at a fixed temperature $\left(677^{\circ} \mathrm{C}\right)$. As shown in Figure 6-11a, defect depths less than $20 \%$ of the wall thickness had little impact on the load bearing capacity of the tubes, the minimum hoop stress at failure was only reduced by about $7 \%$ for a defect depth of $20 \%$, and the average hoop stress at failure was unaffected for defect depths up to 20\%. Conversely, as shown in Figure 6-11b, a defect depth of $50 \%$ reduced the hoop stress at failure by approximately $40 \%$. Therefore, based on both structural analyses and experimental data, localized thin spots or pits with depths less than $20 \%$ of the wall thickness would not be expected to lead to failure.

Room temperature bend and tensile tests performed on safety rod cladding samples, taken both before and after testing, showed a large amount of low-temperature ductility with no signs of extensive secondary cracking; these tests were scoping in nature and were not conducted under an NRTSC technical procedure, and the resulting data were not qualified. Similarly, the burst tests performed on safety rod cladding samples at $550^{\circ} \mathrm{C}$ (see Section 6.1) demonstrated the cladding had good high-temperature ductility. These experimental data show that the safety rod cladding, in general, possessed both low- and hightemperature ductility and was not subject to low failure strains as a result of microstructural defects. These tests do not rule out the possibility that an individual test specimen contained localized material defects. However, the post-test destructive examinations did not indicate any microstructural features that would correspond to locally weak material or degraded material properties relative to the bulk material. Therefore, localized material defects do not appear to be a credible failure mechanism. 


\subsection{Liquid Metal Embrittlement}

As discussed below and in the following section, the term liquid metal embrittlement (LME) may be used to denote a wide range of liquid metal degradation phenomena. In this report, the term LME is used only to refer to the "classic" LME degradation mode; other liquid metal degradation phenomena, such as dissolution or the formation of intermetallics, are treated as separate mechanisms. This notation and treatment of LME is not unique to this report and has been adopted in recent literature. The discussion given below is based primarily on Old (1980a) and (1980b), Kamdar (1983), and Stoloff (1990); information taken from other sources is explicitly cited.

It is important to note that it is impossible to prove that a given solid-liquid metal couple is completely immune to LME, and the available literature suggests that any couple might be subject to LME given the right combination of test conditions. Therefore, the relevant issue examined in this evaluation is the likelihood of susceptibility under conditions representative of those employed in the safety rod thermal tests.

\subsubsection{Characteristics of "Classic" LME}

Classical LME may be considered to be an adsorption-induced reduction in cohesive strength such that a crack nucleates and propagates faster or at lower stresses than in an inert environment, although a comprehensive mechanistic description of LME has not been developed to date. The conditions necessary for LME are:

- good wetting of the solid by the liquid metal,

- a tensile stress,

- some measure of plastic flow, and

- a barrier to plastic flow at the solid-liquid metal interface (or an existing crack).

For stainless steels, the wetting requirement is synonymous with a requirement for rupture or breakdown of the protective oxide film. For example, $\mathrm{Zn}$ will not embrittle SS with a continuous oxide film because the $\mathrm{Zn}$ will not wet the surface; however, $\mathrm{Zn}$ can severely embrittle SS once, the oxide film has been breached (Dillon 1990). A similar situation exists for the embrittlement of $\mathrm{Al}$ by $\mathrm{Hg}$ (Krupowicz and Hampton 1990), and in this system a crack formed via LME may stop growing due to aluminum oxide formation at the crack tip (Wheeler 1989). Based on experimental observations, discussed in later sections, $\mathrm{Cd}$ also does not wet SS. The requirement for plastic flow imposes some minimum strain 
criteria. The requirement for a barrier to plastic flow at the solid-liquid metal interface indicates that crack initiation will occur preferentially at grain boundaries, although other barriers can also serve as crack initiation sites and single crystal specimens can exhibit LME, A characteristic of all systems subject to LME is that the stress-strain (loaddisplacement) curve is essentially unaffected up to the point of fracture (e.g. no change in the yield and plastic flow properties).

In addition to these requirements, two empirical observations have been made which hold true for most, but not all, of the available experimental data: solid-liquid metal couples subject to LME exhibit (a) limited mutual solubility, and (b) little tendency to form intermetallic compounds. This is consistent with physical expectations because dissolution of and/or compound formation would blunt the crack and increase the stress intensity required for propagation.

Intergranular cracking is often associated with $\mathrm{LME}$, however single crystals may be subject to LME and transgranular cracking has also been reported. Grain boundaries are often the preferred site for crack initiation and subsequent growth, but other obstacles to slip which may allow stress concentrations to develop can also serve as crack initiation sites. LME cracks can be mixed-mode (inter- and transgranular) and portions of the fracture surface may appear ductile. Secondary cracking may be present if the energy required for propagation is larger than that required for nucleation, but in some cases only a single crack (that leading to failure) will be observed. Very fast crack growth rates are also often associated with LME and the resulting failures have been described as instantaneous or catastrophic. Crack growth rates for LME are typically several orders of magnitude greater than those for stress corrosion cracking (SCC) (Krupowicz 1989), and values on the order of several hundred $\mathrm{cm} / \mathrm{s}$ have been reported. However this is not true for all solid-liquid metal couples subject to LME and some exhibit relatively slow crack growth rates. Thus, degradation via LME implies a reduction in strength or loss of ductility, and not necessarily a completely brittle and instantaneous fracture. It is exceedingly difficult to confirm or rule out LME as a failure mechanism based solely on an examination of a failed component or specimen.

In addition to embrittlement by liquid metals, some materials are also subject to solid metal embrittlement (SME). In this case, the embrittling species is transported to the crack tip via surface diffusion or vapor transport. In other respects, SME and LME display similar characteristics. 


\subsubsection{Relevant LME Test Variables}

Given that a metal couple is subject to LME, the primary test variables which determine whether embilttlement will actually occur are: temperature, strain rate, the presence or absence of notches, embrittler composition, and microstructure (grain size, slip character, cold work, and precipitate size and spacing). Of these, both temperature and strain rate were variables in the safety rod thermal tests. The safety rod from which the specimens that failed at low temperatures were taken had a smaller grain size than the other rods employed in these tests, as discussed in Section 2.4 , so that effectively grain size was also a test variable.

Sensitivity to LME for a given system is exhibited over a limited range of temperatures. The lower end of this range is the melting point of the embrittling species for most systems, although in some cases embrittlement is exhibited below the melting point (e.g. solid metal embrittlement). Additionally, some systems are not sensitive to embrittlement until well above the melting point of the embrittling species. The lower end of the temperature range is apparently determined by the transport of the embrittling species, although this explanation does not account for all the observed experimental data. Increasing the temperature above the high end of this range gives the solid metal sufficient ductility that the stress concentration required for crack initiation and/or propagation cannot be maintained. The spread between the lower and upper temperatures at which LME may occur is dependent on the metal system and test conditions.

As with other embrittlement mechanisms, such as SCC, LME exhibits a strain rate dependency (Herbsleb and Schwenk 1985). At high strain rates, the supply of liquid to the crack tip is restricted and failure occurs in the same manner as in an inert environment. The physical mechanism underlying the lack of sensitivity at very low strain rates has not been clearly established, but is probably related to crack tip blunting due to stress-assisted dissolution; although in some systems re-establishment of protective films may play a role. While the absolute value of the strain rate range over which LME may occur is dependent on the material system and other test conditions, the lower and upper ends of this range are on the order of $10^{-7}$ and $10^{-2} \mathrm{sec}^{-1}$ (Herbsleb and Schwenk 1985, Krupowicz 1989). Unlike most other embrittlement mechanisms, such as SCC, higher strain rates generally increase the tendency for and severity of LME. Increasing strain rate generally increases the range of temperatures over which a given system is subject to LME, while the lower 
temperature limit is not affected (Johnson et al. 1977); for embrittlement of Ti by liquid Cd, increasing the strain rate from $10^{-5}$ to $10^{-2} \mathrm{sec}^{-1}$ increases the upper temperature for which the system is embrittled from slightly above 400 to approximately $625^{\circ} \mathrm{C}$ (Old $1980 \mathrm{~b}$ ), The degree of embrittlement also generally increases with strain rate (e.g. the failure strain decreases as the strain rate increases). Thure are some systems which exhibit the opposite trend, with embrittlement being less severe at higher strain rates; however, Stoloff (1990) attributes these fullures to grain boundary penetration (as evidenced by extensive secondary cracking) as opposed to the "classic" LME mechanism.

Grain size has 2 main effects on LME susceptibility. First, the fracture stress for metals which are subject to LME varies as $\mathrm{d}^{-1 / 2}$ (Kamdar 1983) in accordance with the Hall-Petch relationship (Reed-Hill 1973 and Dieter 1976). Small grains will therefore increase the stress required to initiate fracture in a liquid metal solution. Second, small grains reduce the maximum temperature for which a LME occurs (Old 1980b)

The liquid metal composition can also have a strong influence on the occurrence and degree of embrittlement. Small additions of other elements to a liquid metal can produce very different results than the pure metal. More importantly for this evaluation, the dissolution of small amounts of a higher melting point material into a liquid metal may result in more severe embrittlement than a molten solution comprised only of the dissolved species. For example, liquid $\mathrm{Cd}$ does not embrittle $\mathrm{Al}$, but $\mathrm{Cd}$ dissolved in $\mathrm{Hg}$ results in LME of $\mathrm{Al}$ alloys at room temperature.

\subsubsection{Applicable Literature Data}

Only two experiments have been reported in the literature which examined the susceptibility of austenitic stainless steels to LME by liquid or solid Cd; in neither case was embrittlement observed. Old (1980b) reports that experiments performed by Kennedy showed no embrittlement of an austenitic stainless steel (SS302) by solid Cd for temperat res between $200^{\circ} \mathrm{C}$ and the melting point of $\mathrm{Cd}\left(321^{\circ} \mathrm{C}\right)$. The composition of SS302 is sinnilar to that of SS304, but SS302 has a slightly higher carbon concentration $(0.15$ vs. $0.08 \%)$. Since the yield strength of SS304 is slightly lower than that of SS302 (235 vs. $240 \mathrm{MPa}$ for the annealed bar form at room temperature (Harvey 1982)), SS304 would be expected to be somewhat more resistant to LME. Dityatkovskiy et al. (1963) tested the susceptibility of a normalized austenitic stainless steel ( $1 \mathrm{Kh} 18 \mathrm{~N} 9 \mathrm{~T})$ to embrittlement by liquid $\mathrm{Cd}$ over a temperature range from 300 to $700^{\circ} \mathrm{C}$ at a strain rate of $2.7 \times 10^{-3} \mathrm{sec}^{-1}$. Normalized steels, 
where the heat treatment uses a faster cooling rate than full annealing, have a higher strength than the fully annealed form (Rollason 1973) and thus would be more susceptible to LME. No evidence for LME of austenitic stainless steel was found in the experiments reported by Kennedy or Dityatkovskiy et al. (1963); furthermore, high strength steels were also tested as purt of both experimental studies, and the susceptibility of high strength steels to embrittlement by liquid and solid Cd was clearly demonstrated.

The susceptibility of high-strength steels (e.g. AISI 4130, 4140 and 4340) to embrittlement by both solid and liquid cadmium has been demonstrated in a number of experiments, as discussed above. The majority of these data are summarized by Old (1980) and Kamdar (1983). These same steels have not exhibited embrittlement when the applied heat treatment resulted in lower yleld strengths or when they are in the annealed condition. The Al-Hg system exhibits analogous behavior (Rostoker et al. 1960).

Aluminum and the constituent elements of austenitic stainless steel (Fe, $\mathrm{Nl}$ and $\mathrm{Cr}$ ) stainless steels form intermetallics and liquid aluminum can dissolve large amounts of these elemcuts (as discussed in the next section). Thus, it is unlikely that Al would cause LME of austenitic stainless steel. The available experimental evidence supports this assumption (Karndar 1983 and Dillon 1990). Based on the "inert carrier" concept (Westwood and Latanision 197() and Karndar 1983), it is possible that small amounts of Al dissolved in liquid $\mathrm{Cd}$ might cause LME of SS despite the fact the liquid Al does not. However, small additions of $\mathrm{Al}(<0.55 \%)$ or $\mathrm{Ni}(<2 \%)$ have been shown to have no significant effect on the susceptibility of high strength steels to embrittlement by liquid $\mathrm{Cd}$.

Thus, the available literature data indicates that SS304 is not susceptible to "classical" LME with $\mathrm{Cd}$ or $\mathrm{Cd}-\mathrm{Al}$ solutions. However, it is possible that conditions different from those employed in the experiments discussed above might lead to LME of SS304 by Cd or Cd-Al solutions. The examinations and experiments discussed below were therefore conducted to examine these couples under conditions representative of the safety rod thernal tests.

\subsubsection{Evidence from Destructive Examinations}

As noted above LME is typically characterized by a fast fracture following the accumulation of a critical strain. This behavior was observed in the experiments and hence the failures were initially thought to be caused by LME. In addition, initial visual inspection of the outer surface of the specimens showed what appeared to be intergranular cracking, which 
Is often associated with LME; further inspection revealed that this cracking was only present in the cadmium oxide layer and was due to differential thermal contraction rates between the cadmium oxide and stainless steel upon cooling. Specimens 11 and 12 show little, if any, signs of intergranular fracture, and the inner portion of the fracture surface for specimen 9 is not intergranular. The $x$-ray backscattex maps taken along the fracture surface near the cladding midpoint of specimen no.9 (Figs. 5-70b through 5-70d) do not reveal the presence of $\mathrm{Cd}$ or Al on cladding grain boundaries (e.g. no secondary cracking). However, secondary cracking and intergranular fracture, while typical of LME, are not present for all solid-liquid metal couples under all test conditions. As discussed in Section 6.4.1, it is exceedingly difficult to confirm or rule out LME as a failure mechanism based solely on an examination of a failed component or specimen. Therefore, although the destructive examinations did not reveal any clear evidence of LME, the examinations were not considered to be conclusive evidence that LME did not play a role.

\subsubsection{U-Bend Tests}

U. Bend tests on SS304 in liquid cadmium were performed as a screening test for liquid metal embrittlement (NRTSC Technical Procedure TP-91-0023 Rev.0). The U-bend tests is normally considered a screening test since the matrix is not being actively strained during the test. Active straining of the matrix while in contact with the liquid metal insures that protective films are mechanically disrupted. However, as discussed below, the surface of the U-bend coupons were sanded to remove the protective oxide film prior to immersion in the liquid cadmium.

The U-bend coupons were made from a ( $11 / 8^{\prime \prime}$ wide $) \times\left(3^{\prime \prime}\right.$ long $) \times\left(1 / 16^{\prime \prime}\right.$ thick $i$ inch piece of SS304. A bolt passed through the ends of the coupon was employed to produce a tensile load on the outer surface. Cadmium metal was heated to the test temperature in a covered alumina crucible. The surface of the U-bend coupon was sanded with 240 grit paper to remove the protective oxide layer, and immediately immersed into the molten cadmium. An immersion time of 1 hour was employed.

Two tests were conducted at $600^{\circ} \mathrm{C}$, and a single test was run at $500^{\circ} \mathrm{C}$. Upon removal of the bolt, the coupon ends relaxed approximately $3 / 32$ ", indicating tensile stresses were present during the entire testing procedure. Metallographic sections were taken through the thickness to determine if cracking had occurred, which would indicate LME, or if the surface had been attacked by the liquid cadmium. No cracking was observed in any of the 
coupons, typical photomicrographs are shown in Figures 6-12a and 6-12b. No attack of the surface by liquid cadmium was observed. While the U-bend tests can only be considered a screening test for the reasons discussed above, these results indicate that SS304 is not subject to LME by liquid cadmium in the range from 500 to $600^{\circ} \mathrm{C}$.

\subsubsection{Tensile Tists}

Tensile tests of SS304 were conducted both in air and Cd-Al solutions over the range of strain rates and temperatures relevant to the safety rod thermal tests in order to verify the results from the U-Bend tests and conclusions based upon the available literature data (Thomas 1992). These tests, conducted at the Westinghouse Science and Technology Center, were considered scoping in nature and were not carried out under an NRTSC technical procedure. However, the guidance given in the NRTSC experimental QA procedures was employed where possible and, since the data do not form the only basis for the LME evaluation (e.g. they are confirmatory), they do not require qualification for critical applicaitons per NRTSC QAP III-2.

The test conditions and results are summarized in Table 6-2 (Thomas 1992). The "fast" strain rate $\left(3 \times 10^{-3} \mathrm{~min}^{-1}\right)$ is intended to bound the highest strain rate expected for the temperature ramp rates predicted for the gamma heating accident. Susceptibility to LME generally increases with increasing strain rate, as discussed in Section 6.4.2. The calculations performed to date for the gamma heating accident indicate that at least 30 minutes is required to reach peak safety rod temperatures less than $600^{\circ} \mathrm{C}$ (Cooper and Taylor 1991). The highest measured hoop strain for specimens tested at or below $600^{\circ} \mathrm{C}$ was $5.5 \%$. Therefore a hoop strain of $6 \%$ and ramp time of 20 minutes were selected as bounding $\left(0.06 / 20=3 \times 10^{-3} \mathrm{~min}^{-1}\right)$. Note that this strain rate is 2 orders of magnitude below the upper end of the LME susceptibility range $\left(10^{-2} \mathrm{sec}^{-1}=0.6 \mathrm{~min}^{-1}\right)$, and is just below the strain rate range employed in standard tensile tests $\left(5 \times 10^{-3}\right.$ to $\left.5 \times 10^{-2} \mathrm{~min}^{-1}\right)$. The "slow" strain rate $\left(8 \times 10^{-5} \mathrm{~min}^{-1}\right)$ is intended to bound the lowest strain rate in the safety rod thermal tests. For this purpose, a minimum hoop strain of $1 \%$ over a period of 2 hours was adopted $\left(0.01 / 120=8 \times 10^{-5} \mathrm{~min}^{-1}\right)$. Only one set of air/Cd-Al tests were conducted at this strain rate since it is expected to give lower LME susceptibility. The tests in air were conducted to obtain baseline tensile properties. Liquid Cd with dissolved Al-6061 was employed as the liquid metal solution since hils reproduces the conditions in the safety rod thermal tests. In addition, the use of pure $\mathrm{Cd}$ would not rule out the possibility that an "inert carrier" effect, as discussed in Section 6.4.3, might induce LME. The notched 
tensile bar tests were included to examine the effect of triaxial loading of LME susceptibility for this system. Specimens 5, 6, and 25 were tested as part of the procedure development and equipment verification efforts.

No reduction in ductility was observed for the tensile tests in Cd-Al liquid metal solution relative to the tests in air (Thomas 1992). Therefore, the results of the tensile tests are in agreement with the conclusion reached above that neither $\mathrm{Cd}$ nor $\mathrm{Cd}-\mathrm{Al}$ mixtures embrittle SS304 under the conditions relevant to this evaluation.

\subsubsection{Conclusions}

The specimens which failed at low temperatures had a comparatively small grain size and slow strain rate; both these factors act to suppress LME. Experiments reported in the literature gave no evidence for the embrittlement of austenitic stainless steels by either solid or liquid $\mathrm{Cd}$. Literature data also showed that additions of $\mathrm{Al}$ to liquid $\mathrm{Cd}$ did not increase the tendency for embrittlement in high-strength steels. Tensile tests with SS304 in liquid Cd-Al solutions with strain rates and temperatures spanning the ranges relevant to the safety rod thermal tests did not show any signs of embrittlement; similar results were obtained with SS304 U-Bend tests in liquid Cd. Thus, based on a literature review and confirmatory separate effects testing, embrittlement of SS304 by Cd or Cd-Al mixtures does not appear to be a credible failure mechanism for the safety rod thermal test specimens.

\subsection{Liquid Metal Dissolution}

Dissolution of the cladding by the liquid metal solution (Cd- $\mathrm{Al})$ is discussed in this report as a separate and distinct phenomena from the "classic" LME degradation mode discussed above. As noted previously, this notation and treatment is based on recent literature, but some authors treat dissolution as a type of LME. In this sense, dissolution of the cladding and its subsequent failure may be termed "dissolution driven LME."

\subsubsection{Expected Behavior Based on Phase Diagrams and Literature Data}

The phase diagrams for the $\mathrm{Cd}-\mathrm{Al}, \mathrm{Cd}-\mathrm{Ni}, \mathrm{Al}-\mathrm{Fe}, \mathrm{Al}-\mathrm{Cr}$ and $\mathrm{Al}-\mathrm{Ni}$ systems were given in Figures 6-2 through 6-7. Liquid $\mathrm{Cd}$ can dissolve 0.5-1 wt.\% Al and 6-7 wt.\% $\mathrm{Ni}$ in the temperature range from $500-600^{\circ} \mathrm{C}$. Therefore, the liquid metal solution will contain both 
$\mathrm{Al}$ (from the $\mathrm{Al}-6061$ core) and $\mathrm{Ni}$ (from the flash coating). The exact composition of the solution depends on the kinetics of these dissolution reactions, which were not examined as part of this evaluation.

As mentioned in section 6.2.2, a number of studies have examined the dissolution of austenitic stainless steel by liquid $\mathrm{Al}$. The concentration of $\mathrm{Al}$ in the liquid $\mathrm{Cd}$ solution for the temperatures of interest in the low-temperature safety rod specimen failures would be less than $1 \mathrm{wt} . \%$. Given this relatively low concentration, it does not seem likely that $\mathrm{Al}$ would be able to attack the cladding. In addition, scoping calculations based on unpublished kinetic data developed at SRS indicated that the time required for liquid $\mathrm{Al}$ at $700^{\circ} \mathrm{C}$ to dissolve through $1 / 2$ the cladding thickness would be much greater than the failure times observed in the safety rod thermal tests. Thus, dissolution of the cladding by $\mathrm{Al}$ dissolved in the liquid Cd does not appear to be a credible failure mechanism.

Liquid Cd can dissolve 6 to $7 \mathrm{wt} . \% \mathrm{Ni}$ (11 to 14 at.\%) in the temperature range from 500 $600^{\circ} \mathrm{C}$. Dissolving the entire Ni flash coating ( $\approx 1$ mil thickness) into the $\mathrm{Cd}$ layer (50 mils thickness) gives a $\mathrm{Ni}$ concentration in the liquid $\mathrm{Cd}$ of less than 4 at.\%; therefore the liquid $\mathrm{Cd}$ solution could dissolve additional $\mathrm{Ni}$ from the cladding. The solubility of $\mathrm{Fe}$ and $\mathrm{Cr}$ in liquid $\mathrm{Cd}$ at these temperatures, however, is quite low; less than 6 appm $\mathrm{Fe}$ and $20 \mathrm{appm}$ $\mathrm{Cr}$ (ASM 1990). Dissolution of stainless steel by liquid Al solutions is non-selective; so that the relative concentration of $\mathrm{Fe}, \mathrm{Cr}$ and $\mathrm{Ni}$ in the liquid $\mathrm{Al}$ solution is the same as that in the base metal (Dybkov 1990). Assuming that this is also the case with liquid Cd, then the limiting factor in the dissolution of the cladding would be the solubility of $\mathrm{Fe}$ in liquid $\mathrm{Cd}$. The maximum concentration of $\mathrm{Cr}$ and $\mathrm{Ni}$ in the liquid $\mathrm{Cd}$ would be the solubility of $\mathrm{Fe}(<6 \mathrm{appm})$ multiplied by the atomic fraction of these elements in SS304. This gives a $\mathrm{Fe} / \mathrm{Cr} / \mathrm{Ni}$ concentration of less than 9 appm in liquid $\mathrm{Cd}$ at 500 to $600^{\circ} \mathrm{C}$. If the cladding dissolution were uniform, this would correspond to a cladding thickness loss of less than $0.001 \%$. If the attack were highly nonuniform and only $1 / 1000$ of the available surface area were attacked, then the local thickness loss would still be less than $1 \%$. Therefore it may be concluded that a pure liquid $\mathrm{Cd}$ solution will not significantly dissolve the cladding if the dissolution products cannot be removed from the solution.

If the limiting dissolution products ( $\mathrm{Fe}$ and $\mathrm{Cr}$ ) could be removed from solution, then the dissolution reaction could continue. Flow loop experiments have been performed using liquid $\mathrm{Cd}$ with a stainless steel test coupon located in a heated section. Dissolution products were deposited in the cooled section (since the solubility of the dissolution 
products decreases with temperature), and the liquid $\mathrm{Cd}$ was returned to the heated section able to dissolve additional material. In this case, the resistance of austenitic stainless steels to dissolution by liquid $\mathrm{Cd}$ was characterized as poor, the same rating as given for resistance to liquid $\mathrm{Al}$ (Lyon 1952). The composition of the liquid metal solution in the safety rod thermal tests ( $\mathrm{Cd}-\mathrm{Al}$ ) provides a chemical equivalent of the cooled section in the loop experiments. Aluminum forms intermetallics with all the cladding constituent elements $\left(\mathrm{FeAl}_{3}, \mathrm{CrAl}_{7}\right.$ and $\left.\mathrm{NiAl}_{3}\right)$ and could therefore combine with them in the liquid $\mathrm{Cd}$ and allow dissolution to continue. However, since no kinetic data on the dissolution of austenitic stainless steel by liquid $\mathrm{Cd}$ is available, it is not possible to calculate the speed at which cladding dissolution into a liquid $\mathrm{Cd}-\mathrm{Al}$ solution would take place.

\subsubsection{Evidence From Destructive Examinations}

The SEM/EDS and microprobe examinations of the failed tests sperimens showed that a layer of $\mathrm{Al}$-rich $\mathrm{Al} / \mathrm{Fe} / \mathrm{Cr} / \mathrm{Ni}$ is adjacent to the fracture surface and along the inner cladding surface near the fracture. Although the axial length of the fracture over which this layer existed was not specifically determined, it appeared to be restricted to the central portion of the fracture. The outermost portion of the fracture surface was not coated, and the width of this uncoated outer portion varied somewhat between specimens 9,11 , and 12 . Penetration depths of approximately $75 \%$ throughwall were observed for specimen 9 . Penetration depths of 90 to $95 \%$ throughwall were observed for specimen 11 and 12 . It is recognized that the layer could have been hydraulically sheared during rupture so that the depth of penetration observed in the destructive examination may be a slight overestimate.

The presence of the the $\mathrm{Al}$-rich $\mathrm{Al} / \mathrm{Fe} / \mathrm{Cr} / \mathrm{Ni}$ layers is consistent with the dissolution mechanism discussed above. 'The formation of $\mathrm{Al}$ intermetallics would be most favored at locations where the dissolution product concentration is the largest and therefore the $\mathrm{Al}$ intermetallics would be primarily formed and deposited near the site of dissolution. This is consistent with the evidence from the destructive examination (e.g. the $\mathrm{Al} / \mathrm{Fe} / \mathrm{Cr} / \mathrm{Ni}$ deposits were only found on the fracture surface or inner cladding surface near the fracture). The $\mathrm{Al}$ signal strength in the EDS spectra for the $\mathrm{Al} / \mathrm{Fe} / \mathrm{Cr} / \mathrm{Ni}$ layer near the inner cladding surface was strong relative to that for layers farther up the fracture face towards the outer cladding surface. This indicates that the layer on the inner surface had more time for $\mathrm{Al}$ and $\mathrm{Al}$-intermetallics to deposit out of the liquid metal solution into the layer. This is consistent with dissolution of the cladding since attack would begin at the inner surface and progress through the cladding until rupture occurred. 


\subsubsection{Structural Analysis}

As discussed in Section 6.3, Gupta (1991) developed a finite element model of the safety rod cladding to examine the response of the cladding to hemispherical pits of various depths under the range of loading conditions applicable to th? safety rod thermal tests. It was shown that a pit depth of $60 \%$ increased the hoop strain immediately in front of the pit by a factor of 3 relative to that for unattacked cladding. Based on the measured hoop strain for specimen $10(2.5 \%)$, which was tested at $550^{\circ} \mathrm{C}$, the hoop strain for a pit depth of $60 \%$ would be approximately $7.5 \%$. Deeper pits would, of course, give greater hoop strains and extrapolating Gupta's results to $80 \%$ penetration gives a predicted hoop strain of $10 \%$; this is within the range of failure strains predicted for the slow ramp tests. The evidence from the destructive examination discussed above shows that the depth of cladding dissolution was in this range, and possible much larger for specimen 11 and 12. Gupta's morel was not intended to exactly duplicate the geometry that dissolution of the cladding would produce; the destructive examination did not provide sufficient information to allow this level of detail. However, the main result of this analysis, that the strain field at the top of a deep pit is increased significantly relative to that for unattacked cladding, clearly demonstrates that dissolution of the cladding could lead to failure well before the attack penetrated the cladding.

\subsubsection{Conclusions}

The discussions given above demonstrate that a liquid $\mathrm{Cd}-\mathrm{Al}$ solution is capable of dissolving SS304, and that the creation of a deep pit due to localized dissolution will increase the maximum cladding hoop strain sigaificantly relutive to that for unattacked cladding. The evidence from the destructive examination indicates that highly localized cladding dissolution occurred, that dissolution products were taken out of the liquid metal solution by interacting with the dissolved $\mathrm{Al}$, and that the dissolution pit thus created penetrated deeply into the cladding prior to rupture. It is therefore concluded that the lowtemperature safety rod test specimen failures were due to dissolution of the cladding by the liquid $\mathrm{Cd}-\mathrm{Al}$ solution. 


\section{DISCUSSION}

The candidate failure mechanisms considered wrre: mechanical (ductility exhaustion or creep-rupture), low-melting point eutectic formation, material defects, liquid metal embrittlement, and liquid metal dissolution. The high-temperature failures are concluded to be mechanical in nature with little or no environmental interaction. This conclusion is based on the close agreement between the measured cladding hoop strain and that predicted for these loading conditions (temperature $\approx 850^{\circ} \mathrm{C}$, strain rate $\approx 0.02 \mathrm{~min}-1,6 \%$ cladding cold work, and biaxial loading). The low-temperature failures are attributed to dissolution of the cladding by liquid metal $(\mathrm{Cd}-\mathrm{Al})$. The remainder of this section discusses the lowtemperature failures.

The specific proposed mechanism for the low-temperature failures is dissolution of the cladding by liquid $\mathrm{Cd}$. Alumisum dissolved in the $\mathrm{Cd}$ took the dissolution products $(\mathrm{Fe} / \mathrm{Cr} / \mathrm{Ni})$ out of solution by forming $\mathrm{Al}$-intermetallic compounds which subsequently precipitated on nearby cladding surfaces. The observed behavior would not occur in either a pure liquid $\mathrm{Al}$ or a pure liquid $\mathrm{Cd}$ solution in the same temperature regime. A pure liquid $\mathrm{Cd}$ solution would quickly saturate with $\mathrm{Fe}$ and $\mathrm{Cr}$, thus preventing additional dissolution. Dissolution products could be transported axially along the safety rod to colder regions and thus allow dissolution to continue, but the kinetics of this reaction would be very slow. Of course, $\mathrm{Al}$ would not be liquid at the temperatures of interest, but even the kinetics for dissolution of austenitic stainless steel by liquid $\mathrm{Al}$ are also much slower than the failure times involved in the safety rod thermal tests. Therefore, the combination of $\mathrm{Cd}$ and $\mathrm{Al}$ was required for the type of aggressive dissolution observed in these tests.

This conclusion is based on the three points listed and discussed below:

- This is the only failure mechanism considered which was not ruled out by comparison with literature data and/or confirmatory separate effects testing. The available data concerning this mechanism indicates that it could cause failure under the test conditions.

- The evidence from the destructive examination indicates that aggressive localized dissolution of the cladding occurred prior to rupture. The $\mathrm{Al} / \mathrm{Fe} / \mathrm{Cr} / \mathrm{Ni}$ layer would not have been on the fracture surface to the extent observed unless it was deposited prior to rupture. The solubility of $\mathrm{Al}$ in liquid $\mathrm{Cd}$ at the test temperatures is less than $1 \mathrm{wt} . \%$ and, based on the video tapes made of the tests, the liquid metal was ejected 
from the safety rod within approximately 1 second after the rupture occurred. Given this low concentration of $\mathrm{Al}$ and short amount of time during which liquid metal was being ejected past the fracture surface, it is not credible that the Al precipitated out of solution during the rupture, adhered to the cladding surface, and dissolved a layer of the cladding before the specimen cooled. Since the layer was deposited on the fracture surface prior to rupture, it is clear that the portion of the fracture surface coated with the $\mathrm{Al} / \mathrm{Fe} / \mathrm{Cr} / \mathrm{Ni}$ layer must have been created by dissolution.

- The depth of dissolution observed in the destructive examinations is in general agreement with that predicted to produce hoop strains in the rernaining cladding ligament sufficient to cause failure.

No significant cladding attack was observed in any of the unfailed specimens. Since this conclusion it based on the post-test radiography, which has an estimated resolution of a few mils, it might seem reasonable to assume that small areas of attack would not have been observed. However, as discussed in Sections 4.2 and 5.1.2, small features were clearly identified by the post-test radiographs taken for unfailed specimens 10 and 28 . The destructive examination of specimen 10 did not show clear evidence of cladding attack at any location. There were 2 areas on the inner cladding surface identified in the first failed specimen (no.9) which appeared to have been dissolved in addition to the main area of attack (see Figures 5-11a, 5-17a, 5-20 and 5-25). The area just to the left of the rupture site might actually be associated with the main area of attack, and the area further away from the rupture site might have been a pre-existing geometric feature which was subsequently coated with the $\mathrm{Al} / \mathrm{Fe} / \mathrm{Cr} / \mathrm{Ni}$ layer in the same manner as the rest of the inner cladding surface near the fracture. Alternatively, these could be places where the dissolution reaction initiated and then stopped due to excessive deposition of $\mathrm{Al} / \mathrm{Fe} / \mathrm{Cr} / \mathrm{Ni}$, or where the dissolution reaction was initiated well after the main area of attack had been established. The available evidence does not allow a definitive explanation of these observations. In any case, it appears that once dissolution began to any significant extent, it progressed to failure. The controlling process was therefore initiation and not propagation, which implies a fairly rapid dissolution process; the dissolution rate and diffusion data required to construct a kinetic model of this reaction are not available. If the liquid metal solution were capable of chemically breaking down this film in the timetemperature regime relevant to the safety rod thermal tests, then the reaction would not have been localized to the degree observed. Thus initiation of the dissolution reaction requires mechanically rupturing the protective oxide film on the inner cladding surface. 
The identification of the mechanism responsible for the observed failures does not readily explain why other specimens subjected to similar conditions did not fail. The test results suggest that the failure mechanism is dependent on the temperature ramp rate (e.g. cladding strain rate). As discussed above, the controlling process in the failure is mechanical rupture of the protective oxide film on the cladding inner surface. There are a number of mechanistic arguments, discussed below, which indicate that the temperature ramp rates and cladding strain rate would influence the tendency for mechanical rupture of the oxide film.

The temperature regime where the failures occurred corresponds to that where serrated flow is observed in austenitic stainless steels (Bamby 1965, Jenkins and Smith 1969, and Ruggles and Krempl 1991). Serrated flow, the appearance of serrations in the stress-strain curve, is caused by the Portevin-LeChatelier phenomenon and related to dynamic strain aging (Reed-Hill 1973 and Dieter 1976); it has also been referred to as "jerky" flow. Dislocations locking by impurities and precipitates, and the subsequent generation of additional dislocations and/or unlocking of dislocations, causes the stress required for plastic flow (e.g. the flow stress) to increase and decrease sharply, thus introducing serrations to the stress-strain curve. Increased flow stresses and work-hardening rates accompany serrated flow. For austenitic stainless steels at relatively low temperatures, serrated flow is caused by carbon (C) atoms interacting with dislocations; at higher temperatures, $\mathrm{Cr}$ is sufficiently mobile that chromium carbides can precipitate on dislocation lines. The severity of the effect is dependent on the diffusion rates for $\mathrm{Cr}$ and $\mathrm{C}$, which are in turn dependent on vacancy concentration. Therefore, cold worked steel will exhibit serrated flow more severely and at lower temperatures than annealed steel. The tensile tests performed on lightly cold worked SS304 (see Section 6.4.6) exhibited severely serrated stress-strain curves; the load displacement curves for the tests conducted in air at 500,550 and $600^{\circ} \mathrm{C}$ are shown in Figure 7-1a through 7-1c. The serrations shown in the figures are more severe and occur at lower strains than those typically reported for austenitic stainless steels (Barnby 1965 and Jenkins and Smith 1969). Slow strain rates can also enhance serrated flow since the dislocation line velocity will decrease and hence the required $\mathrm{Cr}$ and $\mathrm{C}$ diffusion rates will decrease; this will decrease the temperature at which serrated flow is observed. The strain rates for the failed safety rod thermal test specimens were approximately an order of magnitude lower than those employed to generate the load-displacement curves shown in Figure 7-1. The safety rod cladding thickness varies circumferentially, as discussed in Section 2.2 , and since the liquid metal solution will apply a uniform load to the inner cladding surface the cladding hoop strain 
will vary in a like manner. If the stress-strain curve were smooth, this might only give rise to small differences in the resulting cladding hoop strain. However, severely serrated flow, as expected with the slow ramp tests, could produce significant local cladding hoop strain variations. Such variations would lead to localized shearing and hence could cause mechanical rupture of the protective oxide film on the inner cladding surface. The destructive examination of the failed specimens provided evidence of just this type of localized shearing prior to rupture. The cladding grains adjacent to the portion of the fracture coated with the dissolution product had undergone severe shear deformation; this deformation must have occurred prior to dissolution since force could not be transmitted across these grains after dissolution had separated the sides of the fracture. Specimen 12 (Figure 5-65a) shows a shear band which extends through the cladding thickness and is associated with a discontinuity in the cladding outer surface. The 4 th grind on the bottom half of specimen 9 also shows some evidence of shear line extending through the cladding thickness. Additionally, shear bands could be present which did not propagate normal to the rod axis and hence would not be clearly evident. It is also possible that a similar region is present in specimen 11 but was not observed due to the cursory nature of the destructive evaluation for this specimen, or was contained in the region destroyed by sectioning or grinding operations. Thus, localized shear deformation due to severely serrated flow could cause mechanical rupture of the protective oxide film and initiate the dissolution reaction. Evidence of localized shear deformation was observed in the destructive examinations. This would also explain the highly localized nature of the dissolution attack observed in the destructive examinations. Slow temperature ramp rates (e.g. cladding strain rates) will increase the severity of serrated flow and hence would be more likely to cause failure.

Keduced cladding strain rates would also be expected to effect the ductility of the protective oxide film on the inner surface of the cladding. For the safety rod thermal tests, the microstructure of the film itself will also be influenced by the time-temperature history to which it is exposed prior to immersion in liquid Cd. Slow temperature ramp rates will expose the film to internal rod environment for a longer period of time. The film may be partially hydrated and longer exposure times will result in more severe dehydration; presumably this would reduce the ductility of the film. A number of studies have been performed which examined the protection offered by oxide films on austenitic stainless steels formed at various temperatures to corrosive environments. Tomari et al. (1990) reported that the resistance of SS316L to attack by $\mathrm{HCl}$ solutions increased with oxidation temperature up to $500^{\circ} \mathrm{C}$ and attributed this to an increased thickness of the uniform amorphous oxide film; higher oxidation temperatures gave reduced protection. Bianchi et 
al. (1972) found that the resistance of SS304 to pitting increased sharply with oxidation temperature up to $300^{\circ} \mathrm{C}$ for oxidation times ranging from $1 / 2$ to 4 hours; oxidation temperatures above $400^{\circ} \mathrm{C}$ increased the pitting attack. These data clearly show that the structure of the oxide film on the inner cladding surface would be impacted by the timetemperature history to which it is exposed prior to immersion in liquid $\mathrm{Cd}$, and hence to the temperature ramp rate employed in the safety rod thermal tests.

In addition to the dependence on temperature ramp rate, it is possible that differences in the safety rods from which the test specimens were obtained is partially responsible for the observed behavior. All of the specimens which failed below $600^{\circ} \mathrm{C}$ came from a single safety rod. Only 2 differences between this rod (no.1) and the other 3 tested in these experiments (nos. $2,3 \& 4$ ) were found. First, the cladding grain size for rod 1 was approximately $1 / 2$ that for the other 3 rods. According to the Hall-Petch relationship (Reed-Hill 1973 and Dieter 1976), the yield and ultimate strengths for cladding of rod 1 would be approximately $50 \%$ higher than those for rods 2,3 and 4 . This would also decrease the ductility of the rod 1 cladding and could increase the severity of serrated flow. Secondly, the serial number for rod 1 was different than that of the other 3 rods (e.g. S\#\# vs. K\#\#). Both these differences indicate that rod 1 might have been made by a different manufacturer, made using a different process, or made using a different lot of materials. However, these differences do not completely explain why specimens from rod 1 failed when specimens from the other rods, subjected to similar conditions, did not. That is, it is not possible to conclude that additional test specimens taken from rods 2,3 , or 4 (or additional safety rods identical to these) would not fail under the conditions similar to those which caused failure in specimens taken from rod 1.

The differences in the microstructural features observed in the destructive examination of specimen 9 with respect to those observed for specimens 11 and 12 also merit discussion. The $\mathrm{Al} / \mathrm{Fe} / \mathrm{Cr} / \mathrm{Ni}$ layer present on the fracture surface of specimen 9 was very well defined and relatively thick $(\approx 10 \mu \mathrm{m})$; alternatively, the $\mathrm{Al} / \mathrm{Fe} / \mathrm{Cr} / \mathrm{Ni}$ layer observed with specimens 11 and 12 was not nearly as well-defined and was thinner $(\approx 1-2 \mu \mathrm{m})$. These observations are attributed to differences in the peak cladding temperatures reached after rupture. During the test, heat is transferred from the cladding through the Cd layer to the Al-6061 core, and then up the core to the cooled ends. Once rupture occurs, the Cd layer in the hot zone is lost and heat must flow axially up the cladding. The conductivity of SS304 is quite low relative to that of Al, so that rupture will cause the cladding temperature to increase rapidly until the furnace is turned off. The first failure (no.9) was not 
anticipated and it required approximately 1 minute to shut off the furnace. Conversely, the other failures were anticipated and the furnace was shut off within 5 to 10 seconds after the rupture occurred. Thus, the peak cladding temperature reached after rupture for specimen 9 would be expected to be much higher than those for specimens 11 and 12. The measured peak cladding temperature for specimen 9 was approximately $750^{\circ} \mathrm{C}$, while those for specimens 11 and 12 were 575 and $625^{\circ} \mathrm{C}$, respectively, It is recognized that the thermocouple readings after rupture are somewhat suspect since the thermocouple lead may shift on the surface or lose contact with it due to the mechanical shock of the rupture. However, the values given above are in qualitative agreement with those expected based on the times required to shut down the furnace after rupture. The Al will melt and the Alintermetallics will begin to decompose at $660^{\circ} \mathrm{C}$, as shown in Figures 6-5 through 6-7, well below the peak cladding temperature for specimen 9 and above those for specimens 11 and 12. Melting and decomposition of the $\mathrm{Al} / \mathrm{Fe} / \mathrm{Cr} / \mathrm{Ni}$ layer could obviously cause a drastic change in appearance, porosity, and thickness. The destructive examination of specimen 9 did provide evidence of "mixing" between this layer and adjacent $\mathrm{Cd}$ (see Figure 5-12). Additionally, the higher test temperature with specimen 9 would increase the solubility of $\mathrm{Al}$ in the liquid $\mathrm{Cd}$ and could lead to differences in the resulting $\mathrm{Al} / \mathrm{Fe} / \mathrm{Cr} / \mathrm{Ni}$ layer; increased temperature would also increase the rate of dissolution and could produce a thicker layer. There are also distinct differences in the appearance of the grain structure near the outer cladding surface for specimen 9 compared to specimens 11 and 12. For specimen 9 , there was a sharp transition from a highly sheared region which extended $1 / 2$ to $3 / 4$ through the thickness of the cladding (corresponding to dissolution) to an intergranular region (corresponding to mechanical failure). Conversely, the sheared region extended much further for specimens 11 and 12 , the failure of the remaining ligament was at least partially ductile, and the cladding appeared to have :ndergone marked local thinning prior to rupture. These differences are probably directly attributable to the test temperature. As shown in Figure 6-1, the ductility of SS304 decreases rapidly with temperature in the range from 500 to $600^{\circ} \mathrm{C}$ for the strain rates of interest and the resulting failure is increasingly intergranular. Specimen 9 failed at $590^{\circ} \mathrm{C}$, while specimens 11 and 12 falled at 533 and $521{ }^{\circ} \mathrm{C}$. This temperature difference could well explain the observed microstructural features. The increased failure temperature for specimen 9 would reduce ductility so that failure would nccur with a thicker remaining cladding ligament (hence less dissolution penetration) and would promote intergranular failure. Thus, the differences in the appearance of the $\mathrm{Al} / \mathrm{Fe} / \mathrm{Cr} / \mathrm{Ni}$ layer and cladding microstructure observed in specimen 9 relative to those for specimens 11 and 12 are directly attributable to the peak cladding temperature reached after rupture. 


\section{CONCLUSIONS}

Based on the data and discussions presented in this report, it is concluded that the liquid metal dissolution was responsible for the 3 low-temperature $\left(521-590^{\circ} \mathrm{C}\right)$ fallures which occurred at very slow temperature ramp rates $\left(<5^{\circ} \mathrm{C} / \mathrm{min}^{\prime}\right)$, and that the high-temperature $\left(830.870^{\circ} \mathrm{C}\right.$ ) failures which occurred with very fast temperature ramp rates $\left(>100^{\circ} \mathrm{C} / \mathrm{mln}\right.$.) were mechanical in nature with little if any environmental interaction.

It is concluded that localized shear deformation breached the protective layer on the inner cladding surface and allowed the Cd-Al liquid metal solution to dissolve the cladding. The cladding ruptured when loss of wall thickness due to dissolution increased the cladding strain beyond its ductility limit. It is concluded that slow temperature ramp rates would increase the severity of the localized shear deformation and thus increase the tendency for failure. It is also recognized that the temperature ramp rate influences the nature of the protective film of the cladding inner surface, although the exact relationship between the film structure and time-temperature history was not established.

It is concluded that differences observed in the destructive examination of the tost specimens which failed at low temperatures are directly attributable to differences in peak cladding temperatures reached after rupture and to differences in test temperatures. These differences are not attributed to any difference in the failure mechanism for these specimens.

The grain size for the safety rod 1, from which the specimens which failed at low temperatures were taken, was approximately $1 / 2$ that for the other rods. In addition, the serial number for rod 1 had a different form than those for the other rods (S\#\# vs. K\#\#). It is therefore possible that rod 1 might have been made by a different manufacturer, made using a different process, or made using a different lot of materials. However, no differences were found which would provide definitive evidence that specimens taken from the other rods could not fail under conditions similar to those which caused fillure in rod 1 .

The data and information presented in this report serve to identify the safety rod thermal test specimen failure mechanisms. Differences arnong specimens observed in the destructive examinations are also explained. Evidence was presented that indicates that slow temperature ramp rates will increase the tendency for failure, and that differences among the safety rods may have played a role in the response of the test specimens to similar test 
conditions. However, it is not possible to identify a ramp rate and/or test temperature below which it can be completely guaranteed that fallure will not occur. Based on engineering judgement and the avallable test data, it is concluded that fallure would not occur below $500^{\circ} \mathrm{C}$ even for slow temperature ramp rates with test specimens as prone to fallure as those from safety rod 1 . The test results also indicate that fast temperature ramp rates will greatly decrease the probability that attack via dissolution would oocur, thus delaying fallure until temperatures above $8000^{\circ} \mathrm{C}$. For peak cladding temperatures above 5()()$^{\circ} \mathrm{C}$, the fast ramp rates are more prototypic of those predicted for the gamma heating accident. 


\section{ACKNOWLEDGEMENTS}

A large number of people were involved in the tests and examinations described in this report. The authors gratefully acknowledge the contributions listed below:

- Doug Leader (SRL-MTS) was heavily involved in the design of the safety rod thermal tests.

- Andy Cheek, Bobby Hartley, and Ross Lathrop (SRL-MTS Fabrication Laboratory) were responsible for the work involved in actually running the safety rod thermal tests and made many valuable suggestions for improving the experimental apparatus and test prooedures.

- Boyd Howard (SRL-EES) and the staff of the Ebasco radiography facility were responsible for the test specimen radiography work.

- Frank Odom and Sam Brunson (SRL-MTS Metallography Laboratory) carried out the metallurgical specimen preparation and optical microscopy.

- Mike Summer, Jack Durden and Dan Steedly (SRL-ADS) carried out the SEM/EDS examinations.

- Laura Tovo and Shirley McDaniel (SRL-ADS) conducted the electron microprobe examinations.

- Lynda Wingard and Ross Lathrop (SRL-MTS Fabrication Laboratory) carried out the U-Bend tests.

- Andy Cheek and Greg Chandler (SRL-MTS) obtained the post-test safety rod profilimetry data.

- Jim Marra and Gina Robbins (SRL-MTS) conducted the DTA testing.

- The SRL standards lab worked closely with the Fabrication Laboratory tearn and the authors to develop calibration procedures for the instrumentation employed.

- Frank Heckendorn (SRL-EED) provided the video equipment used to record selected tests and proluced still shots from the video tapes.

- Jim Begley and the staff at Westinghouse Science and Technology Center conducted the confirmatory separate effects pressurized tube burst and SS304 tensile tests.

- Kevin Stoner, Bob Sindelar, Greg Mertz, George Caskey, Bob Ondrejcin, Bill A wadalla, Scott West, Mac Louthan and Tom Rankin (SRL-MTS) all provided technical consultation on various aspects of this project.

The long hours put in without complaint hy the staff of the MTS Fabrication Laboratory, MTS Metallography Laboratory, ADS electron microscopy and electron microprobe facilities were greatly appreciated. The authors also acknowledge the help and efforts of the staff at SRS Photographic Services (Sandra Pierce) and Printing (Bob McClearen) groups. 


\section{REFERENCES}

Ahlblom, B. and R. Sandstrom (1982) "Hot Workability of Stainless Steels: Influence of Deformation Parameters, Microstructural Components, and Restoration Processes," Intl.Mater Rev, 27(1): 1-27.

Anderson, M.H. (1991) "Training on ASTM Standard for Grain Size Measurement," SRLRTD-91-0019, Interoffice Memorandum, Savannah River Laboratory, Alken, SC, 28 Feb. 1991.

ASM (1979) Metals Handbook - 9th Edition. Volume 2 - Properties and Selection: Nonferrous Alloys and Pure Elements, American Society for Materials (ASM), Materials Park, $\mathrm{OH}$.

ASM (1990) Binary Alloy Phase Diagrams, Second Edition, American Society for Materials (ASM), Materials Park, OH.

Barnby, J.T. (1965) "Effect of Strain Aging on the High-Temperature Tensile Properties of an AISI 316 Austenitic Stainless Steel," LJron and Steel Inst., pp. 392-7.

Bianchi, G., A. Cerquetti, F. Mazza and S. Torchio (1972) "High Temperature Oxidation of Fe-Cr-Ni Alloys in Oxygen", Proceedings of the 4th International Congress on Metallic Corrosion, pp. 614-9, NACE, Houston, TX.

Brinkman, C.R., V.K. Sikka and R.T. King (1977) "Mechanical Properties of LiquidMetal Fast Breeder Reactor Primary Piping Materials," Nucl.Tech, 33: 76-95.

Cooper, R.E. and J.R. Taylor (1991) "RE: Heat Transfer Data for MTS Gamma Heating Task," NES-CDG-910038, Interoffice Memorandum, Westinghouse Savannah River Co., Aiken, SC 17 March 1991.

Dieter, G.E. (1976) Mechanical Metallurgy, McGraw-Hill, New York, NY.

Dillon, C.P. (1990) "Liquid Metal Cracking of Stainless Steels in Chemical Plants," Matls.Perf, 29: 54-5.

Dityatkovskiy, Y.M., I.V. Andreyev and V.F. Gorshkov (1963) "Effect of Fusible Metal Coatings on the Mechanical Properties of Engineering and Stainless Steels," Physics of Metals and Metallography, 15: 94-7.

Dybkov, V.I. (1990) "Interaction of 18Cr-10Ni Stainless Steel with Liquid Aluminum," LMater.Sci., 25: 3615-33.

Dyer, T. (1991) "Information Concerning Safety Rod," RRD-ROCH-910128, Interoffice Memorandum, Westinghouse Savannah River Co., Aiken, SC, 4 March 1991.

Embury, J.D. and J.L. Duncan (1981) "Formability Maps," Ann.Rev.Mater.Sci. pp. 505 $-21$.

Gold, M., W.E. Leyda and R.H. Zeisloft (1975) "The Effect of Varying Degrees of Cold Work on the Stress-Rupture Properties of Type 304 Stainless Steel," LEng.Mater.Tech. (Trans ASME), pp. 305-12. 
Gupta, N.K. (1991) Sumuary Report - Reactor Component Response to Gamma Heating Accident - Response of the Safety Reds, WSRC-TR-91-411, Savannah River Laboratory, Aiken, SC, Oct. 1991.

Harvey, P.D., ed. (1982) Engineering Properties of Steel, ASM, Metals Park, OH.

Hecker, S.S. (1975) "Formability of Aluminum Alloy Sheets," L.Eng.Matl.Tech. (Trans.ASME), pp. 66-73.

Herbsleb, G. and W. Schwenk (1985) "The Influence of Dynamic Mechanical Parameters on Stress Corrosion Cracking of Steel - A Review," Corr., 41: 431-7.

Iyer, N.C. (1991) "Reactor Components Response to Gamma Heating Accident Component Definition," SRL-MTS-91-2009, Interoffice Memorandum, Westinghouse Savannah River Co., Aiken, SC, 13 August 1991.

Jenkins, C.F. and G.V. Smith (1969) "Serrated Plastic Flow in Austenitic Stainless Steel," Trans.Met.Soc.AIME, 245: 2149-56.

Johnson, K.L., N.N. Breyer and J.W. Dally (1977) "Environmental Sensitivity of Structural Metals: Some Dynamic Aspects of Liquid Metal Embrittlement," in Environmental Degradation of Engineering Materials, pp. 91-103.

Kamdar, M.H. (1983) "Liquiu Metal Embrittlement" in Treatise on Materials Sci. and Tech. - Vol 25 - Embrittlement of Engineering Alloys, C.L. Briant and S.K. Banerji, eds., Academic Press, New York, NY, pp. 361-459.

Kirby, R.F. (1962) Evaluation of 300 Series Stainless Steel Tubing for Fuel Cladding, GEAP-4095, General Electric, San Jose, CA, Oct. 1962.

Krupowicz, J.J. (1989) "Slow Strain Rate Fracture Characteristics of Steel and Aluminum Alloy: Tested in Mercury Environments," LEng.Matl.Tech. (Trans. ASME), 111: 229-34.

Krupowicz, J.J. and D.S. Hampton (1990) "Cracking of Aluminum Alloy 5083 in Mercuric Salt Solutions," Corr., 46: 159-61.

Lyon, R.N. (1952) Liquid Metals Handbook, 2nd Edition, Office of Naval Research, June 1952.

Manjoine, M.J. (1975) "D"ictility Indices at Elevated Temperature," Trans.ASME. L.Eng.Mater.Tech, 97: 156-61.

Marra, J.C. (1991) "Differential Thermal Analysis of Safety Rod Component Materials," SRL-MTS-91-4004, Interoffice Memorandum, Savannah River Laboratory, Aiken, SC, 21 May 1991.

Marshall, P. (1984) Austenitic Stainless Steels - Microstructure and Mechanical Properties, Elsevier Applied Sci. Publ., London.

McAlister, A.J. (1982) "The Al-Cd (Aluminum-Cadmium) System," Bull.Alloy Phase Diagrams, 3(2): 172-7. 
Moen, R.A. and G.V. Smith (1975) "A Consideration on Limits of Cold Working in Nuclear Construction," JEng.Mater.Tech. (Trans. ASME), 162-71.

Moen, R.A. and D.R. Duncan (1976) Cold Work Effects: A Compilation of Data for Types 304 and 316 Stainless Steel, HEDL-TI-76005, Westinghouse Hanford Co., Richland, WA.

Myers, J. (1962) "Hot Ductility of Three Austenitic Steels," Brit.Welding J, 9: 106-14.

Nazarchuk, T.N., G.T. Kabannik and V.I. Dybkov (1985) "Kinetics of Solution of 12Kh18N10T Steel in Molten Aluminum," Sov.Mater.Sci, 21(5): 413-6.

Newby, J.R. (1979) "Formability of Steel Sheet," in Metals Handbook. 9th Edition. Vol.1 Properties and Selection: Irons and Steels, American Society for Metals (ASM), Metals Park, OH, pp. 545-60.

Old, C.F. (1980a) "Micromechanisms of Crack Growth in Liquid Metal Environments," Metal Sci, 14: 433-440.

Old, C.F. (1980b) "Liquid Metal Embrittlement of Nuclear Materials," L.Nucl.Mater, 92: $2-25$.

Ondrejcin, R.S. (1967) Metallurgical Investigation of Aluminum-Clad Cadmium Control Rods, DP-1101 (TID-4500), Savannah River Laboratory, Aiken, SC, Sept. 1967.

Phillips, H.W.L. (1959) Annotated Equilibrium Diagrams of Some Aluminum Alloy Systems, Institute of Metals Monograph and Report Series No. 25, Institute of Metals, London.

Reed-Hill, R.E. (1973) Physical Metallurgy Principles, 2nd Edition, Brooks/Cole Engineering Div., Monterey, CA.

Reynolds (1954) The Aluminum Data Book, Reynolds Metals Co., Louisville, KY.

Rivlin, V.G. and G.V. Raynor (1981) "Phase Equilibria in Iron Ternary Alloys - 4: Critical Evaluation of Constitution of Aluminum-Iron-Silicon System," Inth.Metals Rev, 26(3): 133-52.

Rollạson, E.C. (1973) Metallurgy for Engineers, Edward Arnold, Great Britain.

Rostoker, W., J.M. McCaughey and J. Markus (1960) Embrittlement by Liquid Metals, Reinhold Publ. Corp., Ney York, NY.

Ruggles, M.B. and E. Krempl (1991) "Rate Sensitivity and Short-Term Relaxation Behavior of AISI Type 304 Stainless Steel at Room Temperature and at $650^{\circ} \mathrm{C}$; Influence of Prior Aging," L.Press.Vessel Tech. (Trans.ASMEL, 113: 385-91.

Rust, J.H. (1979) Nuclear Power PlantLi gineering, Haralson Publ., Buchanan, GA.

Sikka, V.K. and M.K. Booker (1977) "Assessment of 'Tensile and Creep Rupture Data for Types 304 and 316 Stainless Steels," LPress.Vess.Tech. (Trans.ASME), 298-313.

Sikka, V.K. (1978) Elevated Temperature Ductility of Types 304 and 316 Stainless Steel, ORNI_TM-6608, Oak Ridge National I aboratory, Oak Ridge, TN. 
Simmons, W.F. and H.C. Cross (1952) Report on the Elevated-Temperature Properties of Stainless Steels, ASTM Special Tech. Publ. No. 124, American Society for Testing and Materials, Philadelphia, PA.

Simmons, W.F. and J.A. Van Echo (1965) Report on the Elevated-Temperature Properties of Stainless Steels, ASTM Data Series Publ. DS 5-S1, American Society for Testing and Materials, Philadelphia, PA.

SRS (1952) Savannah River Plant Drawing No W151954 - 'S-Rod Arrangement.' Savannah River Site, Aiken, SC, 6/25/52.

SRS (1982) SRP Reactor Assemblies, DPSOP-134, Rev.6, Savannah River Site, Aiken, SC, July 1982.

Stoloff, N.S. (1990) "Metal-Induced Fracture," in Environment-Induced Cracking of Metals (Proc. of the 1 st International Conf.), R.P. Gangloff and M.B. Ives, eds., NACE, Houston, TX, pp. 31-41.

Swindeman, R.W. and C.R. Brinkman (1982) "Progress in Understanding the Mechanical Behavior of Pressure Vessel Materials at Elevated Temperatures," in Pressure Vessels and Piping Design Technology - 1982 - A Decade of Progress, S.Y. Zamrik, ed., Am.Soc.Mech.Eng. (ASME), New York, NY, pp.153-69.

Thomas, J.K. (1991) "Reactor Components Response to Gamma Heating Accident," Task 91-001-1 Management/Task Technical Plan, SRL-EDG-90-0002, Interoffice Memorandum, Westinghouse Savannah River Co., Aiken, SC, 4 Jan. 1991.

Thomas, J.K., N.C. Iyer, H.B. Peacock and D.R. Leader (1991) Qverview of the Safety Rod Laboratory Testing Program, WSRC-TR-91-515, Westinghouse Savannah River Co., Aiken, SC, Sept. 1991.

Thomas, J.K. (1992) Tensile and Burst Tests in Support of the Cadmium Safety Rod Eailure Evaluation, WSRC-RP-92-314, Westinghouse Savannah River Co., Aiken, SC, Feb. 1992.

Tomari, H., et al. (1990) "The Effect of Dry Passivation Treatments on the Corrosion Resistance, Moisture Release and Structure of the Surface Oxide Film on Electropolished Stainless Steel", Corr.Sci, 31: 389-94

Tovo, L.L. (1991) "Electron Microprobe Results for Gamma Heating Study," SRL-ADS91-0590, Interoffice Memorandum, Savannah River Laboratory, Aiken, SC, 11 Nov. 1991.

Webb, J.D. and S.L. Pohlman (1980) Reliability and Durability Study of a Thermal Receiver Utilizing ASI Type 316 Stainless Steel in Contact with Molten Aluminum, SERI/TP-641-653, Solar Research Energy Institute, Golden, CO, March 1980.

Wei, B.C. and D.V. Nelson (1982) "Structural Design Criteria for Highly Irradiated Core Components," in Pressure Vessels and Piping Design Technology - 1982 - A Decade of Progress, S.Y. Zamrik and D. Dietrich, eds., ASME, New York, NY, pp. 239 248. 
Westwood, A.R.C. and R.M. Latanision (1970) "Absorption-Induced Embrittlement by Liquid Metals," in Comosion by Liquid Metals (Proc. of the 1969 Fall AIME Metallurgical Soc. Mtg.), J.E. Draley and J.R Weeks, eds., Plenum Press, New York, NY, pp. 405-14.

Wheeler, D.A., R.G. Hoagland and J.P. Hirth (1989) "Evidence for Crack Tip Oxidation Effects During the Liquid Metal Embrittlement of AA 7075 Aluminum Alloy by Mercury," Sorr, 45: 207-12.

Wray, P.J. (1969) "Strain-Rate Dependence of the Tensile Failure of a Polycrystalline Material at Elevated Temperatures," L.Appl.Physics, 40(10): 4018-29. 
Table 2-1 Cladding Thickness and Gap Size Based on Radiographs.

\begin{tabular}{|c|c|c|c|c|}
\hline Specimen & Rod & Cladding Thickness & \multicolumn{3}{|c|}{ SS-Cd Gap Size (mils) } \\
\cline { 3 - 5 } No. & Nu. & (mils) & min. & max. \\
\hline 9 & 1 & 50 & $\approx 0$ & $\approx 0$ \\
10 & 1 & 50 & $\approx 0$ & $\approx 0$ \\
11 & 1 & 50 & $\approx 0$ & $\approx 0$ \\
12 & 1 & 50 & $\approx 0$ & $\approx 0$ \\
13 & 1 & 50 & $\approx 0$ & $\approx 0$ \\
14 & 1 & 50 & $\approx 0$ & $\approx 0$ \\
15 & 1 & 50 & $\approx 0$ & $\approx 0$ \\
16 & 2 & 50 & $\approx 0$ & $\approx 1$ \\
18 & 3 & 40 & 2 & 5 \\
20 & 4 & 50 & $\approx 0$ & $\approx 1$ \\
27 & 3 & 40 & 1 & 20 \\
28 & 3 & 40 & 1 & 15 \\
29 & 3 & 40 & 0 & 10 \\
31 & 4 & 50 & $\approx 0$ & $\approx 0$ \\
32 & 4 & 50 & $\approx 0$ & $\approx 1$ \\
33 & 4 & 50 & $\approx 0$ & $\approx 1$ \\
34 & 4 & 50 & $\approx 0$ & $\approx 0$ \\
41 & 2 & 50 & $\approx 0$ & $\approx 1$ \\
42 & 2 & 50 & $\approx 0$ & $\approx 1$ \\
43 & 2 & 50 & $\approx 0$ & $\approx 1$ \\
44 & 2 & 50 & $\approx 0$ & 3 \\
46 & 4 & 50 & $\approx 0$ & $\approx 1$ \\
47 & 4 & 50 & $\approx 0$ & $\approx 1$ \\
\hline
\end{tabular}

Note: The serial numbers for safety rods $1-4$ are: S-038, K-081, K-062 and K-901. 
Table 2-2 Cladding Thickness Measurements Based on Photomicrographs.

\begin{tabular}{|c|c|c|c|c|c|}
\hline \multirow{2}{*}{$\begin{array}{c}\text { Sample } \\
\text { Idendification }\end{array}$} & \multirow{2}{*}{$\begin{array}{c}\text { Average } \\
\text { (mils) }\end{array}$} & \multirow{2}{*}{$\begin{array}{c}\text { Minimum } \\
\text { (mils) }\end{array}$} & \multirow{2}{*}{$\begin{array}{c}\text { Maximurn } \\
\text { (mils) }\end{array}$} & \multicolumn{2}{|c|}{ Standard Deviation } \\
\hline & & & & $(\%)$ & (mils) \\
\hline Rod 1 Characterization Spec. & 48.3 & 43.1 & 57.1 & 8.2 & 3.9 \\
\hline Rod 2 Characterization Spec. & 49.1 & 46.5 & 51.4 & 3.1 & 1.5 \\
\hline Rod 3 Characterization Spec. & 36.5 & 35.0 & 37.9 & 2.3 & 0.83 \\
\hline Rod 4 Characterization Spec. & 50.2 & 48.5 & 51.8 & 2.1 & 1.0 \\
\hline Rod. 1 (Spec. No. 9 Top) & 48.3 & 46.0 & 51.0 & 3.1 & 1.5 \\
\hline Rod. 1 (Spec. No. 9 Bottom) & 47.7 & 44.0 & 50.9 & 4.6 & 2.2 \\
\hline Rod. 1 (Spec. No. 53) & 49.1 & 47.3 & 50.4 & 1.6 & 0.8 \\
\hline
\end{tabular}

Note: The serial numbers for safety rods 1 through 4 are: S-038, K-081, K-062 and K-901.

Table 2-3 Gap Size Measurements Based on Photomicrographs.

\begin{tabular}{|c|c|c|c|c|}
\hline \multirow{2}{*}{$\begin{array}{c}\text { Safety } \\
\text { Rod } \\
\text { Number }\end{array}$} & \multicolumn{2}{|c|}{ Cladding-Cadmium Gap } & \multicolumn{2}{|c|}{ Cadmium-Al Core Gap } \\
\hline & $\begin{array}{c}\text { Average } \\
\text { (mils) }\end{array}$ & $\begin{array}{c}\text { Standard } \\
\text { Deviation (mils) }\end{array}$ & $\begin{array}{c}\text { Average } \\
\text { (mils) }\end{array}$ & $\begin{array}{c}\text { Standard } \\
\text { Deviation (mils) }\end{array}$ \\
\hline 1 & 1.5 & 0.8 & 0.57 & 0.16 \\
\hline 2 & 3.0 & 2.0 & 1.5 & 0.30 \\
\hline 3 & 8.7 & 1.5 & $\approx 0.1$ & $\approx 0.025$ \\
\hline 4 & $\approx 0.2$ & $\approx 0.05$ & $\approx 0.1$ & $\approx 0.025$ \\
\hline
\end{tabular}

Note: The serial numbers for safety rods 1 through 4 are: S-038, K-081, K-062 and K-901. 
Table 2-4 Composition Data From Electron Microprobe Examination.

\begin{tabular}{|c|c|c|c|c|c|}
\hline \multirow[b]{2}{*}{ Element } & \multicolumn{5}{|c|}{ Concentration (wt. \%) } \\
\hline & $\begin{array}{l}\text { Measured } \\
\text { Value in } \\
\text { Cladding }\end{array}$ & $\begin{array}{c}\text { SS304 } \\
\text { Composition } \\
\text { Specification }\end{array}$ & $\begin{array}{l}\text { Measured } \\
\text { Value in } \\
\text { Core }\end{array}$ & $\begin{array}{c}\text { Al-6061 } \\
\text { Composition } \\
\text { Specification }\end{array}$ & $\begin{array}{c}\text { Measured } \\
\text { Value in } \\
\text { Flash Coating }\end{array}$ \\
\hline $\mathrm{Fe}$ & 67.35 & balance & 0.05 & $0.7 \max$ & 0.18 \\
\hline $\mathrm{Cr}$ & 18.75 & $18-20$ & 0.15 & $0.04-0.35$ & $\approx 0$ \\
\hline $\mathrm{Ni}$ & 9.80 & $8-10.5$ & $\approx 0$ & -.....- & 98.16 \\
\hline $\mathrm{Mn}$ & 1.80 & $2.0 \max$ & 0.02 & $0.15 \max$ & 0.02 \\
\hline $\mathrm{Si}$ & 0.37 & $1.0 \max$ & 0.58 & $0.4-0.8$ & 0.11 \\
\hline $\mathrm{Mg}$ & $\approx 0$ & -.......- & 1.09 & $0.8-1.2$ & 0.28 \\
\hline $\mathrm{Al}$ & 1.94 & -........ & 97.69 & $\approx 97.9$ & 1.05 \\
\hline $\mathrm{Cu}$ & $\approx 0$ & -.......-- & 0.34 & $0.15-0.40$ & $\approx 0$ \\
\hline$Z_{n}$ & $\approx 0$ & -.......- & 0.07 & $0.25 \max$ & $\approx 0$ \\
\hline $\mathrm{Cd}$ & $\approx 0$ & -...-. & $\approx 0$ & -.....- & 0.18 \\
\hline
\end{tabular}

Table 2,-5 Safety Rod Cladding Grain Size Data.

\begin{tabular}{|l|c|c|}
\hline \multicolumn{1}{|c|}{ Sample Identification } & ASTM Grain Size No. & Mean Intercept $(\mu \mathrm{m})$ \\
\hline Rod 1 Characterization Specimen & 8.4 & 18 \\
Rod 2 Characterization Specimen & 6.1 & 39 \\
Rod 3 Characterization Specimen & 5.6 & 46 \\
Rod 4 Characterization Specimen & 5.6 & 46 \\
Rod. 1 (Spec. No. 9 Top) & 7.8 & 21 \\
Rod. 1 (Spec. No. 9 Bottom) & 8.1 & 19 \\
Rod. 1 (Spec. No. 53) & 8.0 & 20 \\
\hline
\end{tabular}

Note: The serial numbers for safety rods 1 through 4 are: S-038, K-081, K-062 and K-901. 
Table 3-1 Summary of Safety Rod Thermal Test Conditions and Results.

\begin{tabular}{|c|c|c|c|c|c|c|c|c|}
\hline $\begin{array}{l}\text { Test } \\
\text { Date }\end{array}$ & $\begin{array}{c}\text { Rod } \\
\text { No. } \\
{[a]}\end{array}$ & $\begin{array}{l}\text { Spec. } \\
\text { No. }\end{array}$ & $\begin{array}{c}\text { Ramp } \\
\text { Type }\end{array}$ & $\begin{array}{c}\text { Target } \\
\text { Maximum } \\
\text { Temp. }\left({ }^{\circ} \mathrm{C}\right)\end{array}$ & $\begin{array}{l}\text { Failure } \\
\text { Temp. } \\
\left( \pm 10^{\circ} \mathrm{C}\right)\end{array}$ & $\begin{array}{c}\text { Time at } \\
\text { Max. Temp. } \\
\text { (hours) }\end{array}$ & $\begin{array}{c}\text { Time Above } \\
321^{\circ} \mathrm{C} \\
( \pm 1 \mathrm{~min} .)\end{array}$ & $\begin{array}{l}\text { Ramp Rate } \\
\text { above } 100^{\circ} \mathrm{C} \\
\text { [b] }\left({ }^{\circ} \mathrm{C} / \mathrm{min}\right)\end{array}$ \\
\hline $4 / 2 / 91$ & 1 & 9 & Slow & 700 & $590[\mathrm{c}]$ & $=1 / 2$ & 101 & 3.9 \\
\hline $4 / 8 / 91$ & 1 & 10 & Slow & 575 & - & 1 & 338 & 3.5 \\
\hline $4 / 9 / 91$ & 1 & 11 & Slow & 600 & 533 & 0 & 51 & 4.5 \\
\hline $4 / 10 / 91$ & 1 & 12 & Slow & 525 & 521 & 0 & 45 & 3.7 \\
\hline $4 / 15 / 91$ & 1 & 13 & Slow & 500 & - & 1 & 292 & 5.6 \\
\hline $4 / 16 / 91$ & 1 & 14 & Slow & 500 & - & 1 & 315 & 7.5 \\
\hline $4 / 17 / 91$ & 1 & 15 & Slow & 500 & - & 1 & 284 & 5.9 \\
\hline $4 / 18 / 91$ & 2 & 16 & Slow & 500 & - & 1 & 287 & 7.6 \\
\hline $5 / 2 / 91$ & 4 & 33 & Slow & 600 & - & 1 & 282 & 9.6 \\
\hline $8 / 22 / 91$ & 2 & 41 & Slow & 600 & - & 1 & 333 & 2.9 \\
\hline $8 / 23 / 91$ & 2 & 42 & Slow & 600 & - & 1 & 340 & 3.2 \\
\hline $8 / 26 / 91$ & 4 & 46 & Slow & 600 & -... & 1 & 334 & 3.5 \\
\hline $8 / 27 / 91$ & 4 & 47 & Slow & 600 & - & 1 & 327 & 2.9 \\
\hline $9 / 3 / 91$ & 2 & 44 & Slow & 600 & - & 1 & $=315$ & $\approx 4$ \\
\hline $4 / 19 / 91$ & 3 & 18 & Slow & 500 & - & 4 & 470 & 6.0 \\
\hline $4 / 22 / 91$ & 4 & 20 & Slow & 500 & - & 4 & 452 & 7.4 \\
\hline $4 / 23 / 91$ & 3 & 27 & Slow & 500 & -.. & 4 & 460 & 6.0 \\
\hline $4 / 24 / 91$ & 3 & 28 & Fast & 550 & - & 1 & 275 & 33 \\
\hline $4 / 25 / 91$ & 3 & 29 & Fast & 600 & - & $i$ & 276 & 26 \\
\hline $4 / 26 / 91$ & 4 & 31 & Fast & 550 & $\ldots$ & 1 & 277 & 31 \\
\hline $4 / 29 / 91$ & 4 & 32 & Fast & 600 & - & 1 & 256 & 38 \\
\hline $5 / 3 / 91$ & 1 & 13 & Fast & 600 & - & 1 & 270 & 48 \\
\hline $5 / 6 / 91$ & 1 & 14 & Fast & 600 & - & 1 & 273 & 83 \\
\hline $8 / 28 / 91$ & 4 & 34 & Fast & 800 & 830 & $\approx 0$ & 6.6 & 110 \\
\hline $8 / 29 / 91$ & 2 & 43 & Fast & 900 & 870 & $\approx 0$ & 6.9 & 230 \\
\hline
\end{tabular}

Notes: [a] The serial numbers for safety rods 1 through 4 are: S-038, K-081, K-062, and K-901.

[b] Ramp rate is the average rate from $100^{\circ} \mathrm{C}$ to the maximum temperature.

[c] Estimated based on adjacent positions (hot zone thermocouple failed prior to cladding rupture). 
Table 4-1 Measured Hoop Strains for Unfailed Specimens.

\begin{tabular}{|c|c|c|c|c|}
\hline $\begin{array}{c}\text { Test } \\
\text { Date }\end{array}$ & $\begin{array}{c}\text { Rod } \\
\text { No. }\end{array}$ & $\begin{array}{c}\text { Spec. } \\
\text { No. }\end{array}$ & $\begin{array}{c}\text { Target Max. } \\
\text { Temp. }\left({ }^{\circ} \mathrm{C}\right)\end{array}$ & $\begin{array}{c}\text { Hoop Strain at Mid- } \\
\text { Plane of Hot Zone (\%) }\end{array}$ \\
\hline $4 / 8 / 91$ & 1 & 10 & 575 & 2.4 \\
$4 / 15 / 91$ & 1 & 13 & 500 & $1.2[\mathrm{~b}]$ \\
$4 / 16 / 91$ & 1 & 14 & 500 & $1.6[\mathrm{~b}]$ \\
$4 / 17 / 91$ & 1 & 15 & 500 & 1.9 \\
$4 / 18 / 91$ & 2 & 16 & 500 & 0.5 \\
$5 / 2 / 91$ & 4 & 33 & 600 & 2.6 \\
$8 / 22 / 91$ & 2 & 41 & 600 & 0.1 \\
$8 / 23 / 91$ & 2 & 42 & 600 & 0.2 \\
$8 / 26 / 91$ & 4 & 46 & 600 & 1.6 \\
$8 / 27 / 91$ & 4 & 47 & 600 & 1.8 \\
$9 / 3 / 91$ & 2 & 44 & 600 & 0.1 \\
& & & & \\
$4 / 19 / 91$ & 3 & 18 & 500 & 0.1 \\
$4 / 22 / 91$ & 4 & 20 & 500 & 0.9 \\
$4 / 23 / 91$ & 3 & 27 & 500 & -0.1 \\
& & & & \\
$4 / 24 / 91$ & 3 & 28 & 550 & 0.1 \\
$4 / 25 / 91$ & 3 & 29 & 600 & 0.1 \\
$4 / 26 / 91$ & 4 & 31 & 550 & 1.8 \\
$4 / 29 / 91$ & 4 & 32 & 600 & 5.5 \\
$5 / 3 / 91$ & 1 & 13 & 600 & $1.8[\mathrm{a}, \mathrm{b}]$ \\
$5 / 6 / 91$ & 1 & 14 & 600 & $1.8[\mathrm{a}, \mathrm{b}]$ \\
\hline
\end{tabular}

Notes: [a] Specimens 13 and 14 were tested twice, these values are relative to the original untested diameter.

[b] The uncertainty in the strains for specimens 13 and 14 may be as large as $50 \%$ (e.g. $1.8 \% \pm 0.9 \%$ ).

Table 6-1 Summary of Predicted Safety Rod Cladding Hoop Strain at Failure.

\begin{tabular}{|c|c|c|c|c|c|}
\hline \multirow{2}{*}{$\begin{array}{l}\text { Test } \\
\text { Type }\end{array}$} & \multirow{2}{*}{$\begin{array}{c}\text { Temperature } \\
\text { Range } \\
\left({ }^{\circ} \mathrm{C}\right)\end{array}$} & \multirow{2}{*}{$\begin{array}{c}\text { Strain Rate } \\
\text { Range } \\
\left(\mathrm{min}^{-1}\right)\end{array}$} & \multicolumn{3}{|c|}{ Predicted Failure Strain (\%) } \\
\hline & & & $\begin{array}{l}\text { uniaxial } \\
\text { annealed }\end{array}$ & $\begin{array}{l}\text { uniaxial } \\
6 \% \mathrm{CW}\end{array}$ & $\begin{array}{l}\text { triaxial } \\
6 \% \mathrm{CW}\end{array}$ \\
\hline low-temp & $521-590$ & $2.7 \times 10^{-4}$ & 30 & 23 & 12 \\
\hline high-temp & $830-870$ & 0.02 & 35 & 32 & 16 \\
\hline burst test & 550 & 0.03 & 40 & 30 & 15 \\
\hline
\end{tabular}


Table 6-2 Tensile Test Conditions and Results.

\begin{tabular}{|c|c|c|c|c|c|c|c|c|c|}
\hline $\begin{array}{c}\text { Spec. } \\
\text { No. }\end{array}$ & $\begin{array}{l}\text { Spec. } \\
\text { Type }\end{array}$ & $\begin{array}{c}\text { Environ- } \\
\text { mont }\end{array}$ & $\begin{array}{c}\text { Strain } \\
\text { Rate } \\
\left(\mathrm{min}^{-1}\right)\end{array}$ & $\begin{array}{c}\text { Temp. } \\
\left({ }^{\circ} \mathrm{C}\right)\end{array}$ & $\begin{array}{c}\text { Yield } \\
\text { Strength } \\
\text { (ksi) }\end{array}$ & $\begin{array}{c}\text { Ultimate } \\
\text { Strength } \\
\text { (ksi) }\end{array}$ & $\begin{array}{l}\text { Uniform } \\
\text { Elong, } \\
(\%)[\mathrm{a}]\end{array}$ & $\begin{array}{l}\text { Total } \\
\text { Elong. } \\
(\%)[a]\end{array}$ & $\begin{array}{c}\text { R.A. } \\
(\%)\end{array}$ \\
\hline 5 & Smooth & Air & $2.2 \mathrm{E} \cdot 2[\mathrm{~b}]$ & 325 & 36.2 & 76.8 & 34.5 & 41.5 & 70.5 \\
\hline 6 & Smooth & Air & $4.5 \mathrm{e}-3[\mathrm{c}]$ & 325 & 40.2 & 78.6 & 34.5 & 41.5 & 69.6 \\
\hline 17 & Smooth & Alt & $3 e-03$ & 325 & 41.6 & 79.1 & 33.2 & 39.0 & 69.8 \\
\hline 19 & Smooth & Air' & $3 e-03$ & 325 & 41.4 & 79.4 & 33,2 & 39.6 & 70.7 \\
\hline 7 & Smooth & Air & $3 e-03$ & 400 & 34.7 & 76.5 & 35.3 & 42.2 & 70.1 \\
\hline 8 & Smooth & Air & $3 e-03$ & 400 & 38.3 & 78.5 & 35.0 & 38.5 & 69.7 \\
\hline 9 & Smooth & Air & $3 e-03$ & 500 & 33.5 & 74.6 & 35.0 & 41.1 & 67.5 \\
\hline 10 & Smooth & Air & $3 e-03$ & 500 & 33.2 & 73.8 & 34.8 & 38.5 & 68.0 \\
\hline 12 & Smooth & Air & $3 e-03$ & 550 & 31.3 & 71.3 & 31.0 & 36.3 & 68.8 \\
\hline 14 & Smooth & Air & $3 e-03$ & 550 & 30.8 & 71.4 & 34.3 & 41.5 & 68.6 \\
\hline 15 & Smooth & Air & $3 e-03$ & 600 & 32.4 & 63.1 & 25.3 & 38.3 & 66.2 \\
\hline 16 & Smooth & Air & $3 e-03$ & 600 & 30.6 & 62.1 & 26.0 & 39.2 & ن6.9 \\
\hline 38 & Smooth & Air & $8 e-05$ & 550 & 32.2 & 60.8 & 23.6 & 29.8 & 42.2 \\
\hline 2 & Notched & Air & [d] & 550 & - & 91.4 & $-m$ & $\ldots$ & 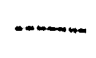 \\
\hline 3 & Notched & Air & [d] & 550 & $-m$ & 90.3 & $\ldots$ & ...- & - \\
\hline 20 & Smnoth & $\mathrm{Cd} \cdot \mathrm{Al}$ & $3 e-03$ & 325 & 37.9 & 78.7 & 36.8 & 41.8 & $-\cdots$ \\
\hline 21 & Smooth & $\mathrm{Cd}-\mathrm{Al}$ & $3 e-03$ & 400 & 37.9 & 77.5 & 35.1 & 38.8 & \\
\hline 22 & Sinooth & $\mathrm{Cd}-\mathrm{Al}$ & $3 e-03$ & 500 & 34.3 & 75.3 & 33.6 & 39.9 & $\ldots$ \\
\hline 13 & Smooth & $\mathrm{Cd}$ & $3 e-03$ & 550 & 33.3 & 70.6 & 30.8 & 38.1 & 5 \\
\hline 18 & Smooth & Cd-Al & $3 e-03$ & 550 & 32.2 & 69.7 & 33.8 & 40.7 & - \\
\hline 23 & Smooth & $\mathrm{Cd}-\mathrm{Al}$ & $3 e-03$ & 600 & 32.2 & 60.3 & 26.2 & 44.3 & - \\
\hline 25 & Smooth & $\mathrm{Cd}-\mathrm{Al}$ & $9 e-04$ & 5.50 & 33.3 & 68.7 & 31.2 & 37.7 & $\cdots$ \\
\hline 26 & Smooth & $\mathrm{Cd}-\mathrm{Al}$ & $8 \mathrm{e}-05$ & 550 & 33.8 & 61.4 & 24.3 & 30.2 & $\cdots$ \\
\hline 1 & Notched & $\mathrm{Cd}-\mathrm{Al}$ & [d] & 550 & -- & 90.6 & - & $\ldots$ & - \\
\hline
\end{tabular}

Notes: [a] Gauge length $=2$ ", gauge diameter to length ratio $=5.7$.

[b] Dummy test, strain rate $=1.3 \mathrm{E}-4 \mathrm{~min}^{-1}$ to $0.025 \%$ strain, then $2.2 \mathrm{E}-2 \mathrm{~min}^{-1}$.

[c] Dummy test, strain rate $=8.0 \mathrm{E}-3 \mathrm{~min}^{-1}$ to $0.8 \%$ strain, then $4.5 \mathrm{E}-3 \mathrm{~min}^{-1}$.

[d] Crosshead speed as for the smooth bar tests with a strain rate of $3 \mathrm{E}-3 \mathrm{~min}^{-1}$. 


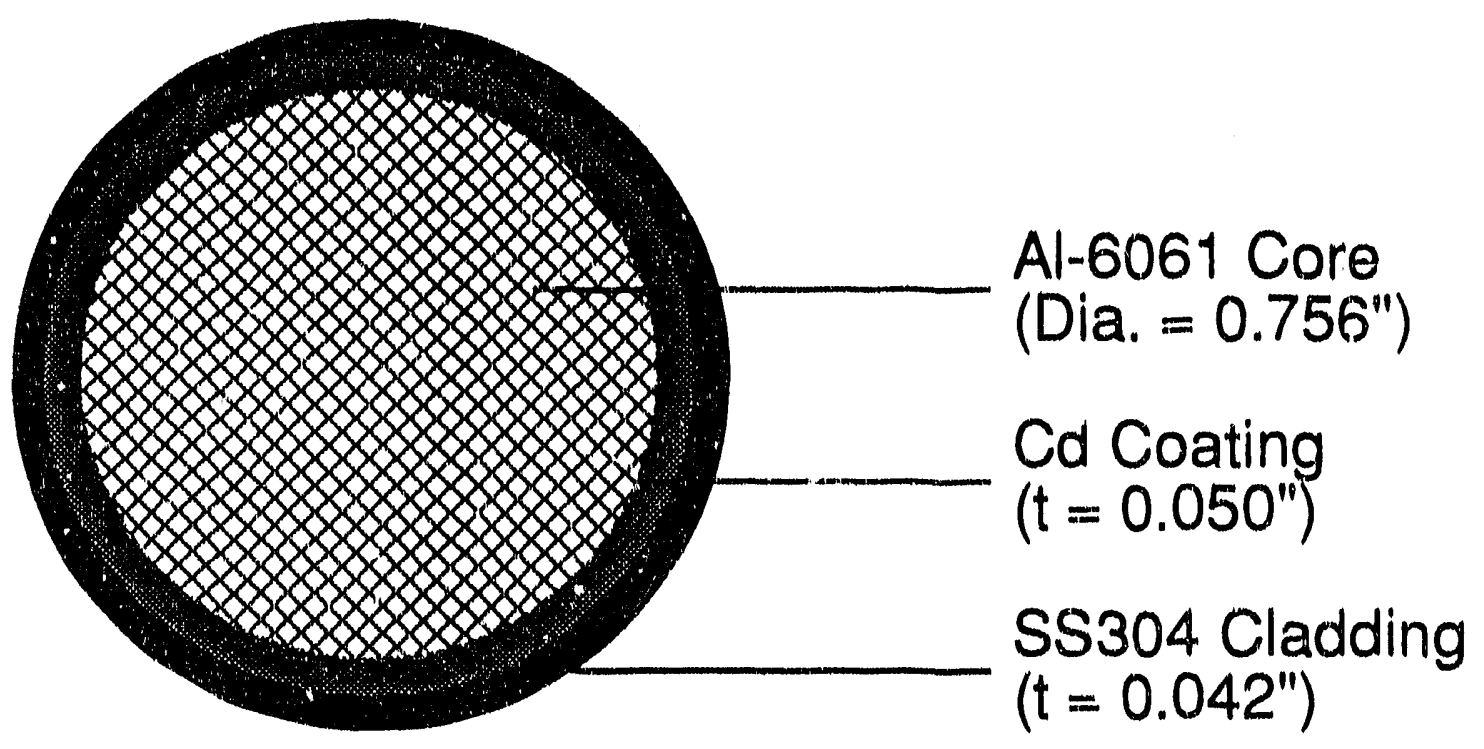

Figure 2-1 Safety Rod Cross Section. 

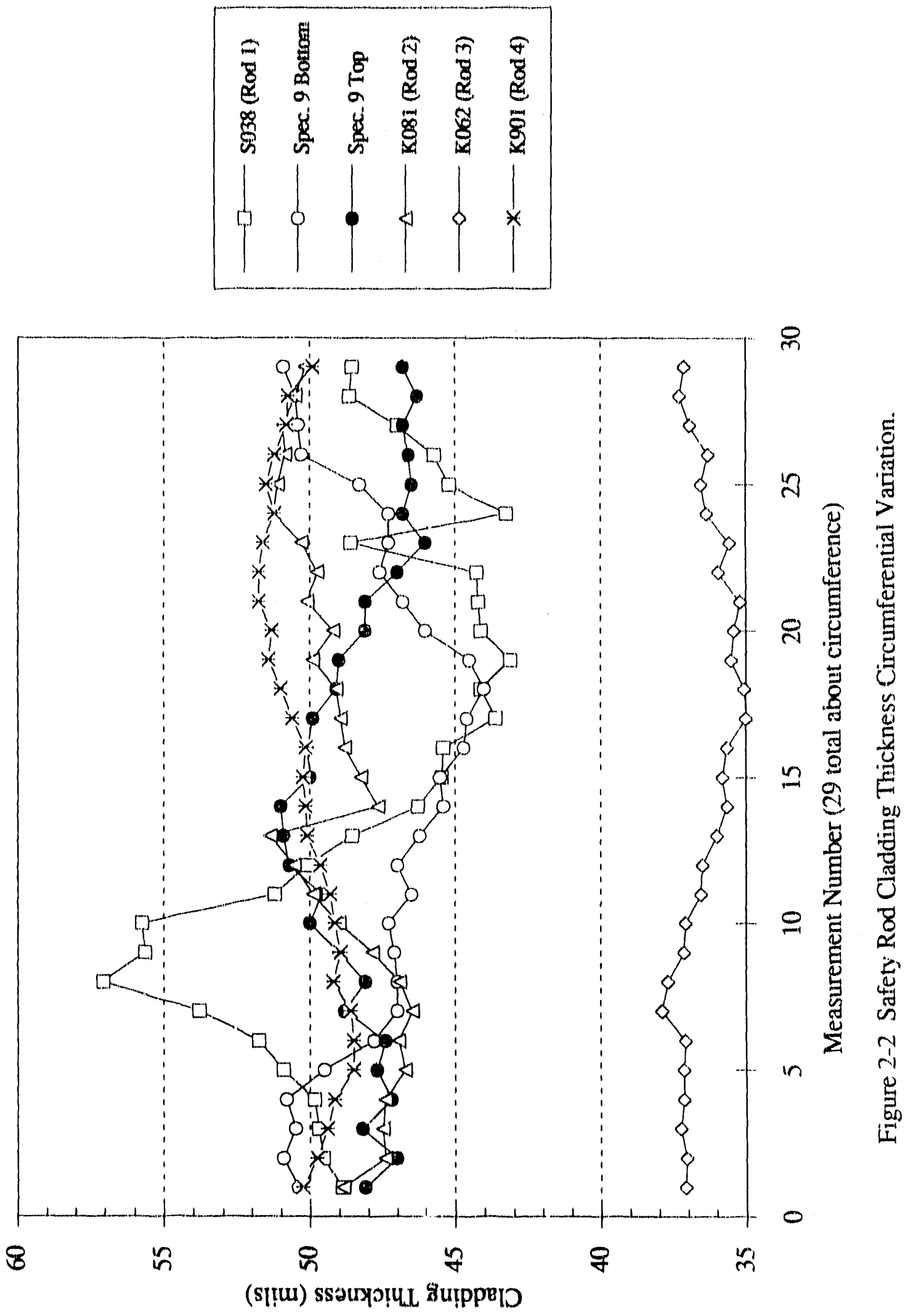


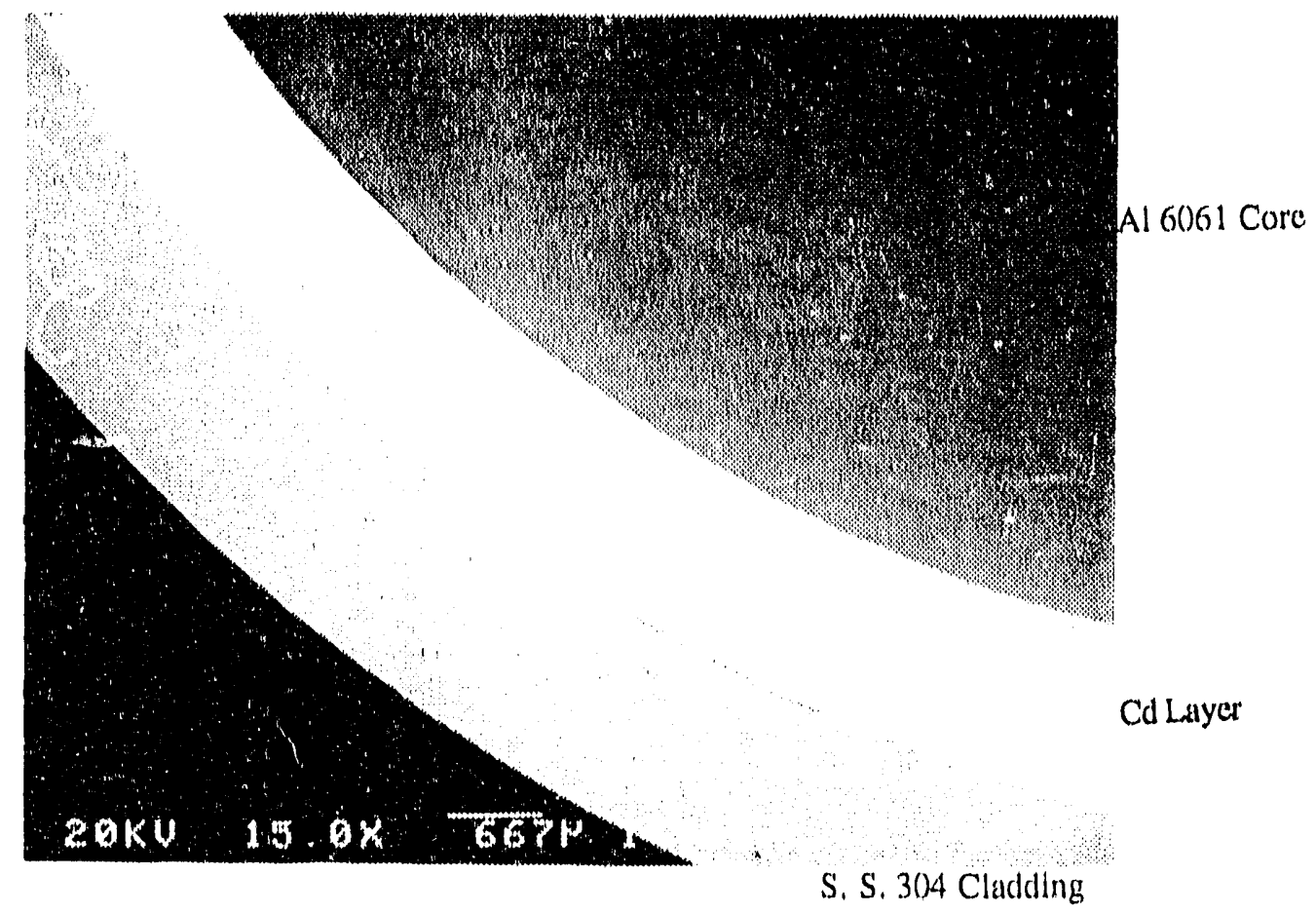

Figure 2-3a SEM Micrograph of Safety Rod 1 Characterization Specimen (BSE, 15x).

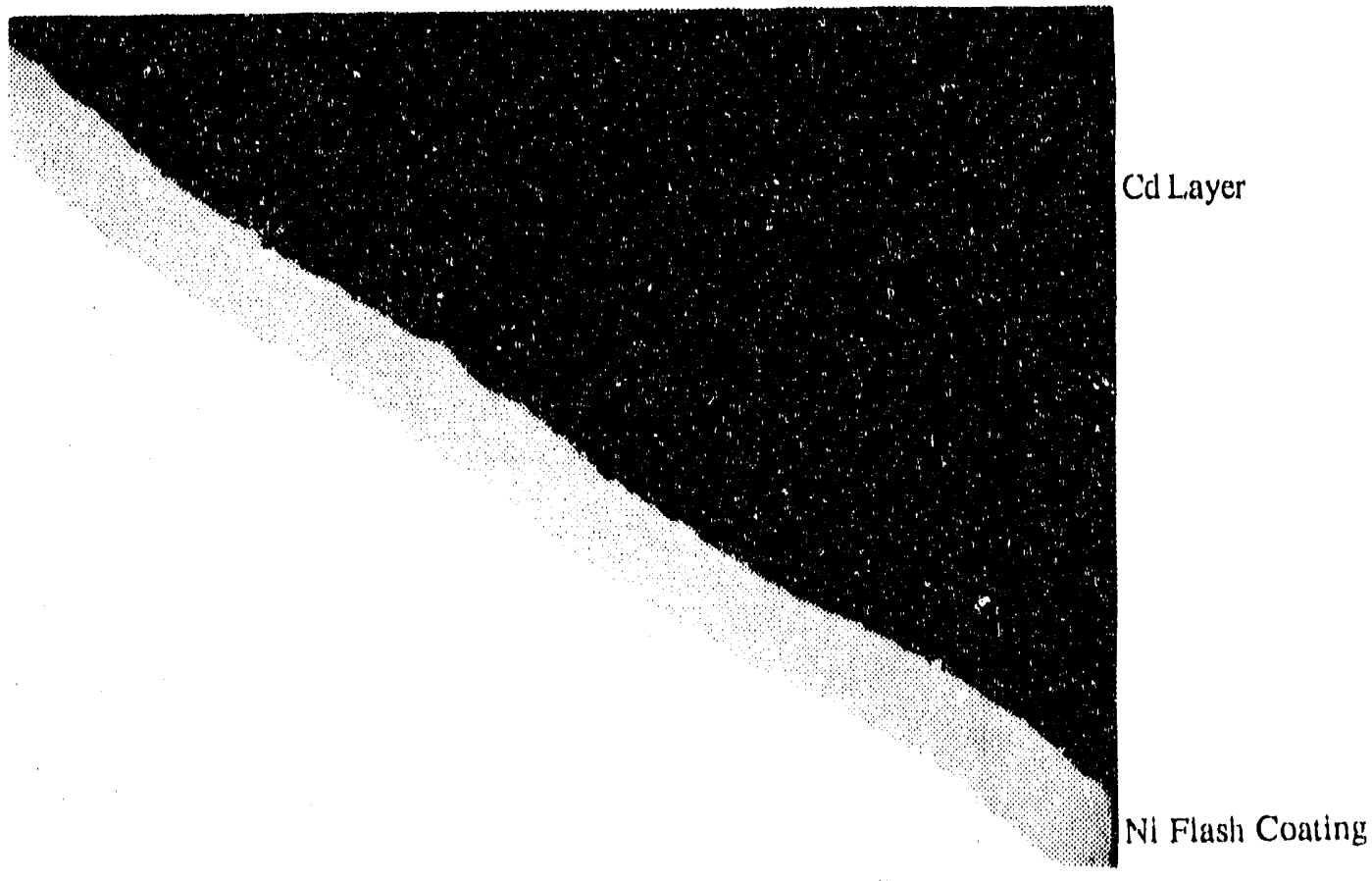

Al 6061 Core

Figure 2-3b SEM Micrograph of Safety Rod 1 Characterization Specimen (BSE, 500x). 


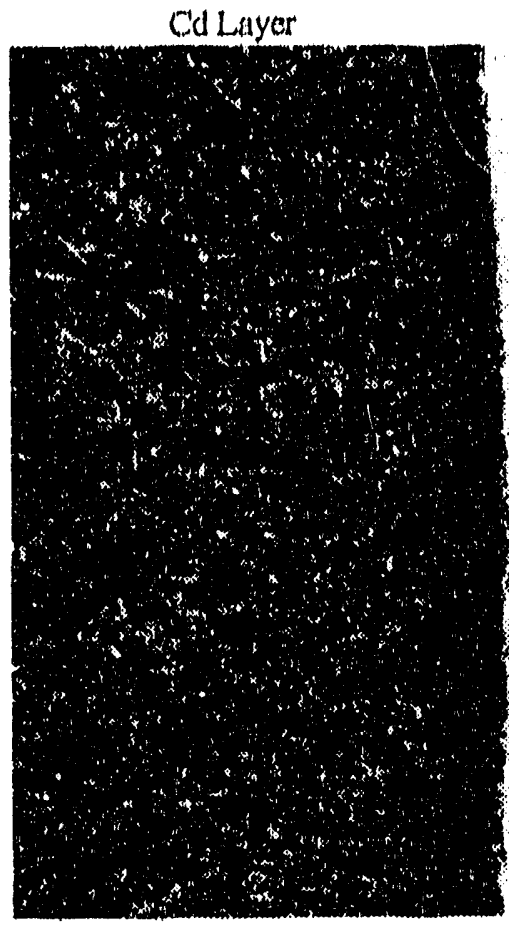

S. S. $3(14$ Claddling

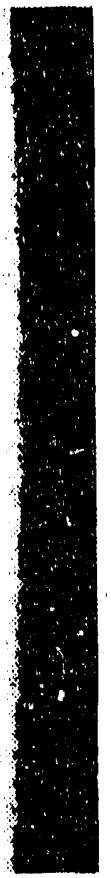

Figure 2-4a Optical Micrograph of Safety Rod 1 Characterization Specimen (50x).

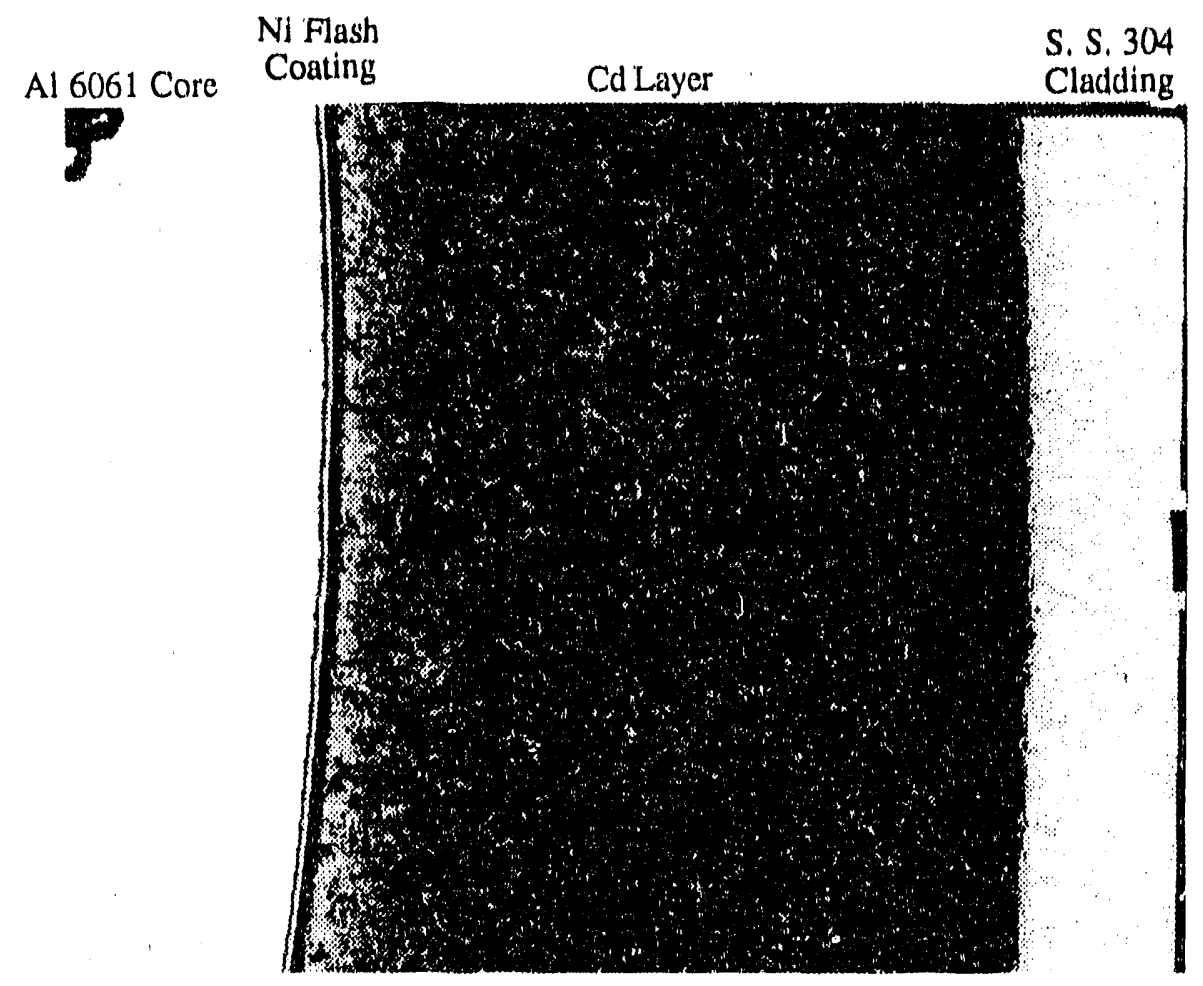

Figure 2-4b Optical Micrograph of Safety Rod 1 Characterization Specimen (50x). 


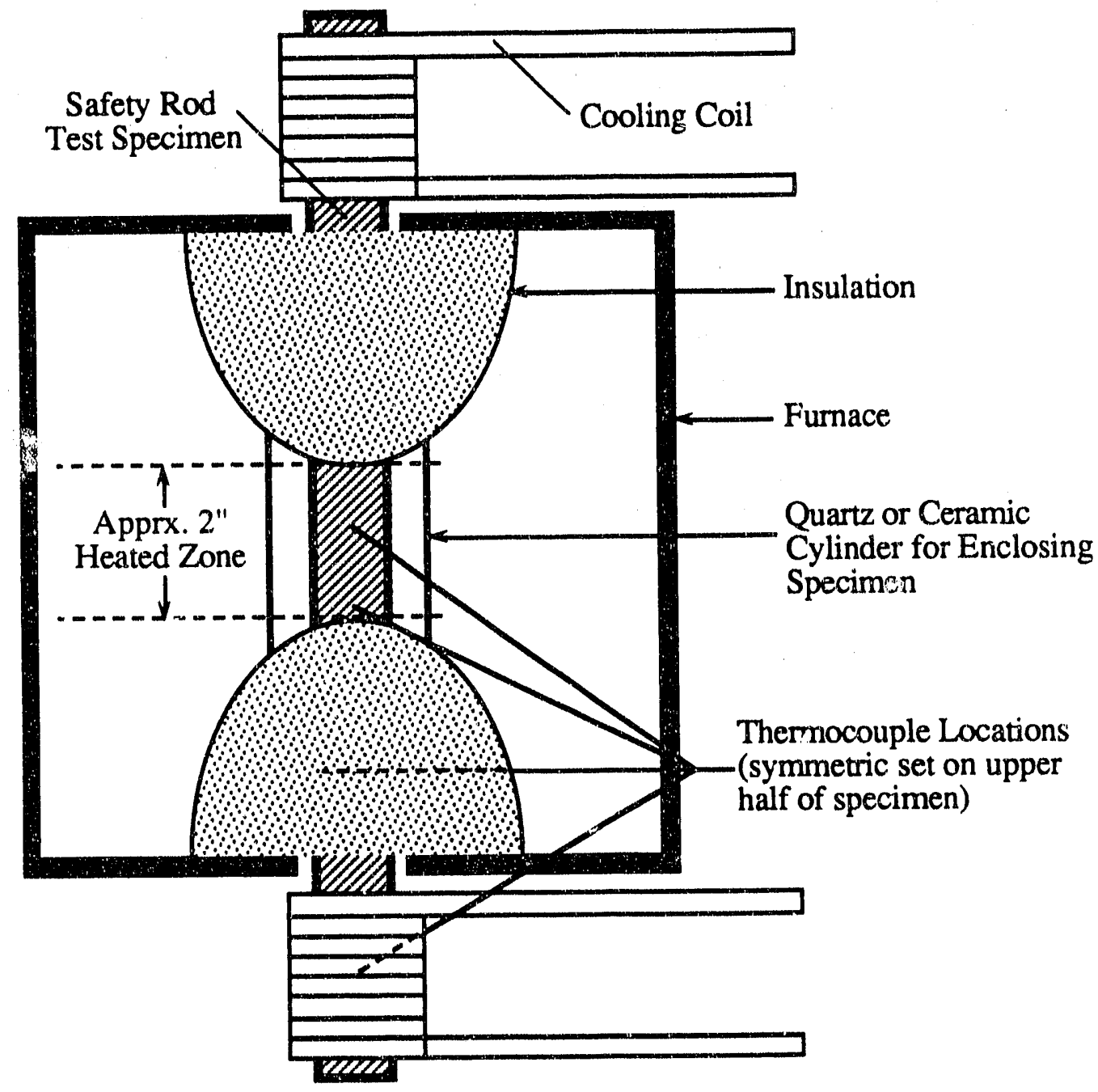

Figure 3-1 Experimental Apparatus. 


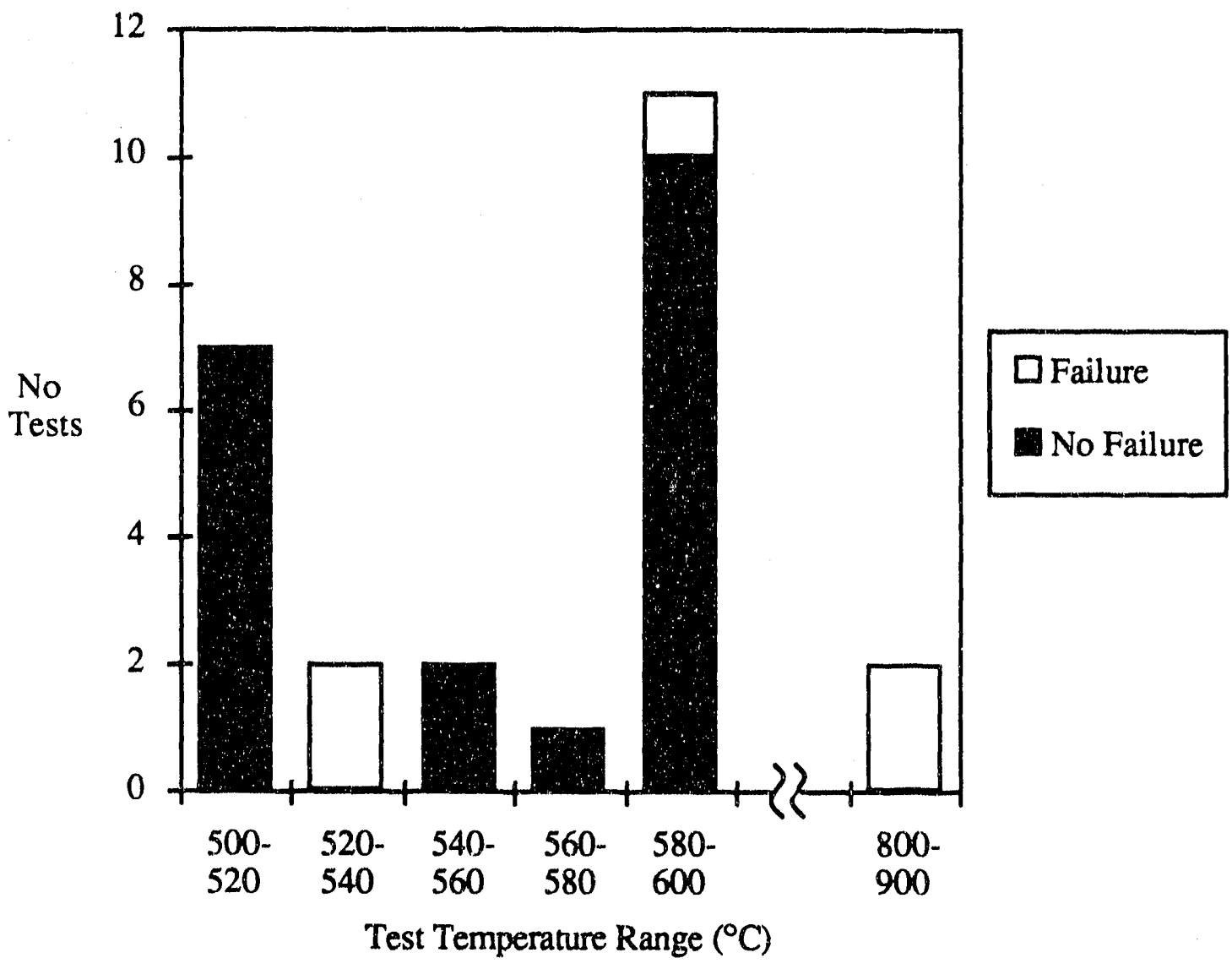

Figure 3-2 Histogram of Test Data. 


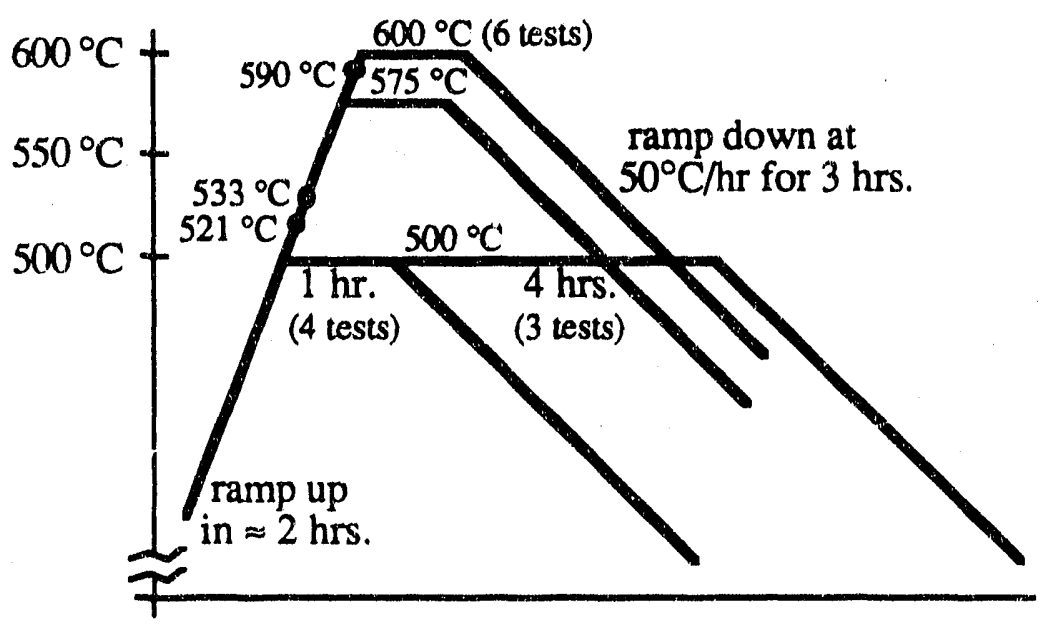

Figure 3-3 Simplified Schematic of Thermal Histories for the "Slow Ramp" Tests.

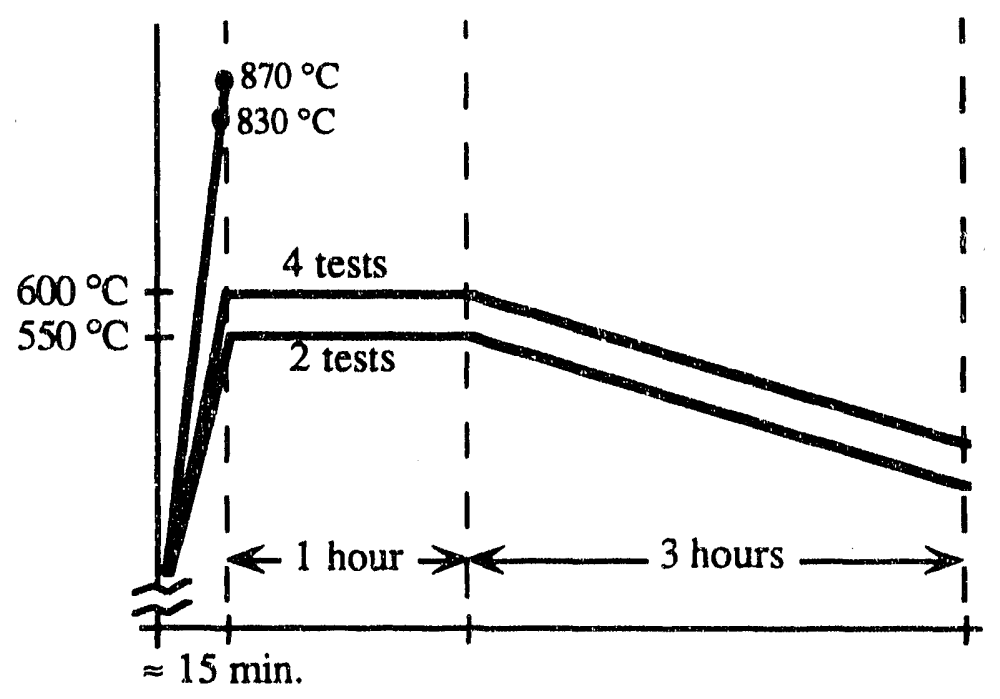

Figure 3-4 Simplified Schematic of Thermal Histoies for the "Fast Ramp" Tests. 


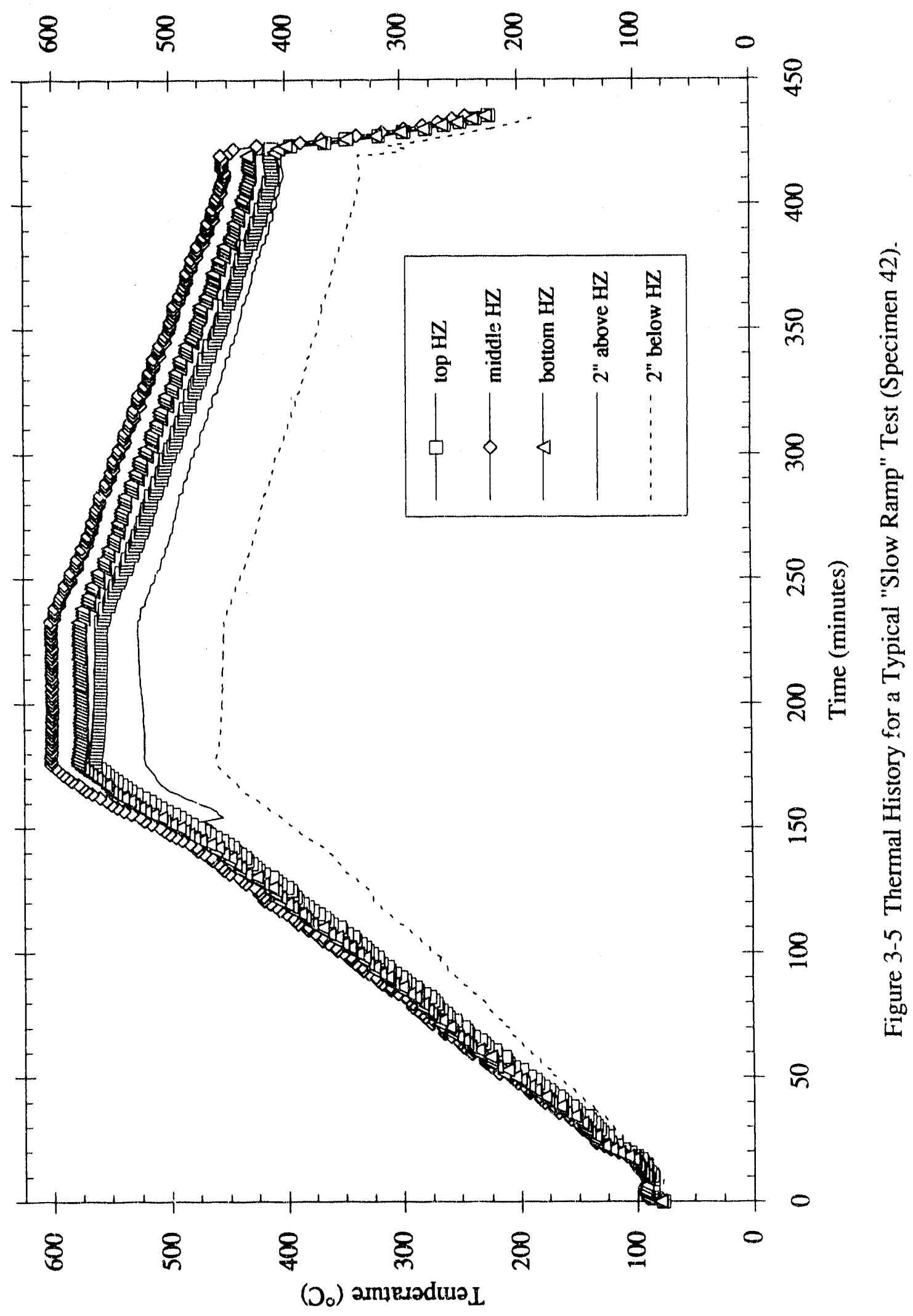




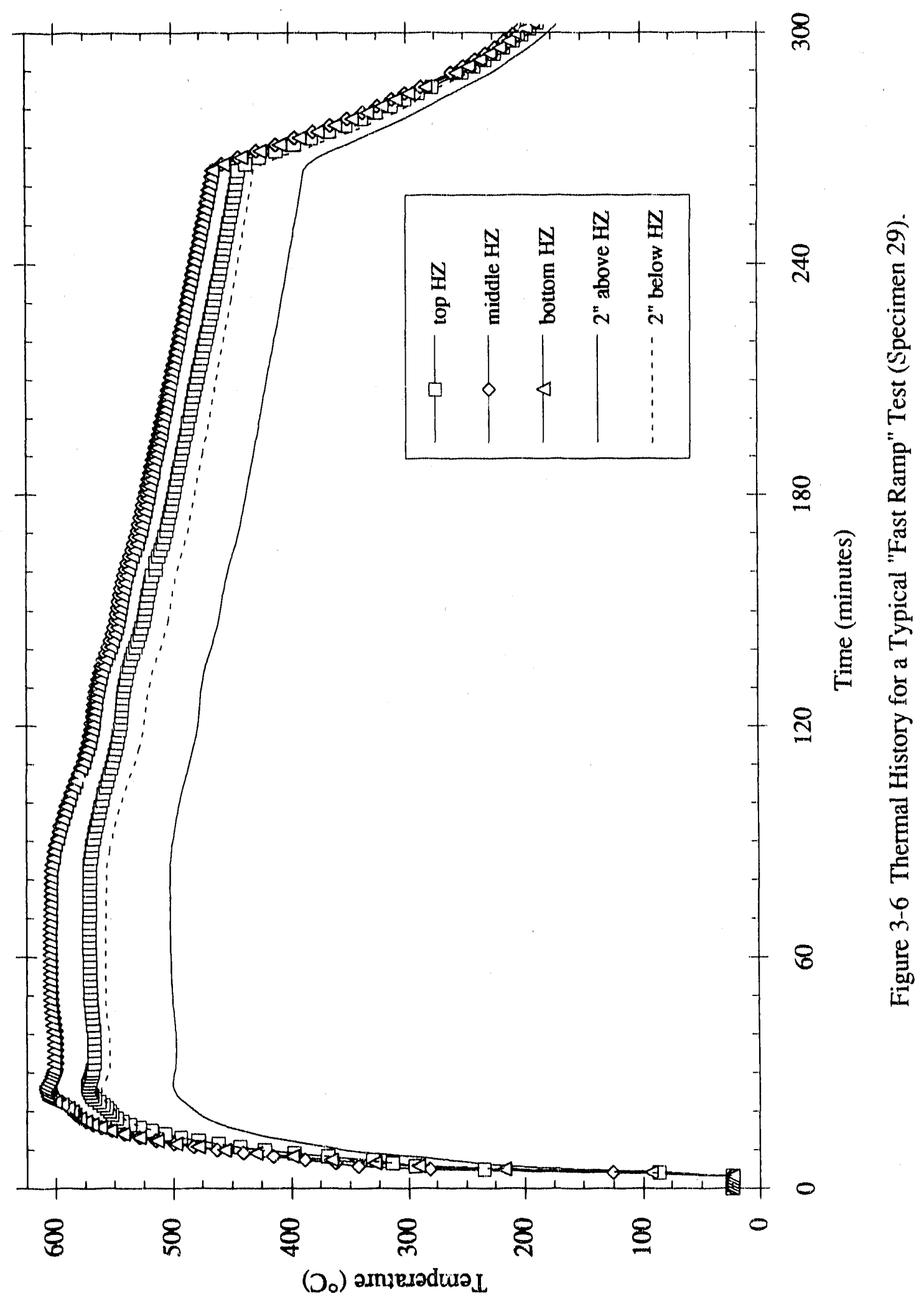




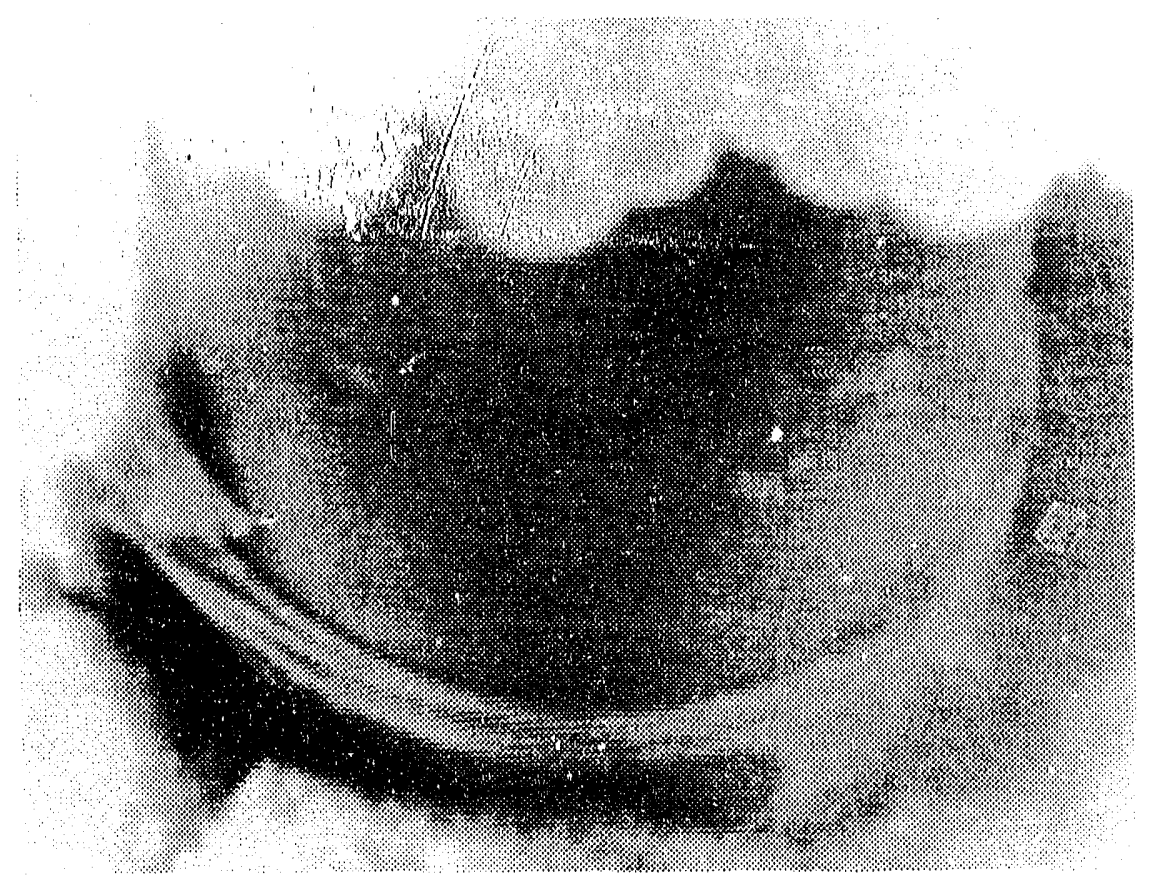

Figure 3-7a Specimen 9, Just Prior to Rupture.

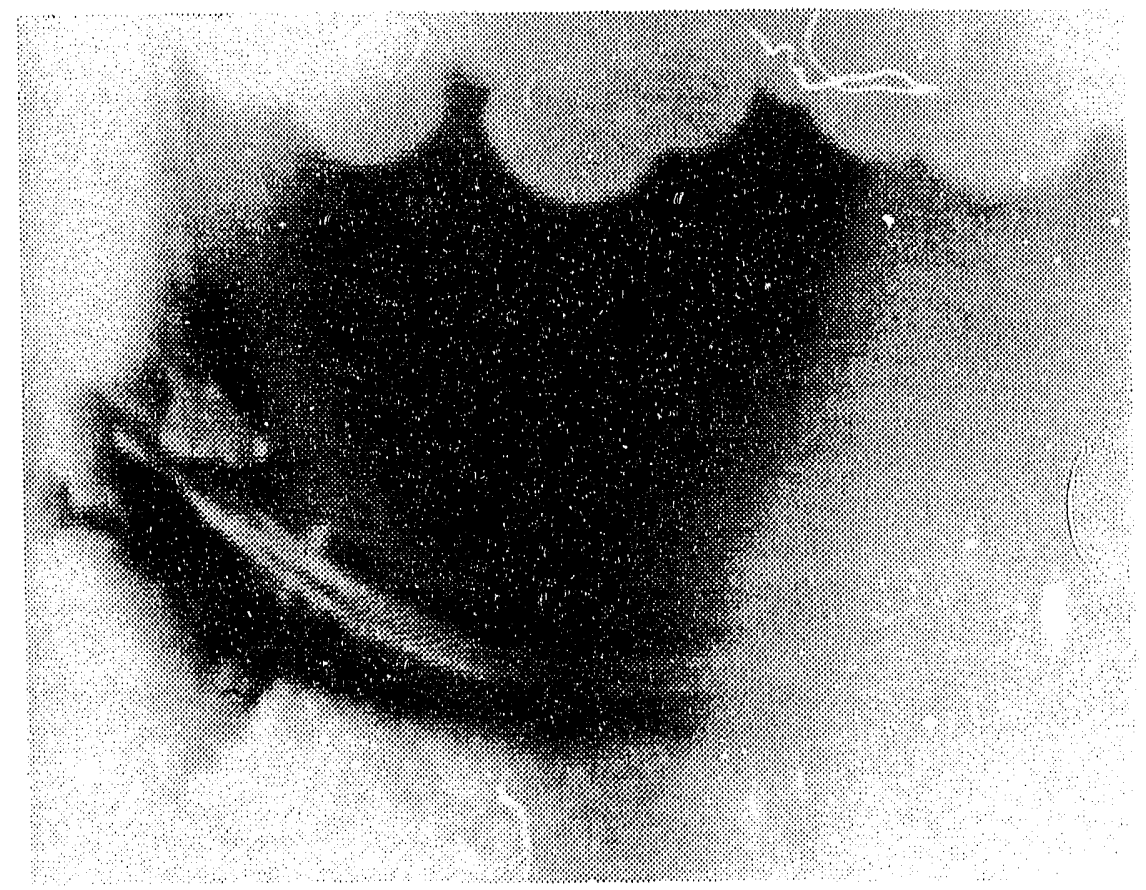

Figure 3.-7b Snecimen 9, 1 Frame (1/30 sec.) After Rupture. 


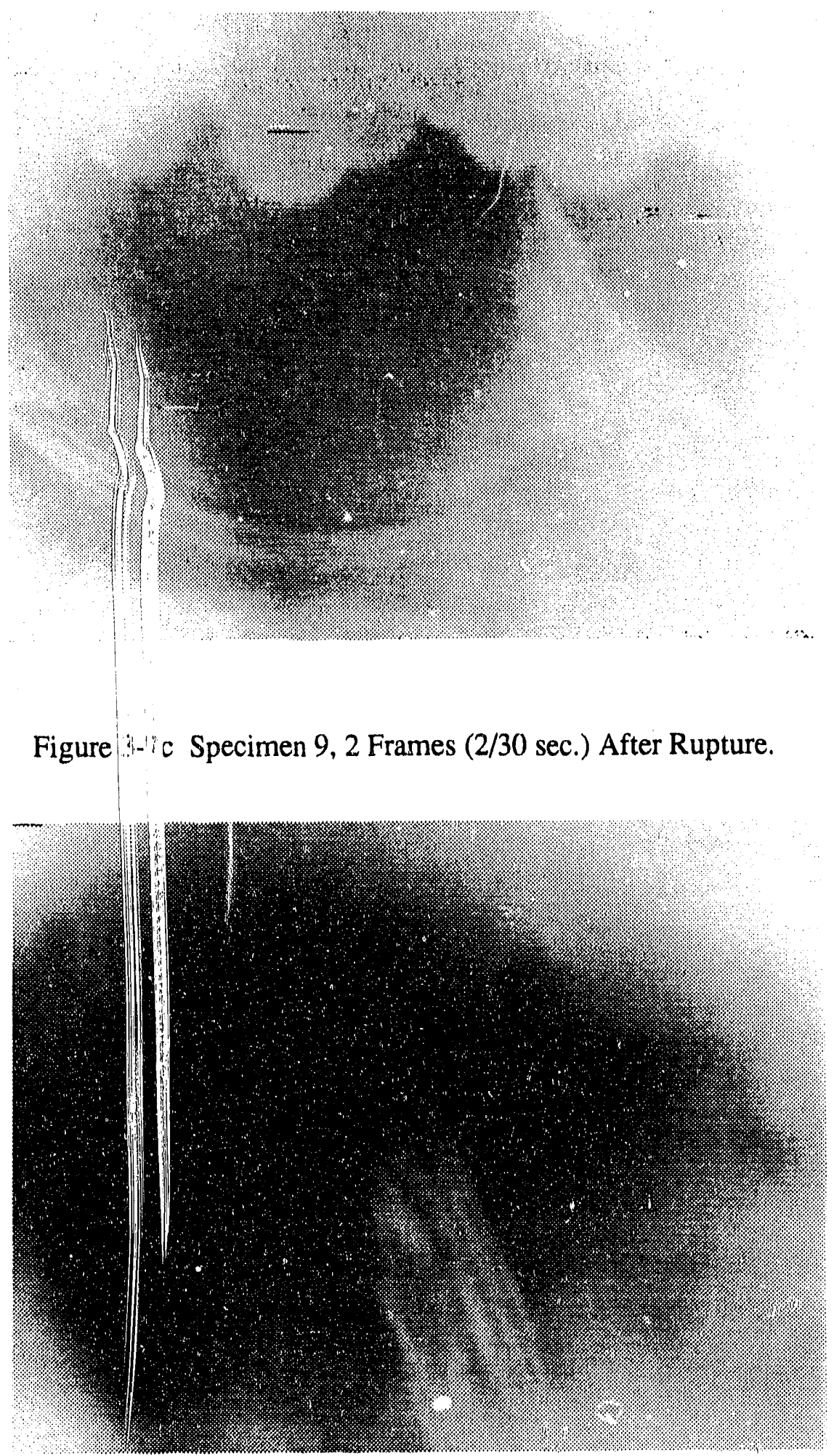

Figure 3-7d Specimen 9, 3 Frames (3/30 sec.) After Rupture. 


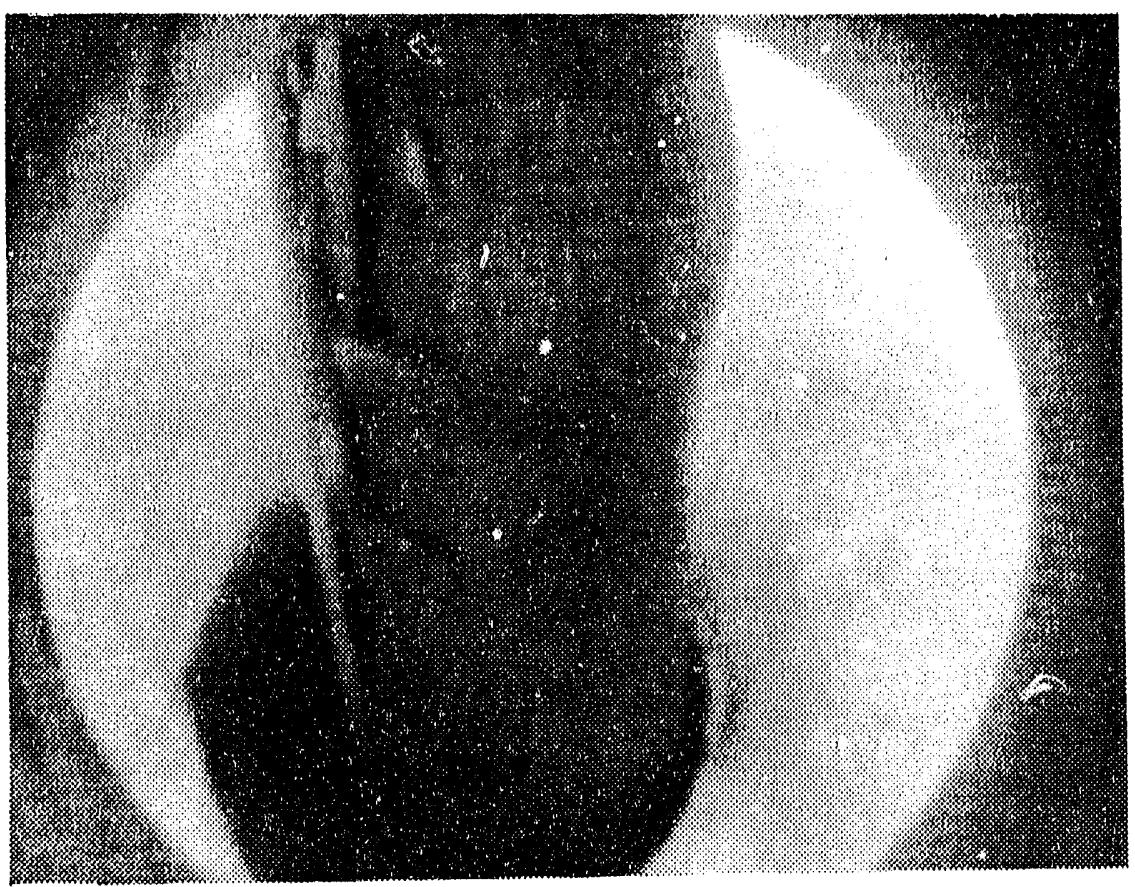

Figure 3-8a Specimen 34, Just Prior to Rupture.

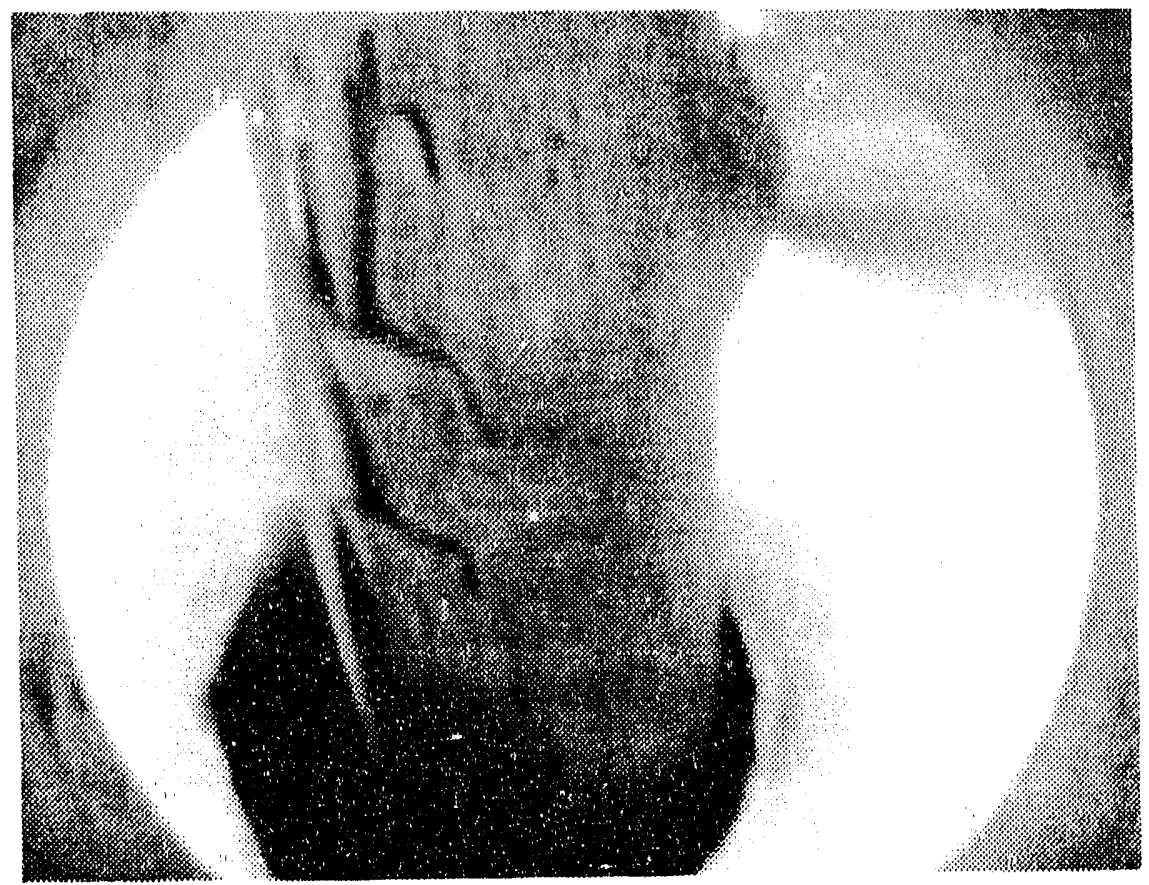

Figure 3-8b Specimen 34, 1 Frame (1/30 sec.) After Rupture. 


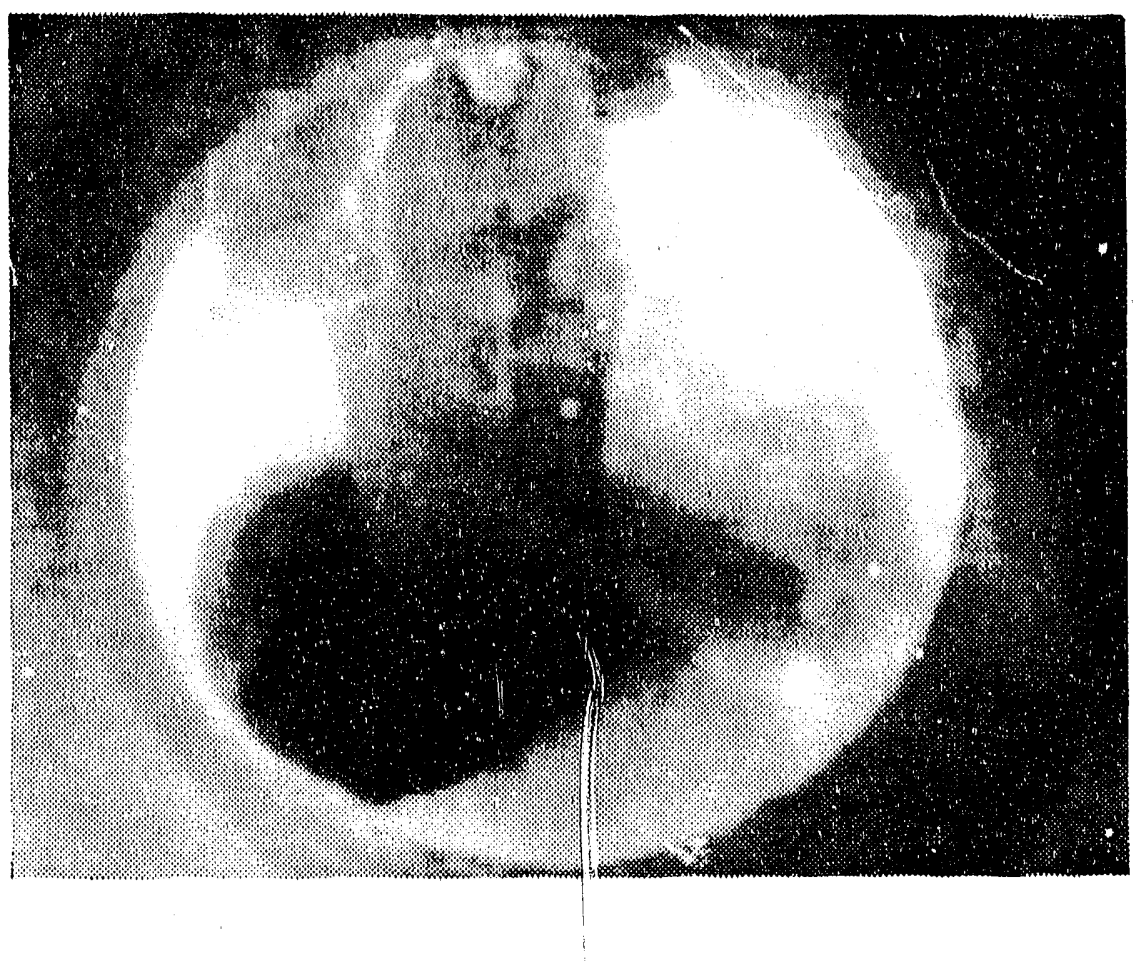

Figure 3-9a Specimen 43. Just Prior to Rupture.

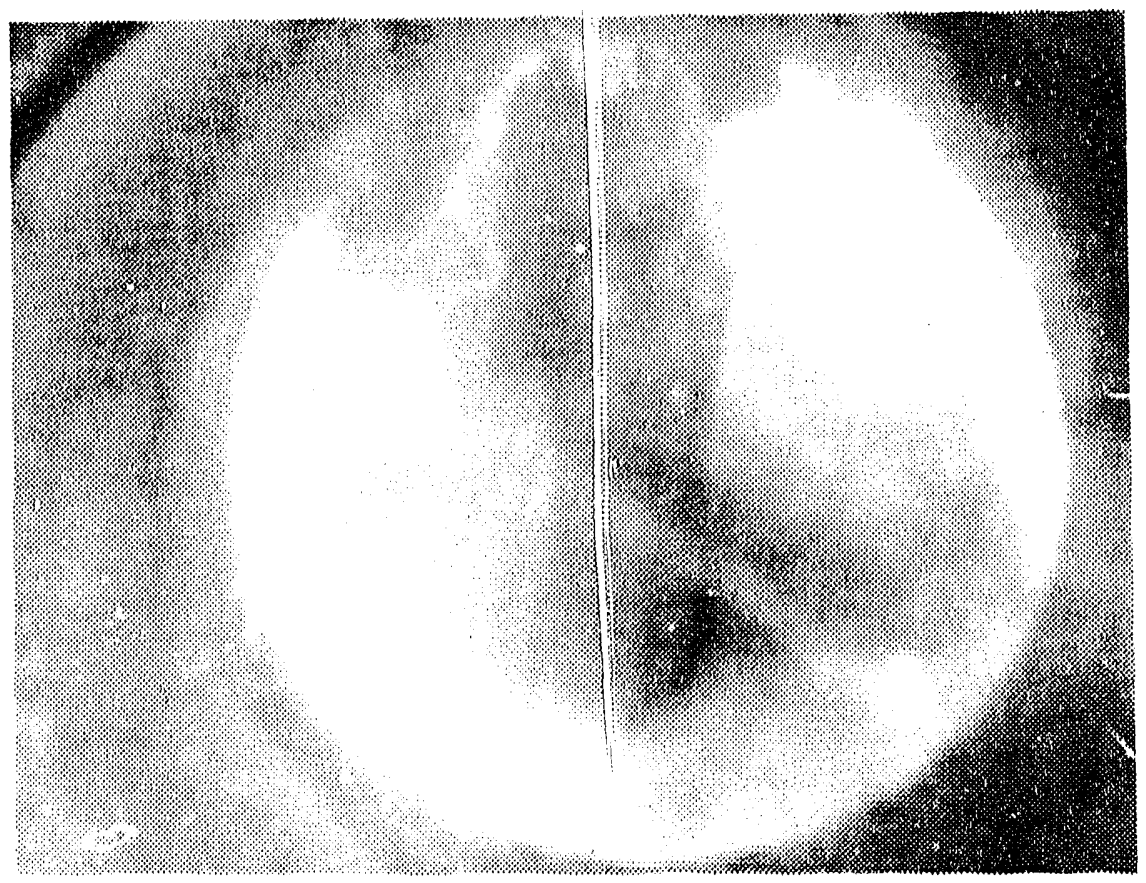

Figure 3-9b Specimen 43, 1 Frame (1/30 sec.) After Rupture. 


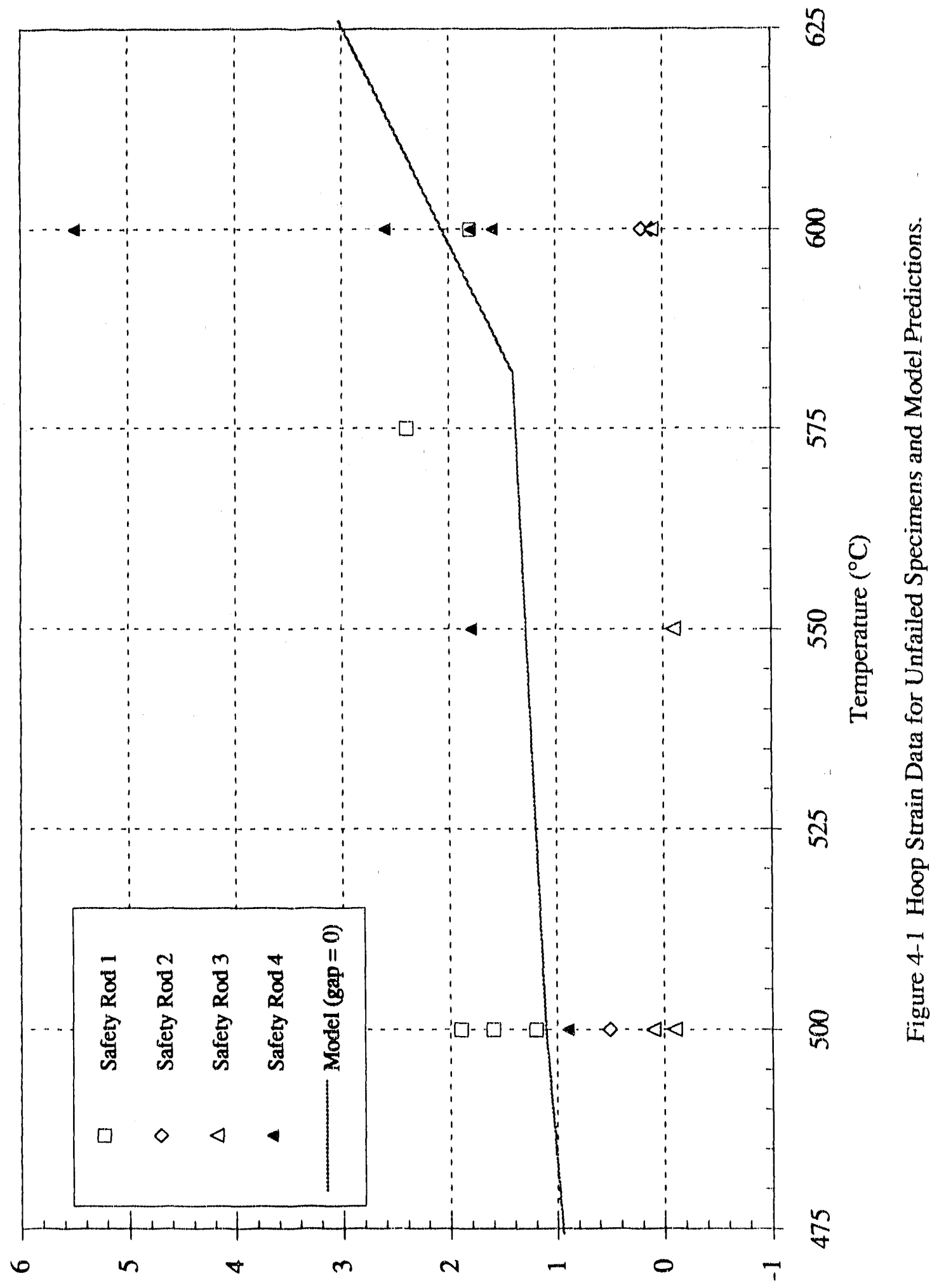

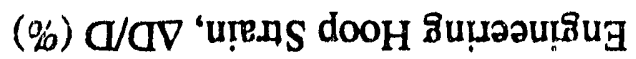




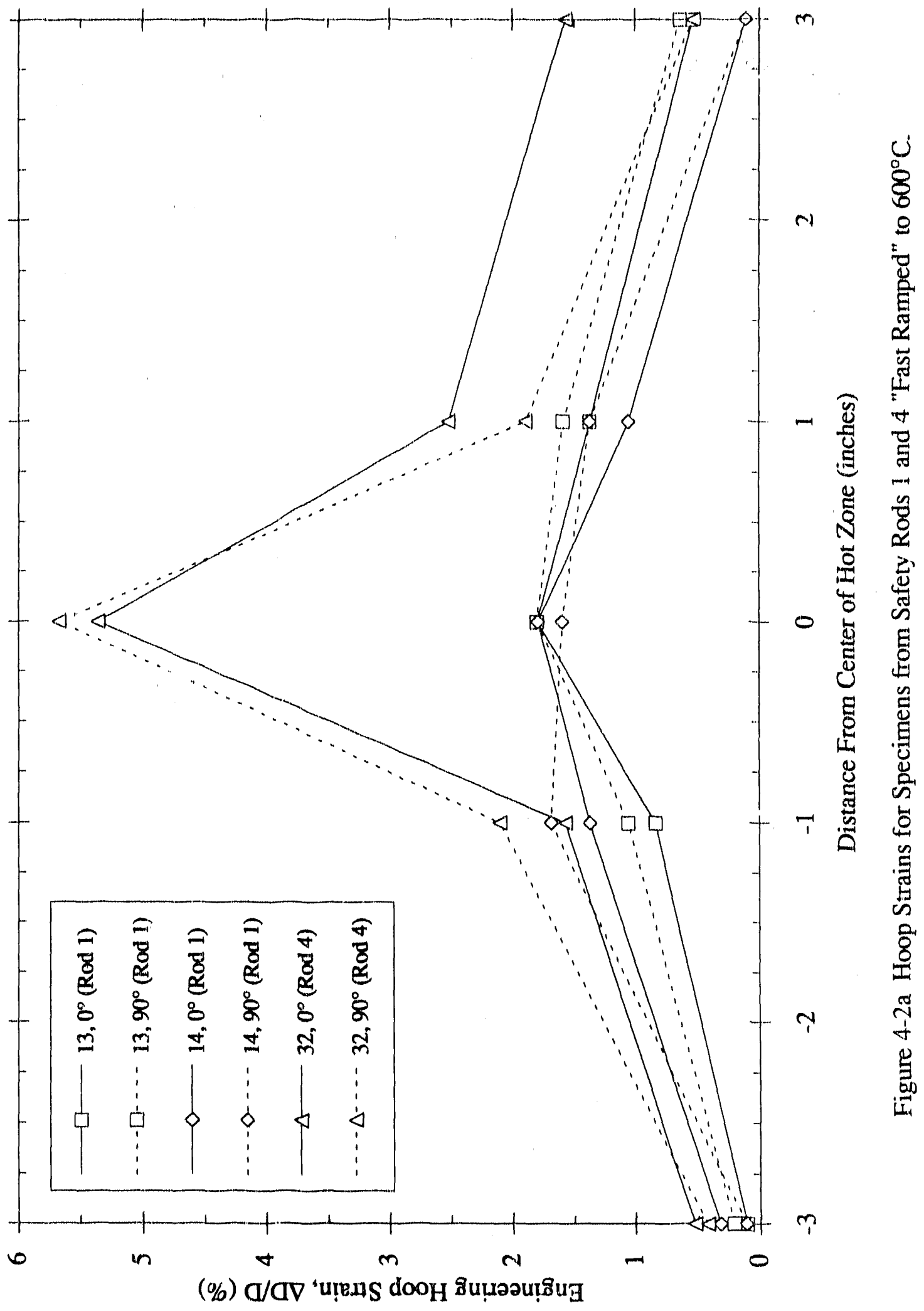




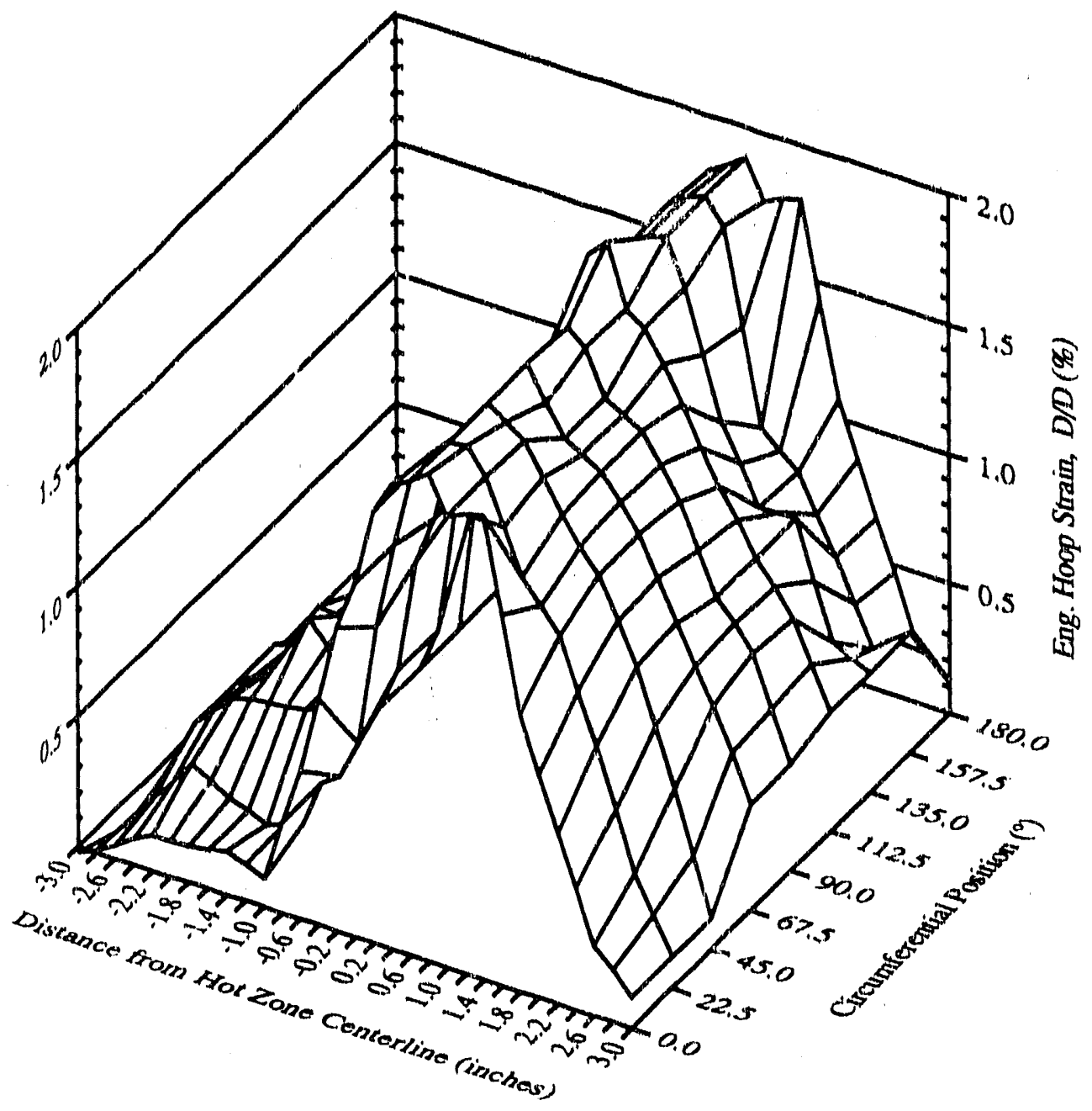

Figure 4-2b Hoop Strain Data for Specimen 14. 


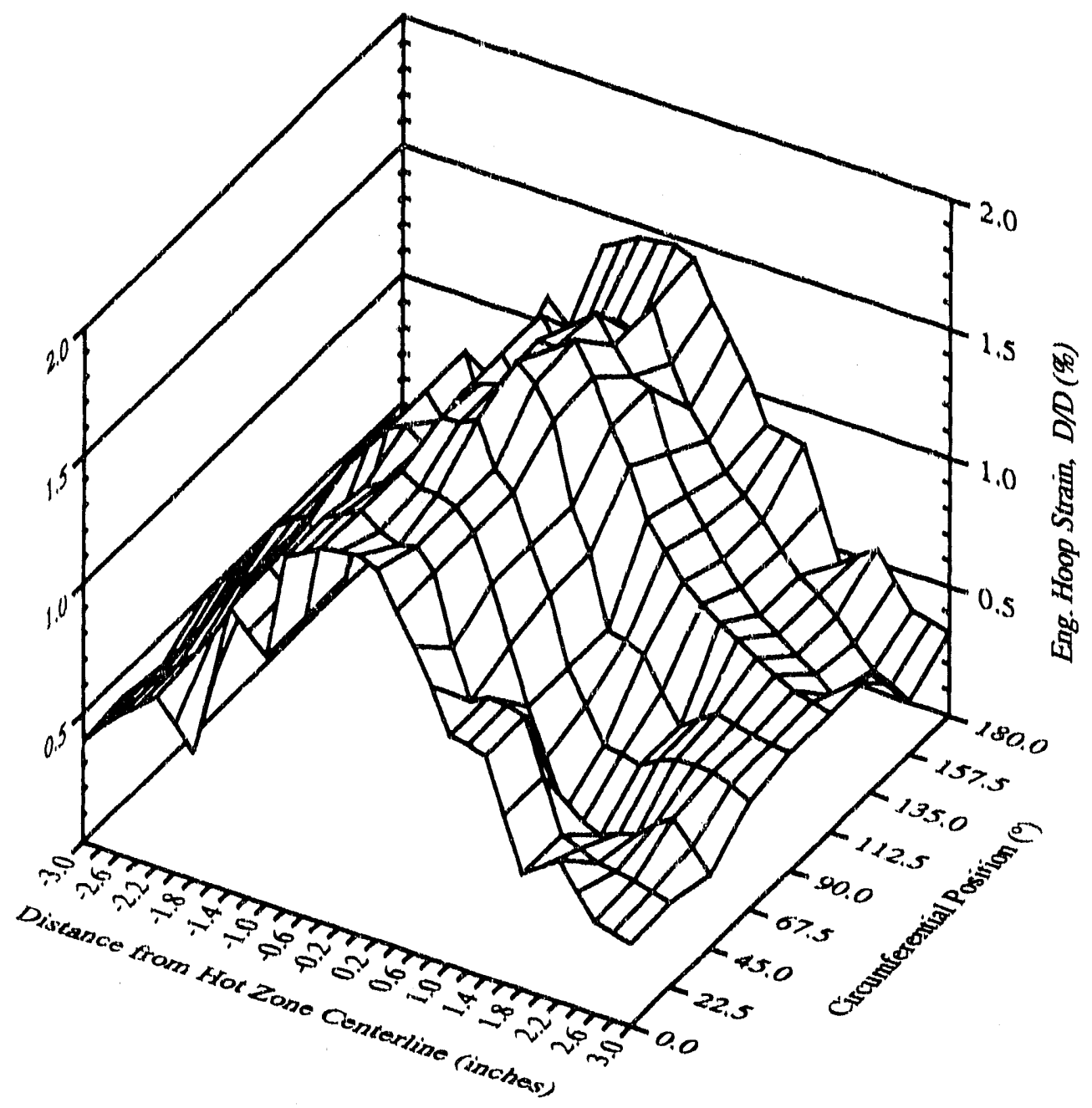

Figure 4-2c Hoop Strain Data for Specimen 15. 

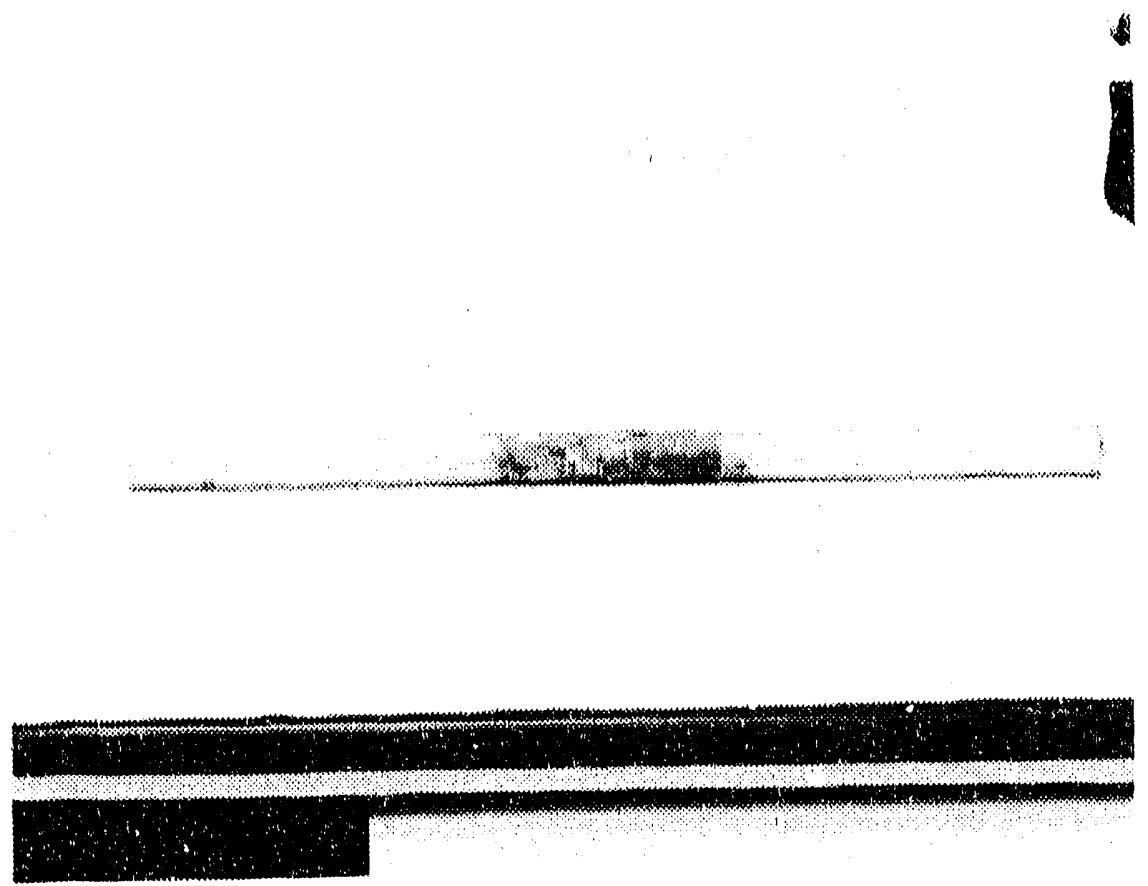

Figure 5-1a Spec.9, Prior to Destructive Examination (Low Magnification).

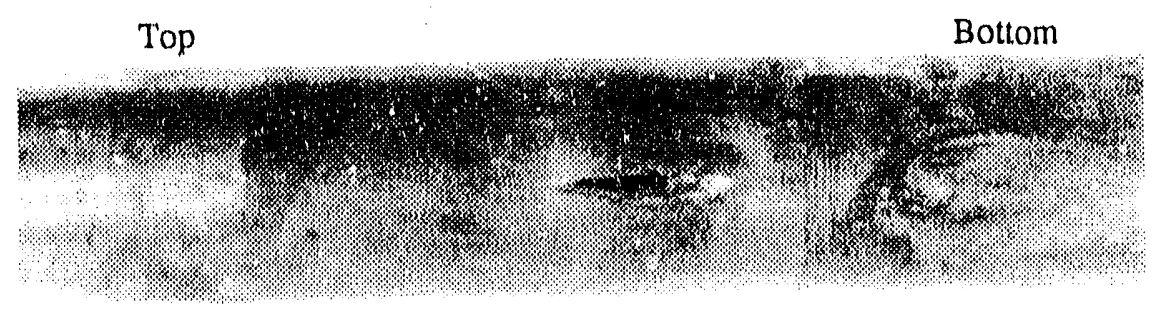

Figure 5-1b Spec.9, Prior to Destructive Examination (1x). 


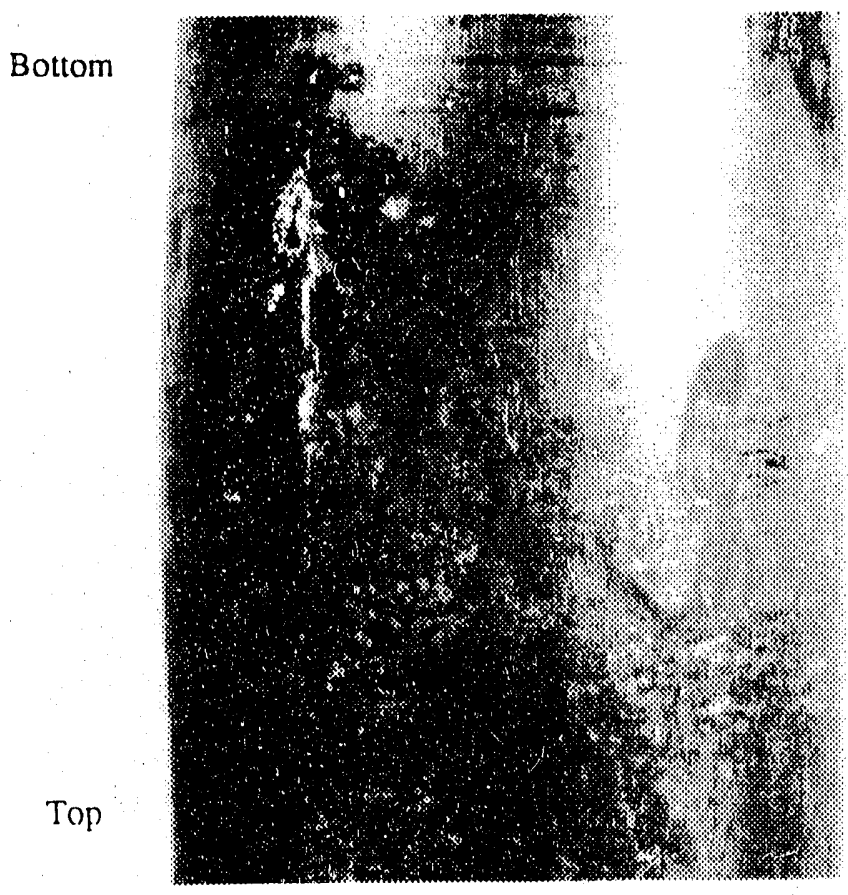

Figure 5-1c Spec.9, Prior to Destructive Examination (High Magnification).

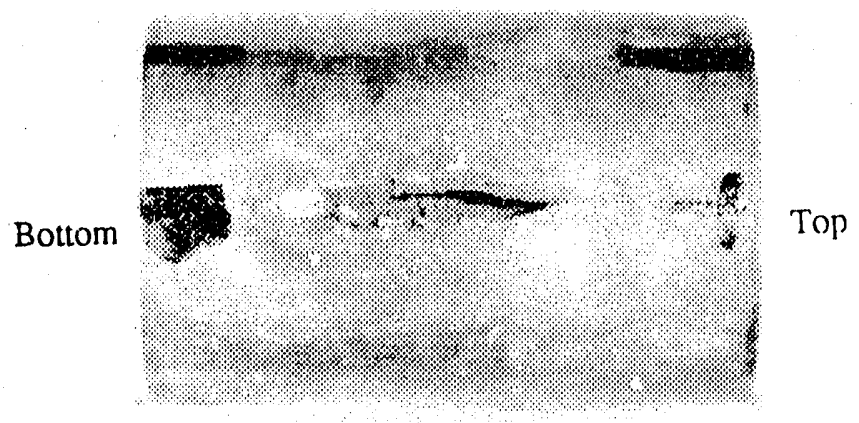

Figure 5-2 Spec.9, After Transverse Sectioning. 
Top
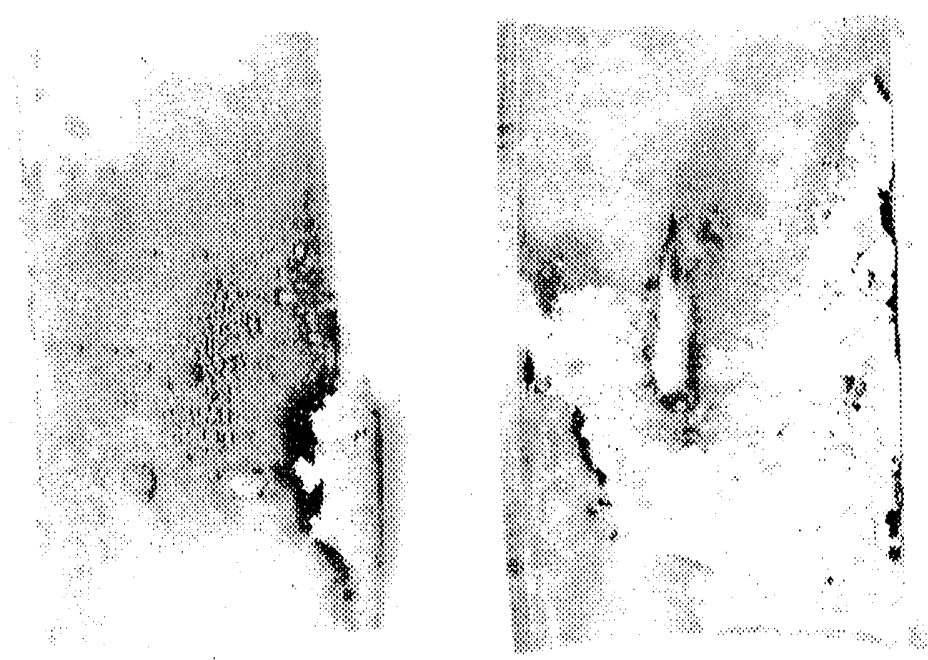

Core

Bottom

Cladding

Figure 5-3 Spec.9, Inner Surface, of Cladding and Outer Surface of Aluminum Core. 


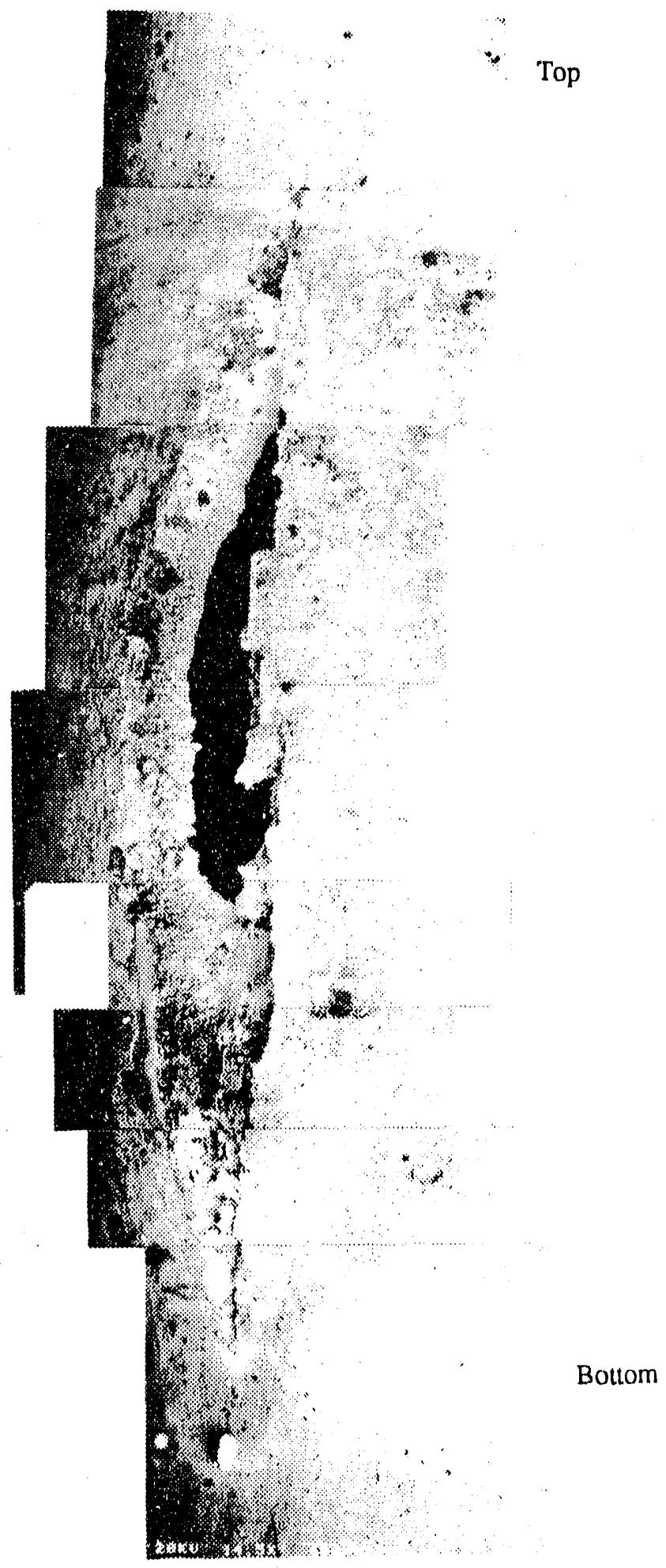

Figure 5-4a Spec.9, Montage of Outer Surface Near Fracture (BSE). 


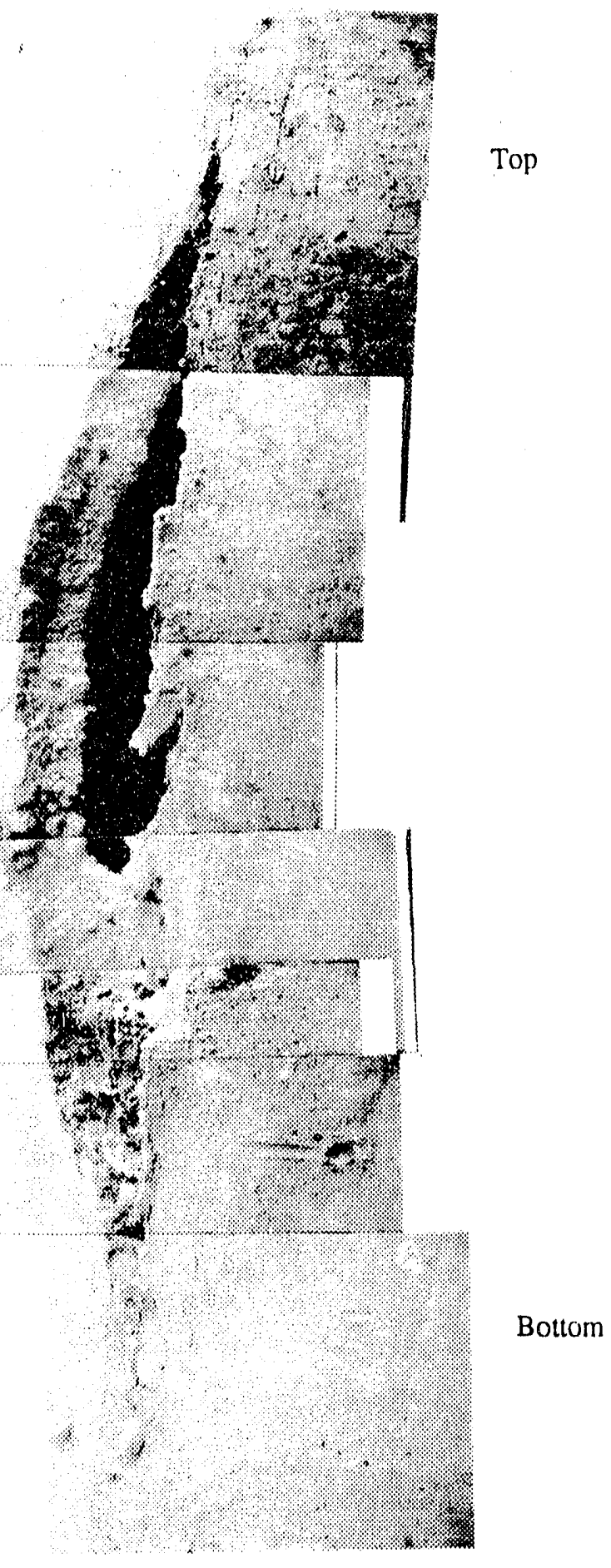

Figure 5-4b Spec.9, Montage of Outer Surface Near Fracture (SE). 


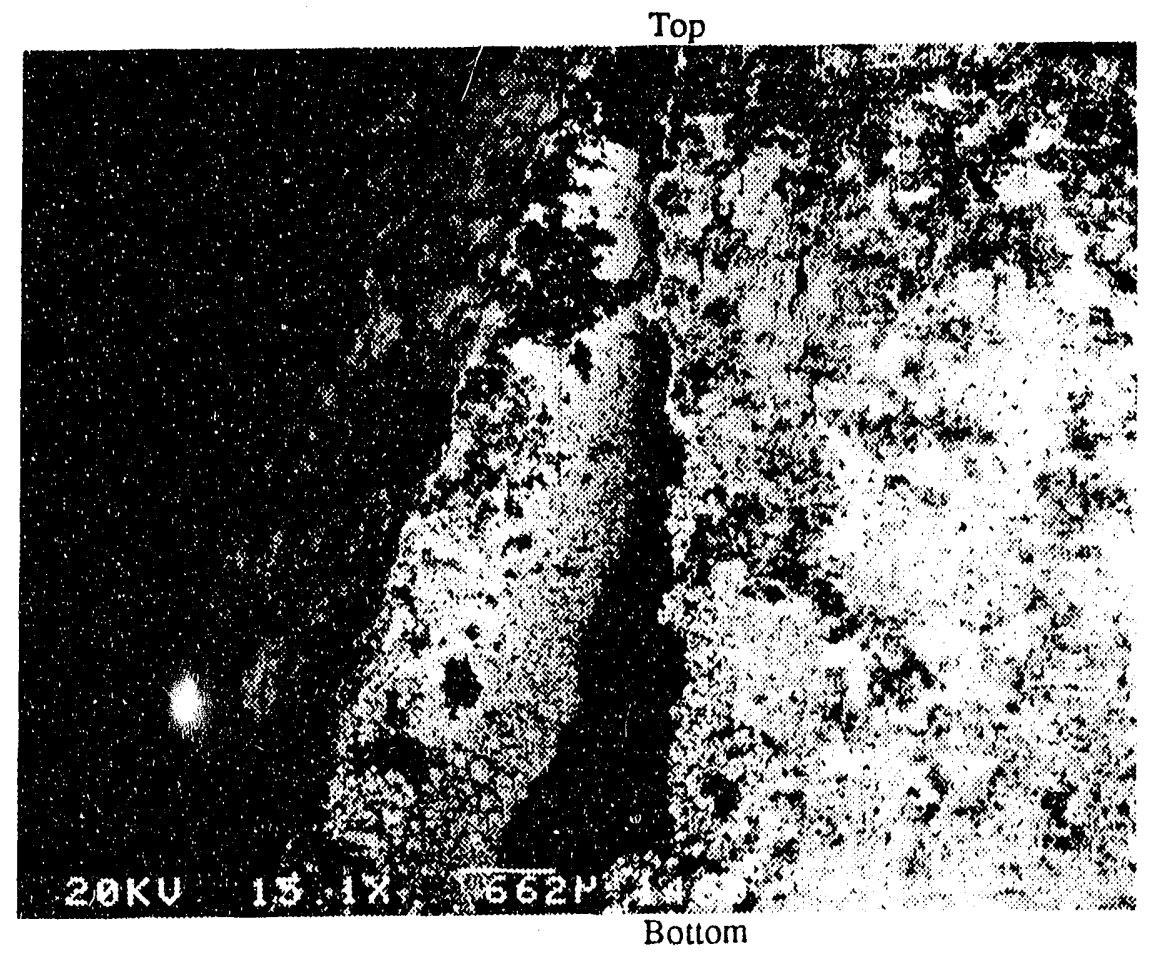

Figure 5-5a Spec.9, Outside of Cladding Surface Near Top of Fracture (BSE, 15.1x).

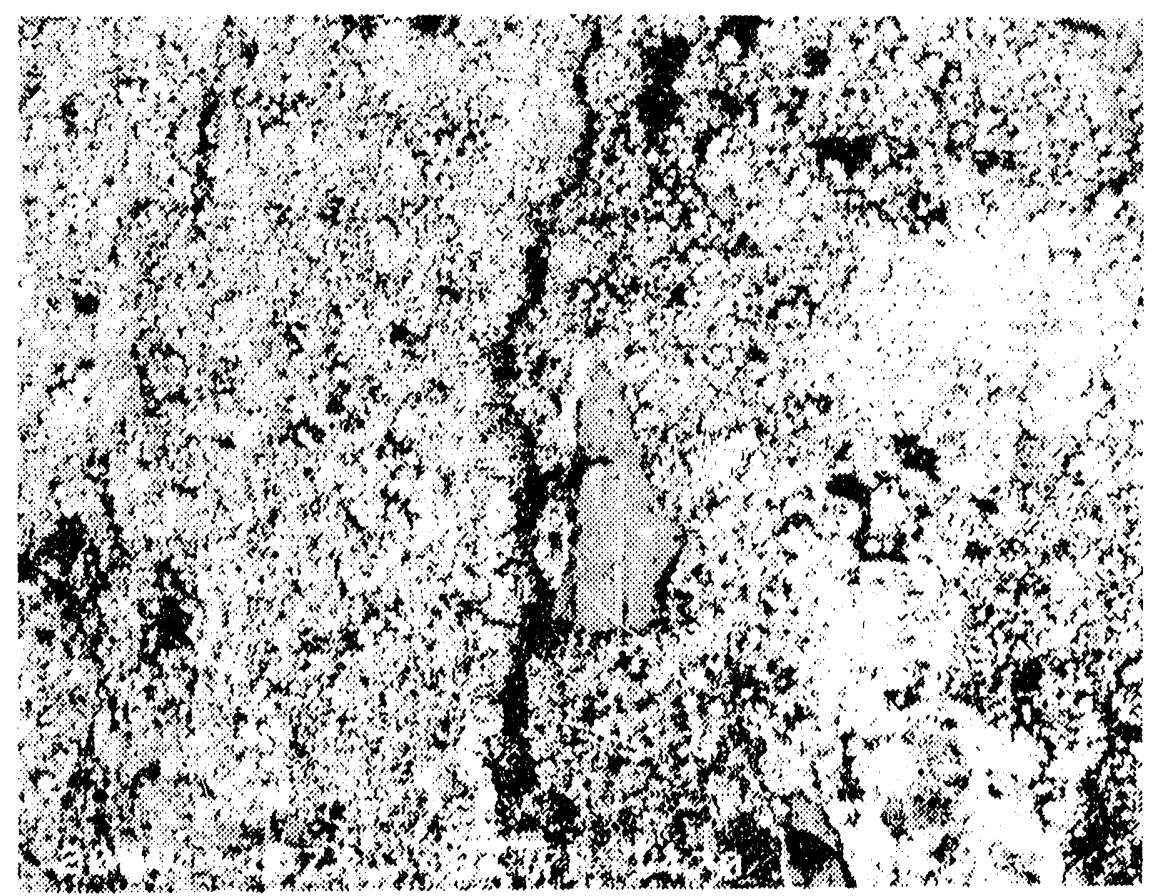

Figure 5-5b Spec.9, Oxide Layer on Outside of Cladding Surface (BSE, 157x). 


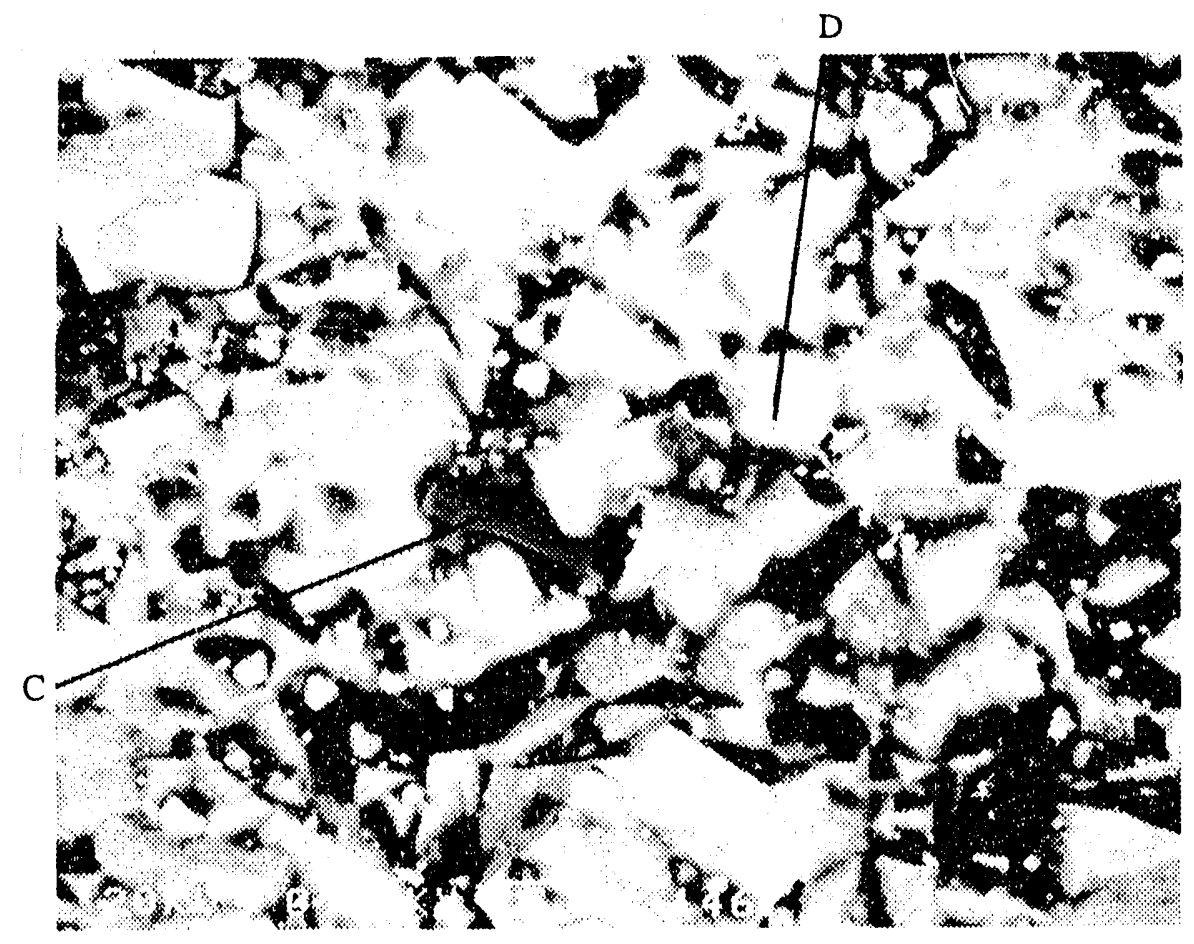

Figure 5-5c Spec.9, High-Magnification Micrograph of Oxide Layer (BSE, 750x).

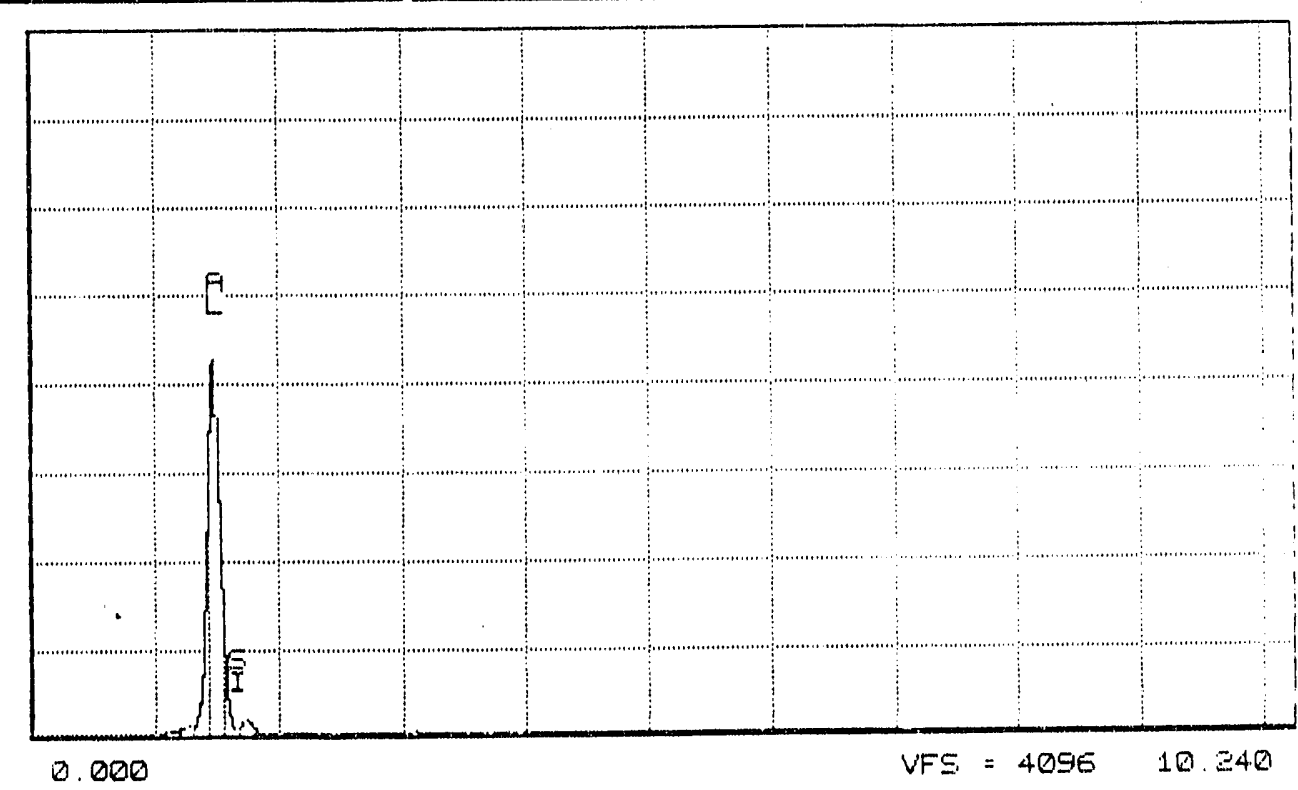

Figure 5-6a Spec.9, EDS Spectrum for Spot "C" on Figure 5-5c. 


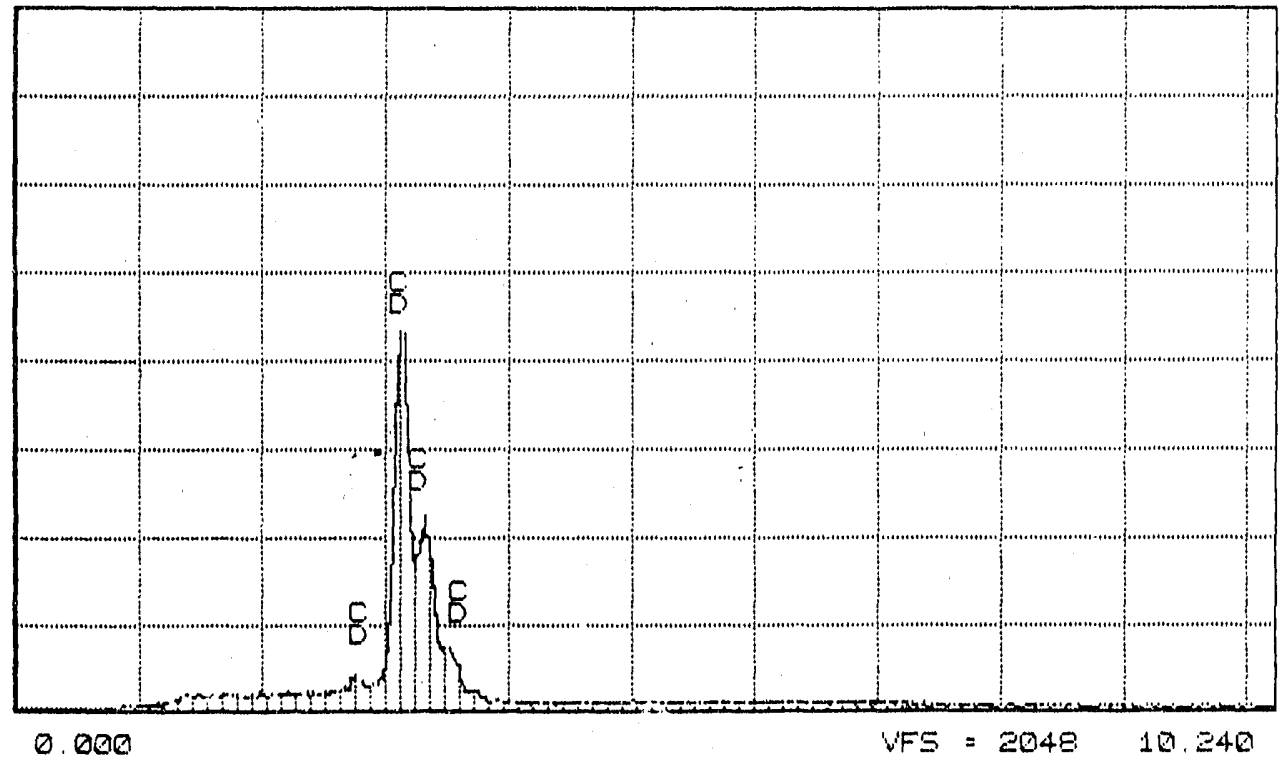

Figure 5-6b Spec.9, EDS Spectrum for Spot "D" on Figure 5-5c.

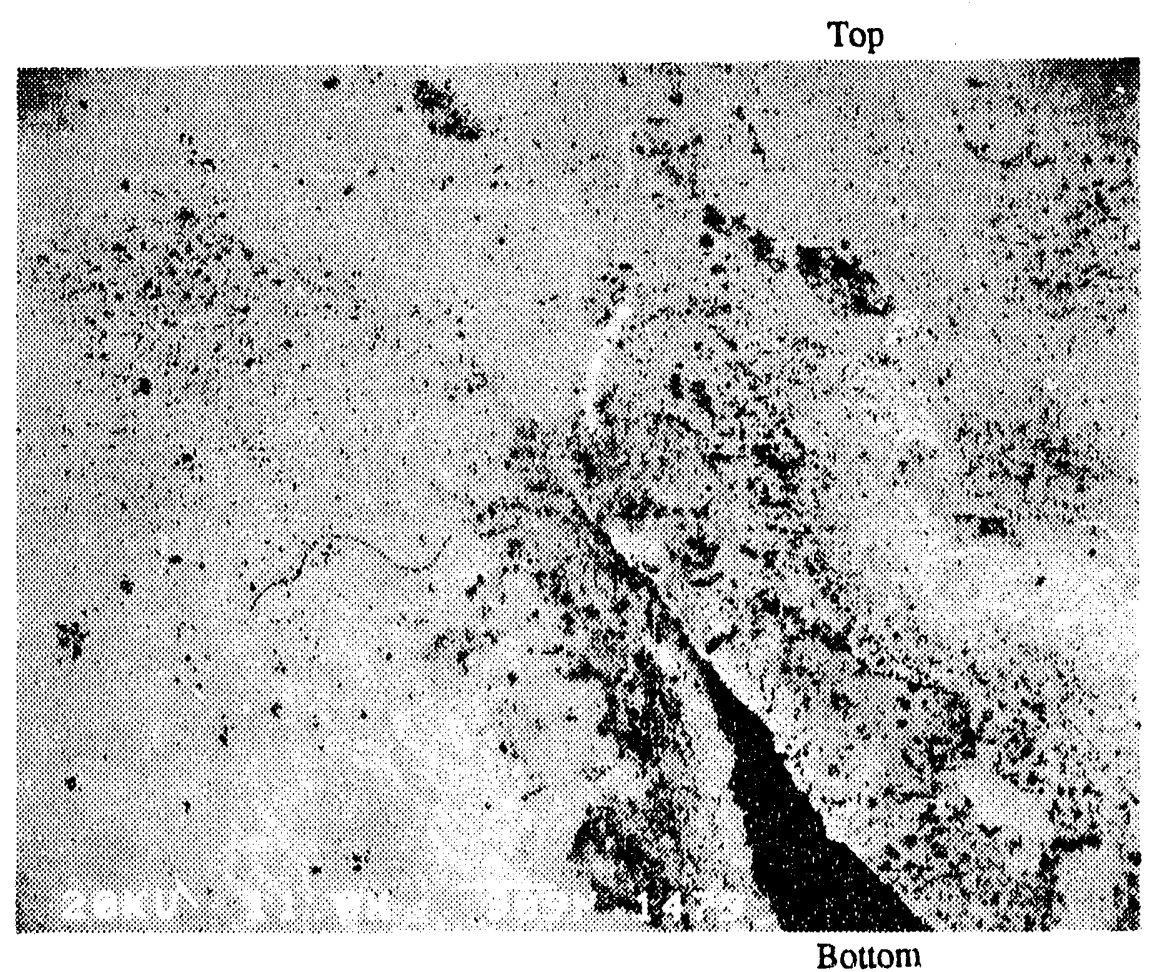

Figure 5-7a Spec.9, Cladding Inner Surface Near Top of Fracture (BSE, 11x). 


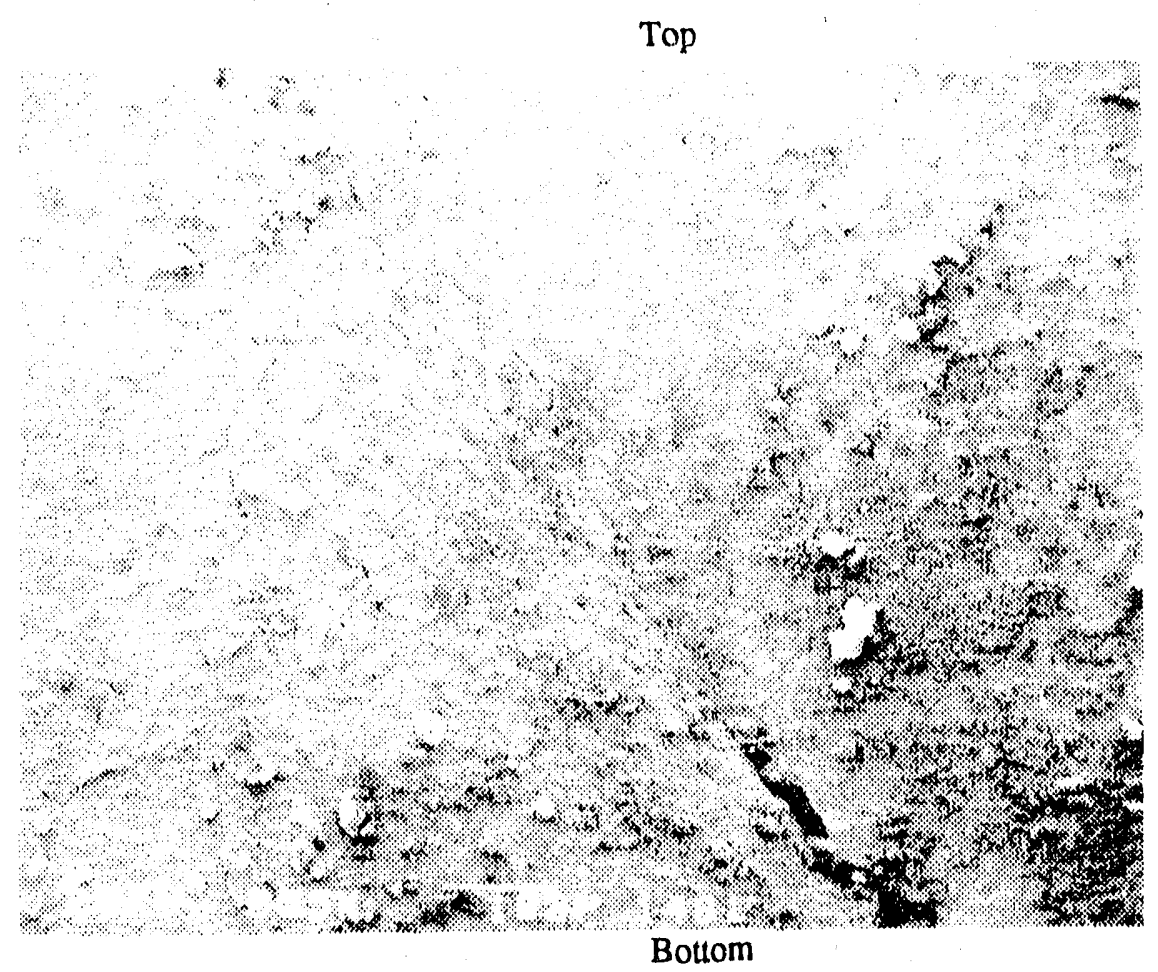

Figure 5-7b Spec.9, Cladding Inner Surface Near Top of Fracture (SE, 55x).

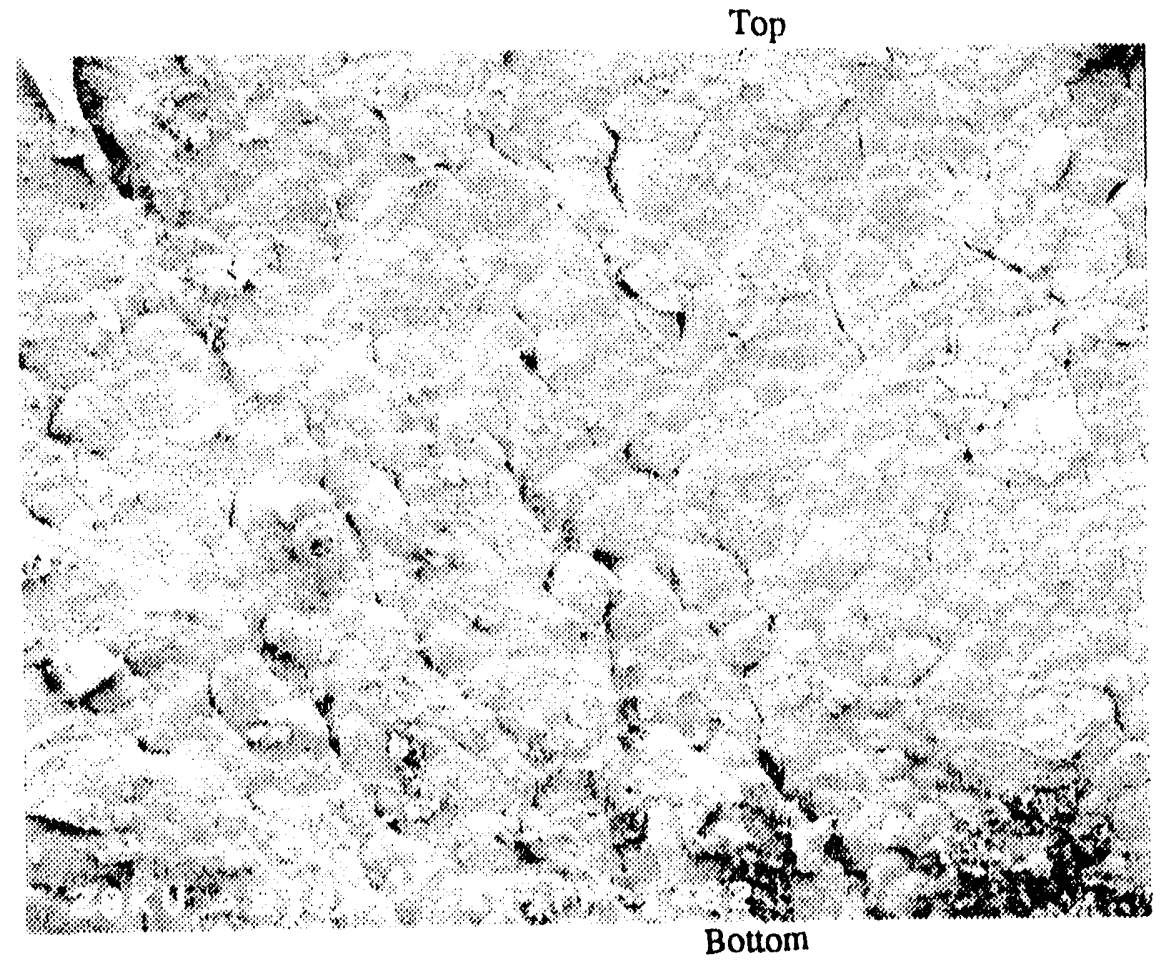

Figure 5-7c Spec.9, Cladding Inner Surface Near Bottom of Fracture (SE, 219x). 


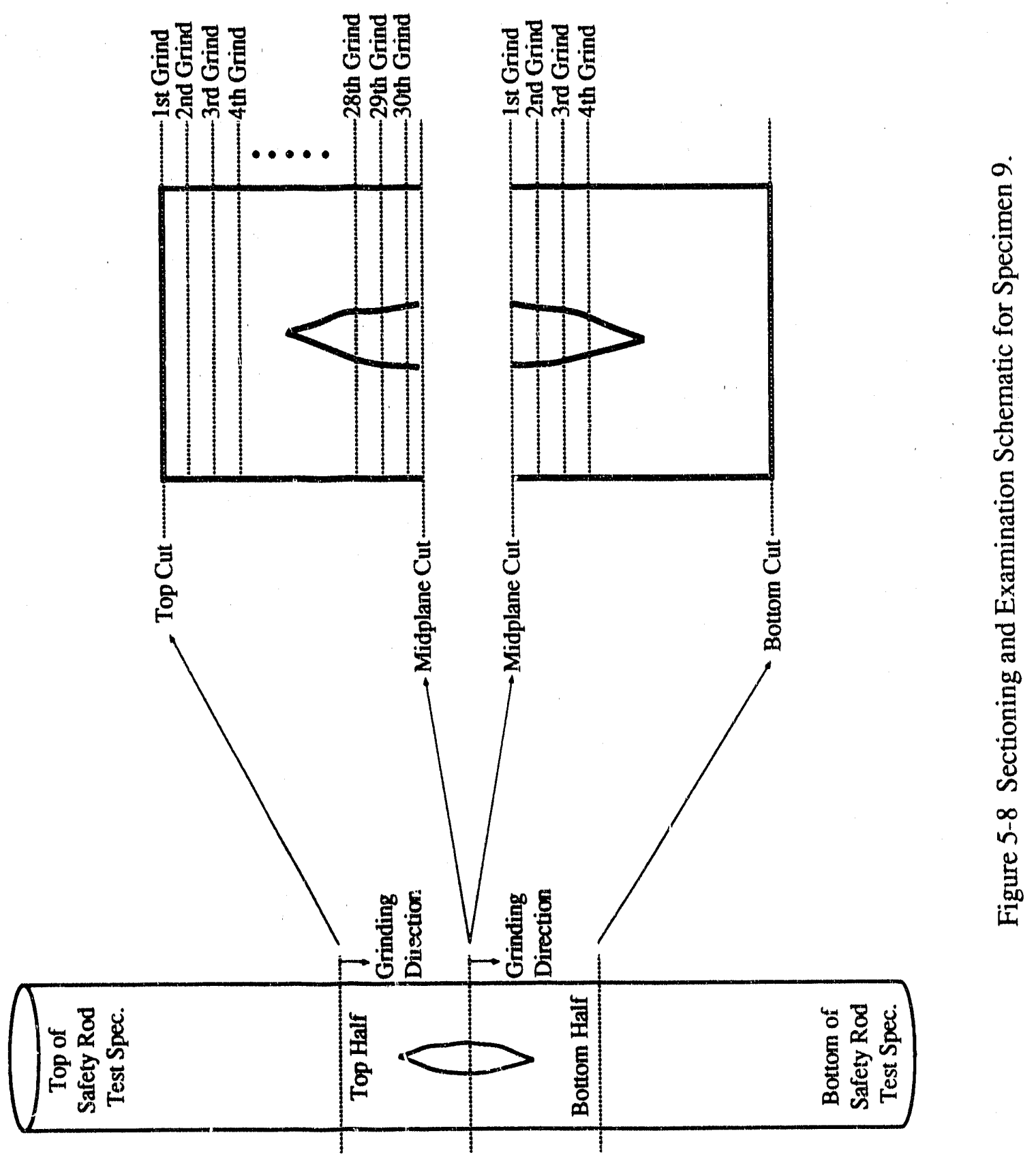




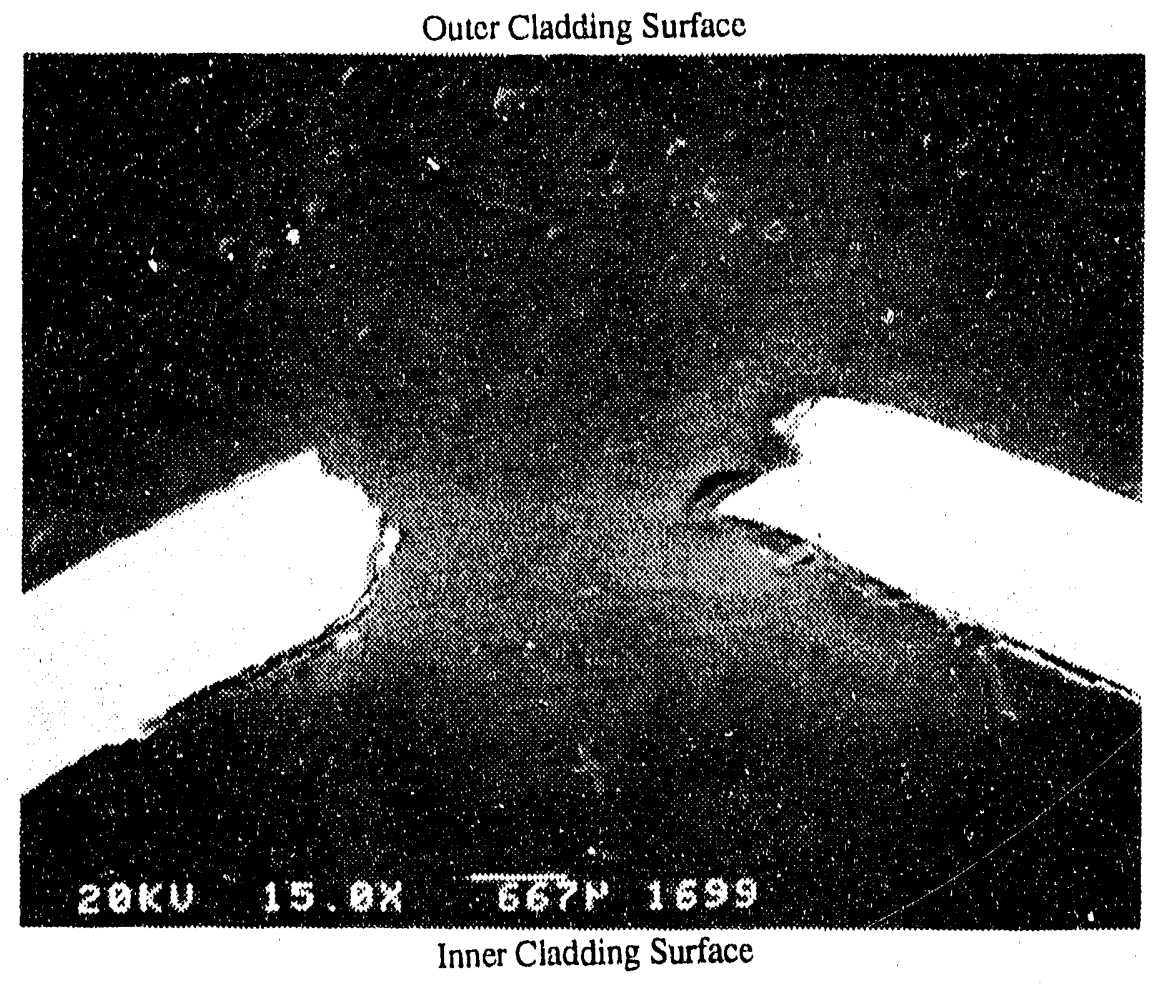

Figure 5-9 Spec.9, 1st Grind, Bottom Half (BSE, 15x).

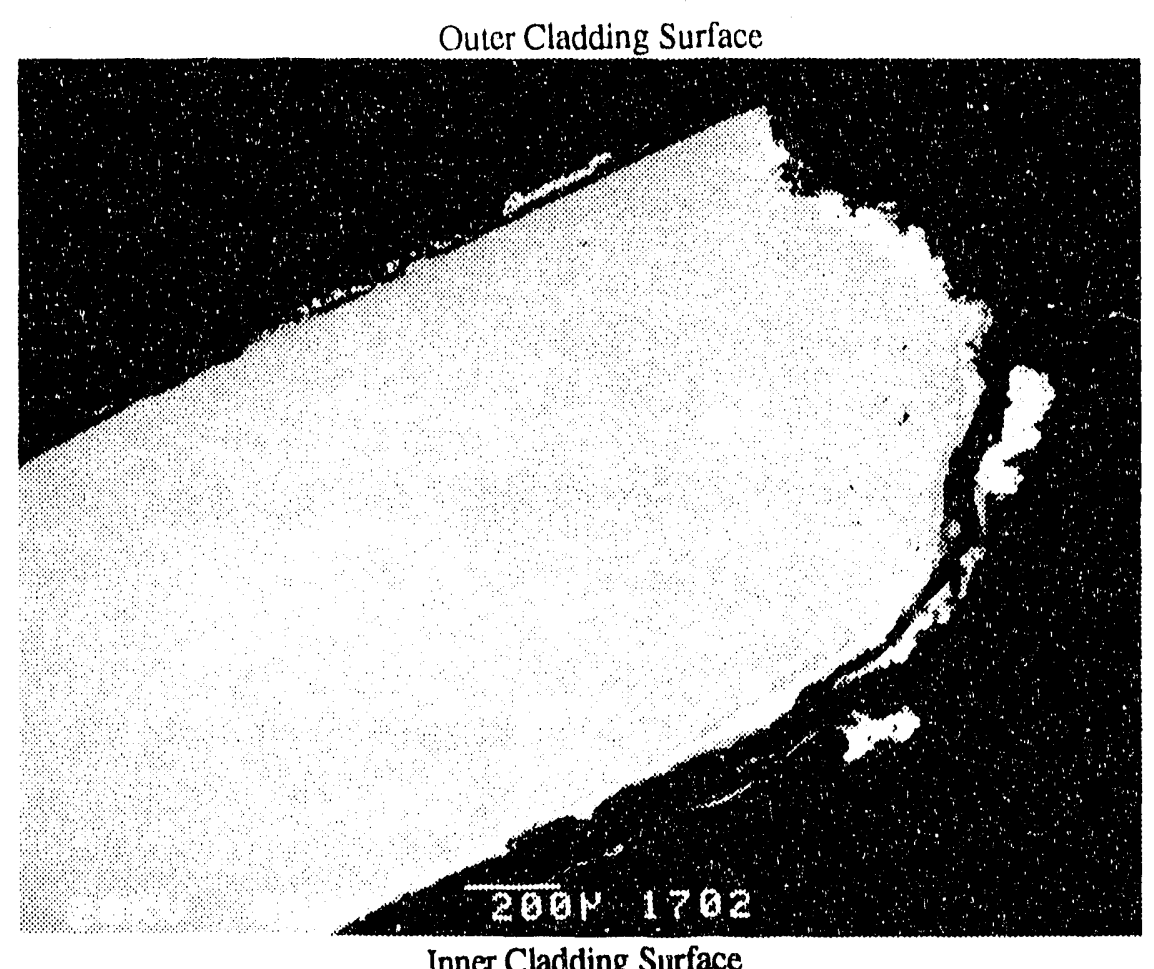

Inner Cladding Surface

Figure 5-10a Spec.9, 1st Grind, Bottom Half, Left Side (BSE, 50x). 


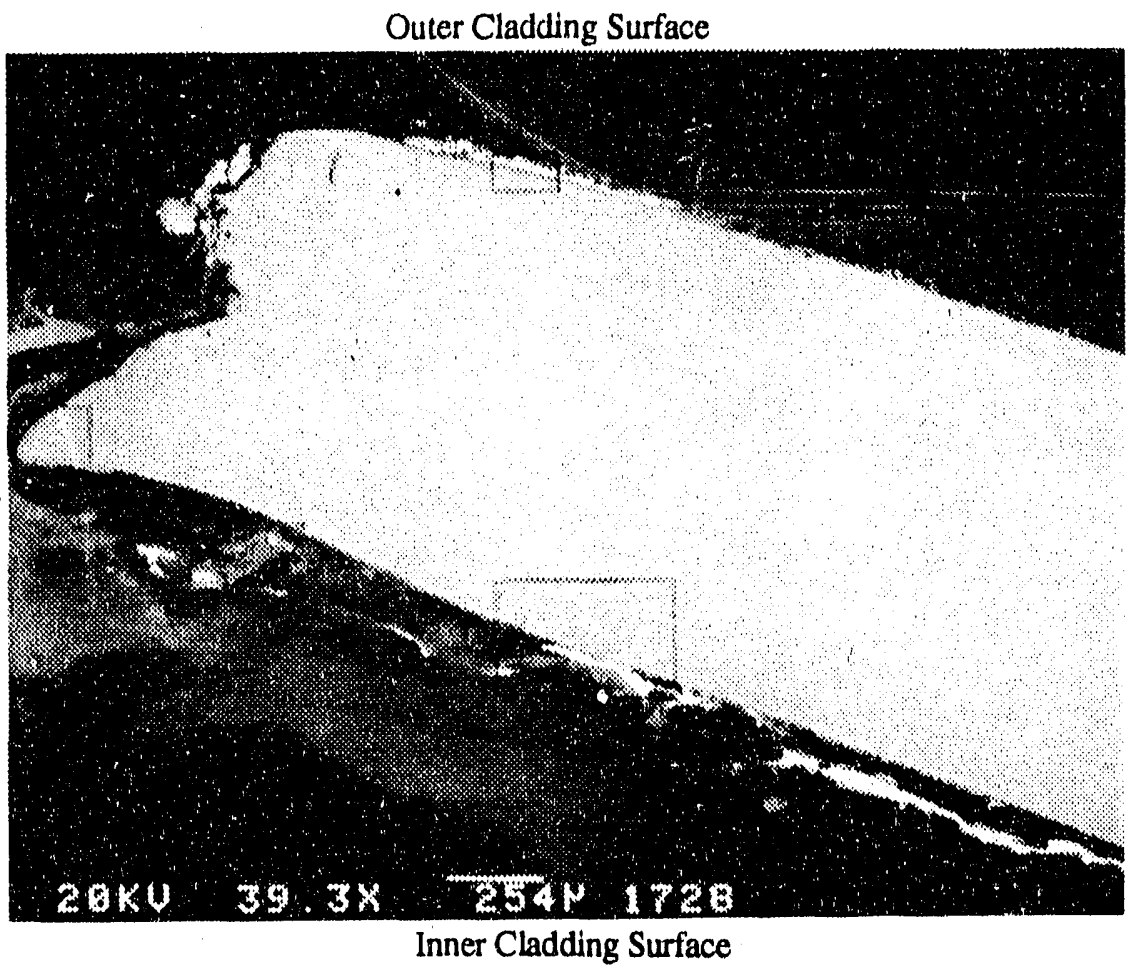

Figure 5-10b Spec.9, 13t Grind, Bottom Half, Right Side (BSE, 39.3x). 


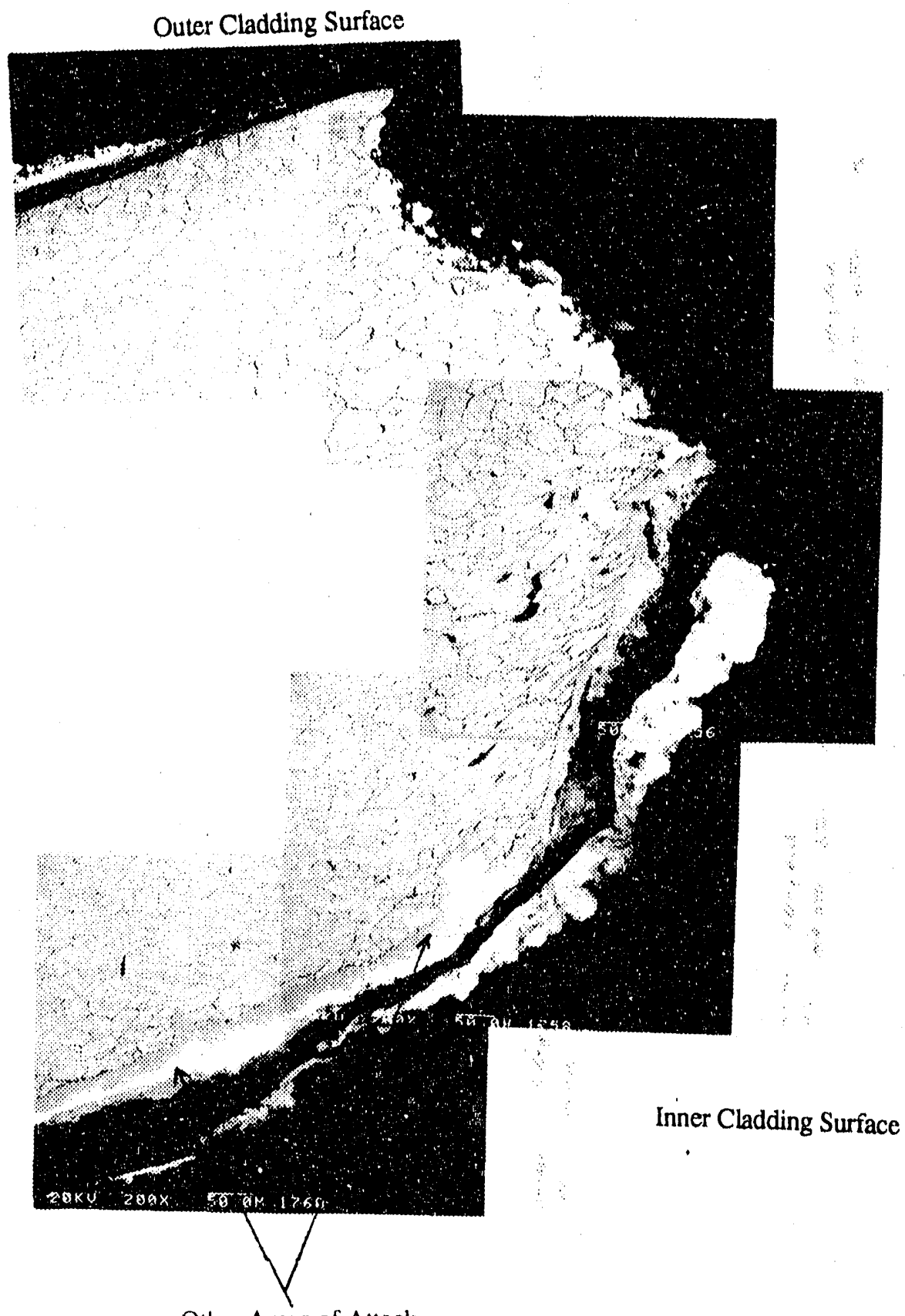

Other Areas of Atlack

Figure 5-11a Spec.9, 1st Grind, Bottom Half, Montage of Left Side (BSE). 
Outer Cladding Surface

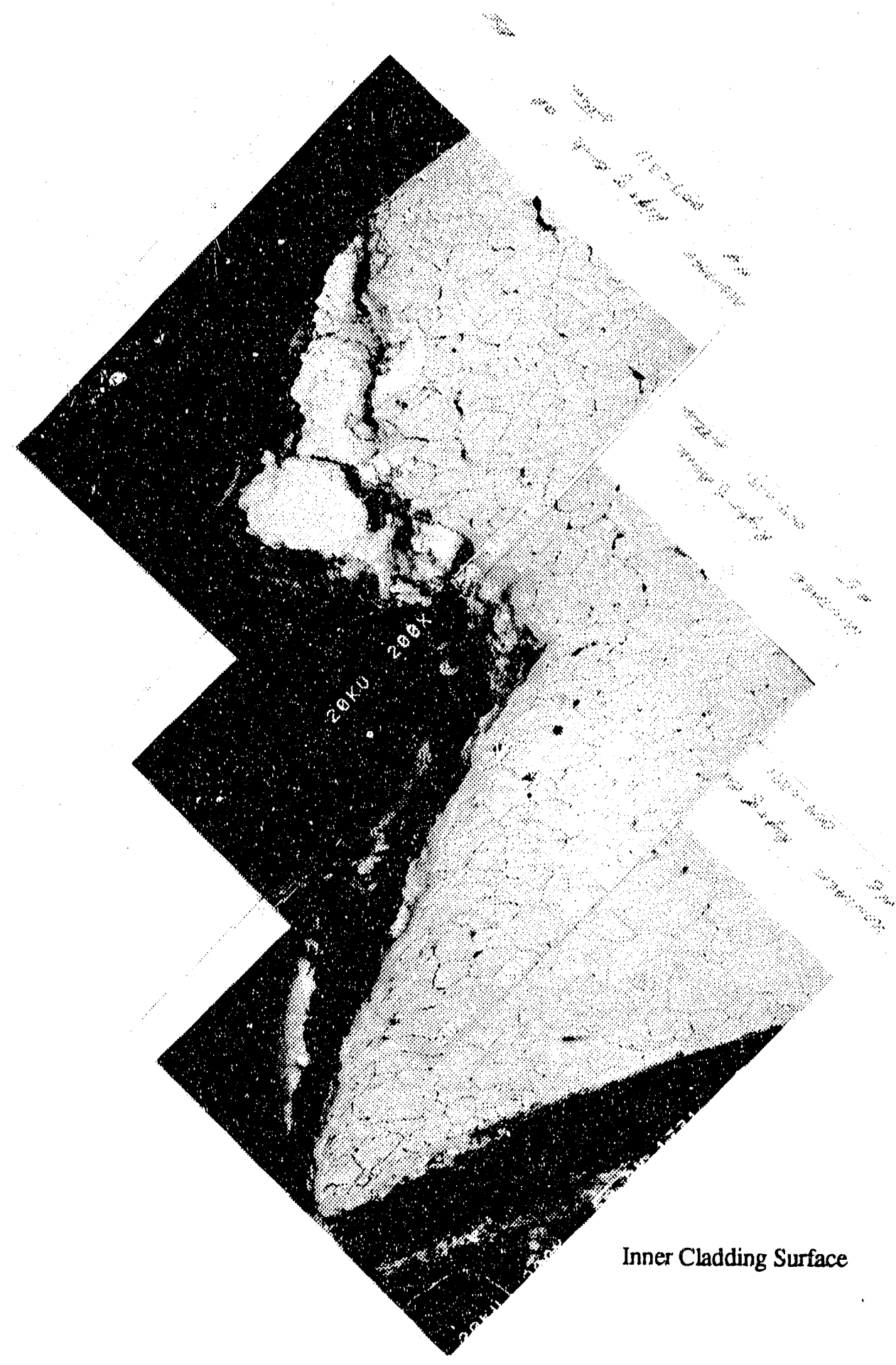

Figure 5-11b Spec.9, 1st Grind, Bottom Half, Montage of Right Side (BSE). 


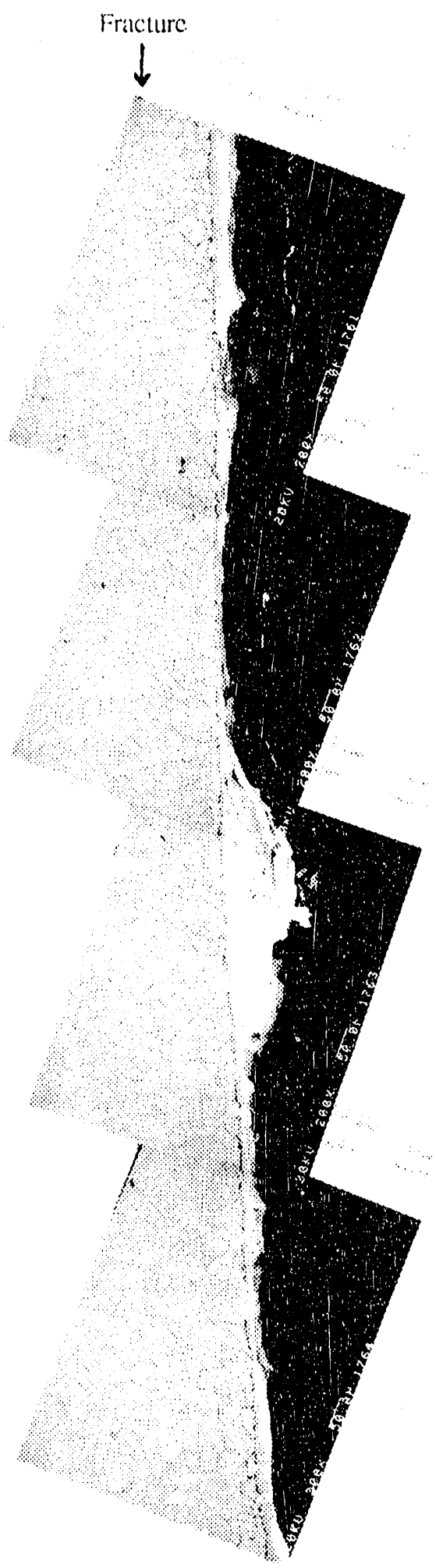

Figure 5-11c Spec.9, 1st Grind, Bottom Half, Montage of Claddin Inner Surface to the Left of the Fracture (BSE). 


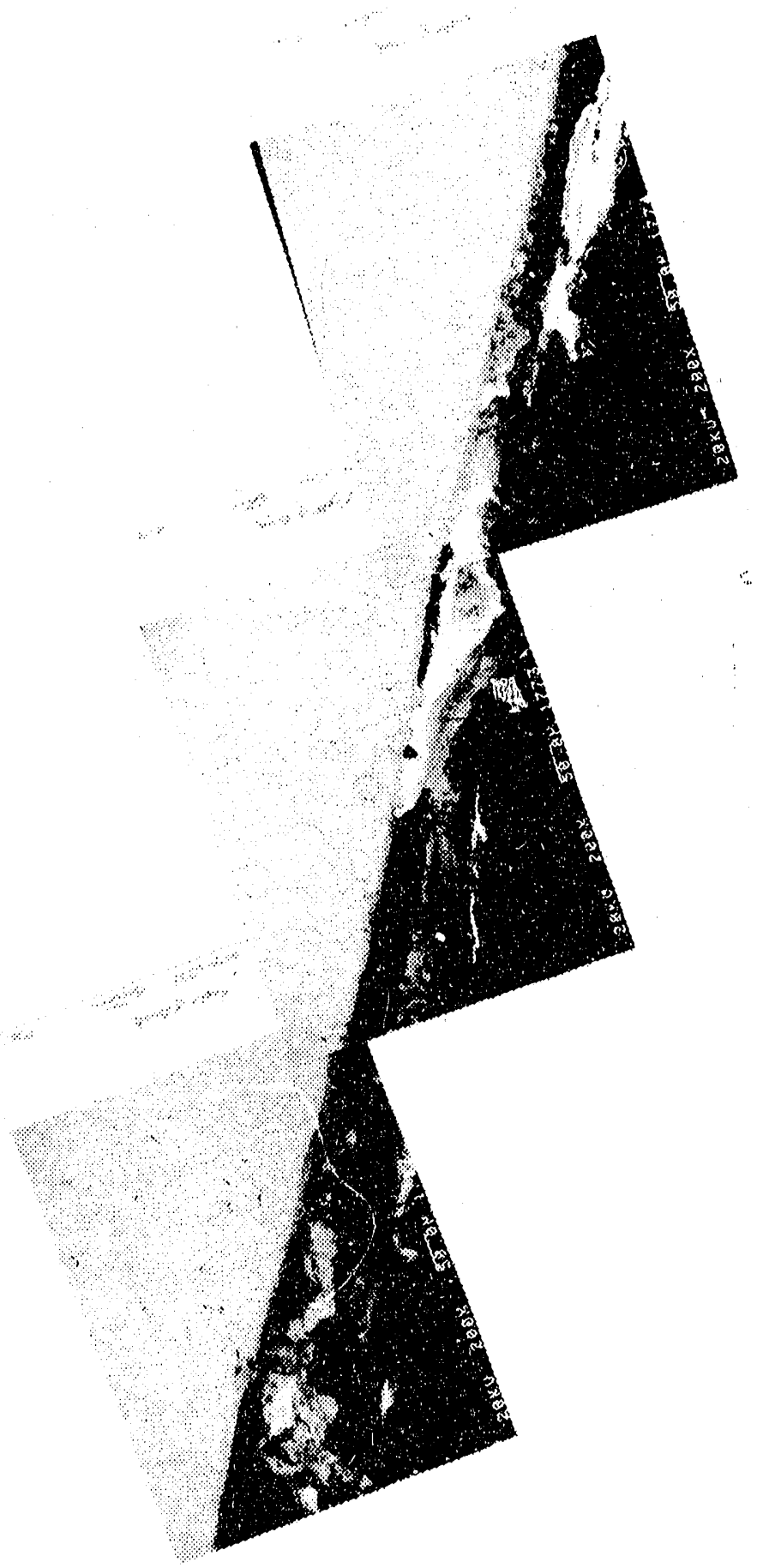

Fracture

Figure 5-11d Spec.9, 1st Grind, Bottom Half, Montage of Cladding Inner Surface to the Right of the Fracture (BSE). 


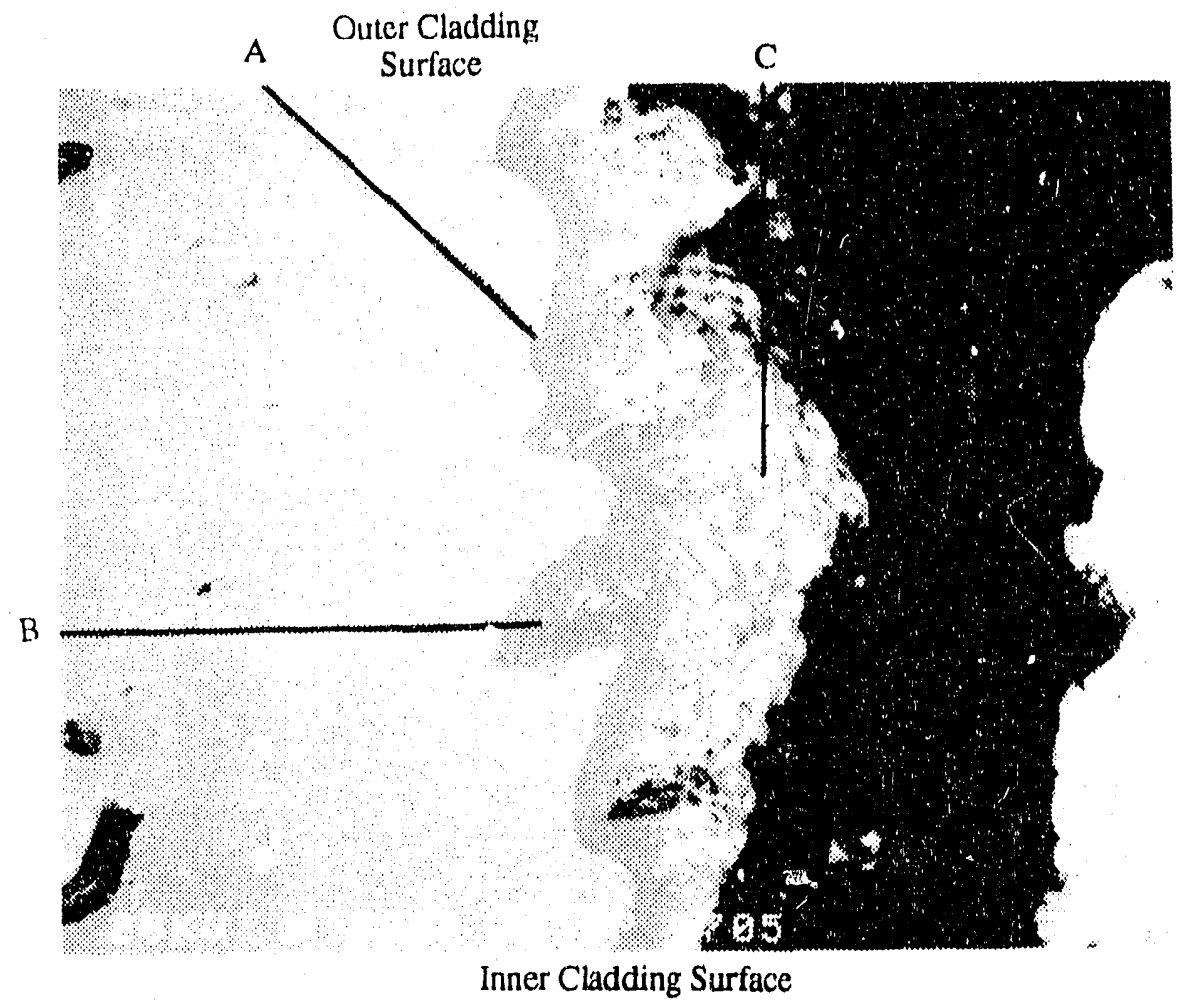

Figure 5-12 Spec.9, 1st Grind, Bottom Half, Left Side Near Cladding Midpoint (BSE, 500x).

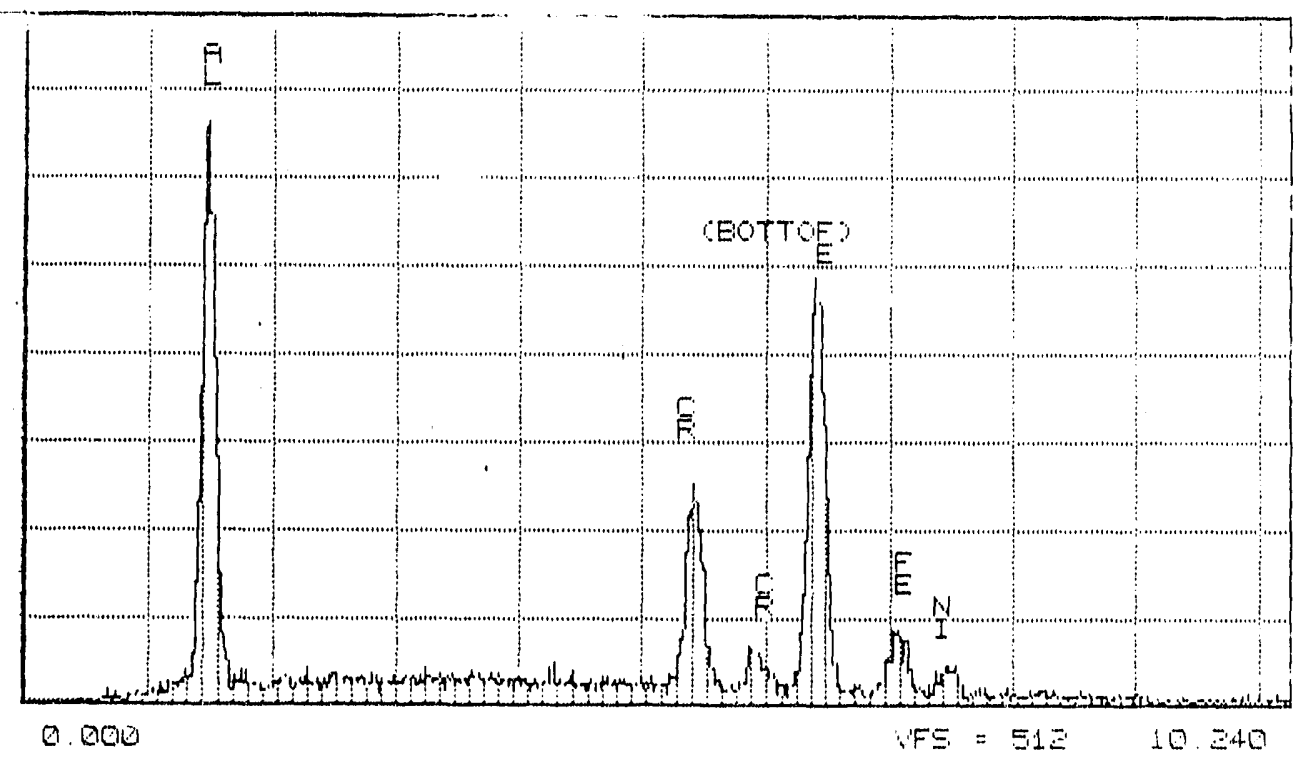

Figure 5-13a Spec.9, 1st Grind, Bottom Half, EDS Spectrum for Spot "A" on Figure 512. 


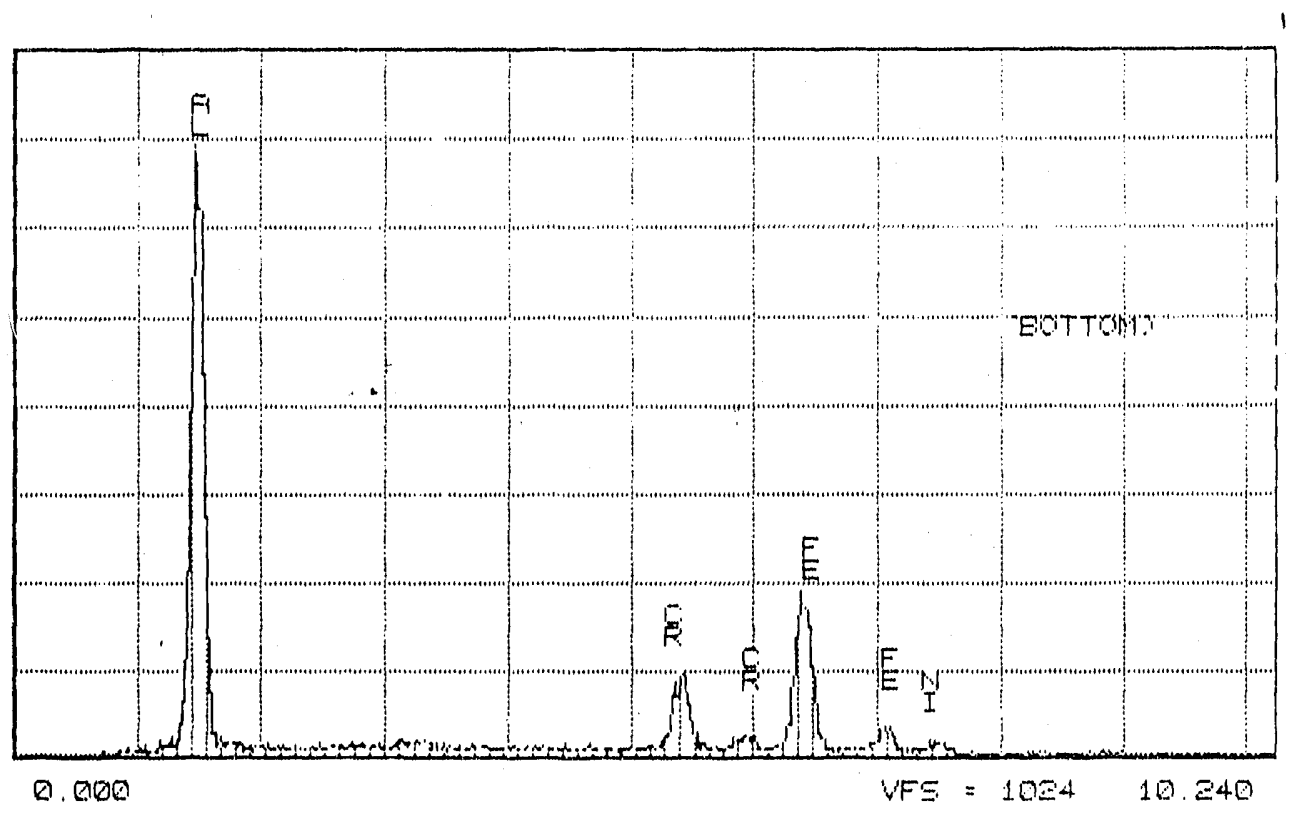

Figure 5-13b Spec.9, 1st Grind, Bottom Half, EDS Spectrum for Spot "B" on Figure 512.

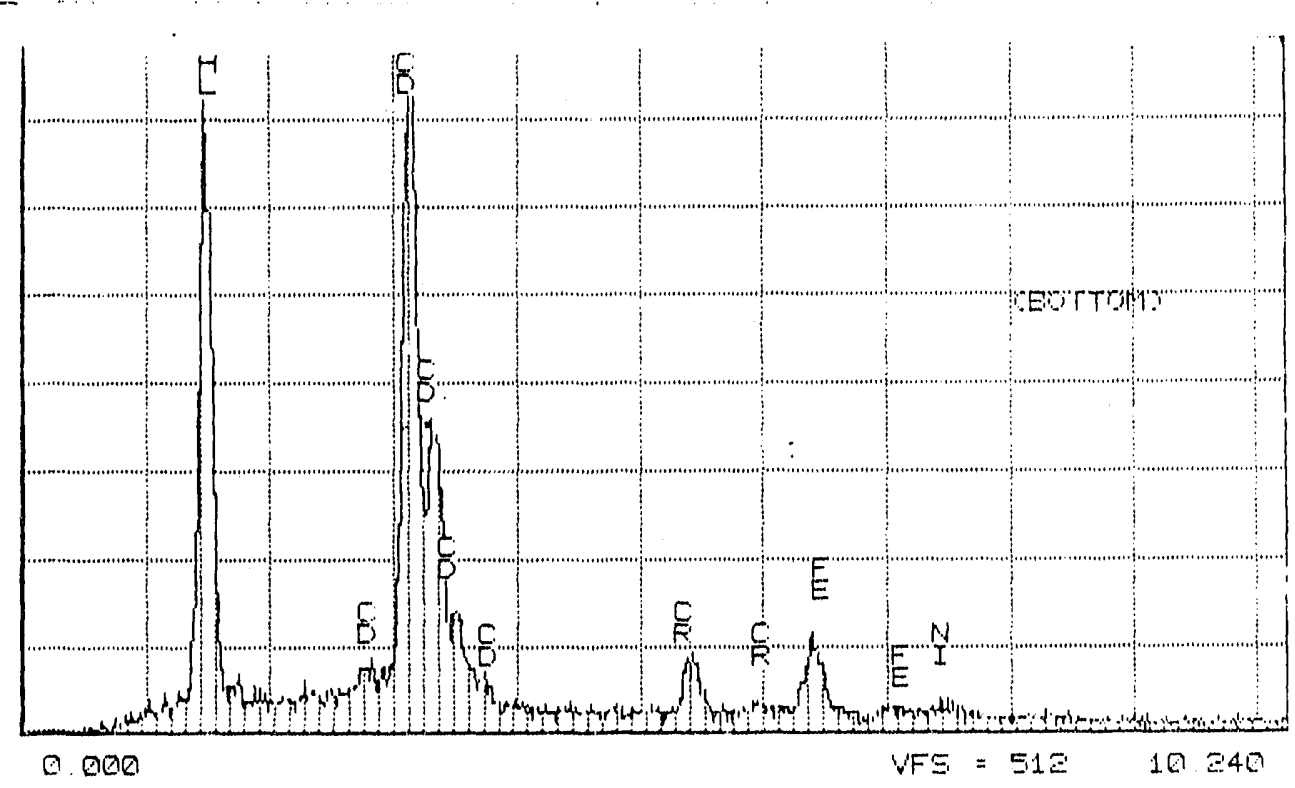

Figure 5-13c Spec.9, 1st Grind, Bottom Half, EDS Spectrum for Spot "C" on Figure 512. 


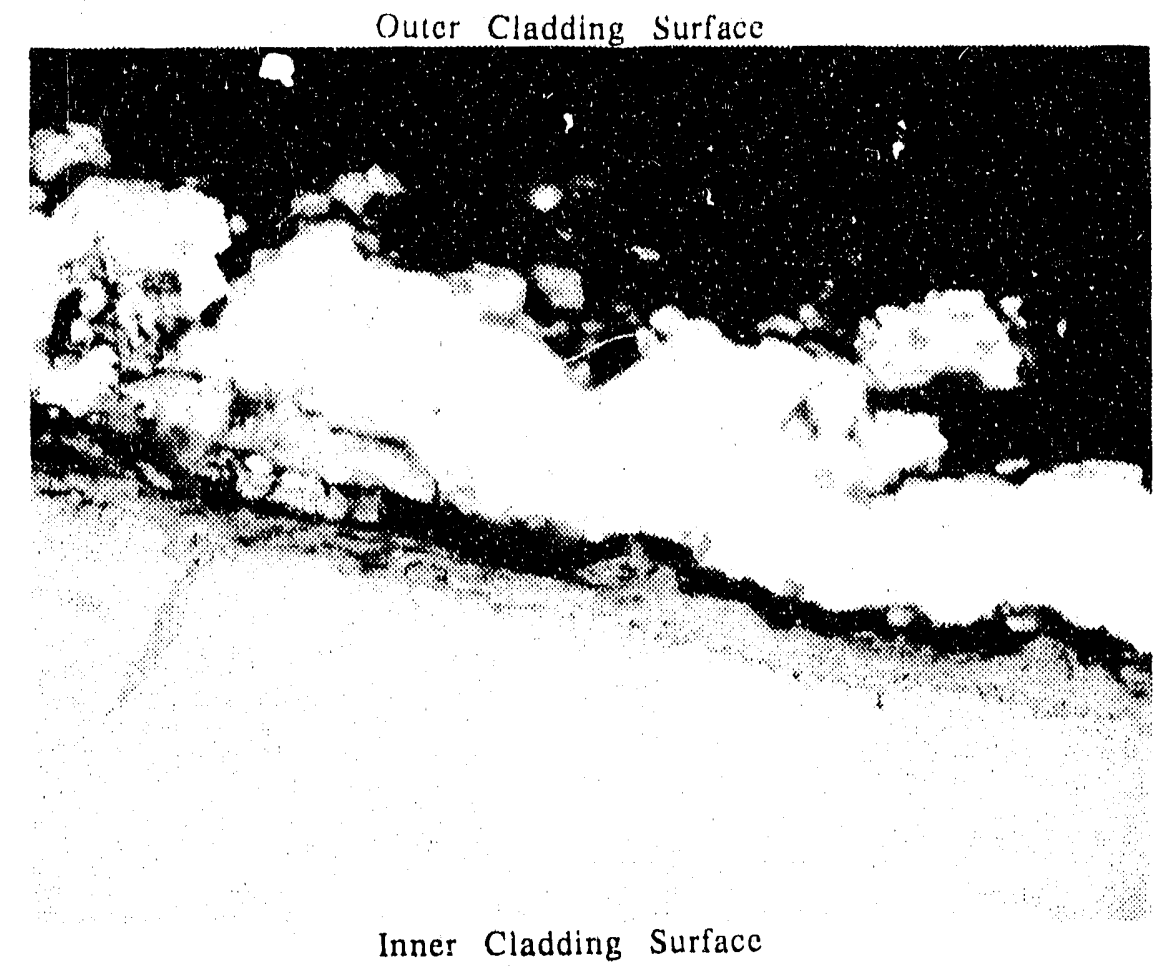

Figure 5-14 Spec.9, 1st Grind, Bottom Half, Right Side on Cladding Outer Surface (BSE, 1000x).

Outer Cladding Surface

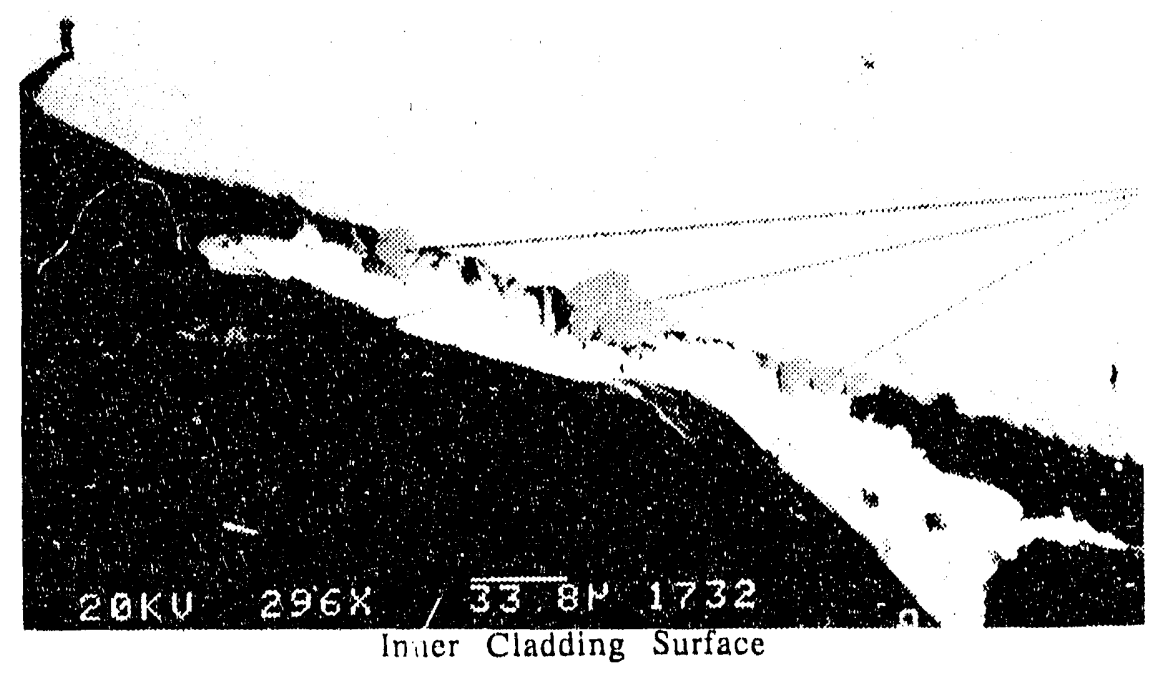

Figure 5-15 Spec.9, 1st Grind, Bottom Half, Right Side on Cladding Inner Surface (BSE, 296x). 


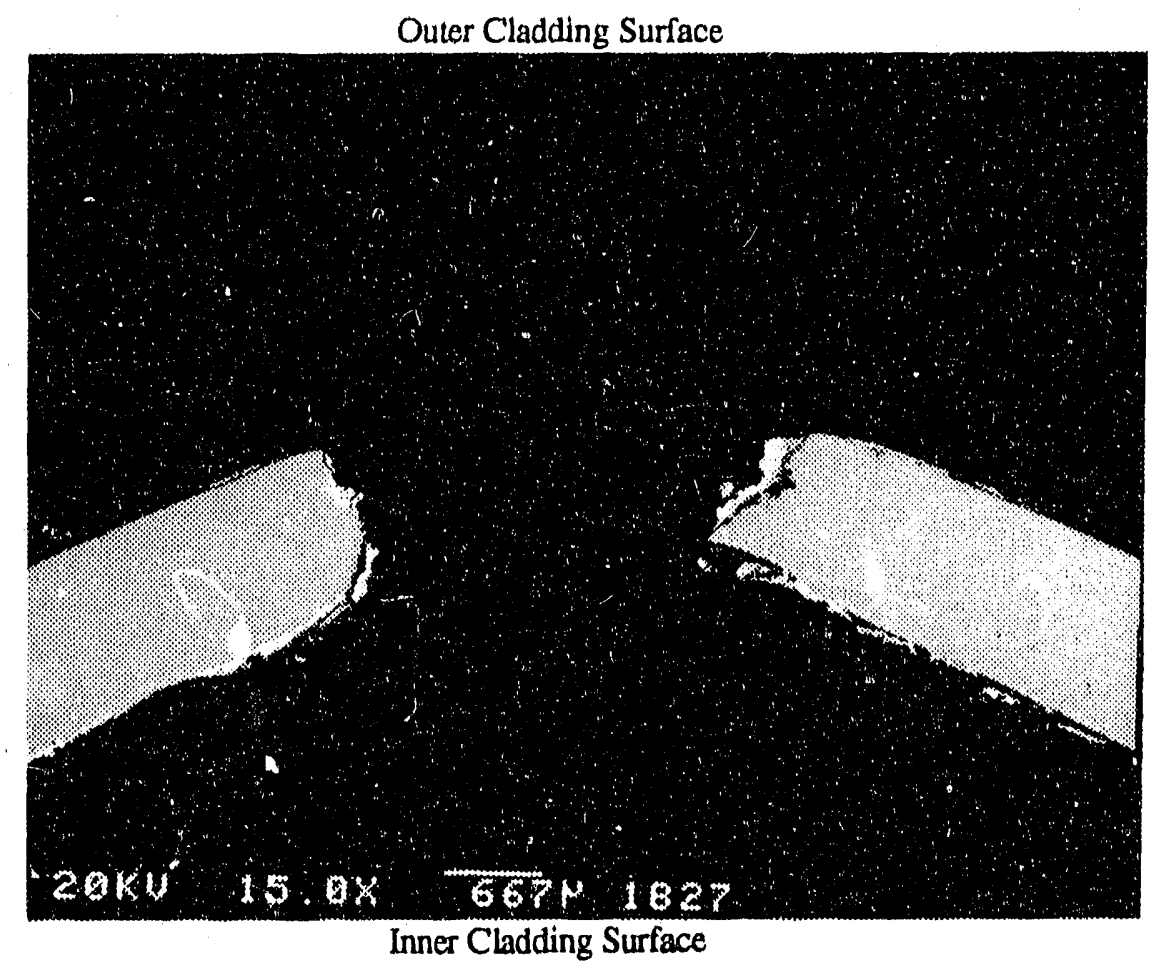

Figure 5-16 Spec.9, 2nd Grind, Bottom Half, Low-Magnification SEM Micrograph (BSE, 15x).

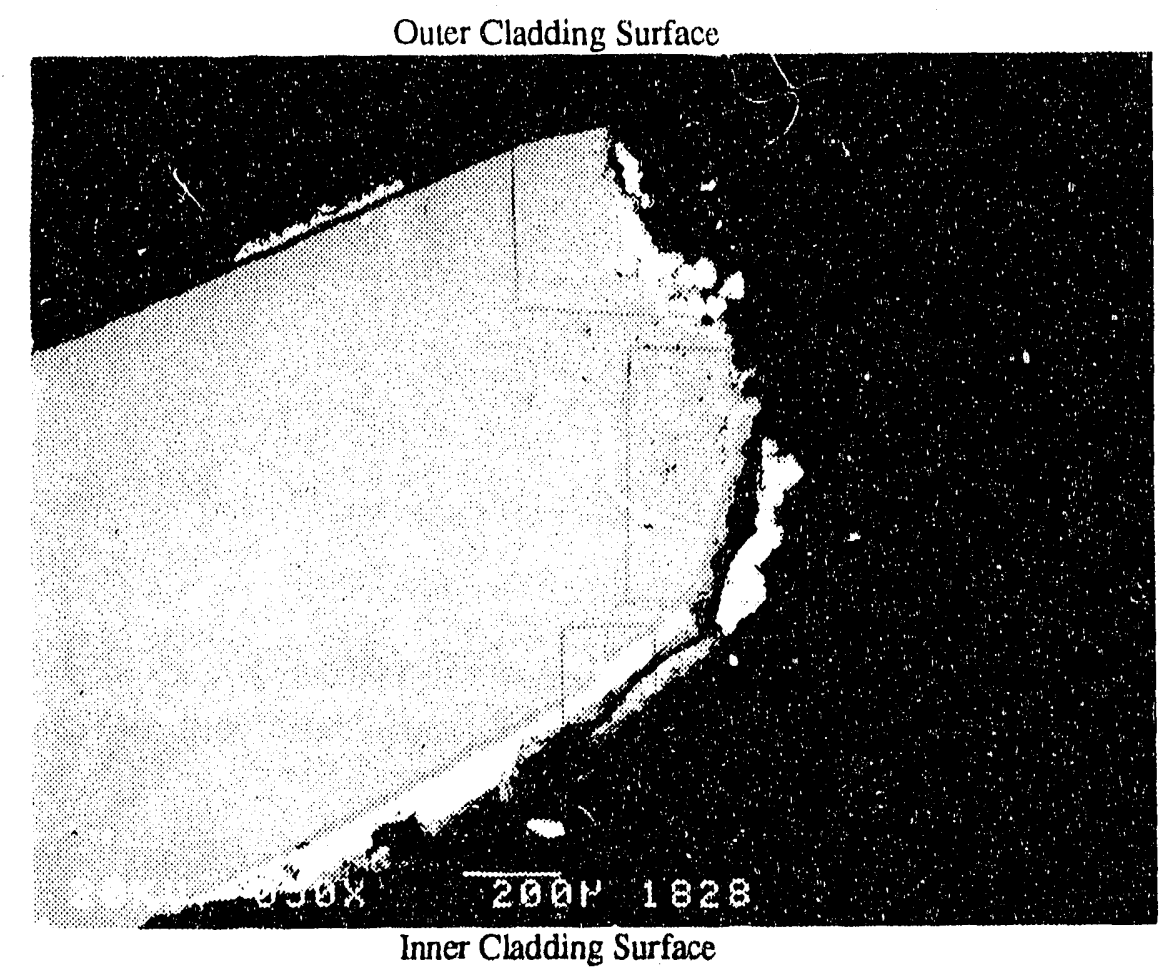

Figure 5-17a Spec.9, 2nd Grind, Bottom Half, Left Side (BSE, 50x). 


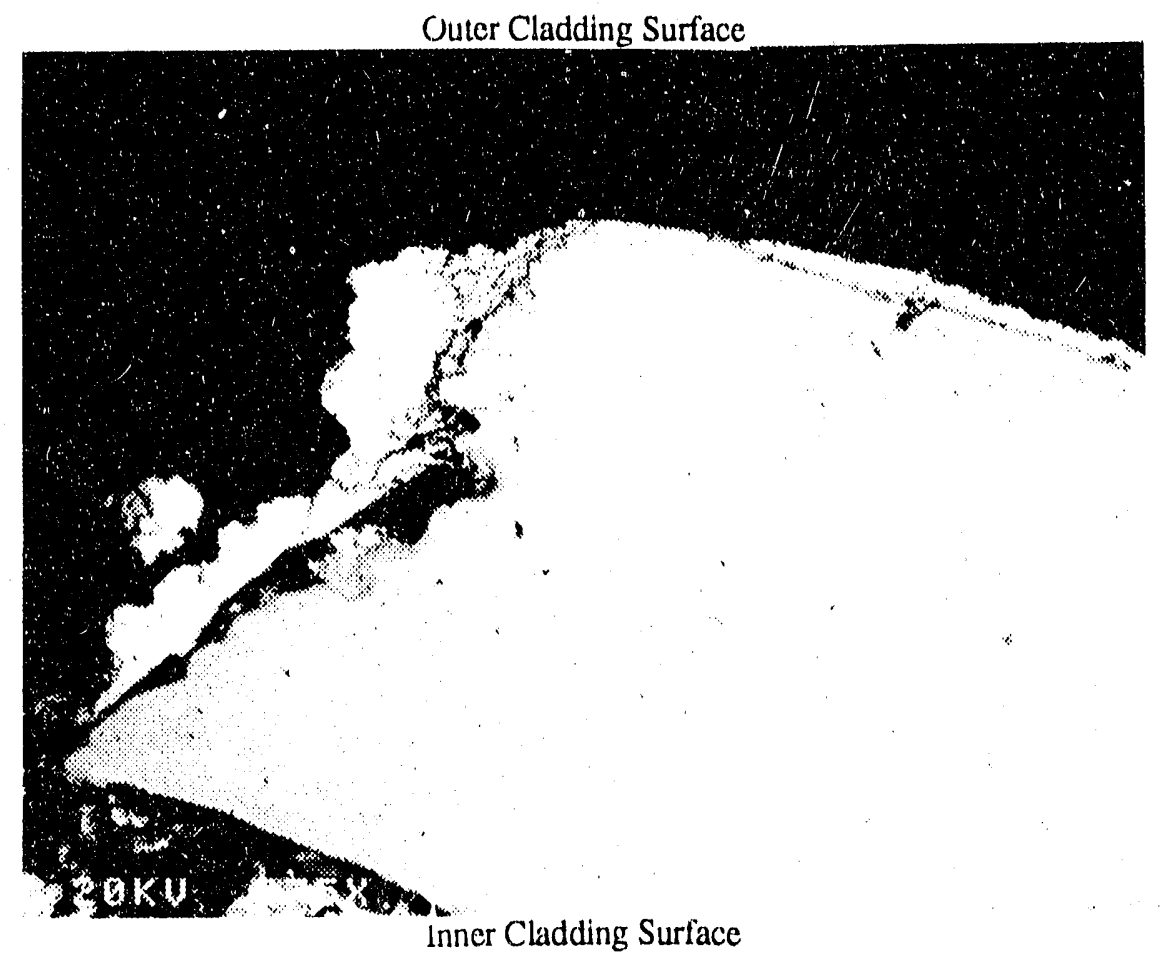

Figure 5-17b Spec.9, 2nd Grind, Bottom Half, Right Side (BSE, 75x). 


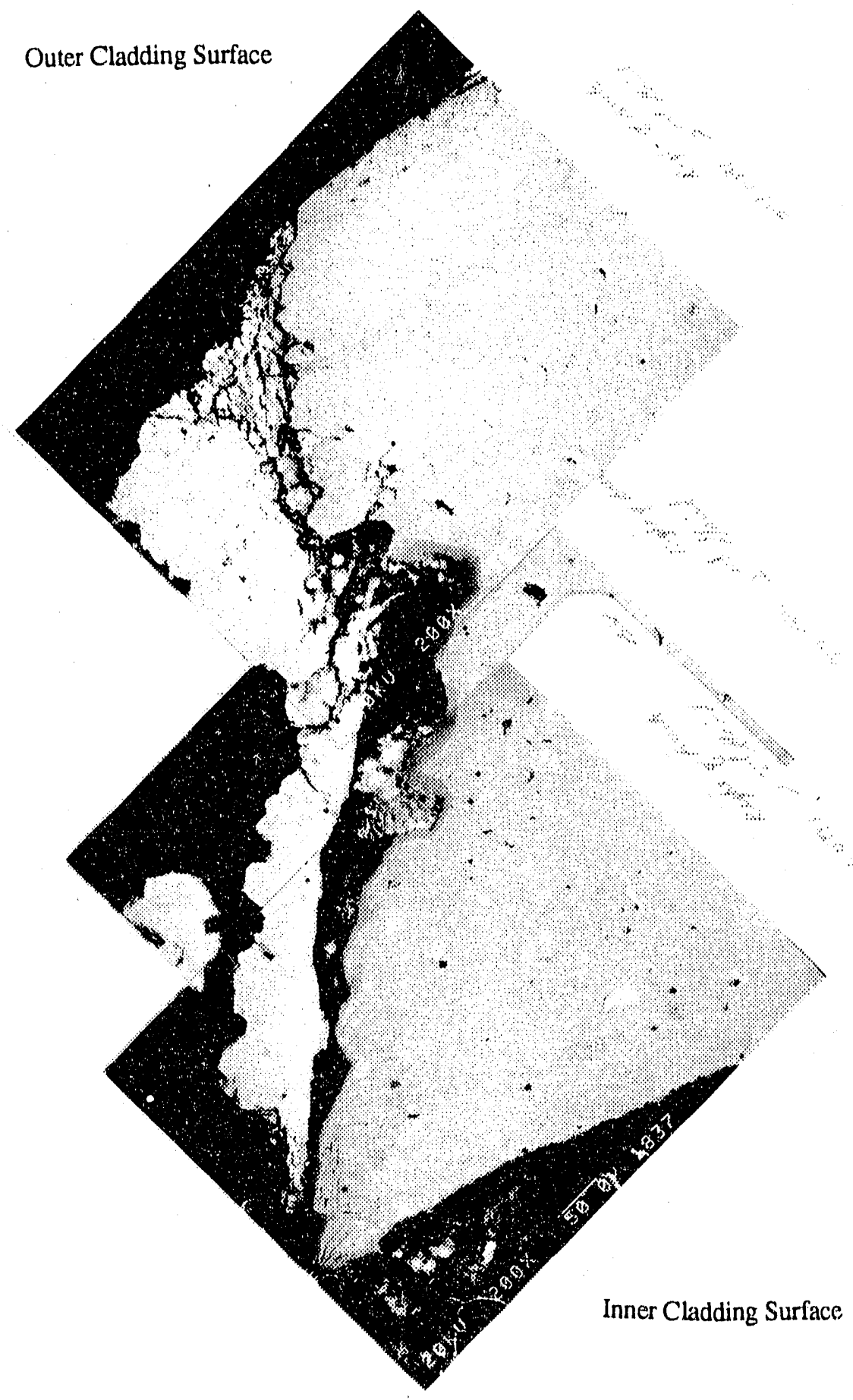

Figure 5-18 Spec.9, 2nd Grind, Bottom Half, Montage of Right Side (BSE). 


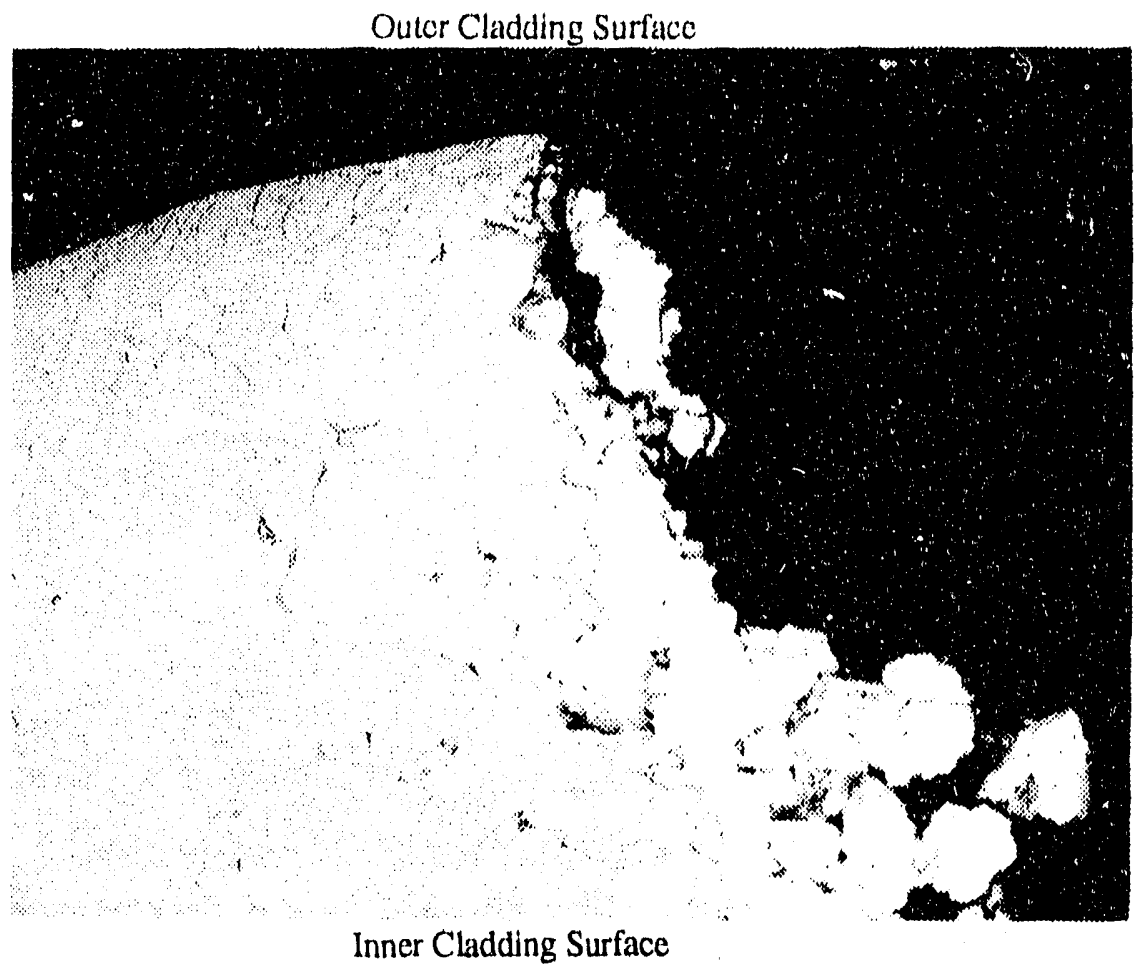

Figure 5-19a Spec.9, 2nd (irind, Bottom Half, Left Side at Cladding O.D. (BSE, 200x).

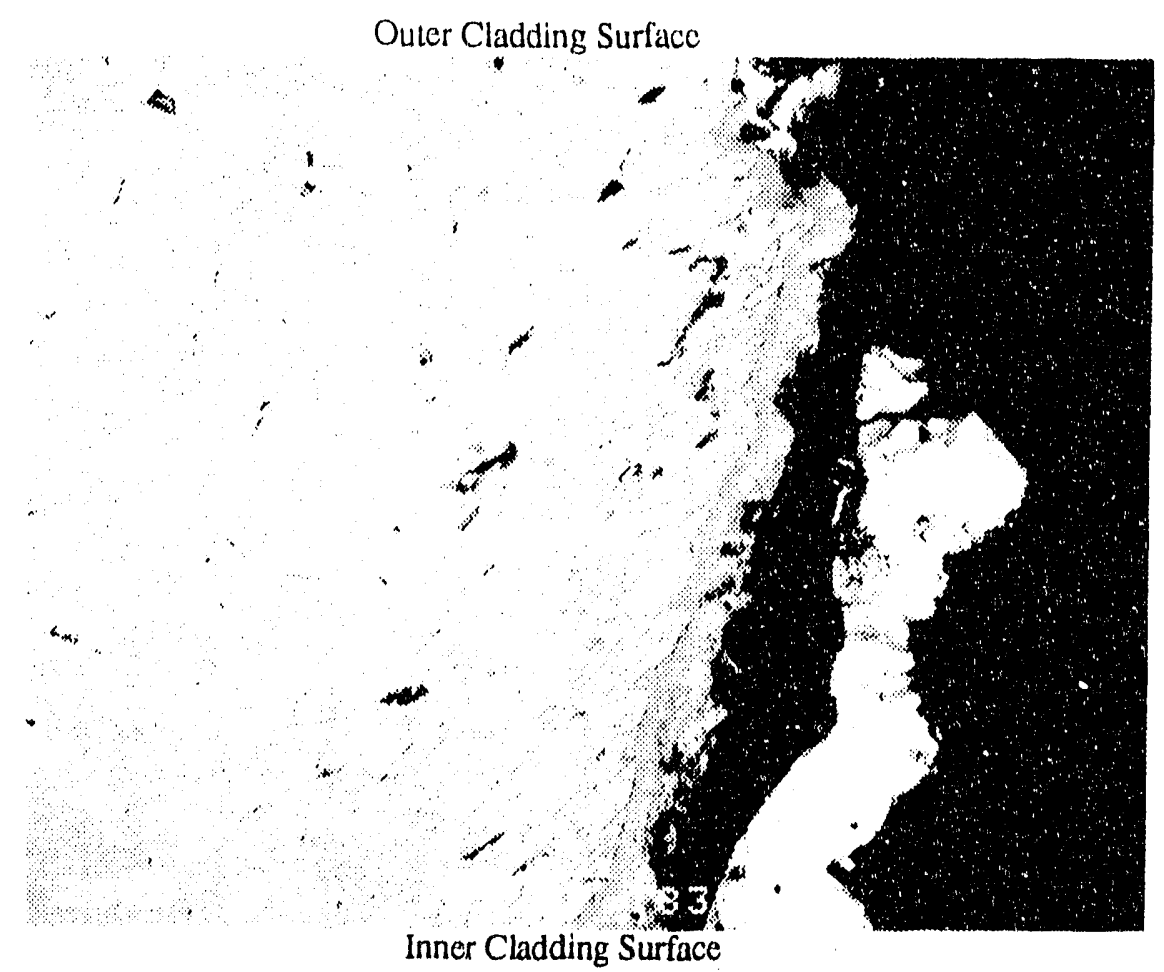

Figure 5-19b Spec.9, 2nd Grind, Bottom Half, Left Side Near Cladding Midpoint (BSE, 200x). 


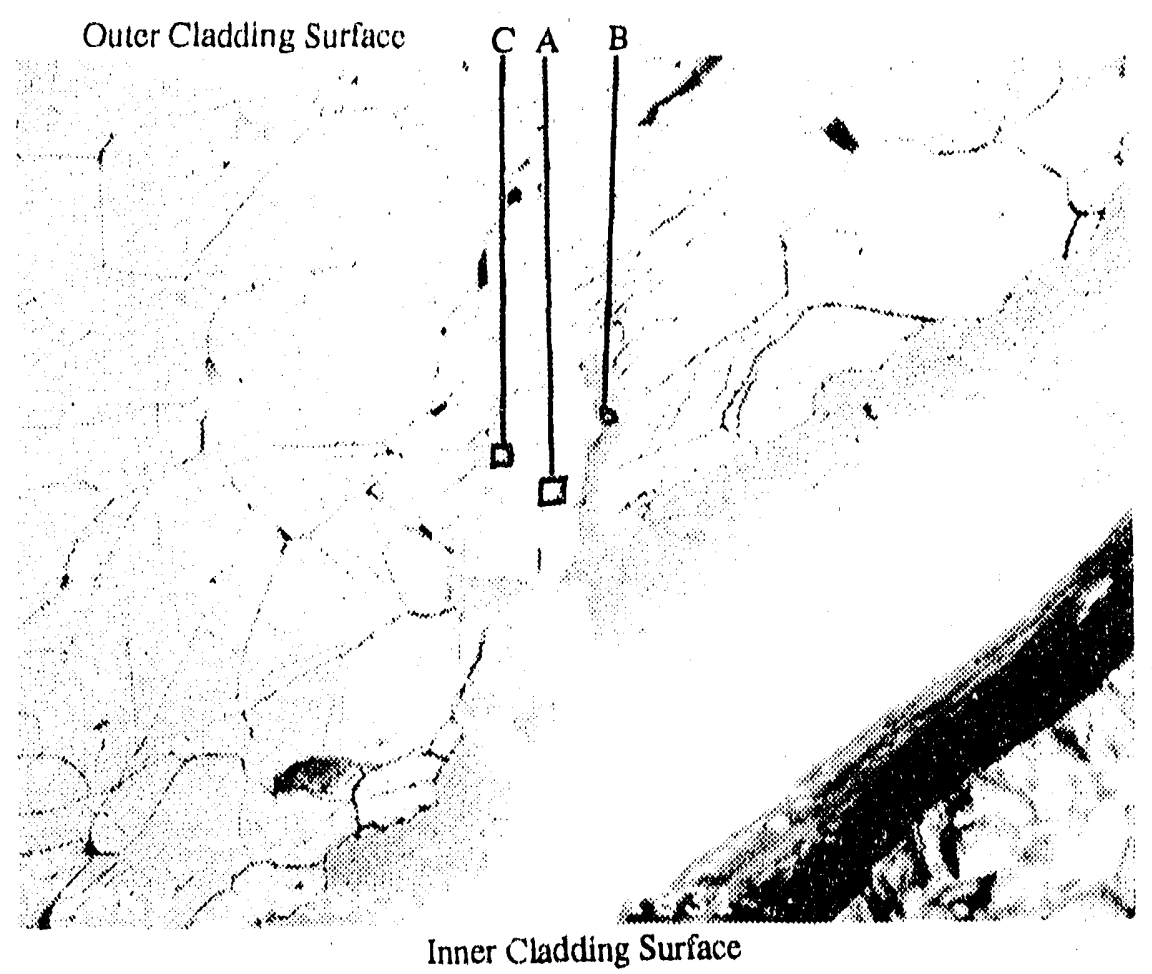

Figure 5-20 Spec.9, 2nd Grind, Bottom Half, Left Side on Cladding Inner Surface (BSE, 500x).

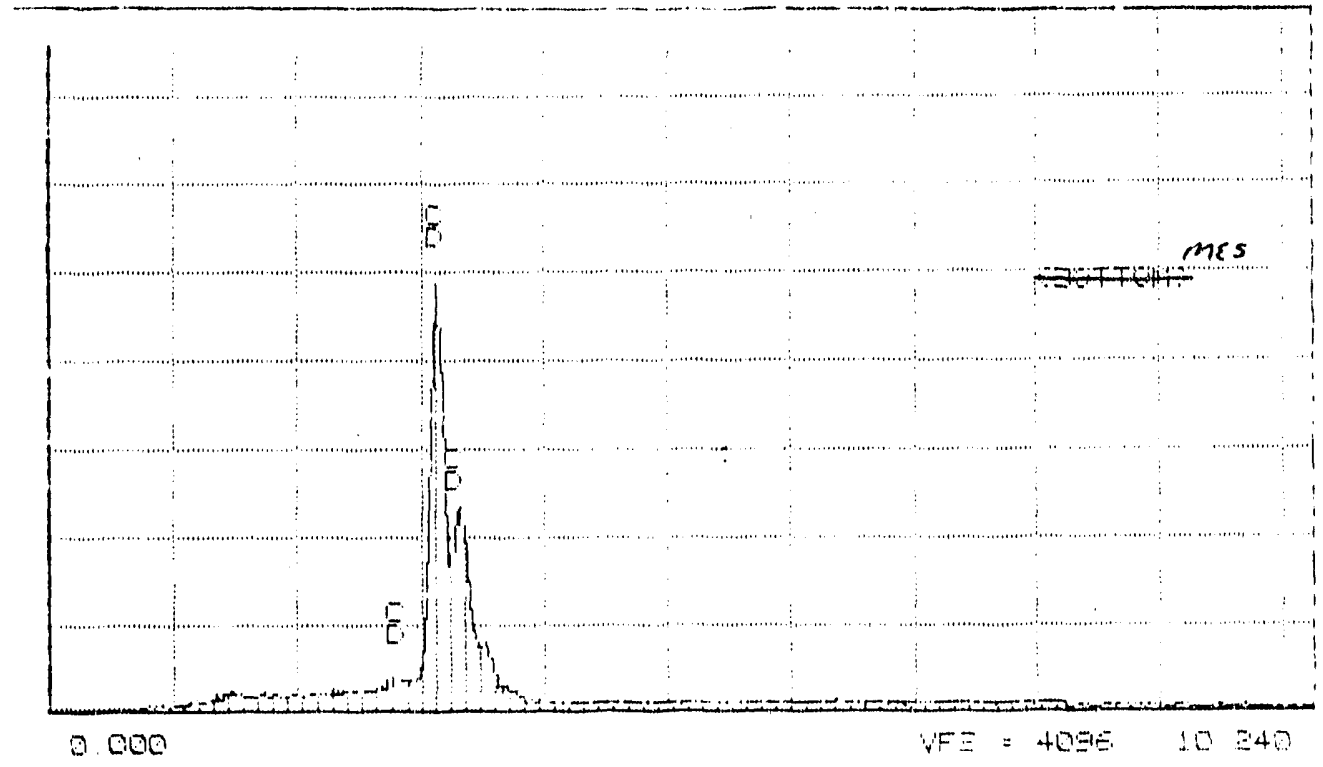

Figure 5-21a Spec.9, 2nd Grind, Bottom Half, EDS Spectrum for Spot "A" on Figure 520. 


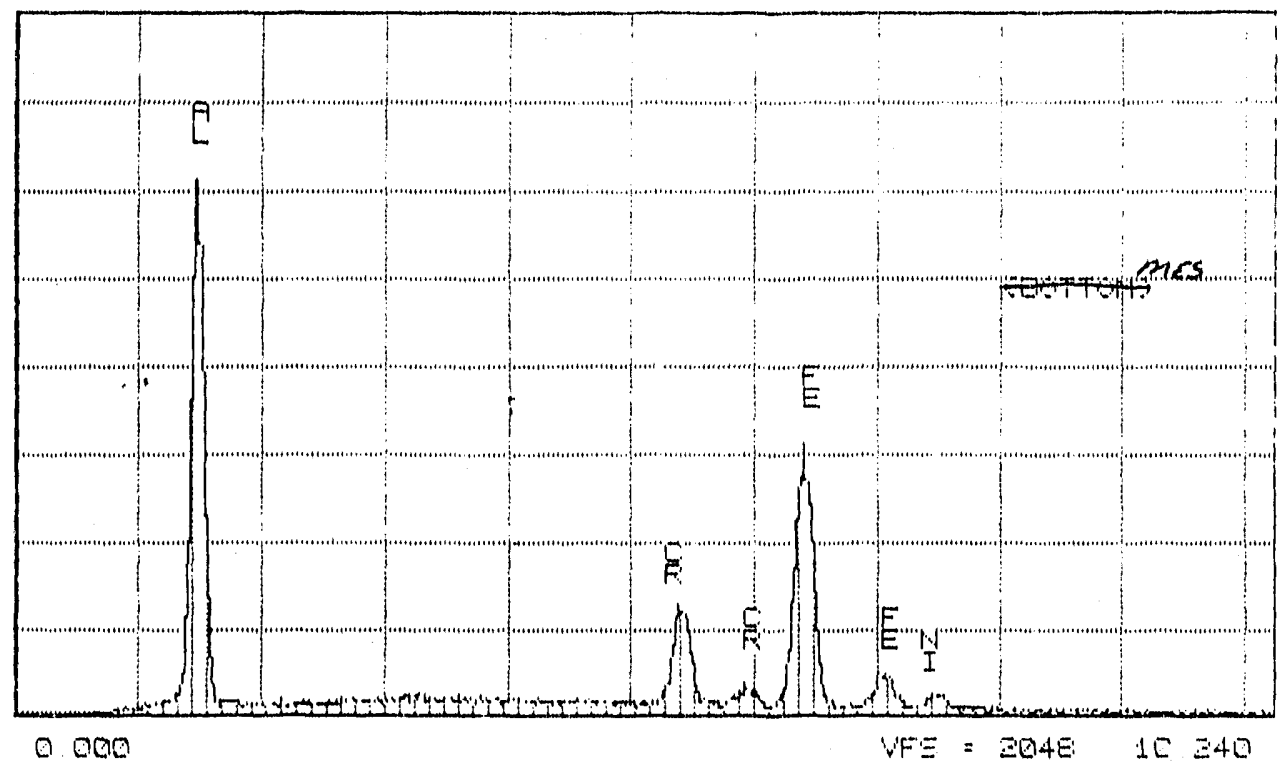

Figure 5-21b Spec.9, 2nd Grind, Bottom Half, EDS Spectrum for Spot "B" on Figure 520 .

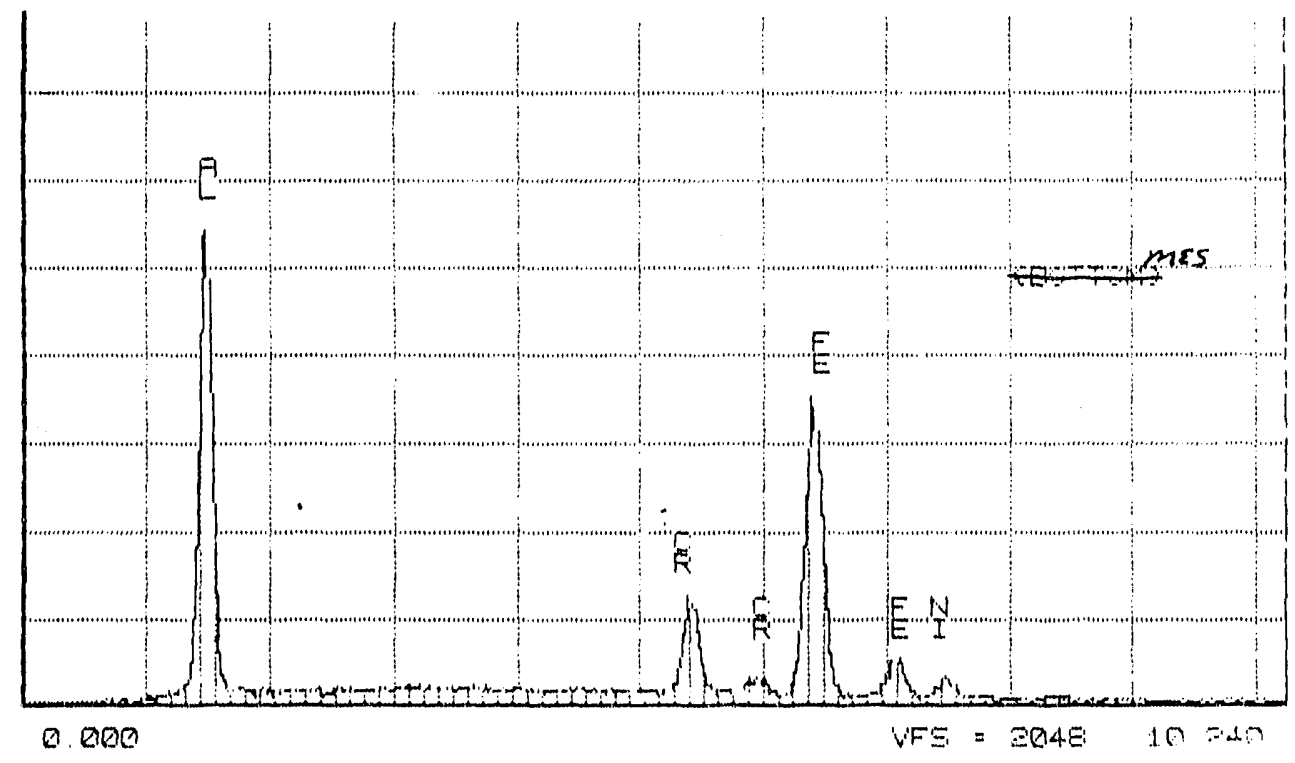

Figure 5-21c Spec.9, 2nd Grind, Bottom Half, EDS Spectrum for Spot "C" on Figure 520. 
Outer Cladding Surface

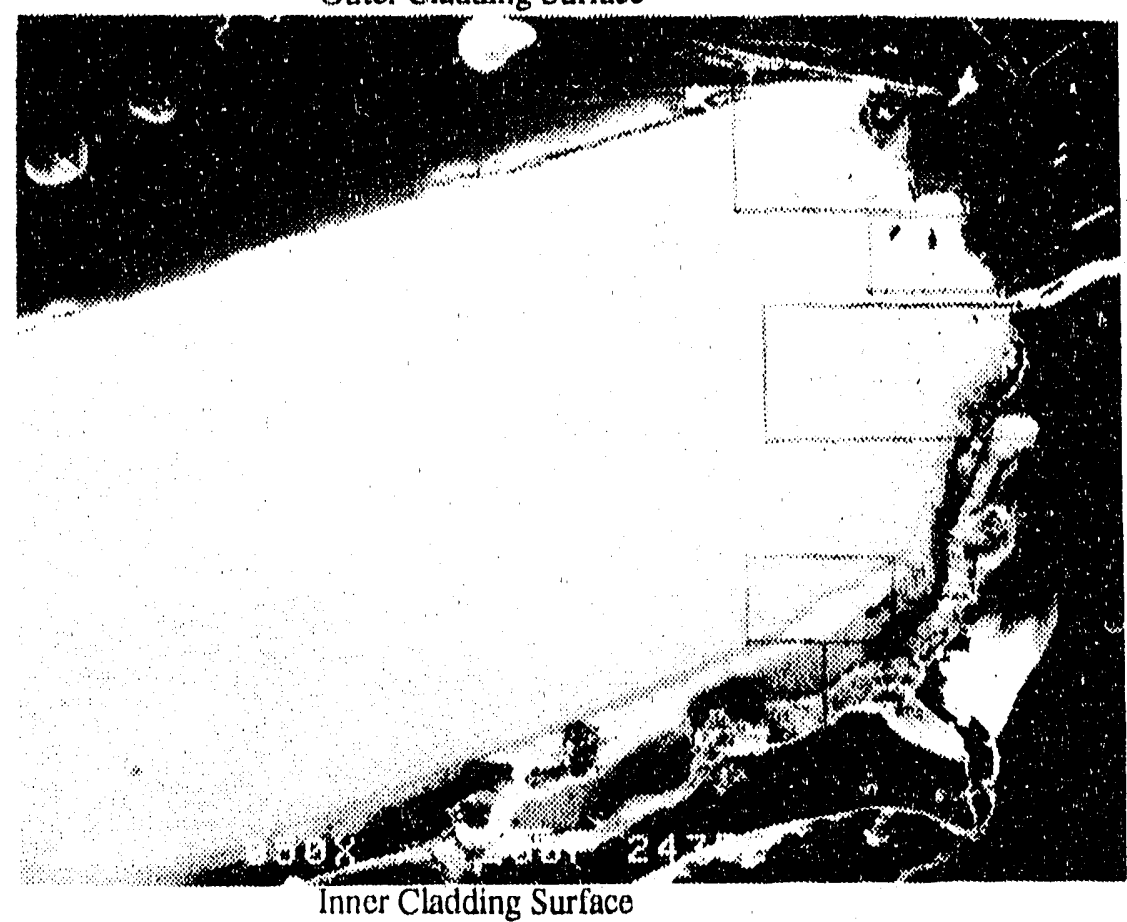

Figure 5-22a Spec.9, 3rd Grind, Bottom Half, Left Side (SE, 50x).

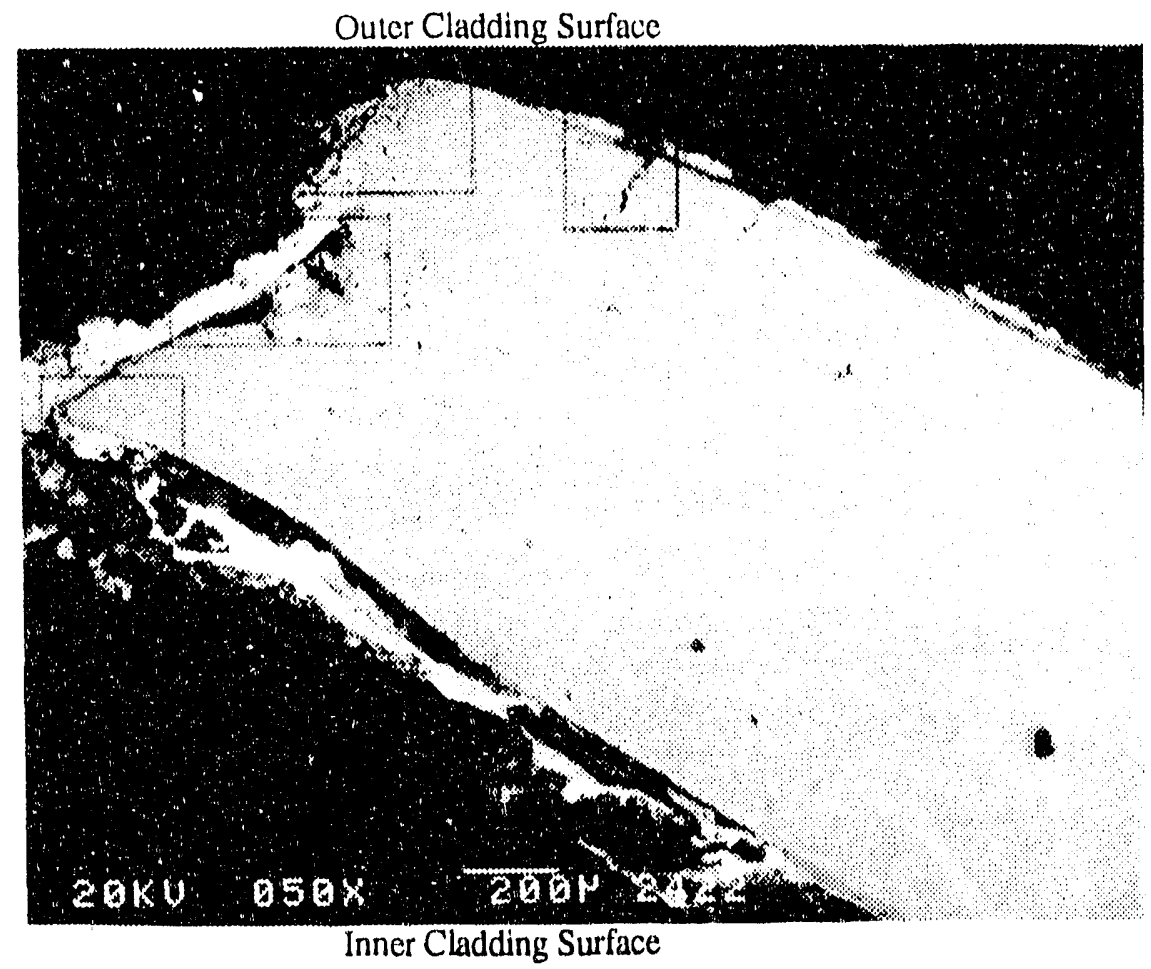

Figure 5-22b Spec.9, 3rd Grind, Bottom Half, Right Side (BSE, 50x). 


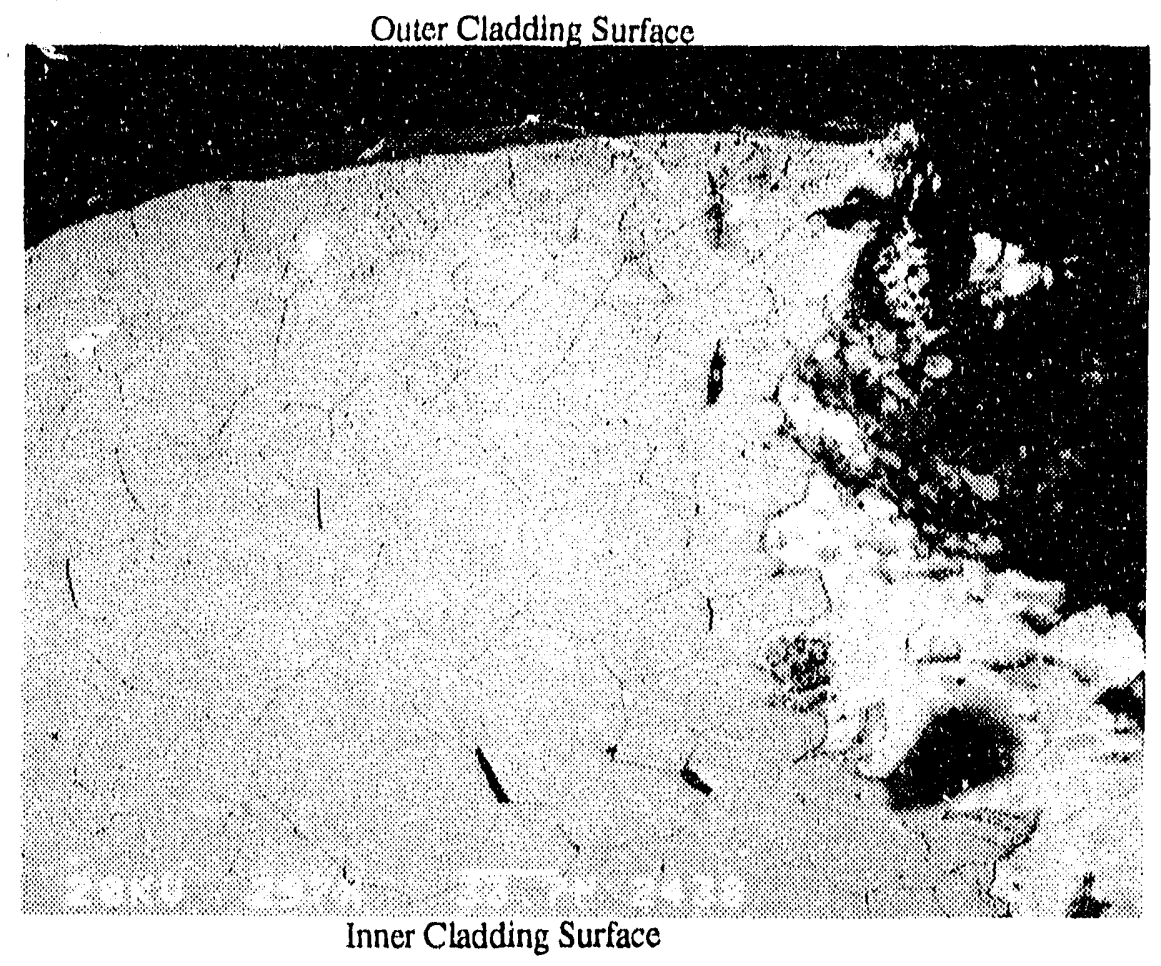

Figure 5-23a Spec.9, 3rd Grind, Bottom Half, Left Side at Cladding O.D. (BSE, 297x).

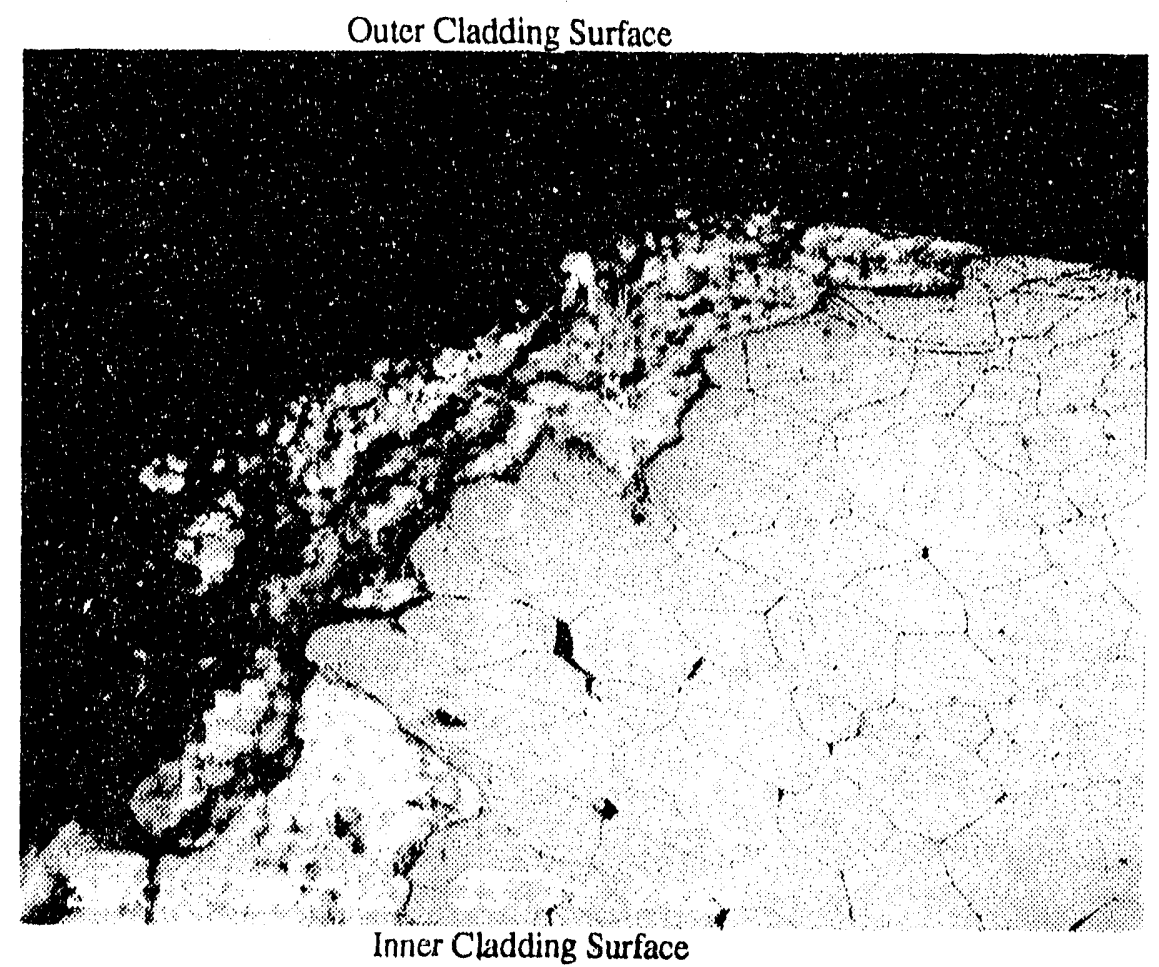

Figure 5-23b Spec.9, 3rd Grind, Bottom Half, Right Side at Cladding O.D. (BSE, 297x). 


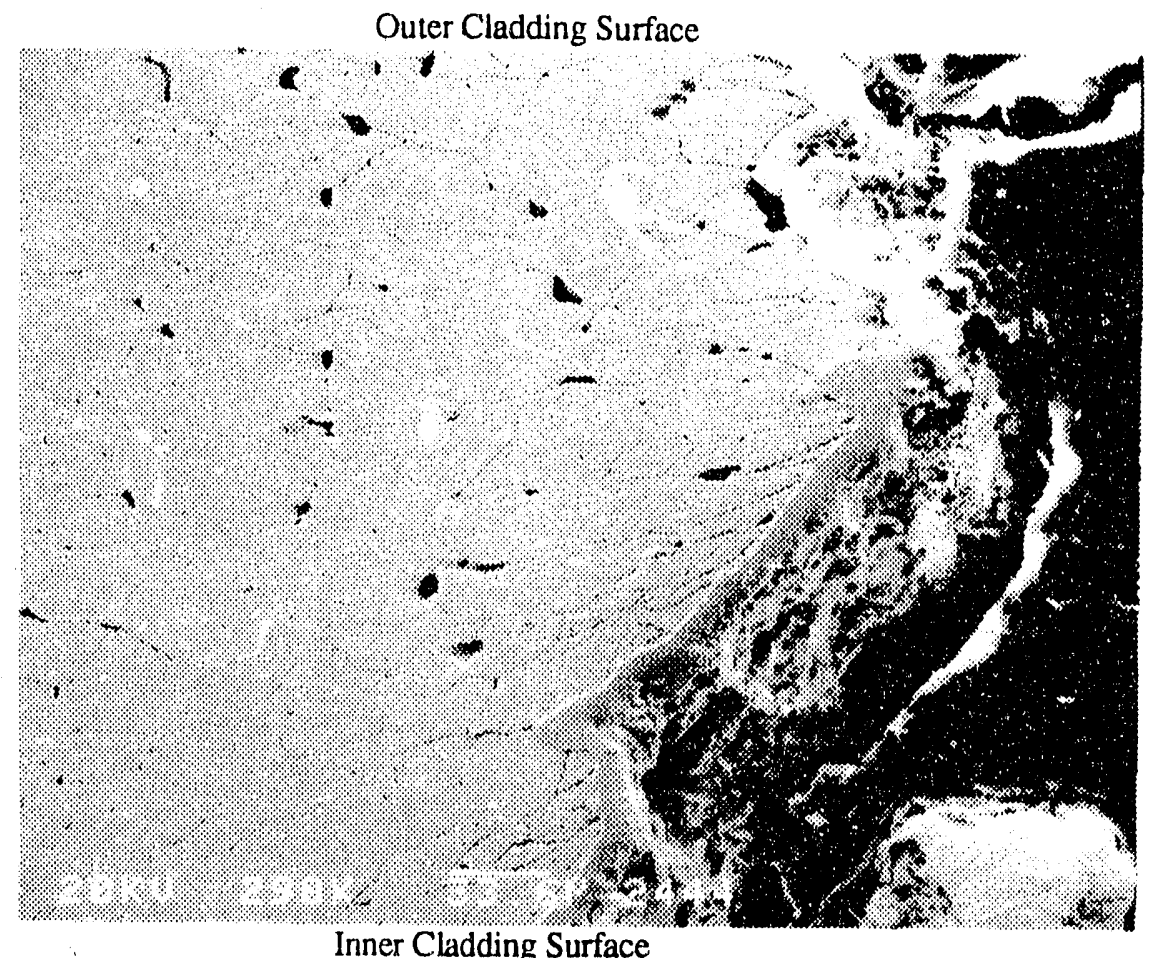

Figure 5-24a Spec.9, 3rd Grind, Bottom Half, Left Side Near Cladding Midpoint (BSE, $298 x)$.

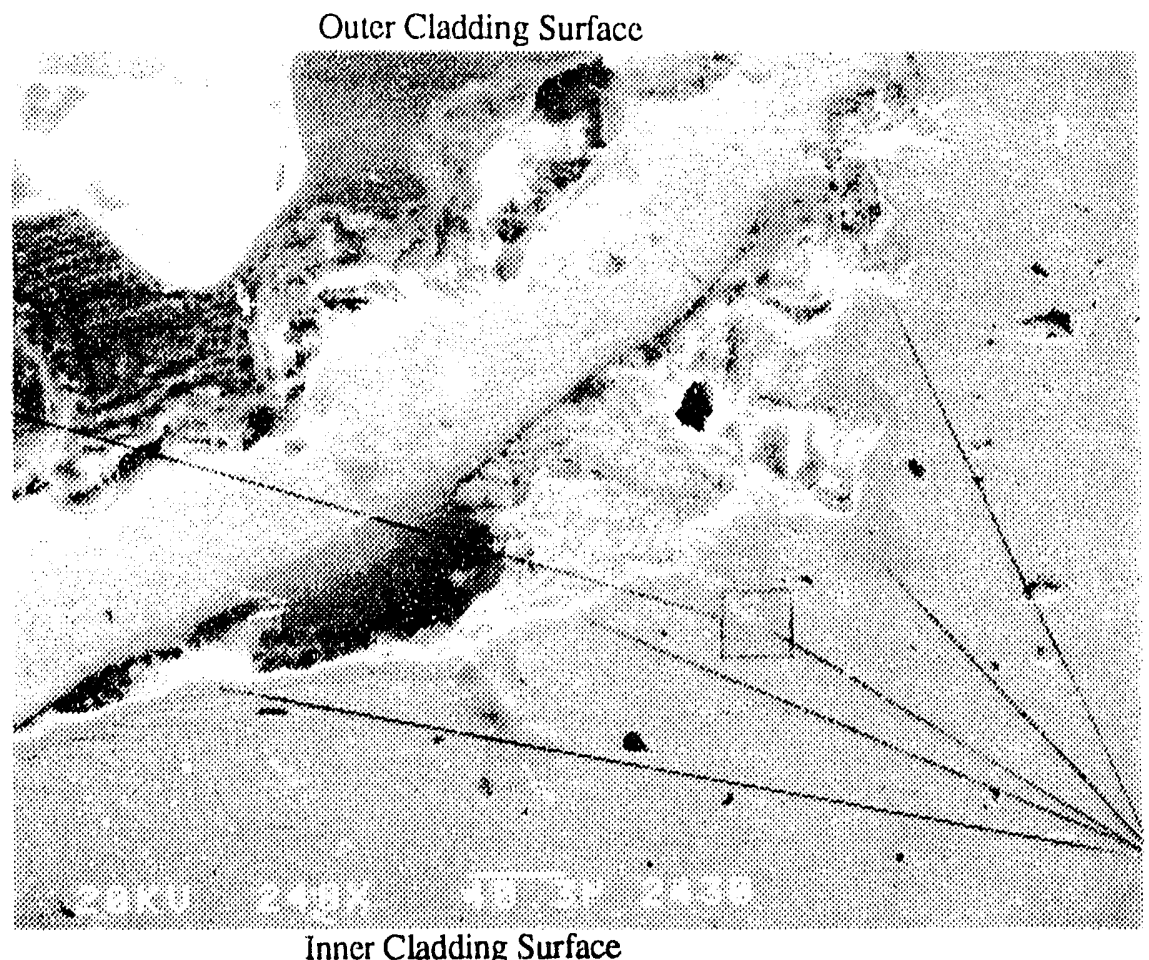

Figure 5-24b Spec.9, 3rd Grind, Bottom Haif, Right Side Near Cladding Midpoint (SE, 248x). 


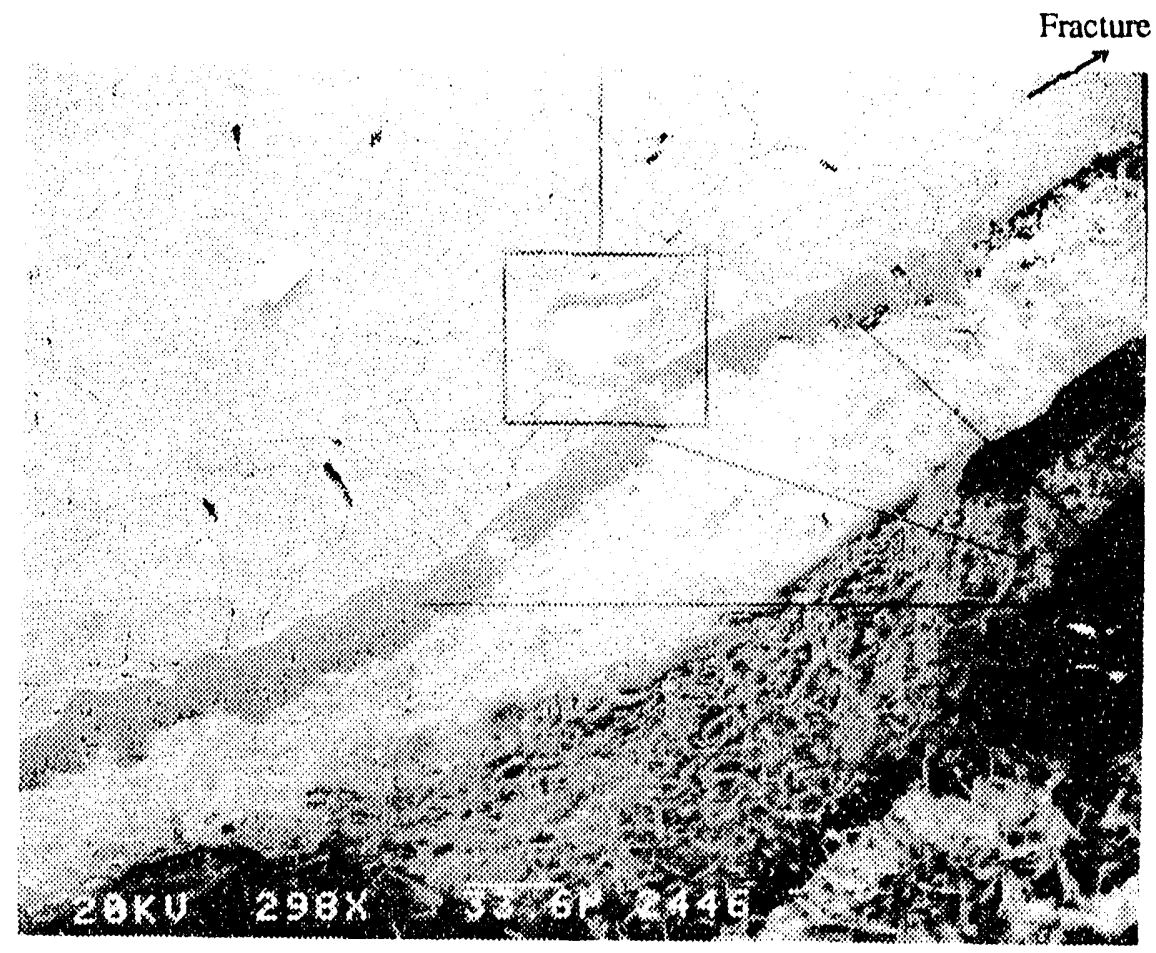

Figure 5-25 Spec.9, 3rd Grind, Bottom Half, Left Side on Inner Surface (SE, 298x).

Outer Cladding Surface

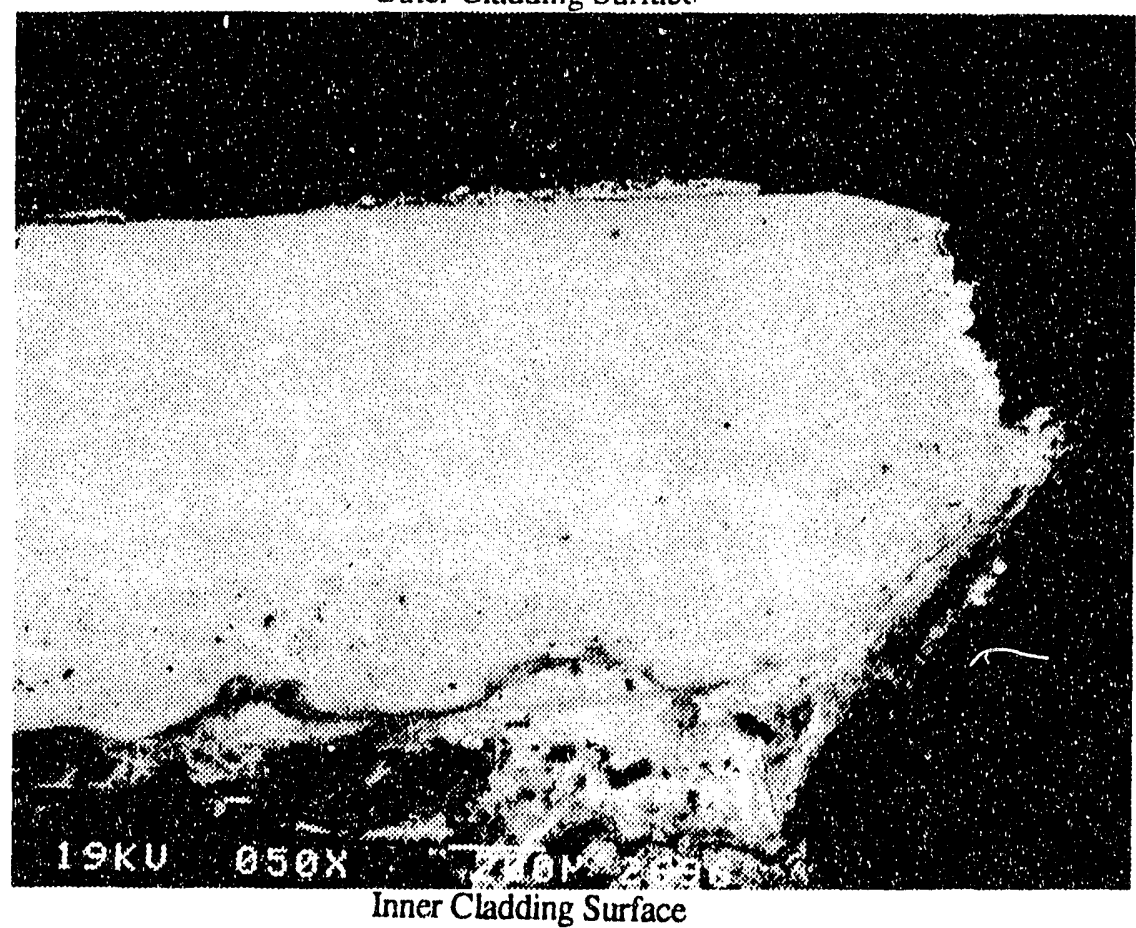

Figure 5-26a Spec.9, 4th Grind, Bottom Half, Left Side (BSE, 50x). 


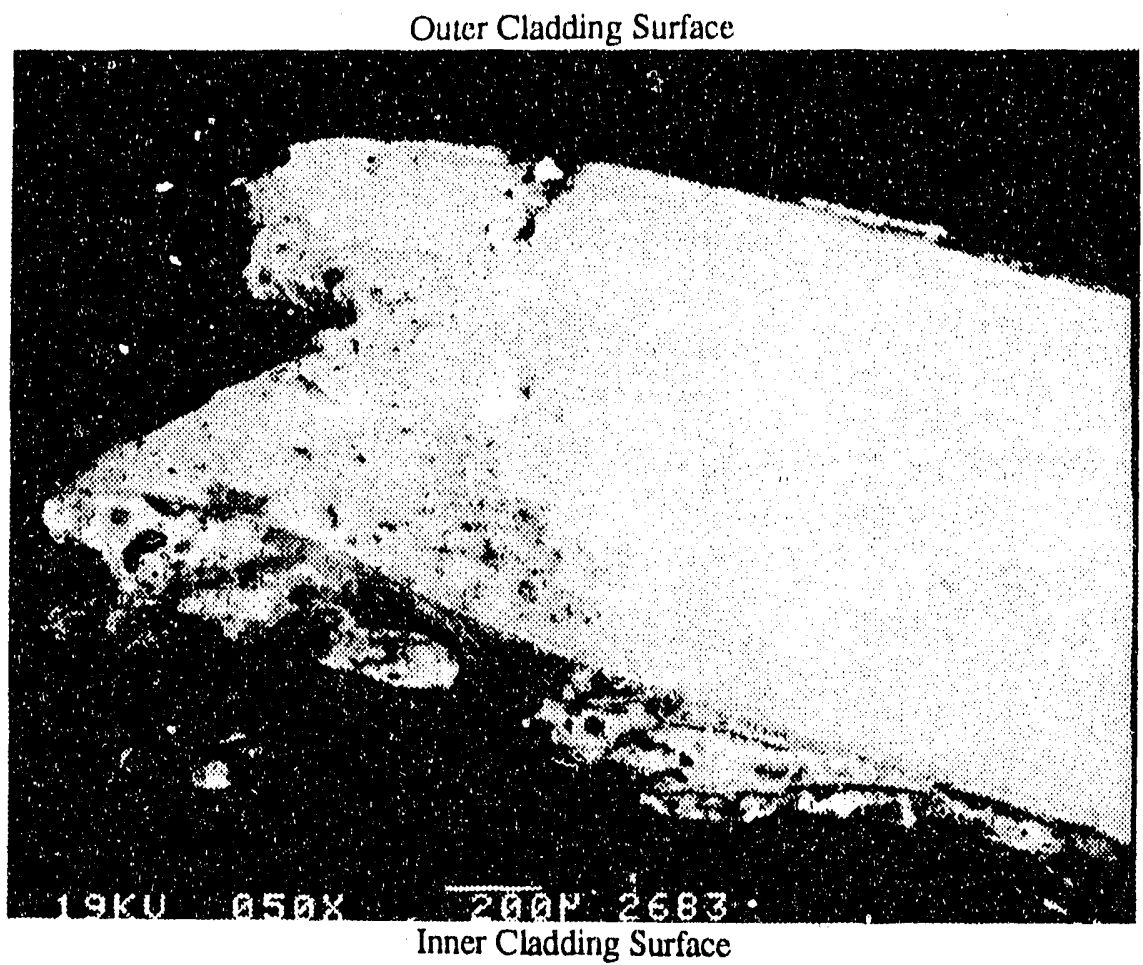

Figure 5-26b Spec.9, 4th Grind, Bottom Half, Right Side (BSE, 50x).

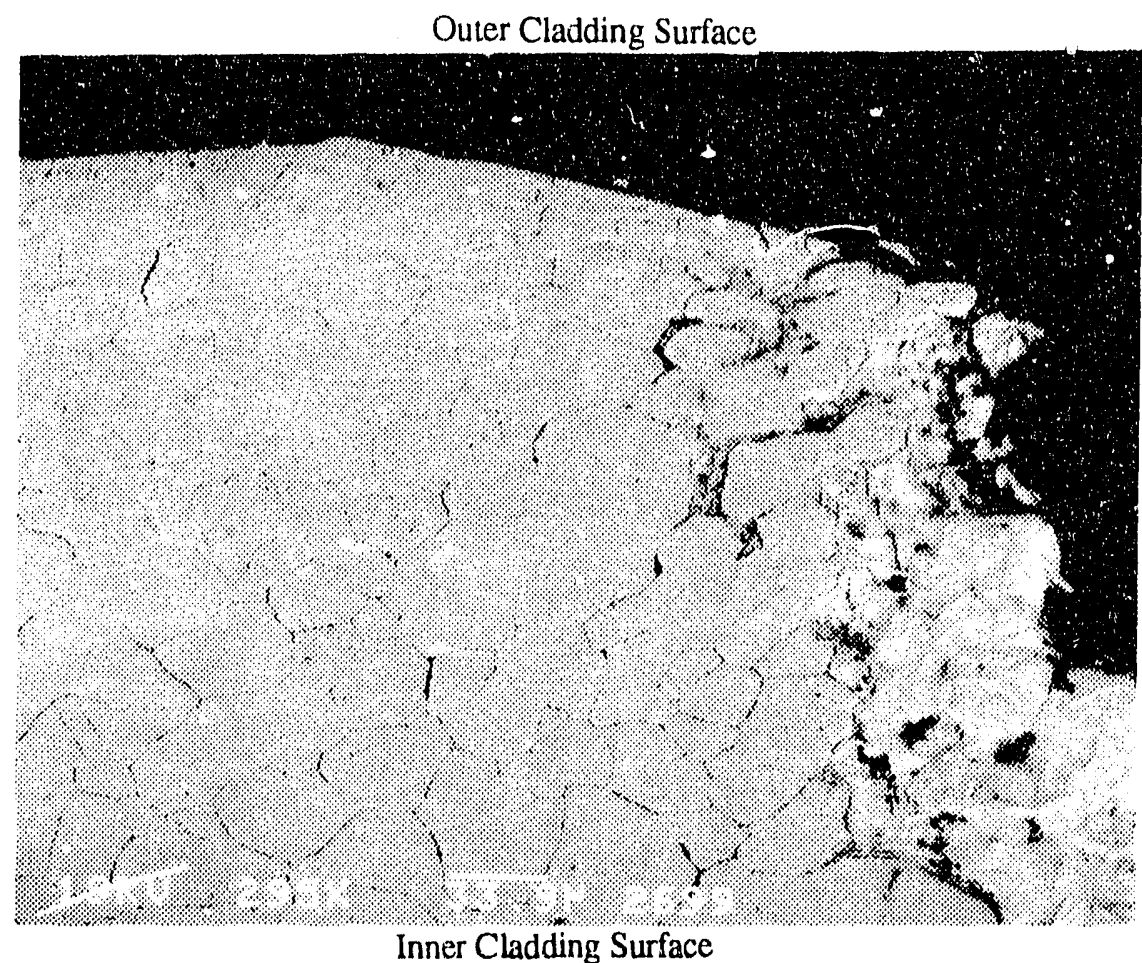

Figure 5-27 Spec.9, 4th Grind, Bottom Half, Left Side at Cladding O.D. (BSE, 295x). 


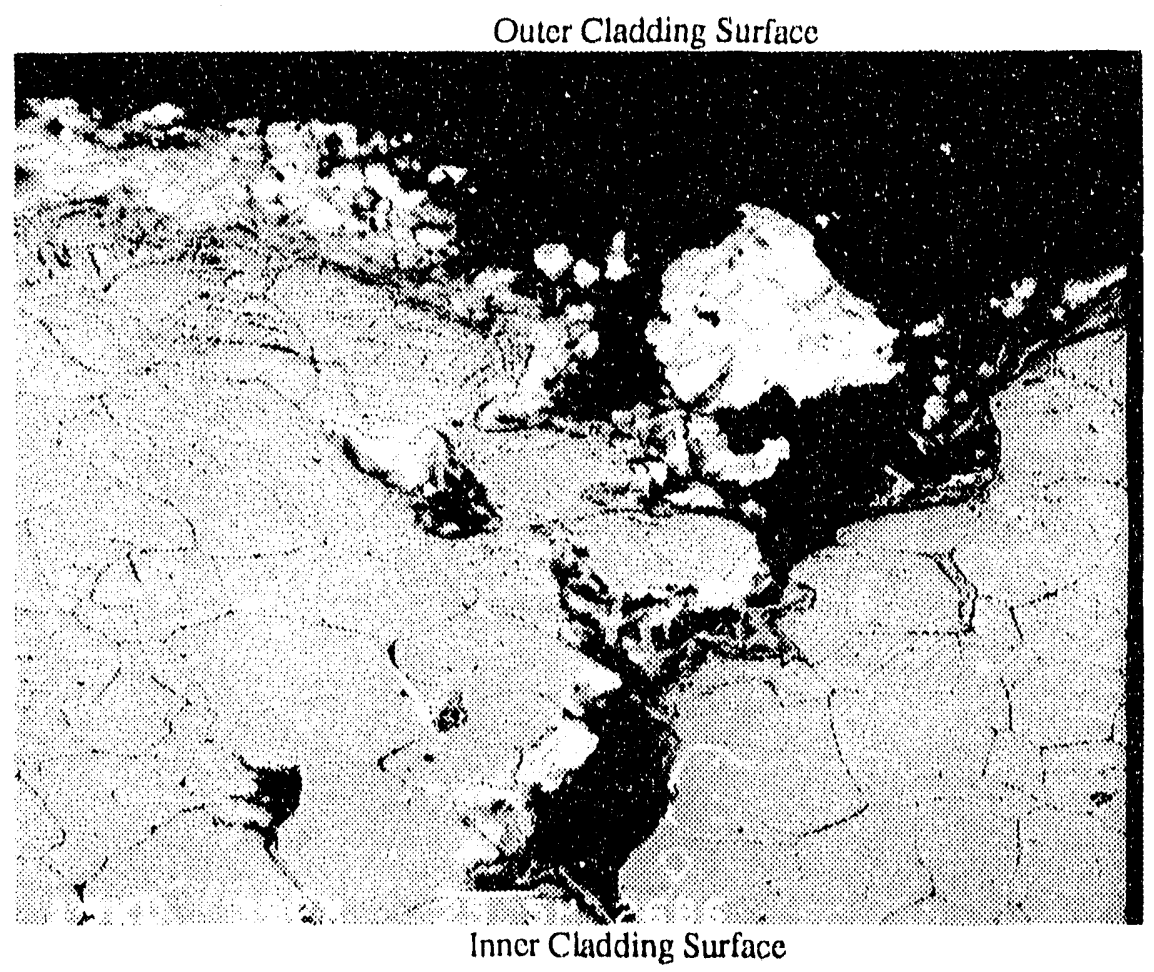

Figure 5-28 Spec.9, 4th Grind, Bottom Half, Cladding Outer Surface to the Right of the Fracture (BSE, 392x).

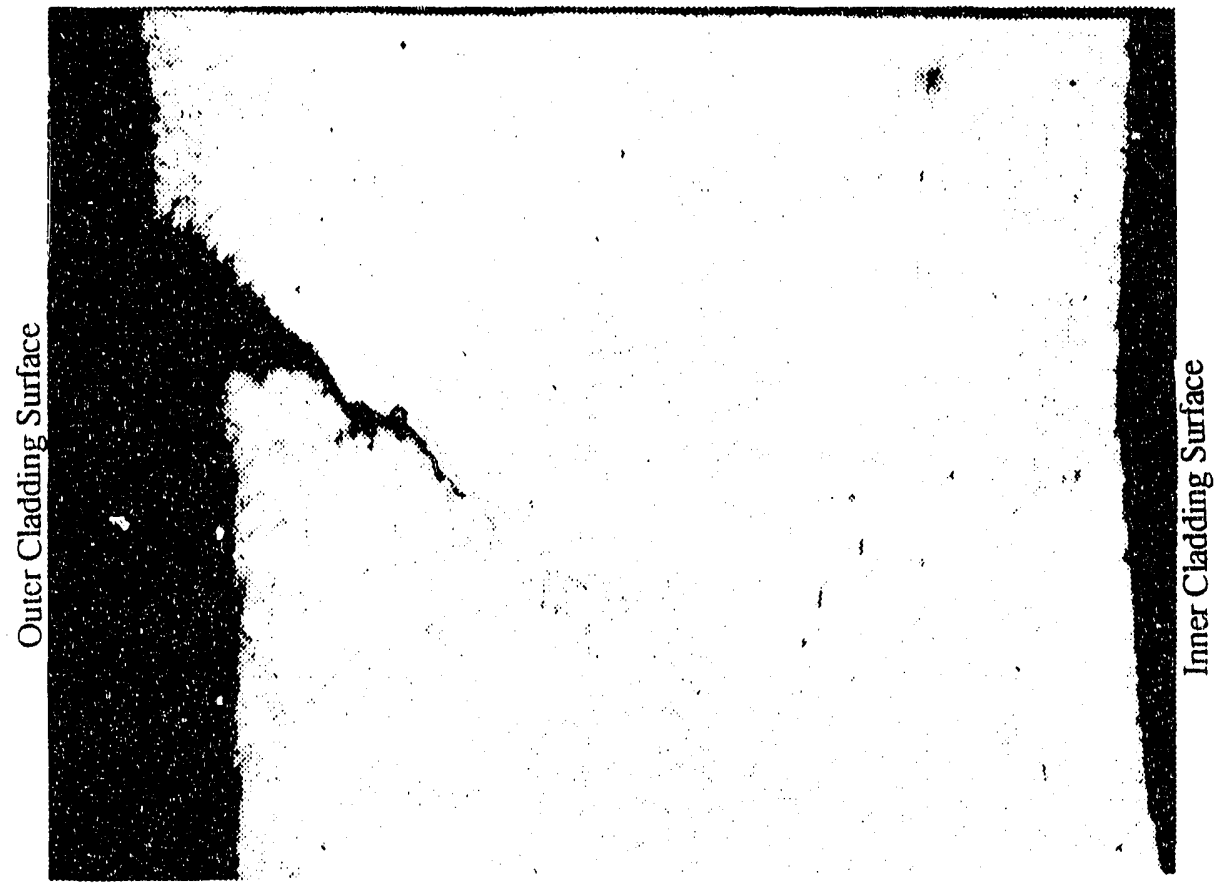

Figure 5-29a Spec.9, 21st Grind, Top Half, Optical Micrograph of Fracture (100x). 


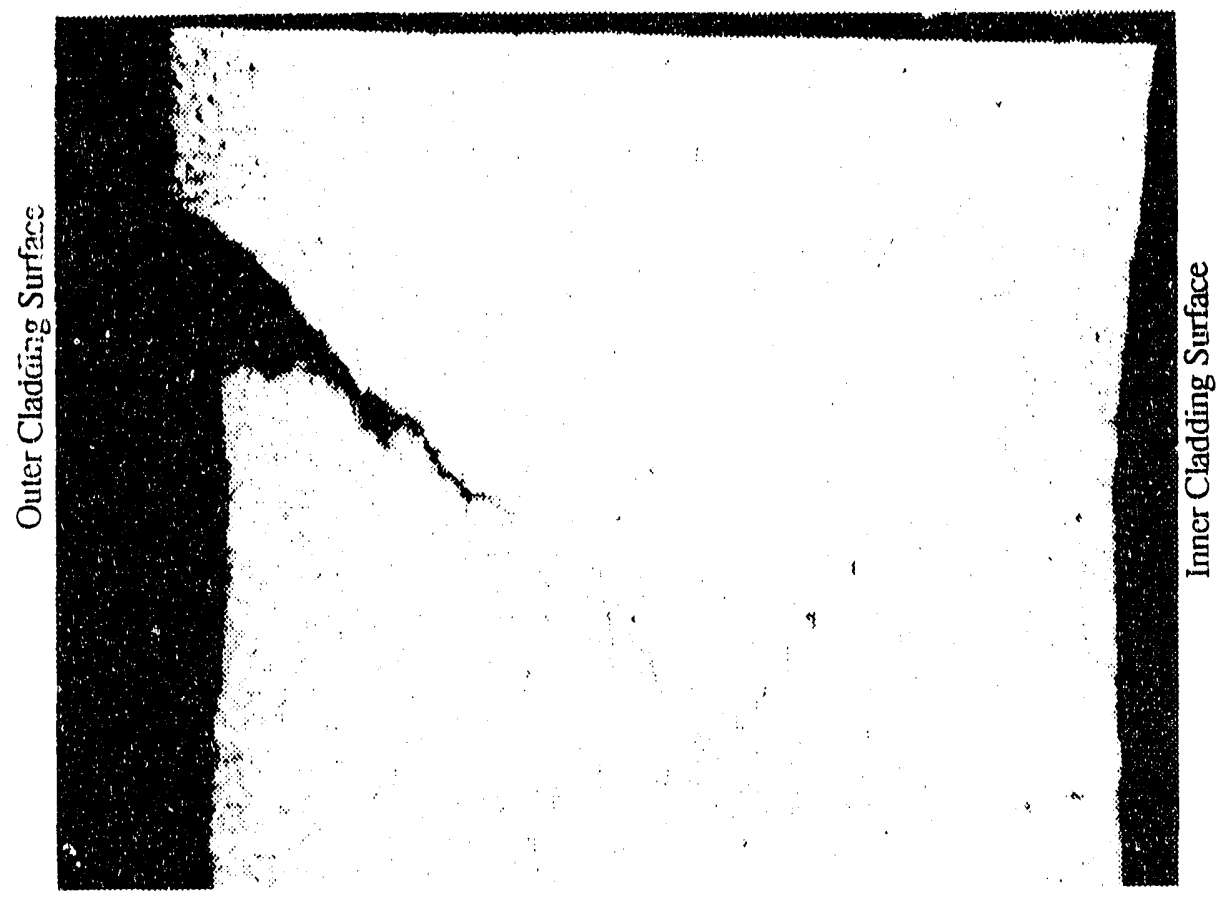

Figure 5-29b Spec.9, 22nd Grind, Top Half, Optical Micrograph of Fracture (100x).

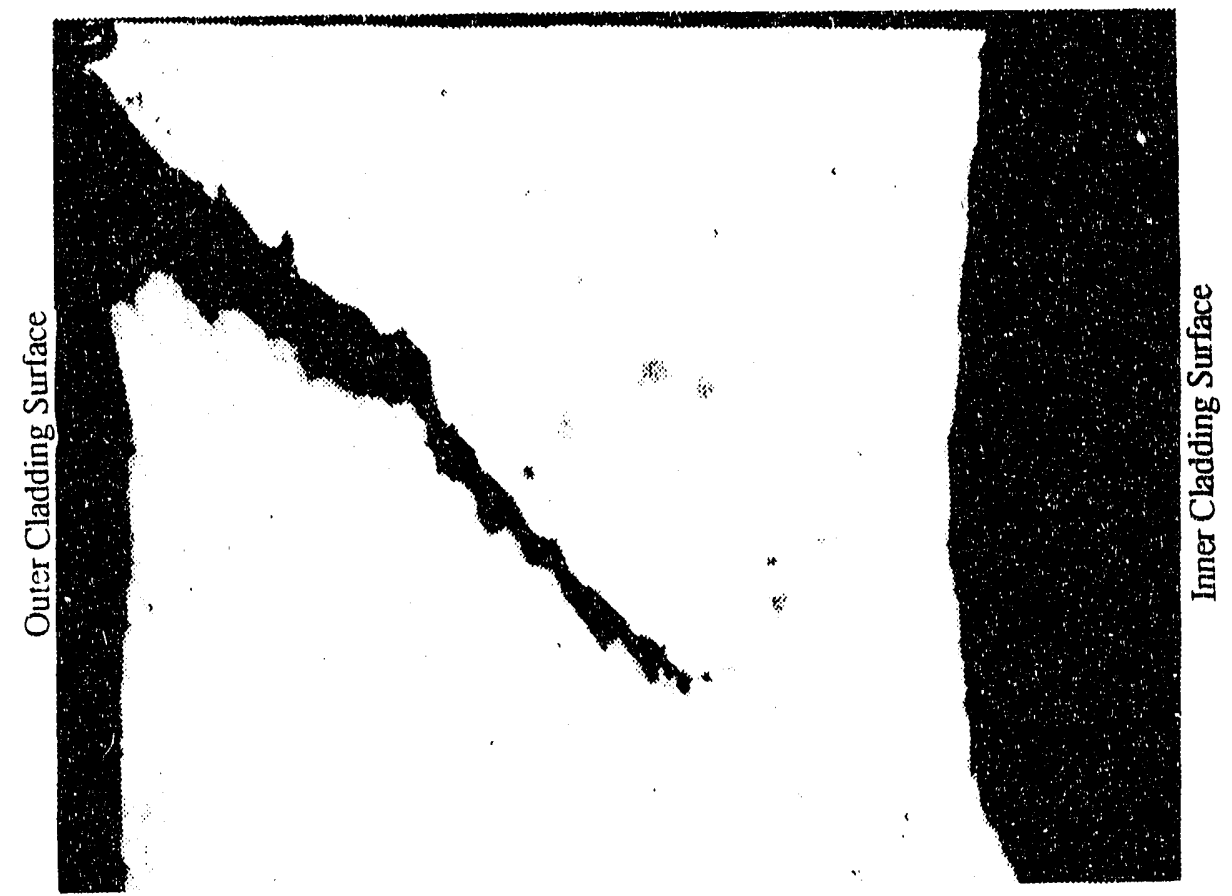

Figure 5-29c Spec.9, 23rd Grind, Top Half, Optical Micrograph of Fracture (100x). 


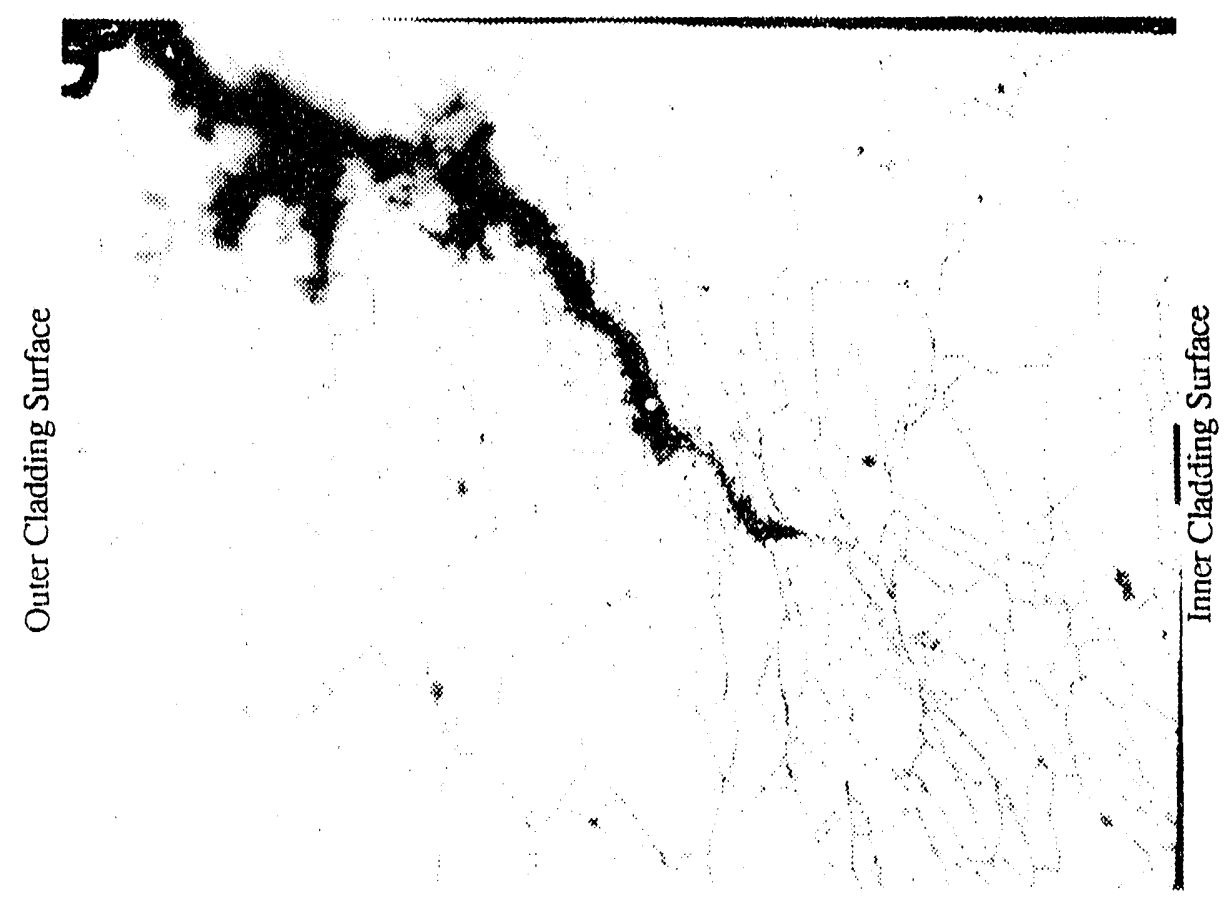

Figure 5-30a Spec.9, 21st Grind, Top Half, Optical Micrograph of Fracture Tip (500x).

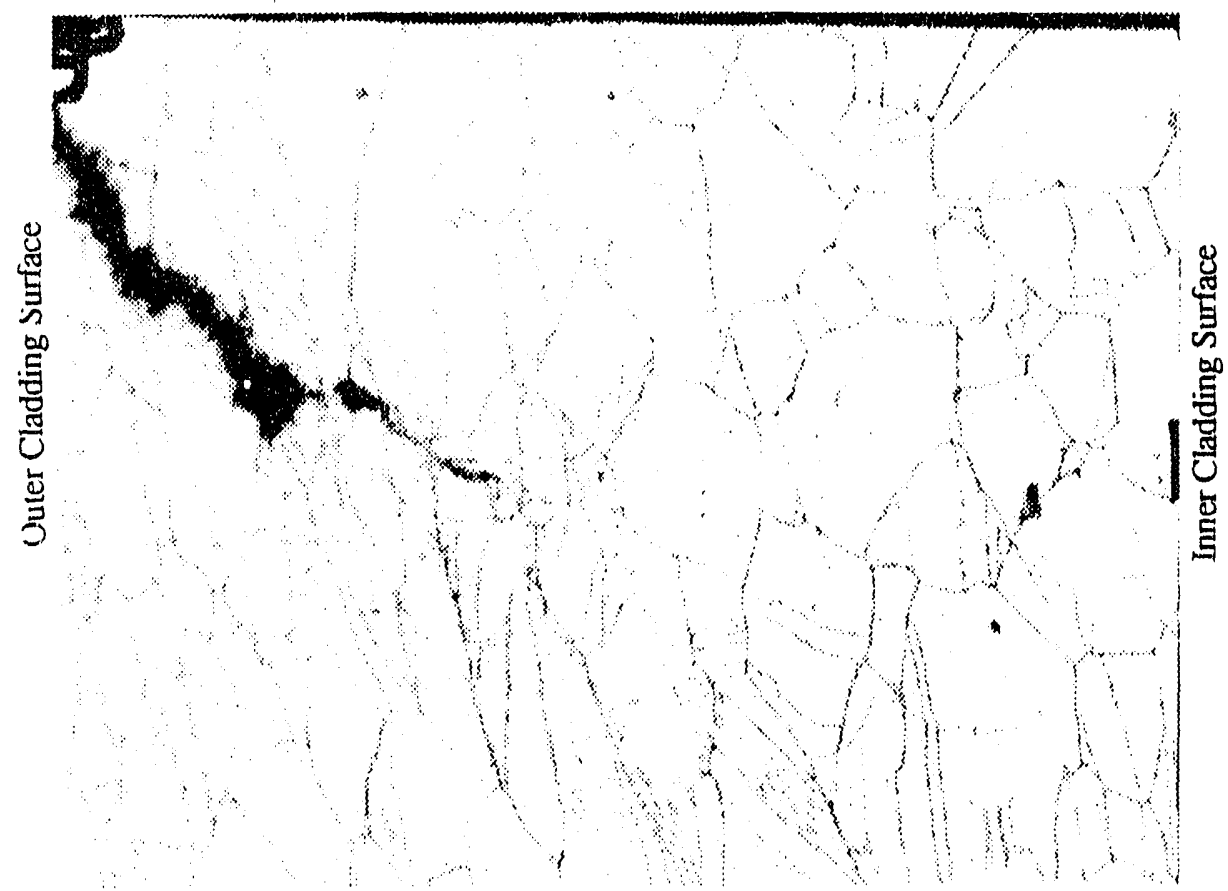

Figure 5-30b Spec.9, 22nd Grind, Top Half, Optical Micrograph of Fracture Tip (500x). 


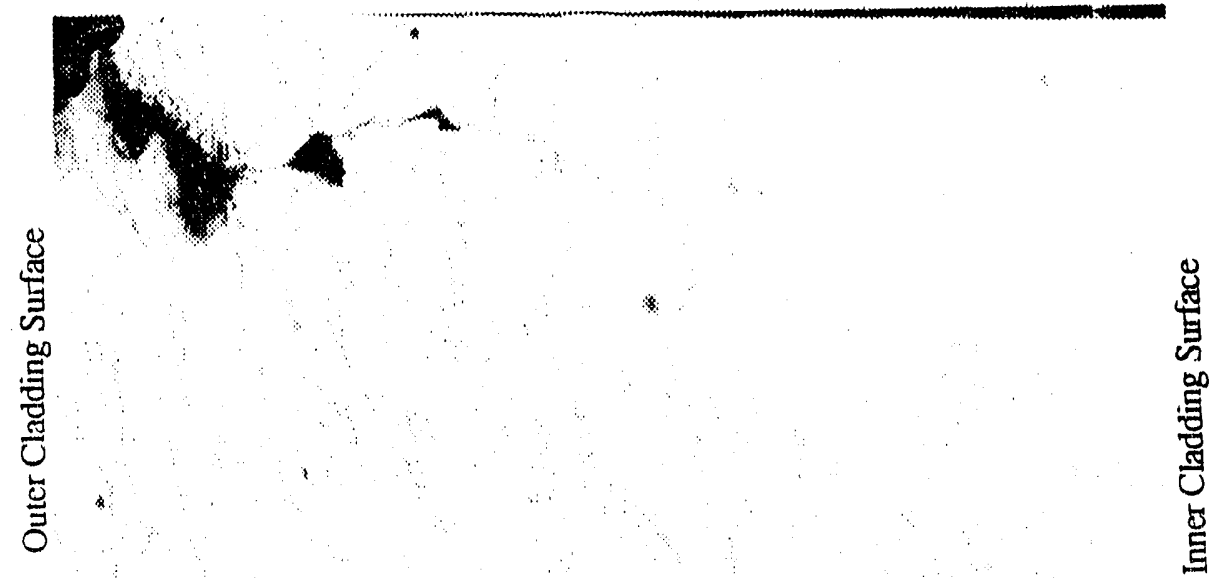

Figure 5-30c Spec.9, 23rd Grind, Top Half, Optical Micrograph of Fracture Tip (500x).

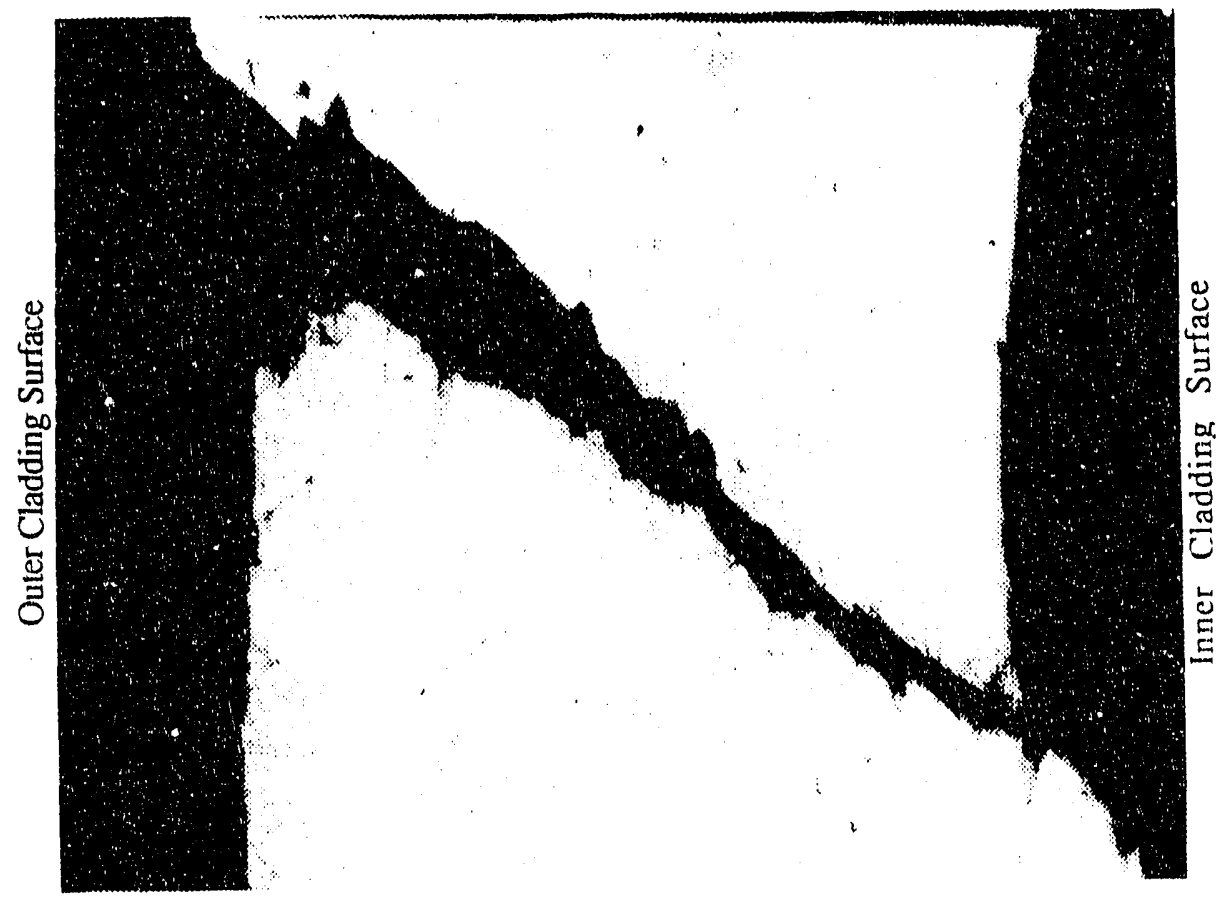

Figure 5-31 Spec.9, 24th Grind, Top Half, Optical Micrograph of Fracture (100x). 


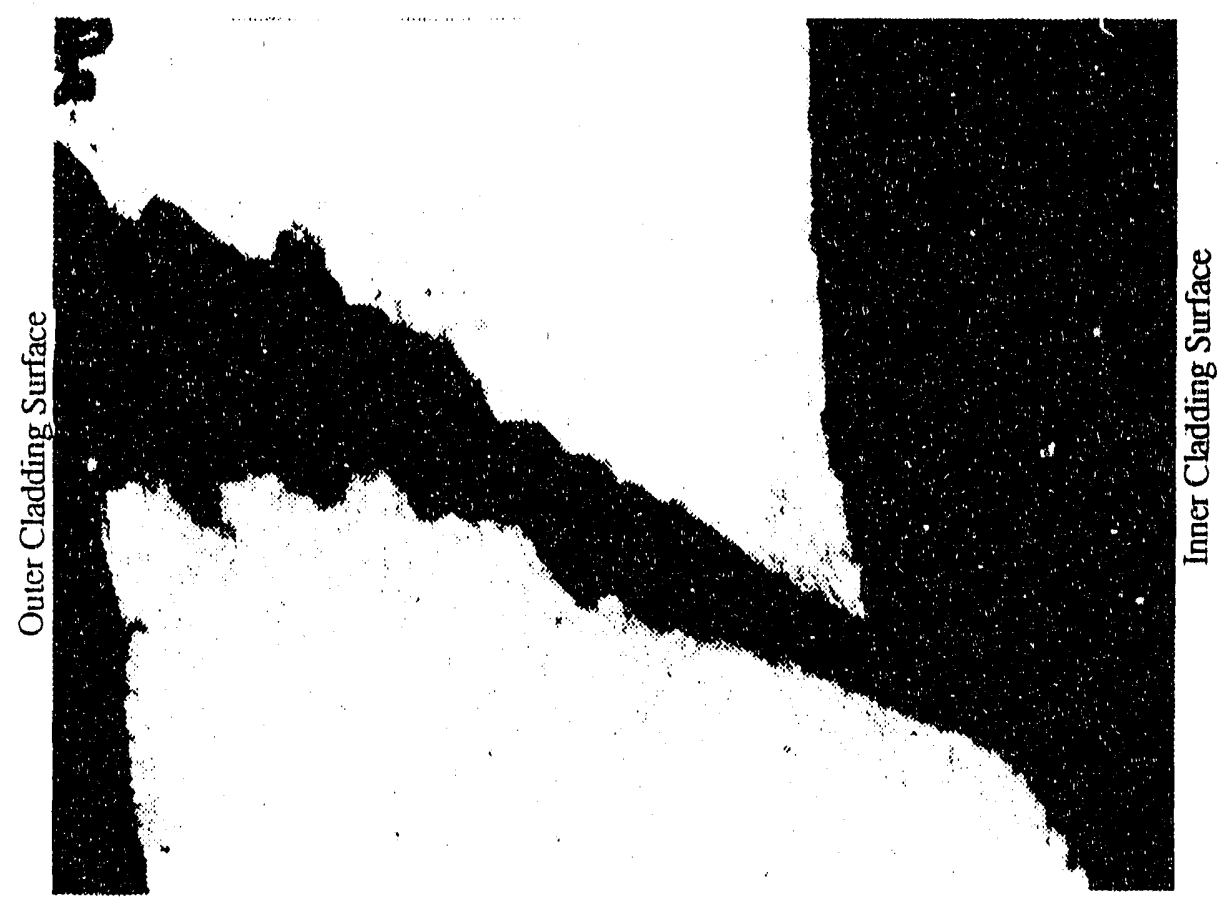

Figure 5-32 Spec.9, 25th Grind, Top Half, Optical Micrograph of Fracture (100x).

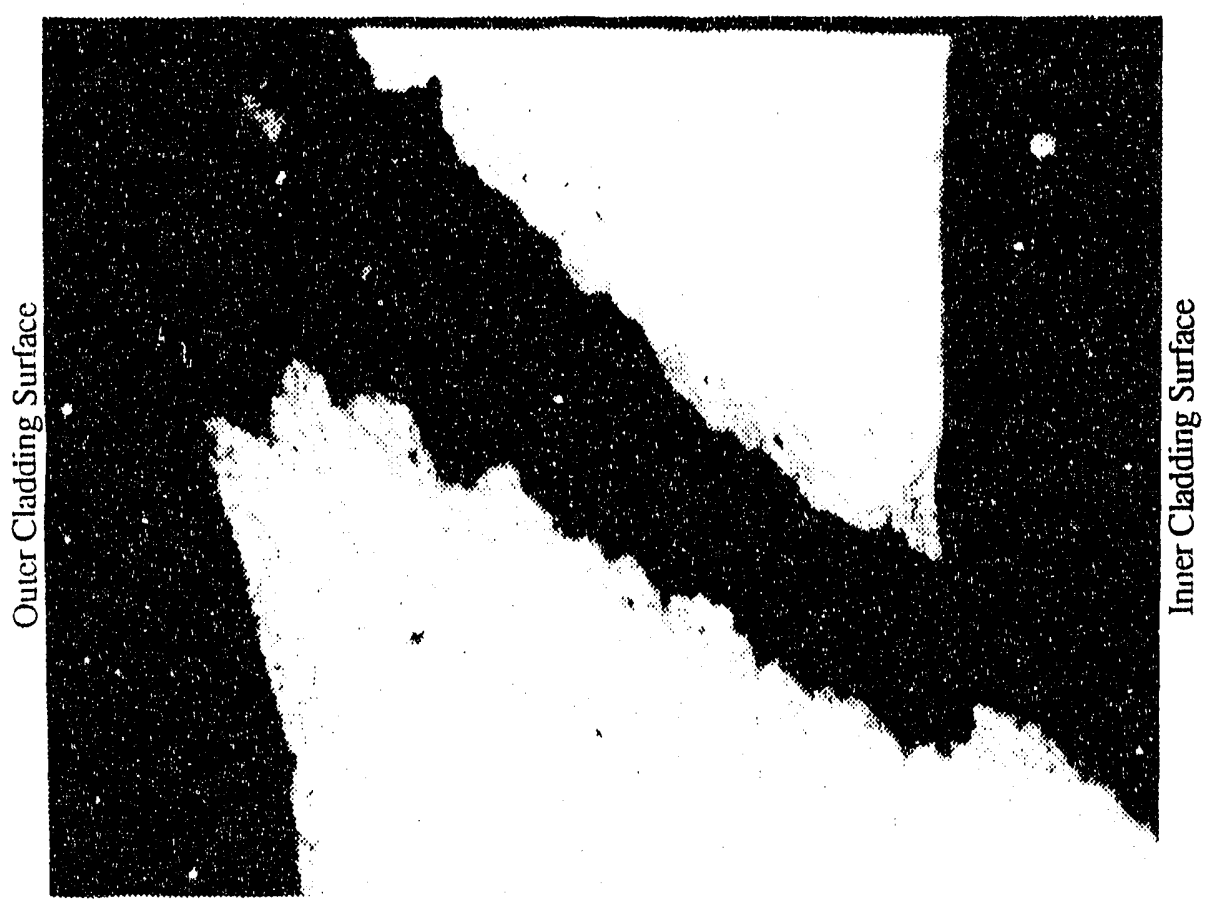

Figure 5-33a Spec.9, 26th Grind, Top Half, Left Side, Optical Micrograph of Fracture (100x). 


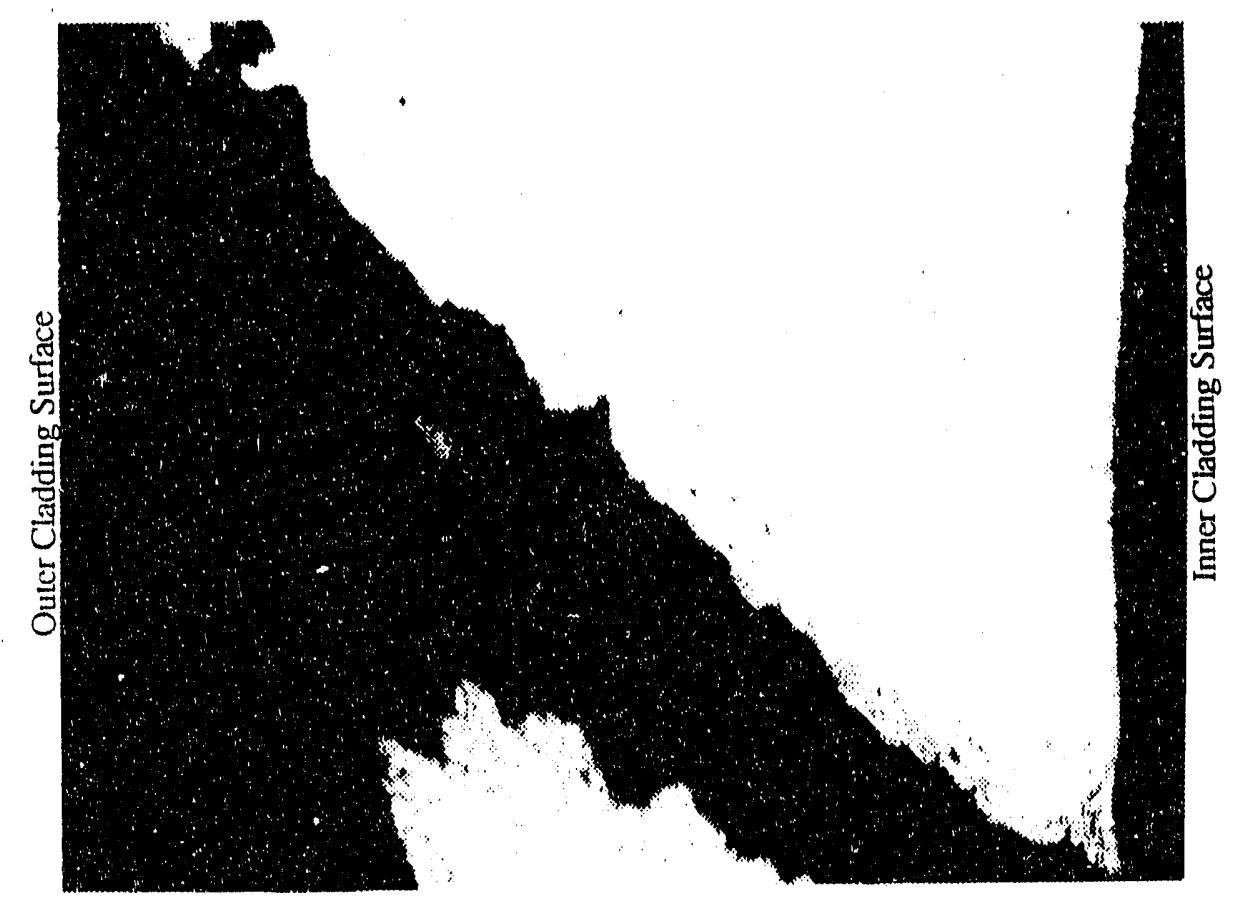

Figure 5-33b Spec.9, 26th Grind, Top Half, Right Side, Optical Micrograph of Fracture (100x).

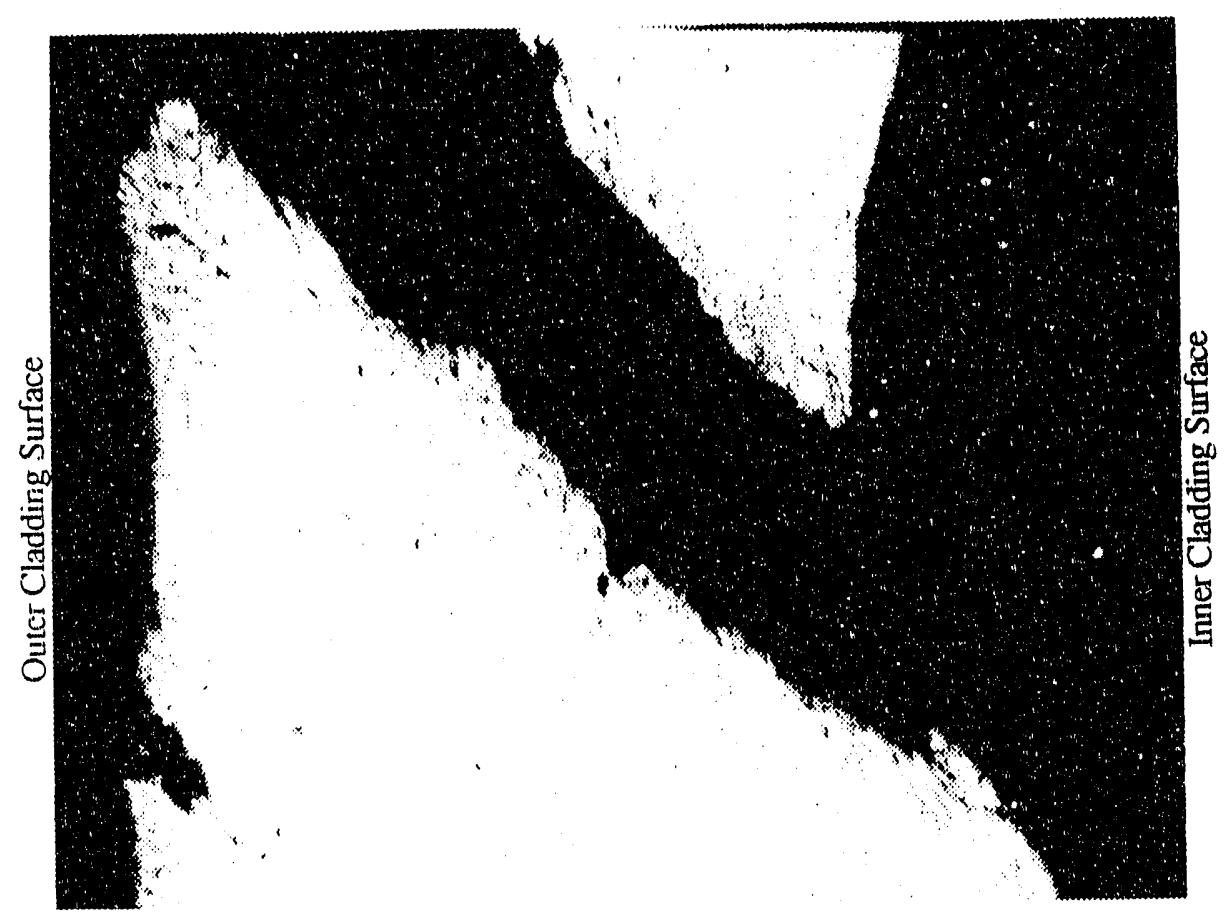

Figure 5-34a Spec.9, 27th Grind, Top Half, Left Side, Optical Micrograph of Fracture (100x). 

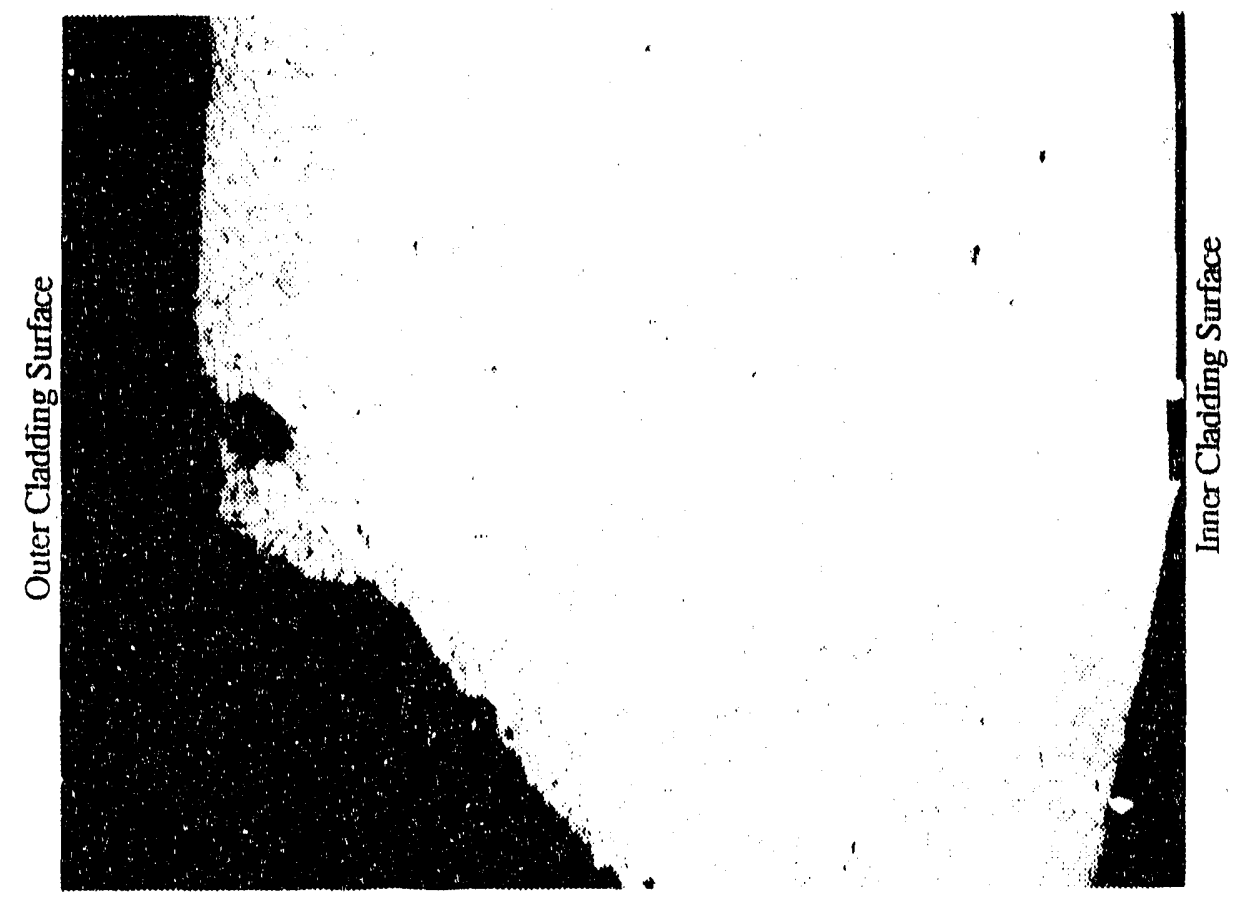

Figure 5-34b Spec.9, 27th Grind, Top Half, Right Side, Optical Micrograph of Fracture (100x).

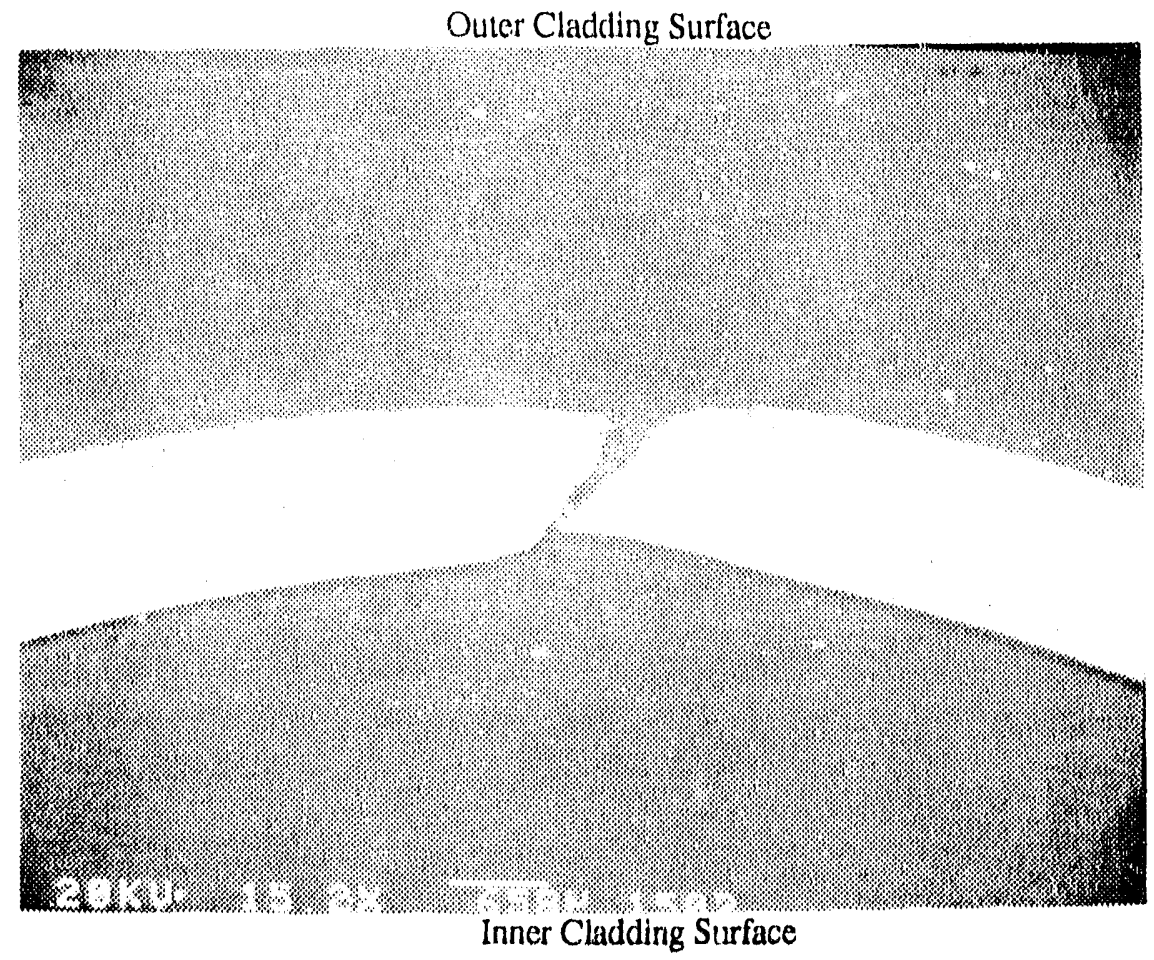

Figure 5-35a Spec.9, 25th Grind, Top Half, Low-Magnification SEM Micrograph (BSE, 15.2x). 


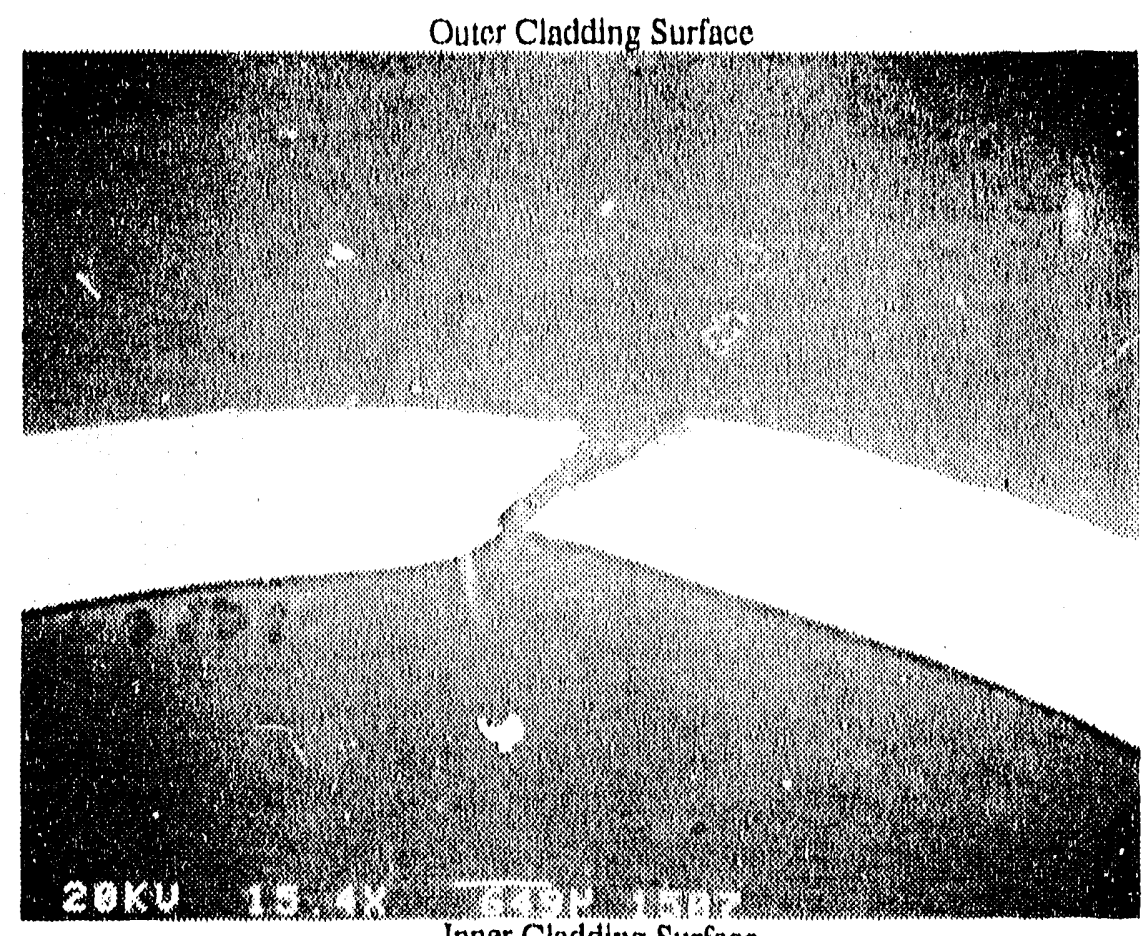

Inner Cladding Surface

Figure 5.35b Spec.9, 26th Grind, Top Half, Low-Magnification SEM Micrograph (BSE, $15.4 \mathrm{x})$.

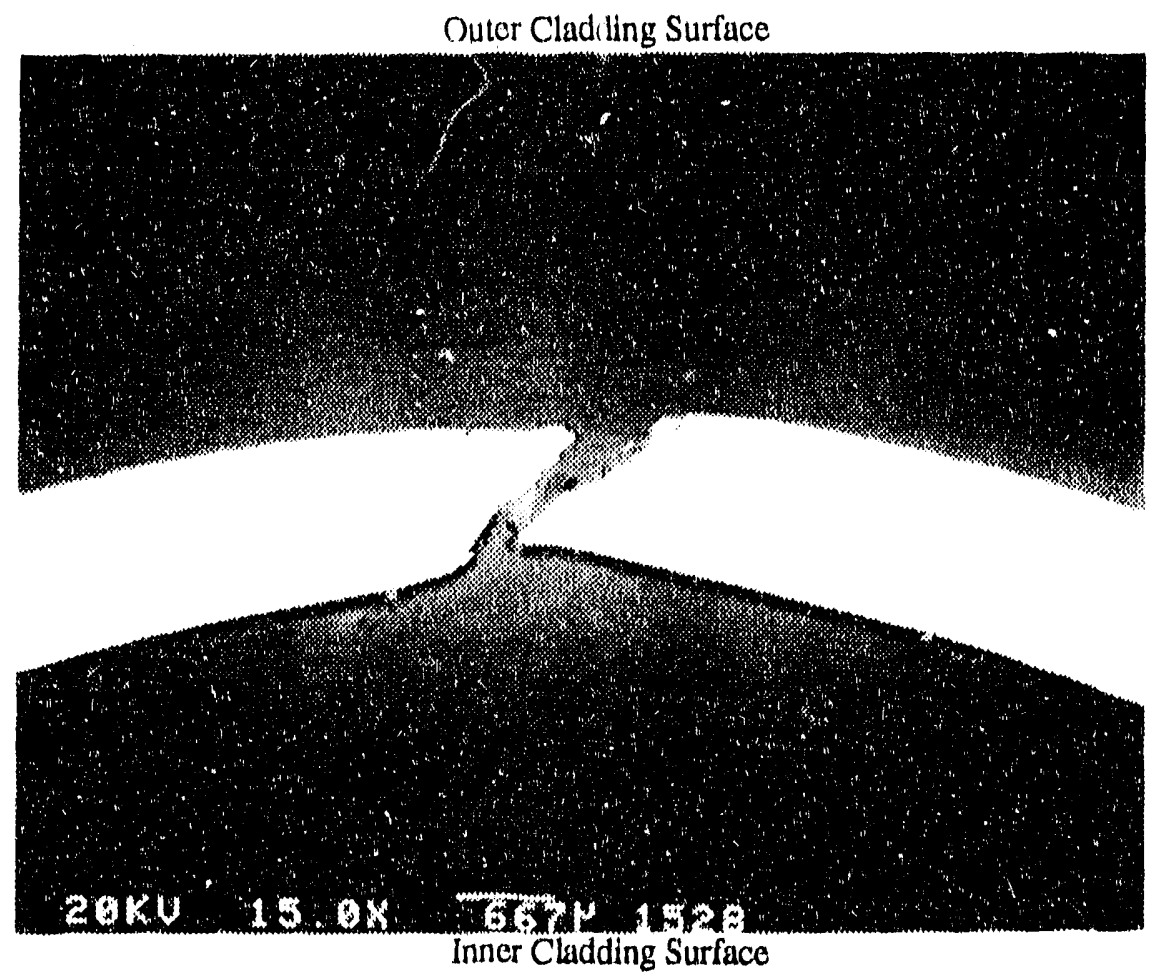

Figure 5-35c Spec,9, 27th Grind, Top Half, Low-Magnification SEM Micrograph (BSE, $15 \mathrm{x})$. 
Outer Claddling Surfuce

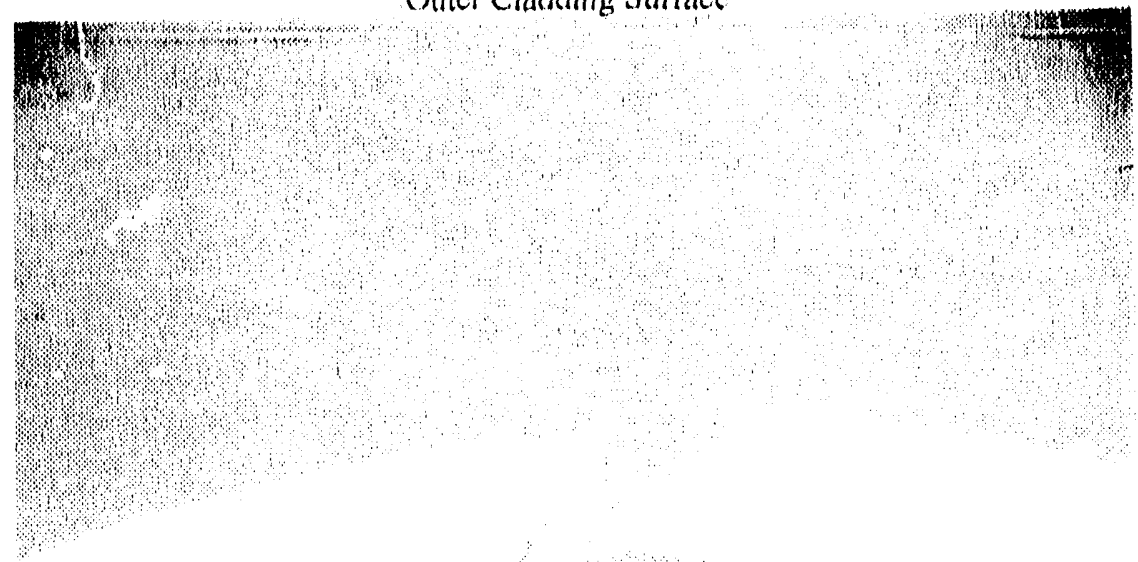

Inner Cladding Surface

Figure 5-35d Spec.9, 29th Grind, Top Half, Low-Magnification SEM Micrograph (BSE, 14.9x).

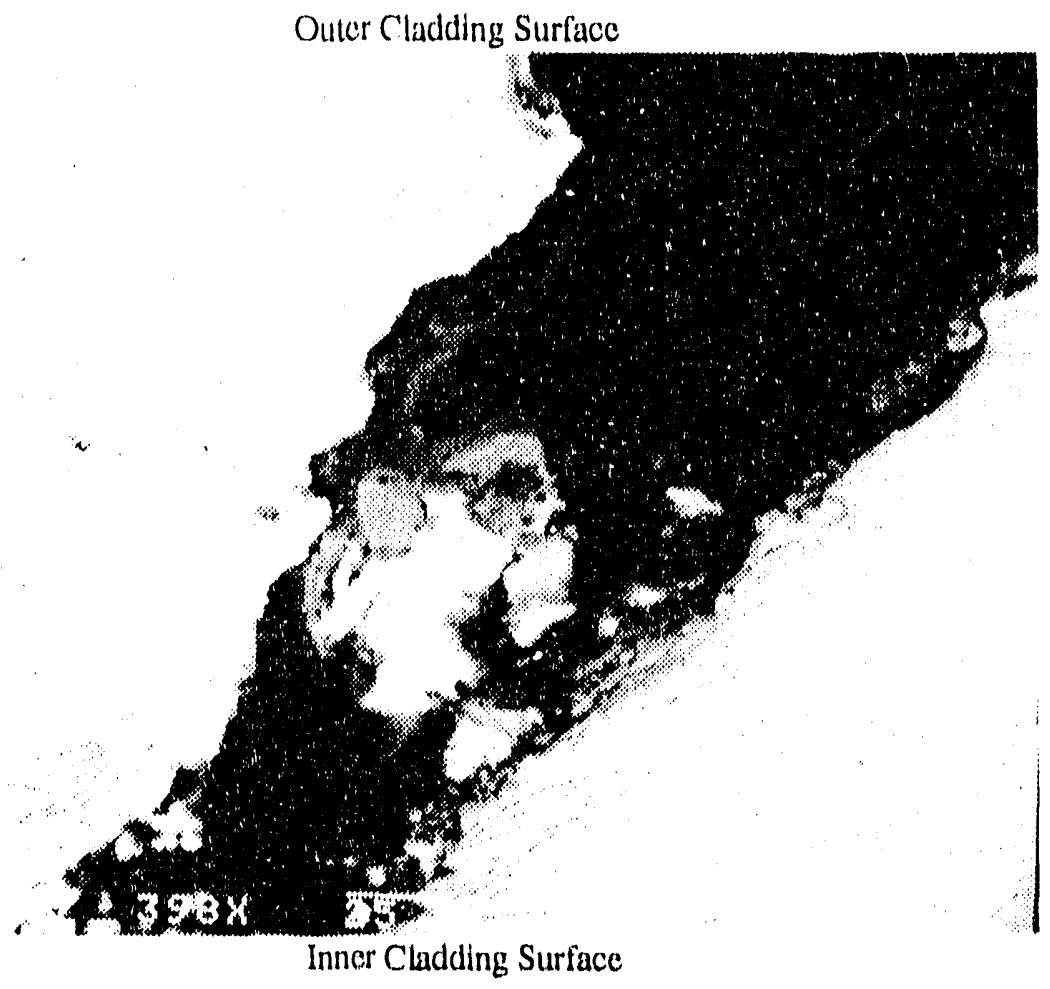

Figure 5-36a Spec.9, 25th Grind, Top Half, Fracture Surface Near I.D. (BSE, 398x). 


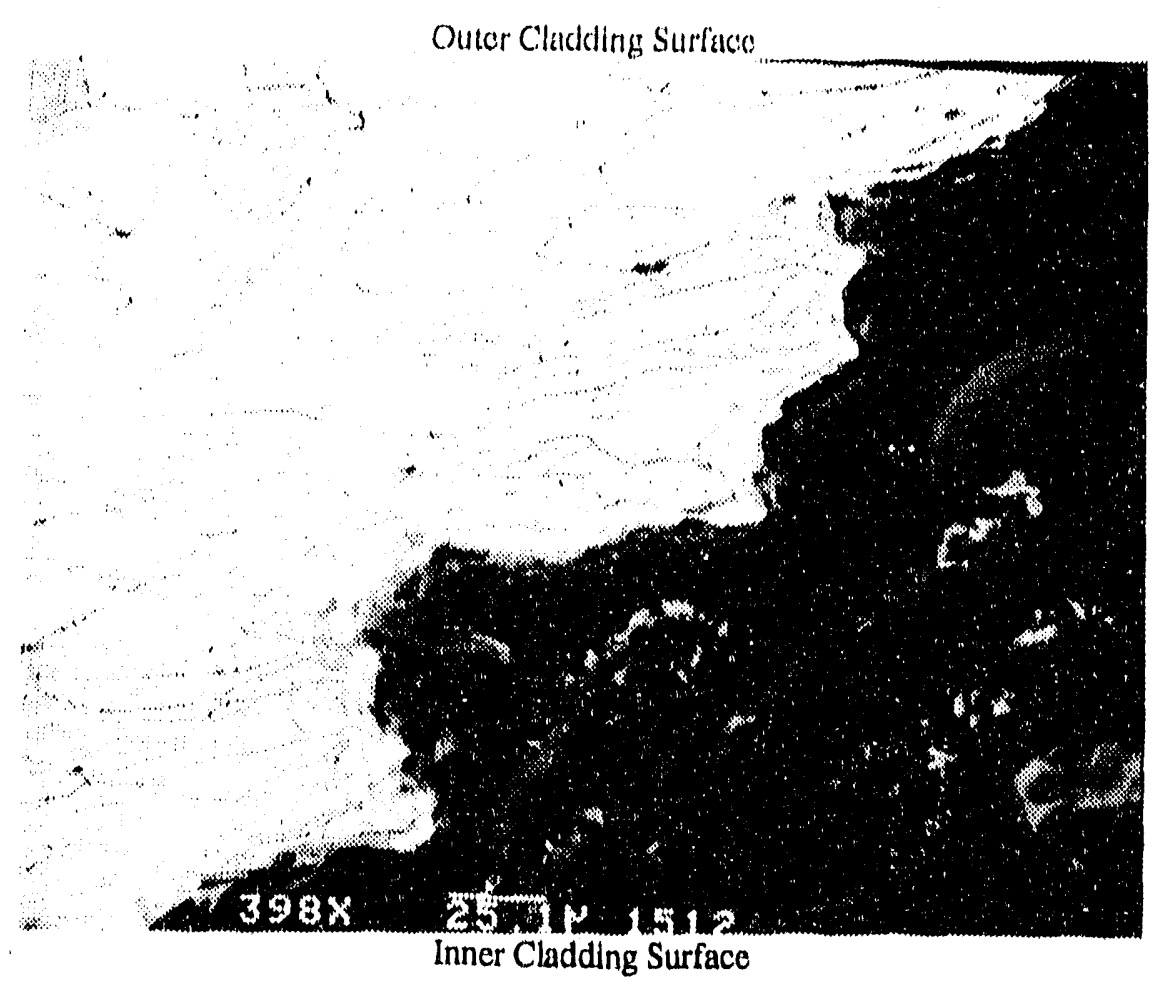

Figure 5-36b Spec.9, 26th Grind, Top Half, Fracture Surface Near I.D. (BSE, 398x).

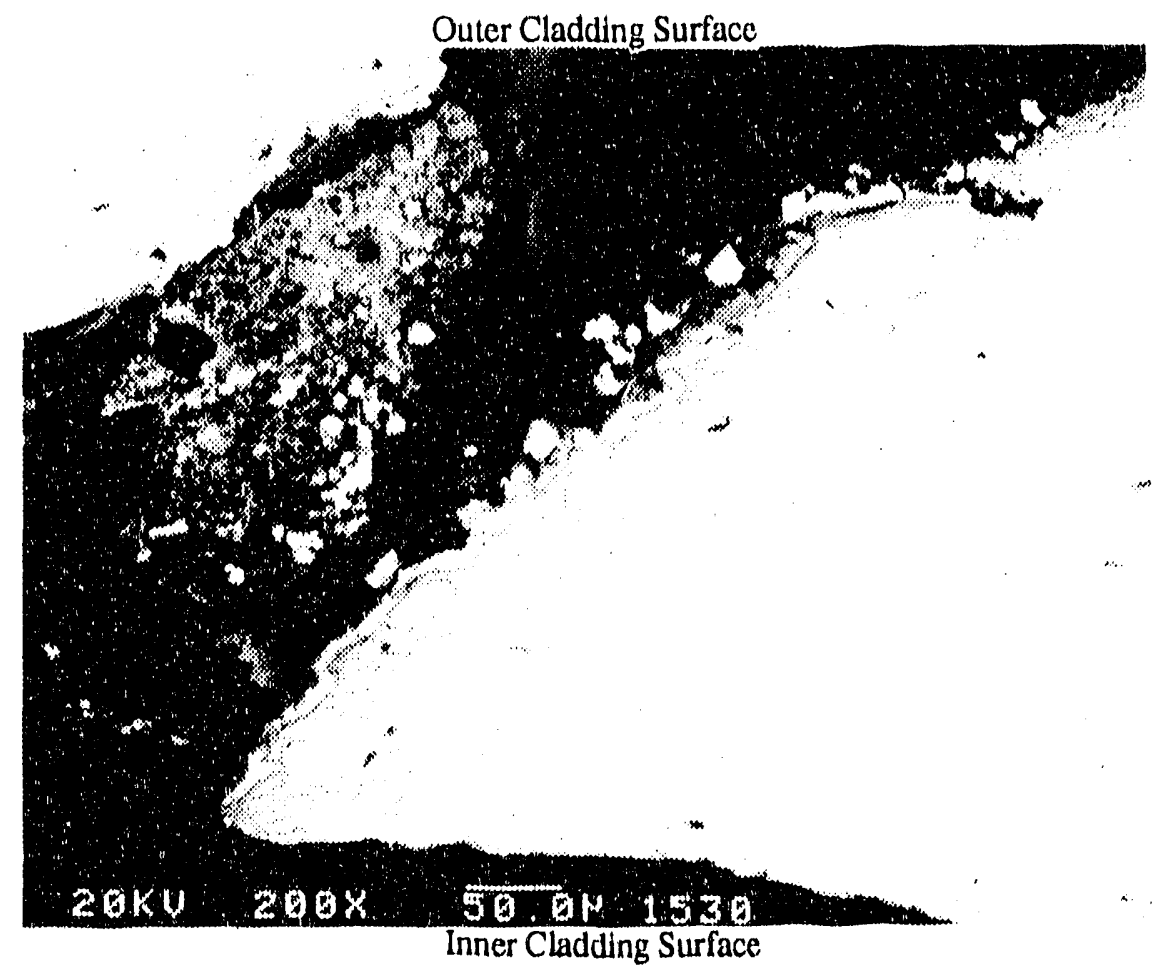

Figure 5-36c Spec.9, 27th Grind, Top Half, Fracture Surface Near I.D. (BSE, 200x). 


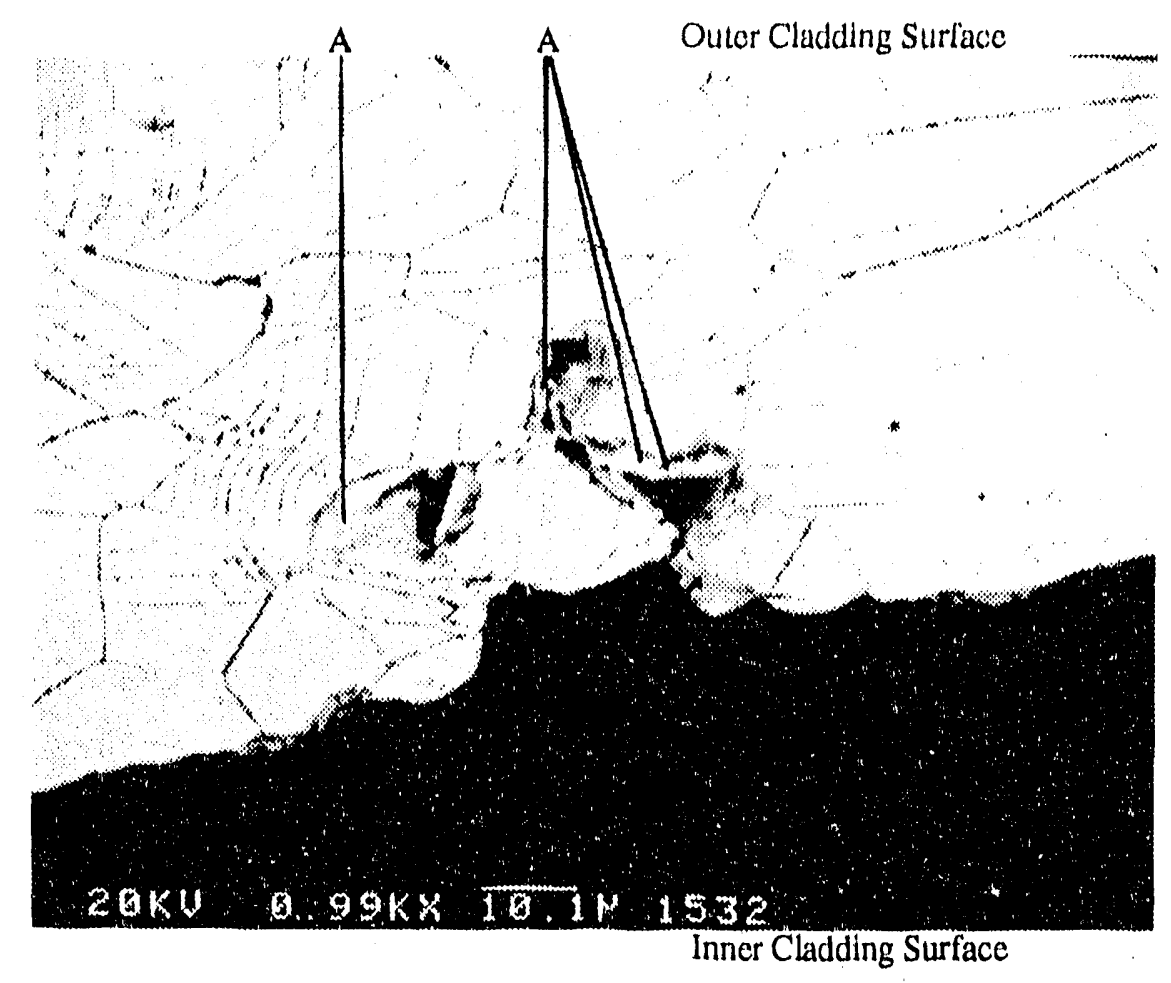

Figure 5-37a Spec.9, 28th Grind, Top Half, Inner Cladding Surface (BSE, 990x).

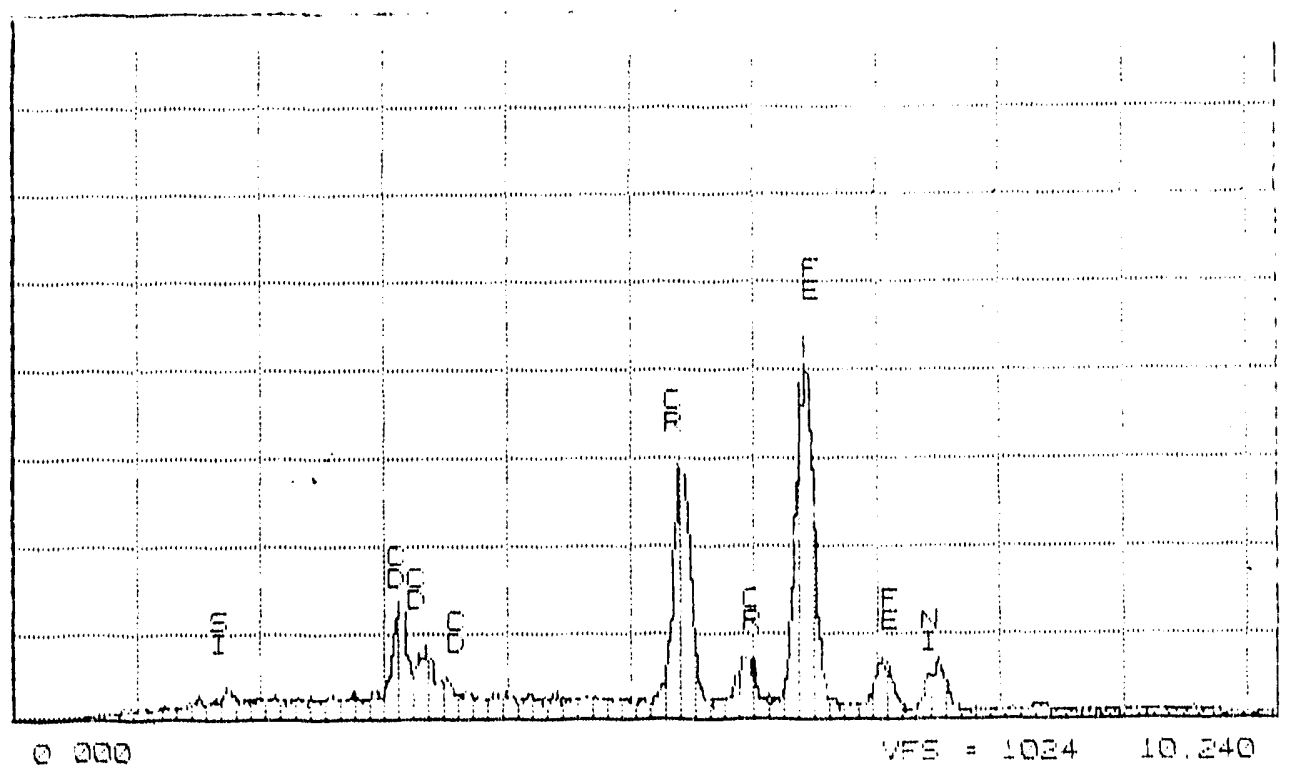

Figure 5-37b Spec.9, 28th ưrind, Top Half, EDS Spectrum for Spot "A" on Figure 5$37 \mathrm{a}$. 


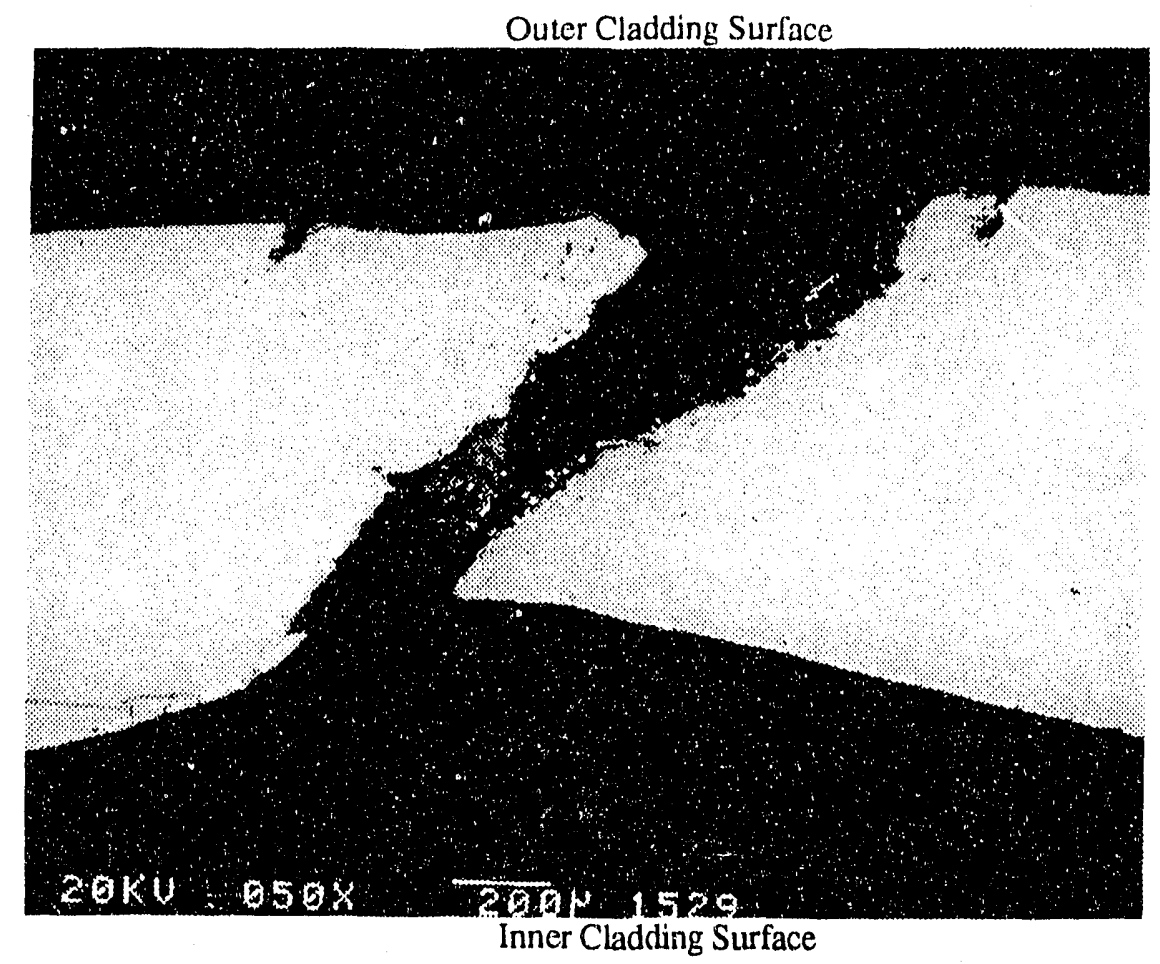

Figure 5-38 Spec.9, 27th Grind, Top Half, Low-Magnification SEM Micrograph (BSE, 50x).

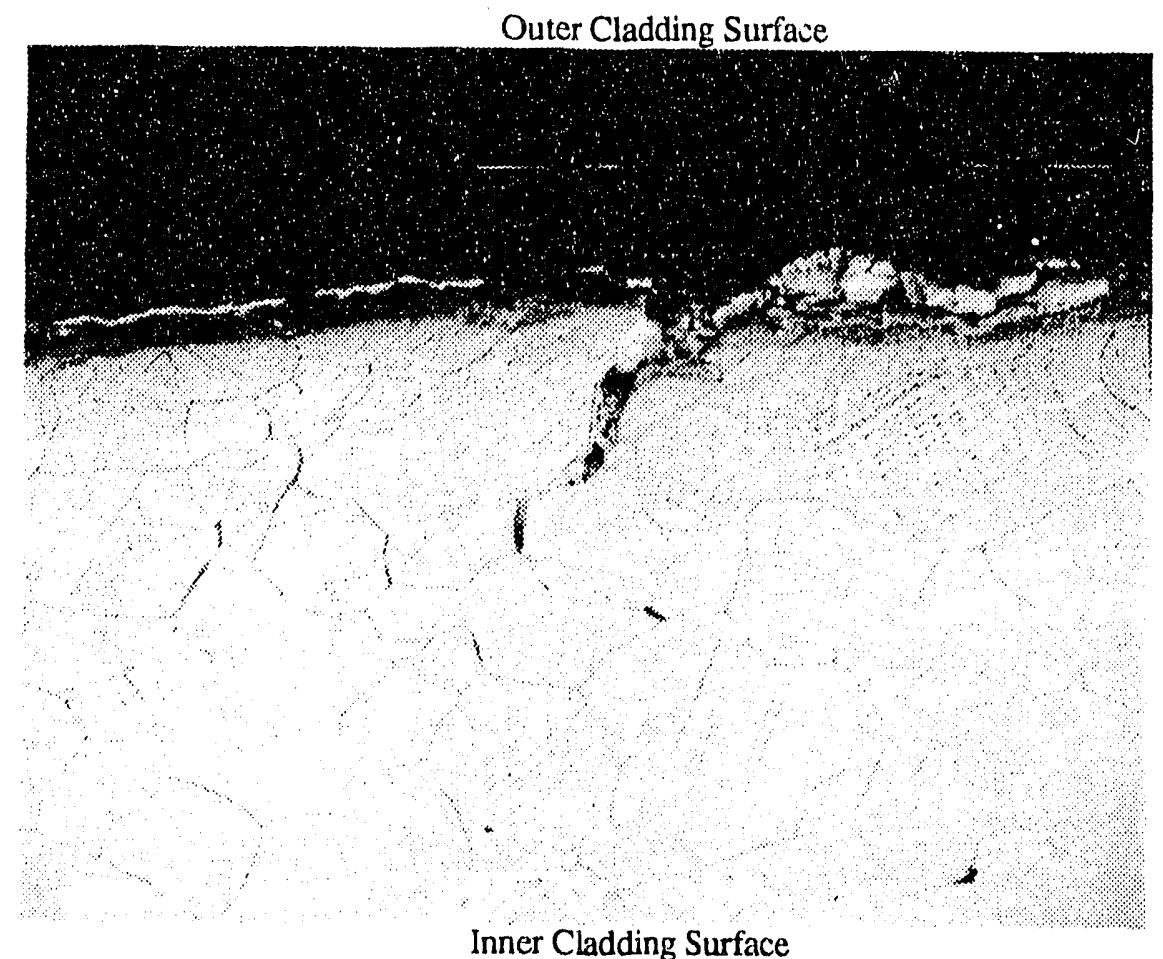

Figure 5-39 Spec.9, 29th Grind, Top Half, Outer Cladding Surface (BSE, 394x). 


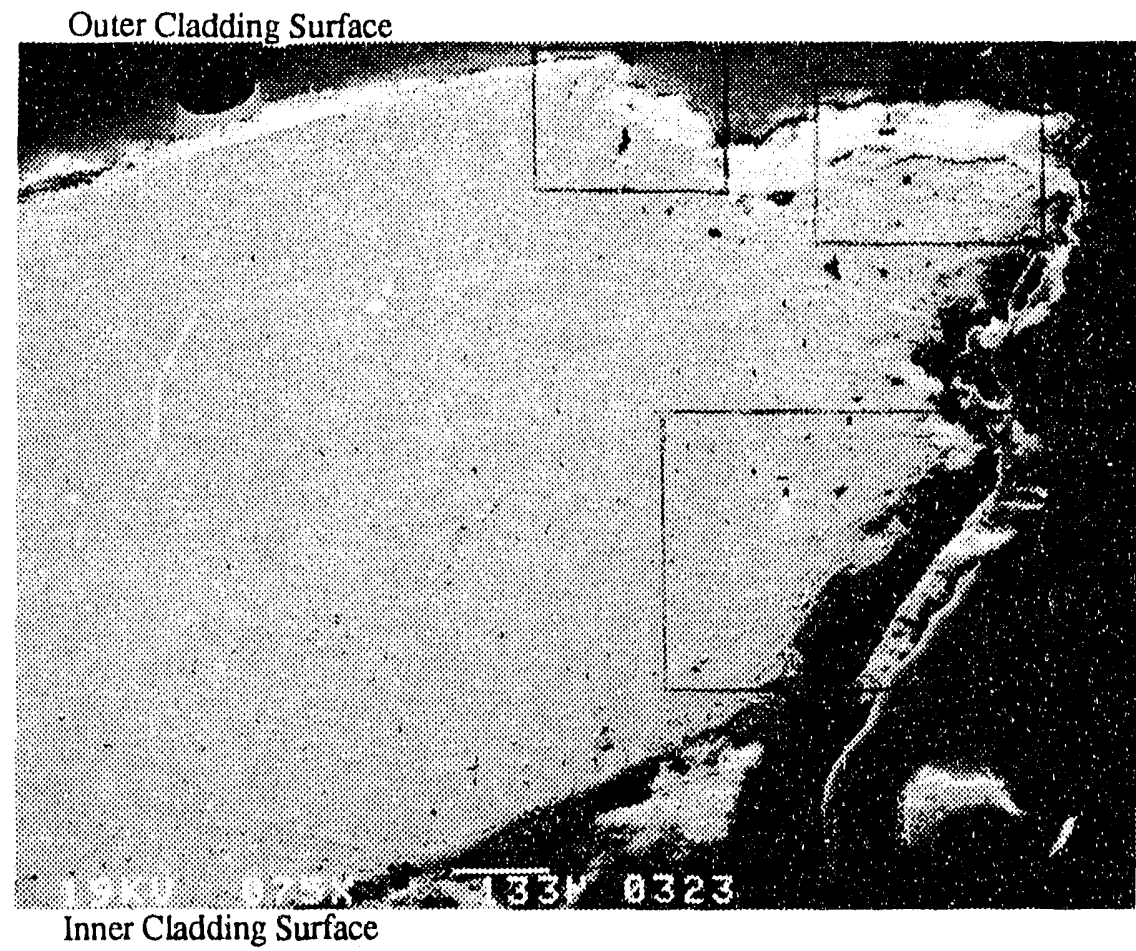

Figure 5-40a Spec.9, 30th Grind, Top Half, Left Side (BSE, 75x).

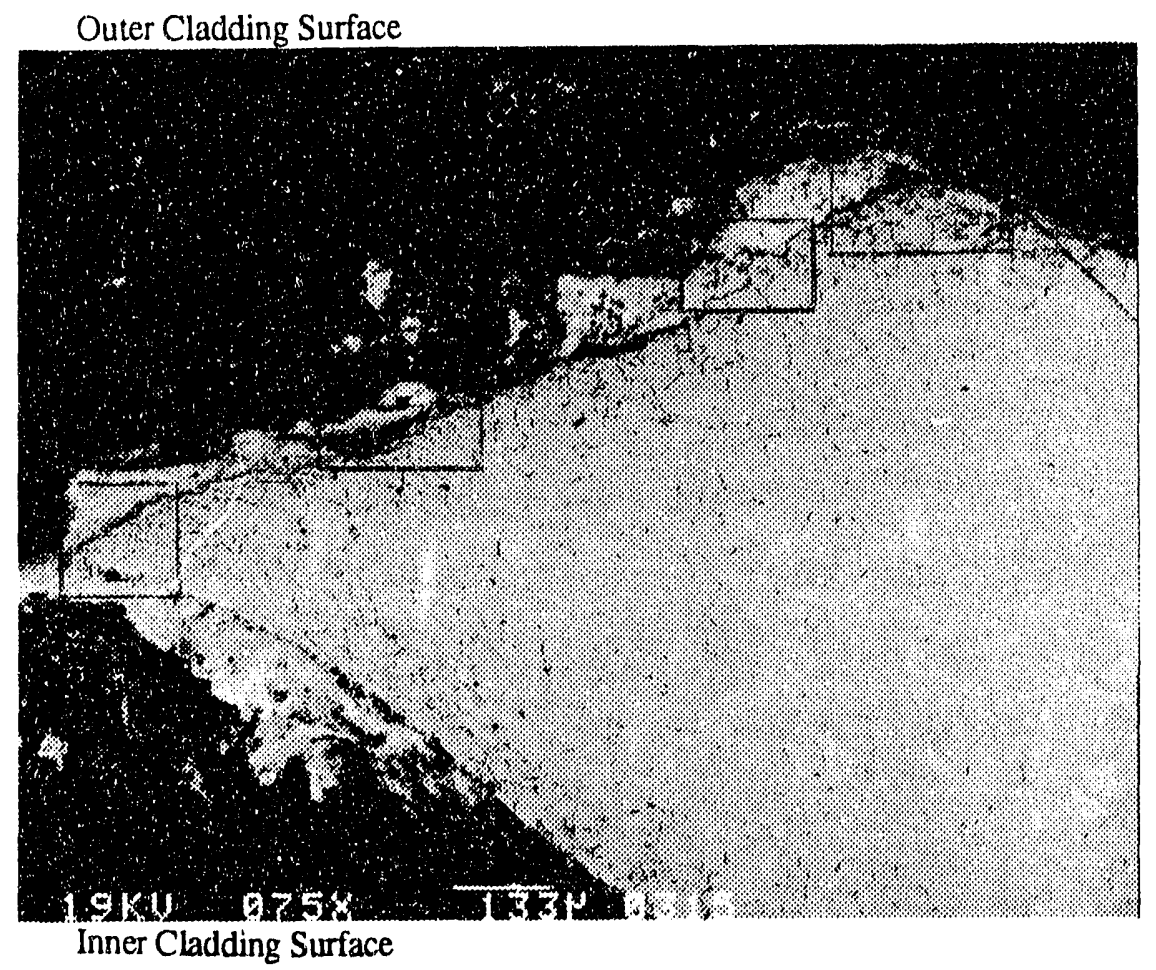

Figure 5-40b Spec.9, 30th Grind, Top Half, Right Side (BSE, 75x). 


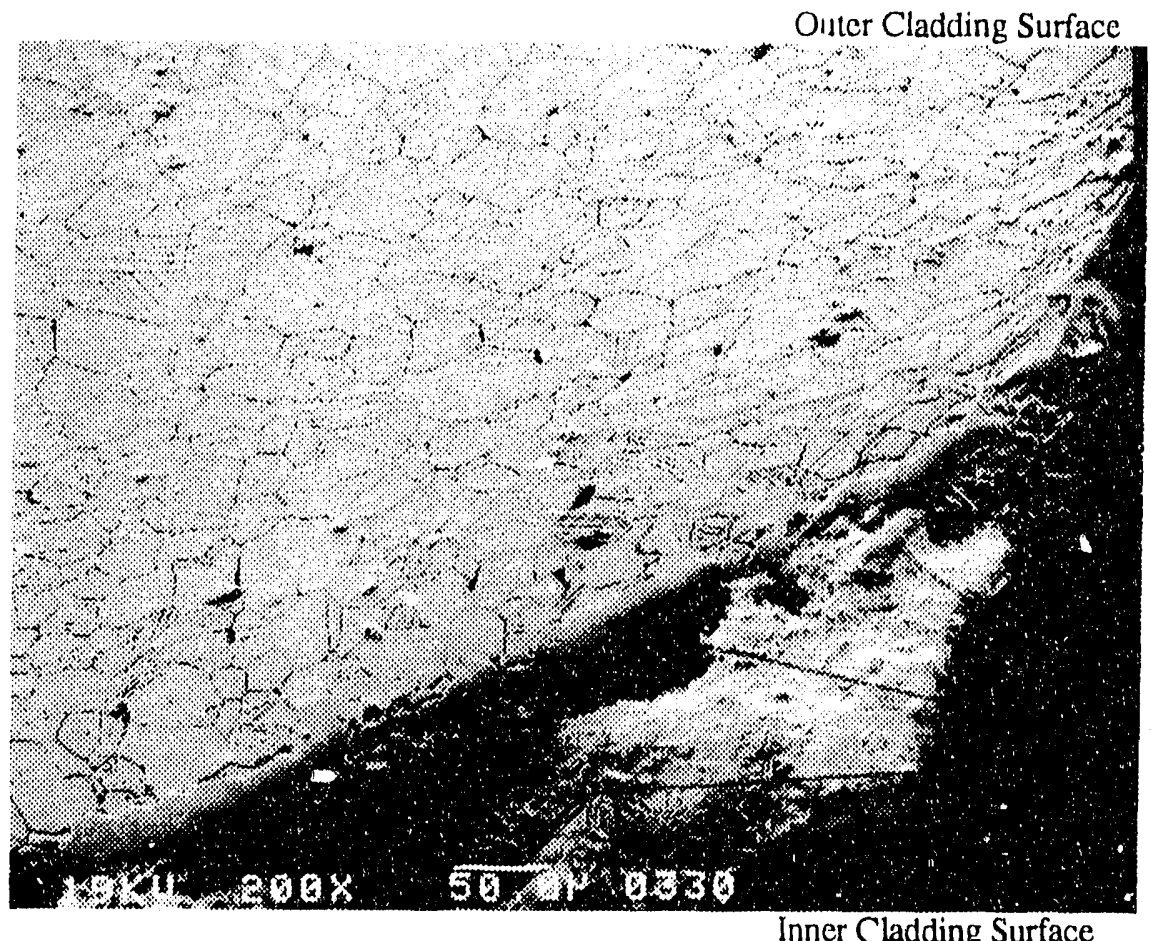

Figure 5-41a Spec.9, 30th Grind, Top Half, Left Side, Fracture Surface Near I.D. (BSE, 200x).

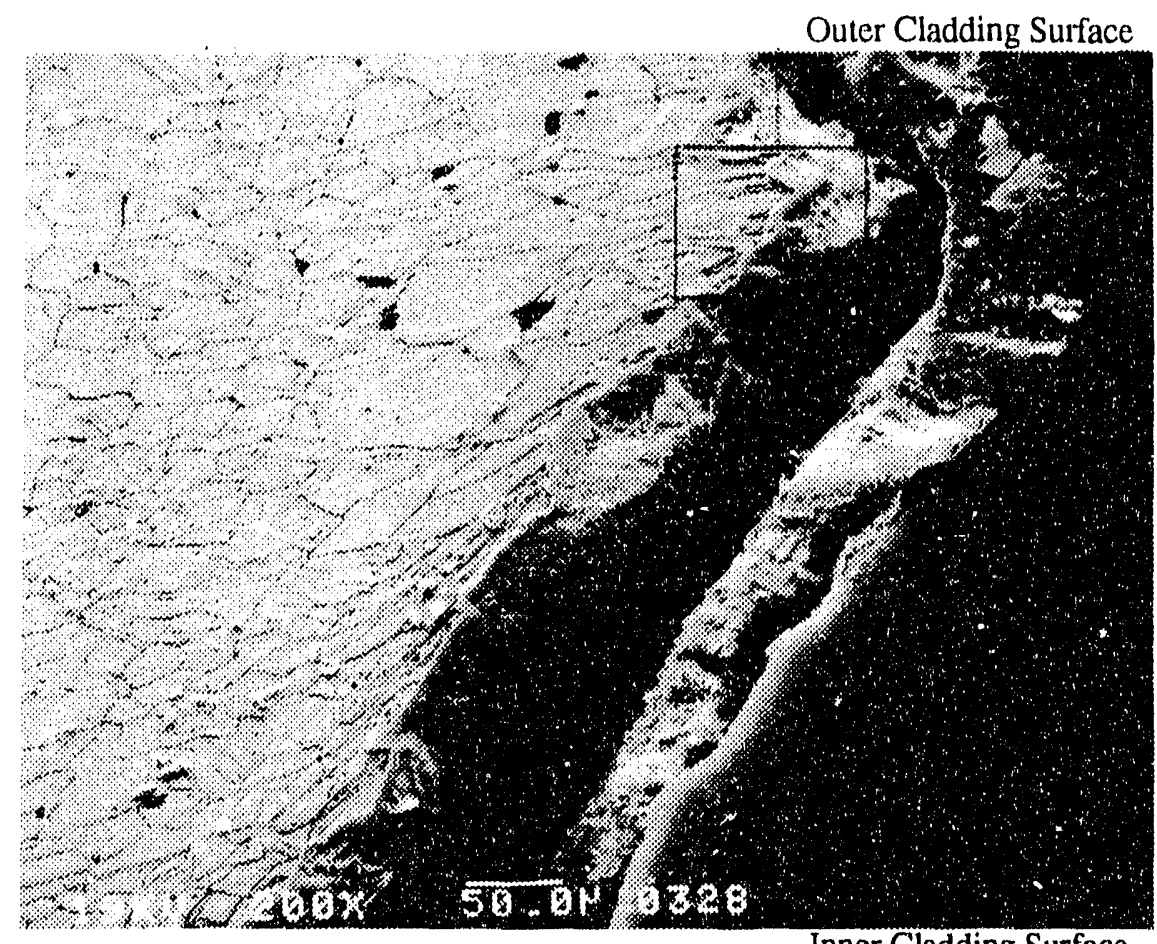

Inner Cladding Surface

Figure 5-41b Spec.9, 30th Grind, Top Half, Left Side, Fracture Surface $\approx 1 / 3$ throughwall (BSE, 200x). 


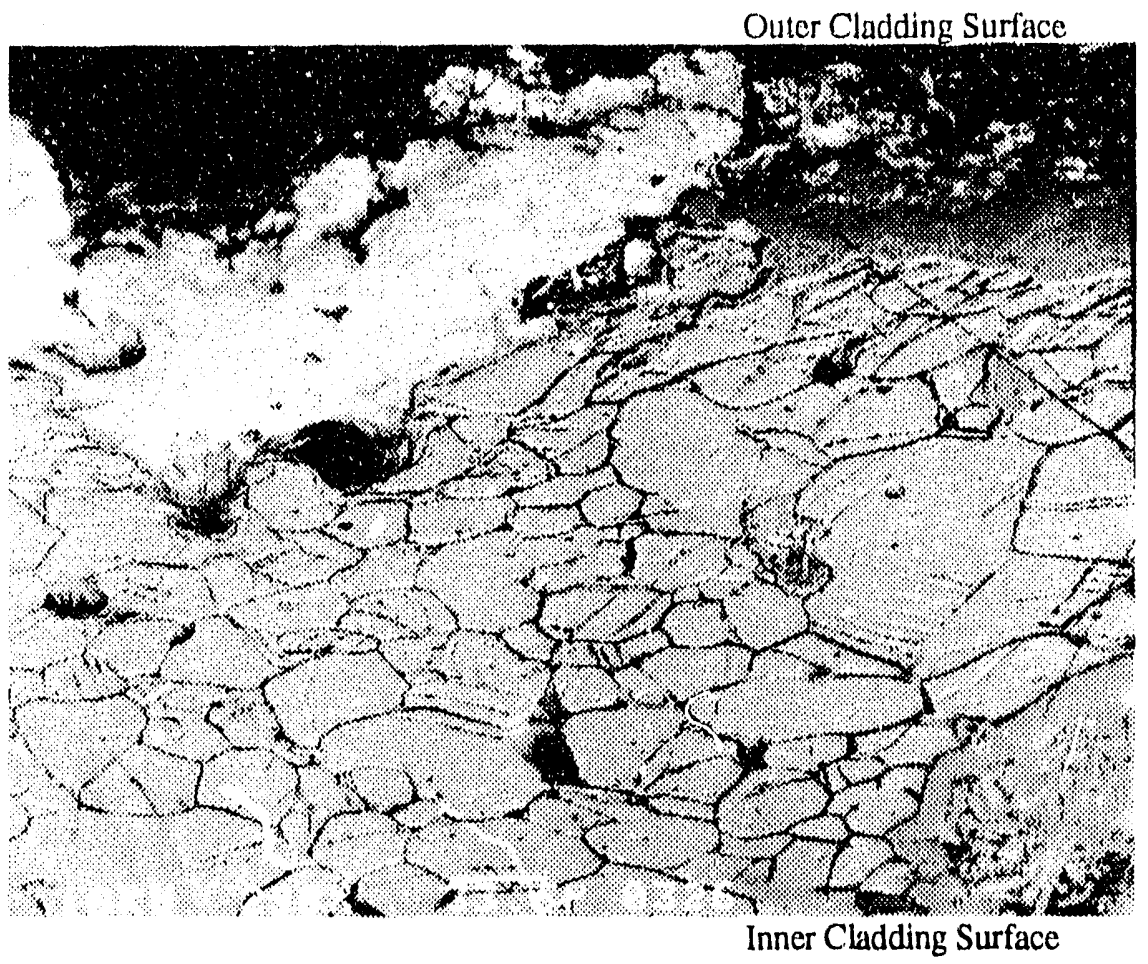

Figure 5-41c Spec.9, 30th Grind, Top Half, Left Side, Fracture Surface $\approx 3 / 4$ throughwall (BSE, 298x).

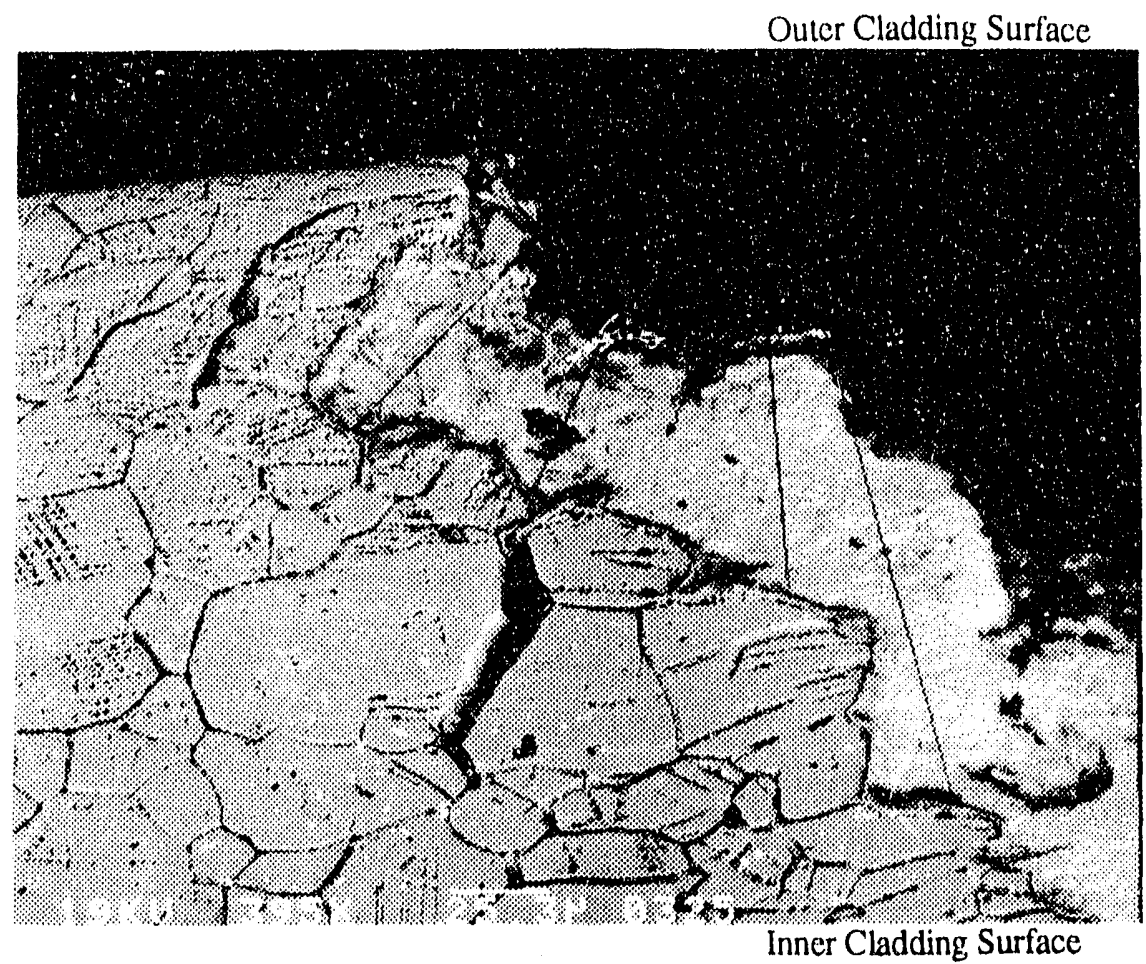

Figure 5-41d Spec.9, 30th Grind, Top Half, Left Side, Fracture Surface at O.D. (BSE, 395x). 


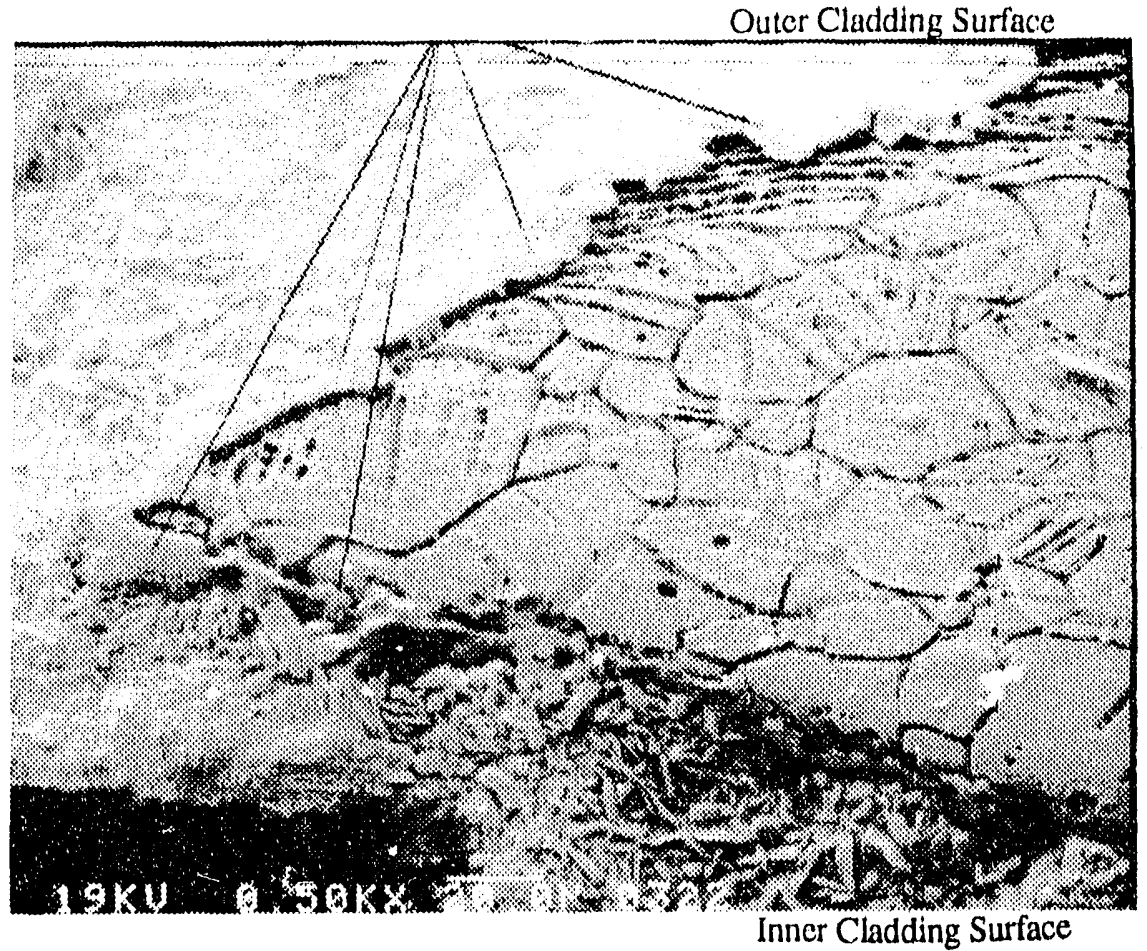

Figure 5-42a Spec.9, 30th Grind, Top Half, Right Side, Fracture Surface Near I.D. (BSE, 500x).

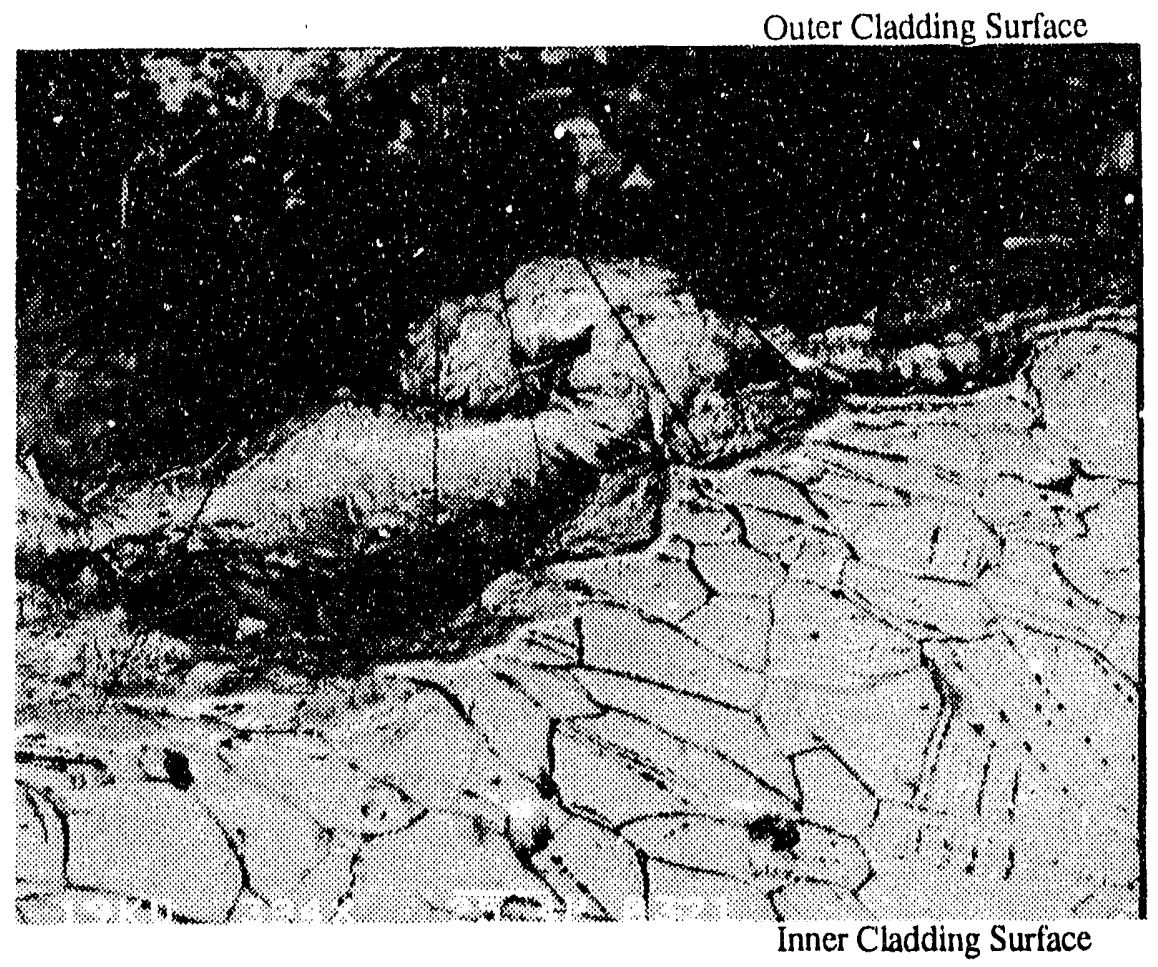

Figure 5-42b Spec.9, 30th Grind, Top Half, Right Side, Fracture Surface $\approx 1 / 3$ throughwall (BSE, 394x). 


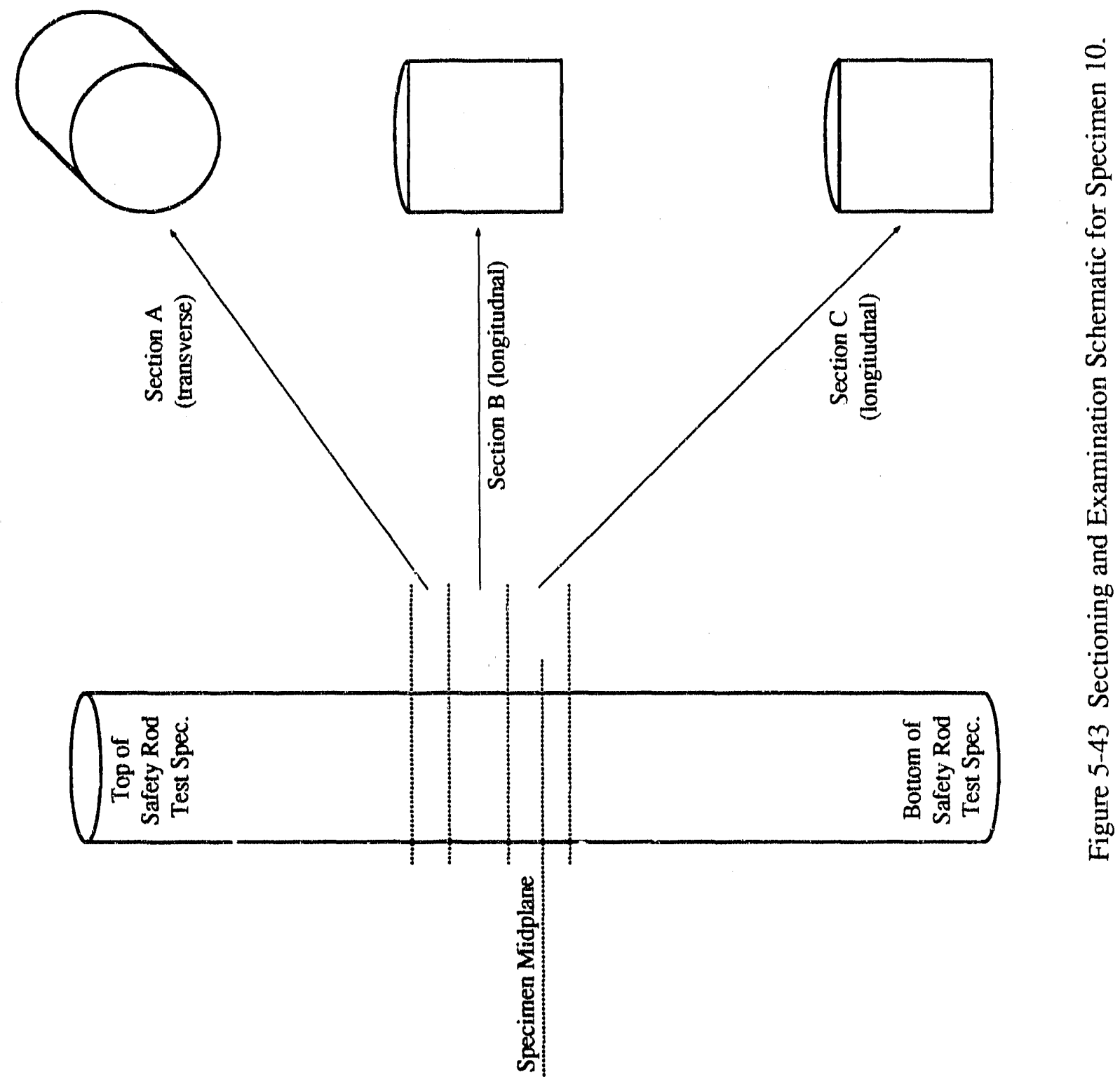




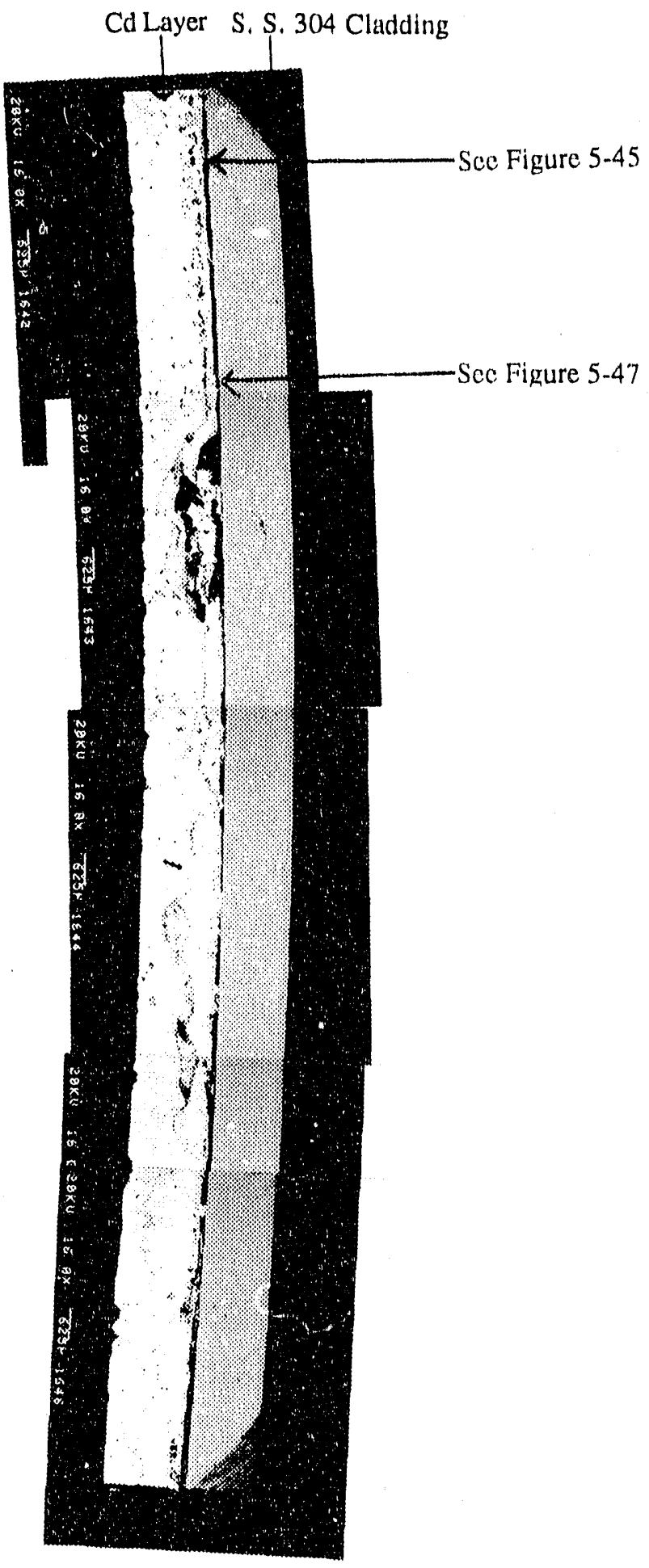

Figure 5-44 Spec.10, Section B, Montage (BSE). 


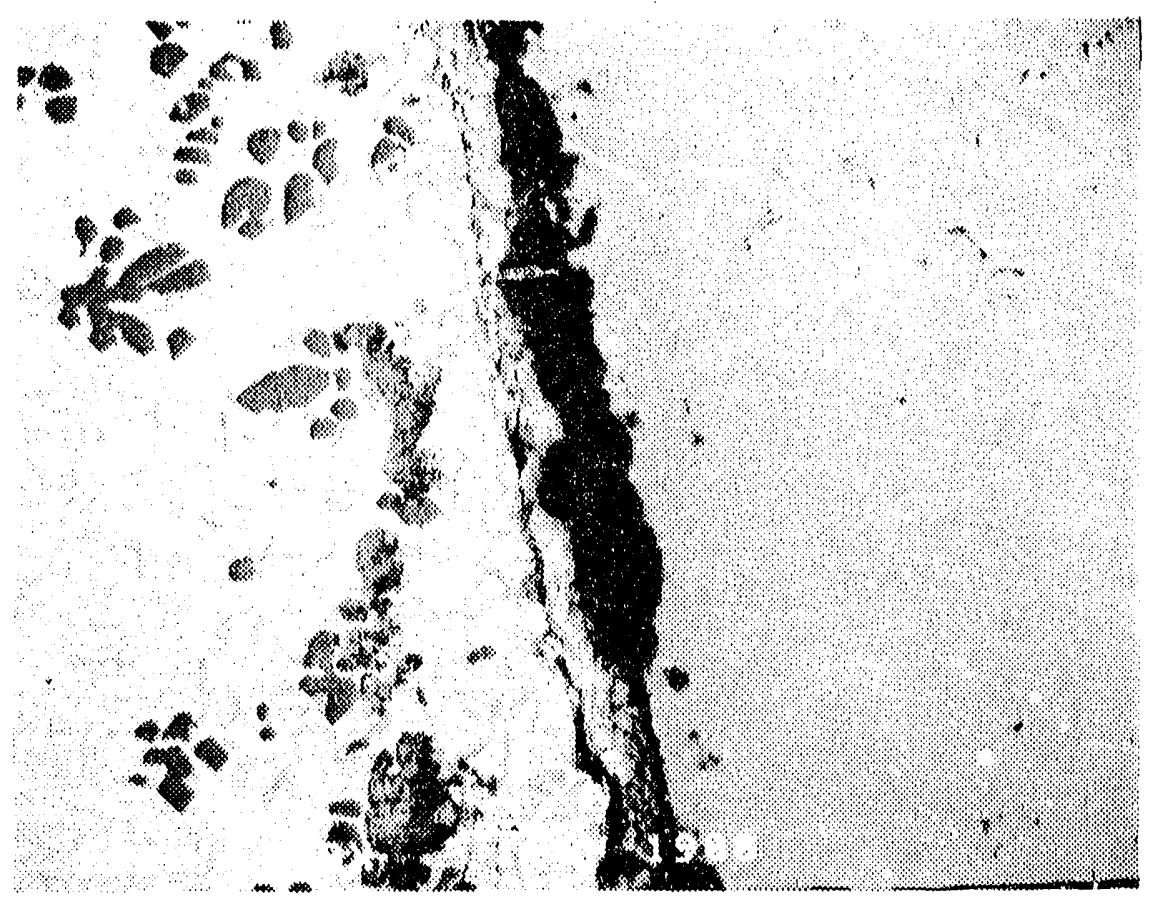

Figure 5-45a Spec.10, Section B, Area Identified as Possible Cladding Attack on Radiograph (BSE, 100x).

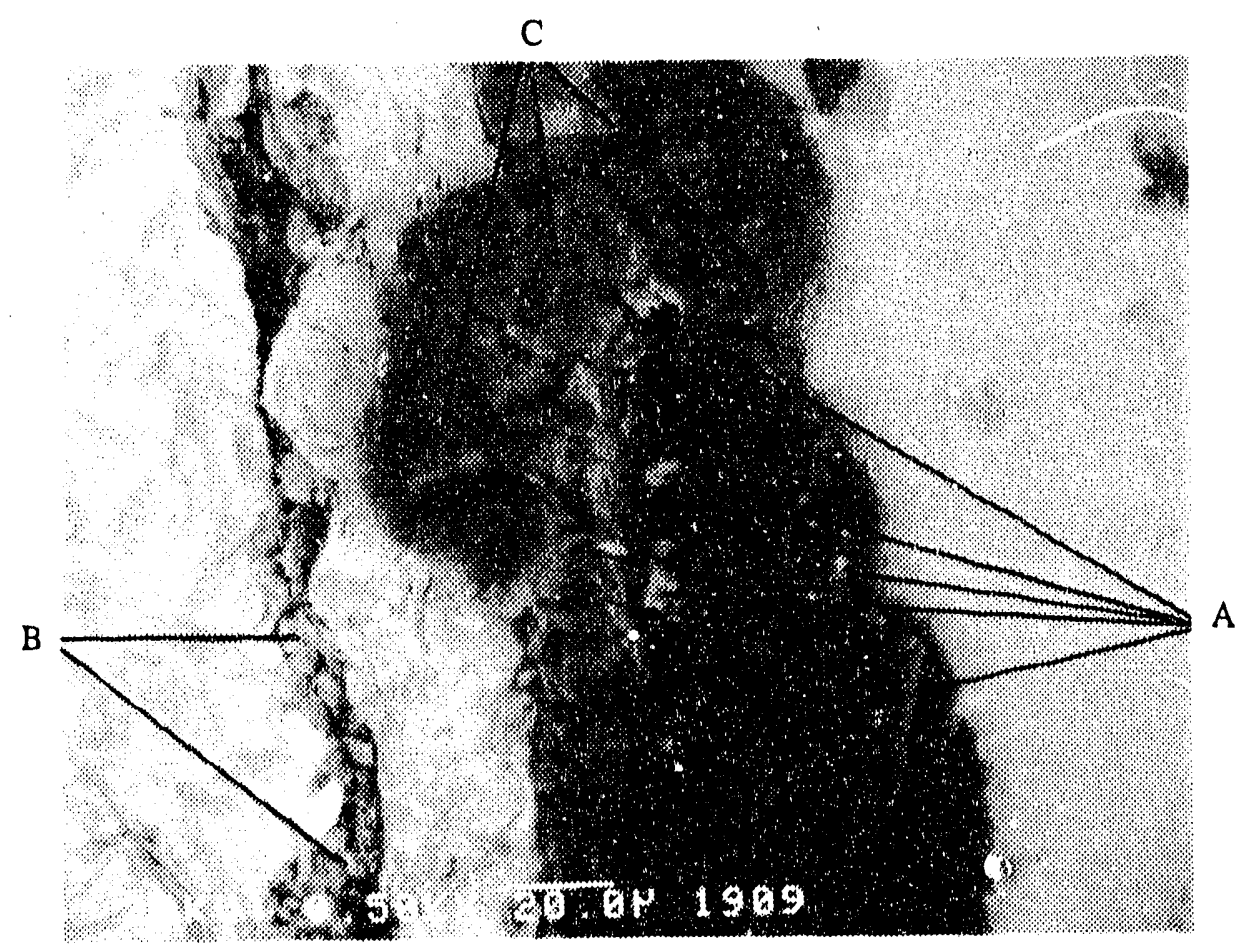

Figure 5-45b Spec.10, Section B, Area Identified as Possible Cladding Attack on Radiograph (BSE, 500x). 


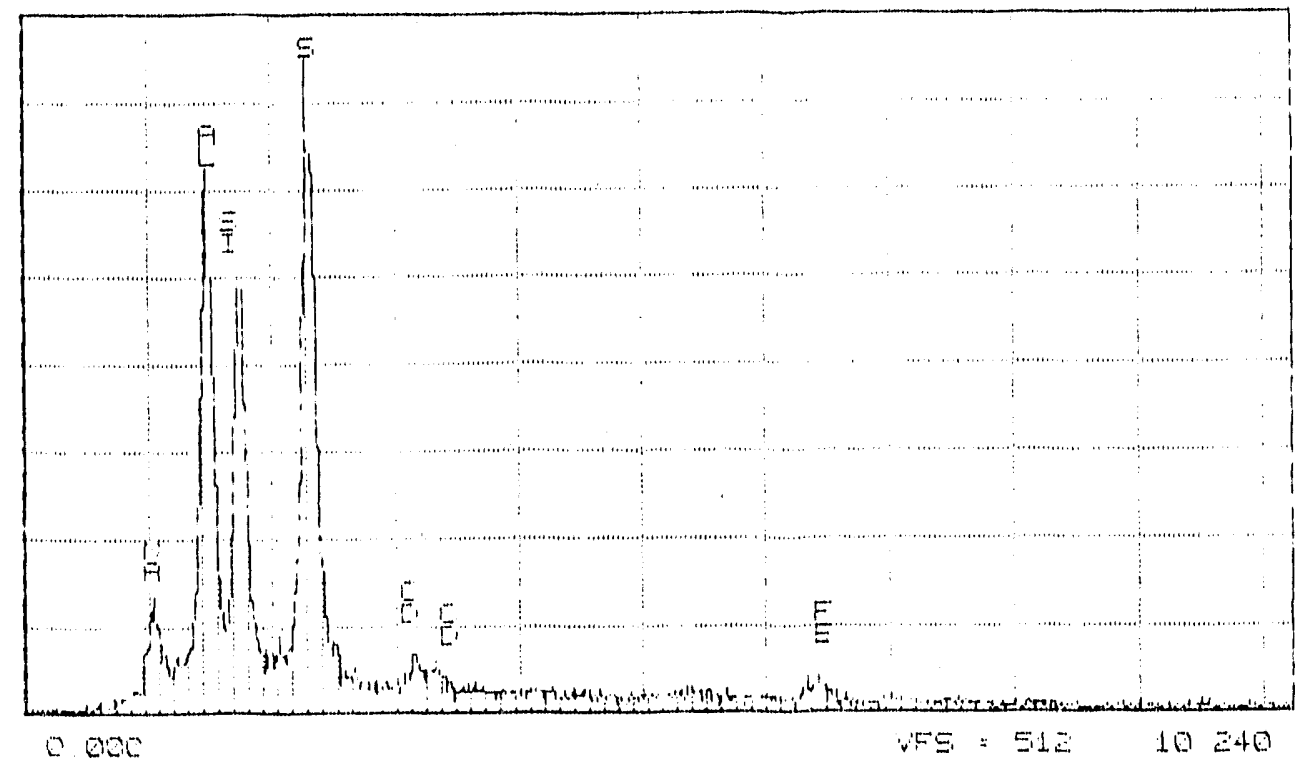

Figure 5-46a Spec.10, Section B, EDS Spectrum for Spot "A" on Figure 4-45b.

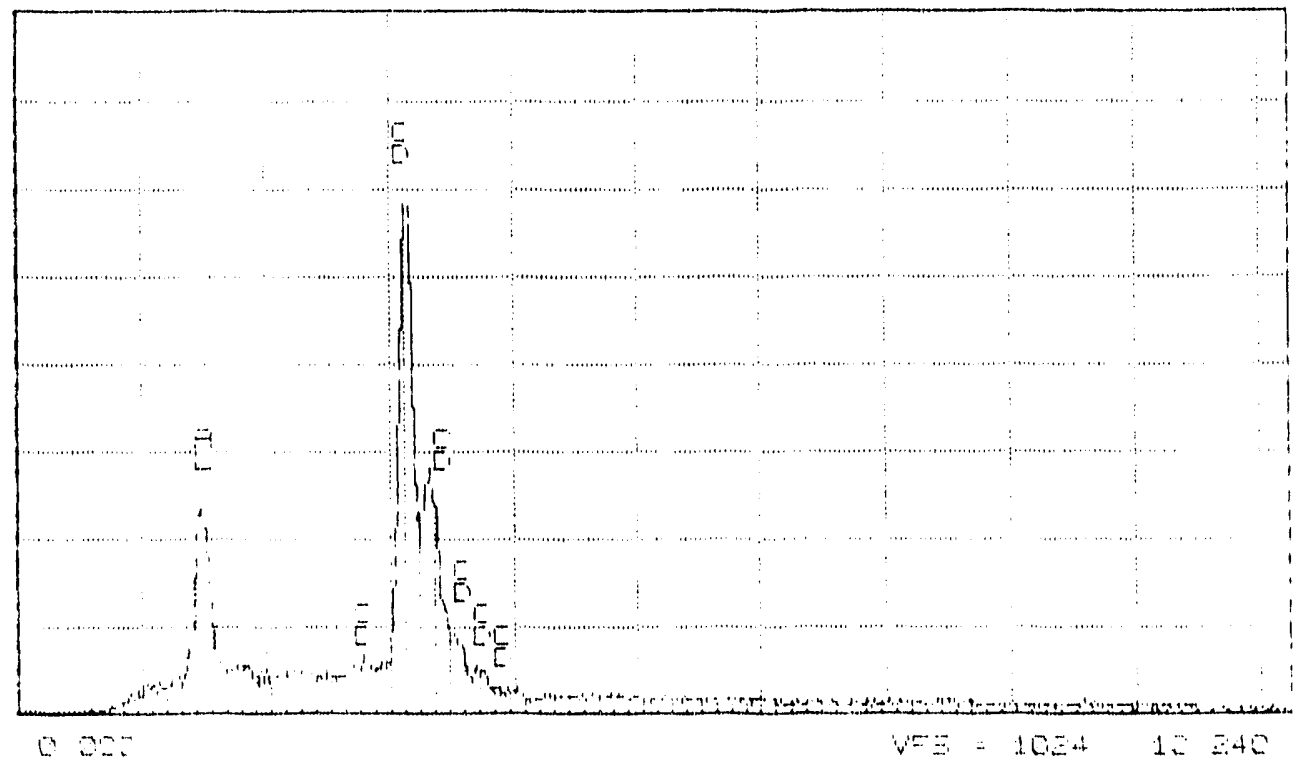

Figure 5-46b Spec.10, Section B, EDS Spectrum for Spot "B" on Figure 4-45b. 


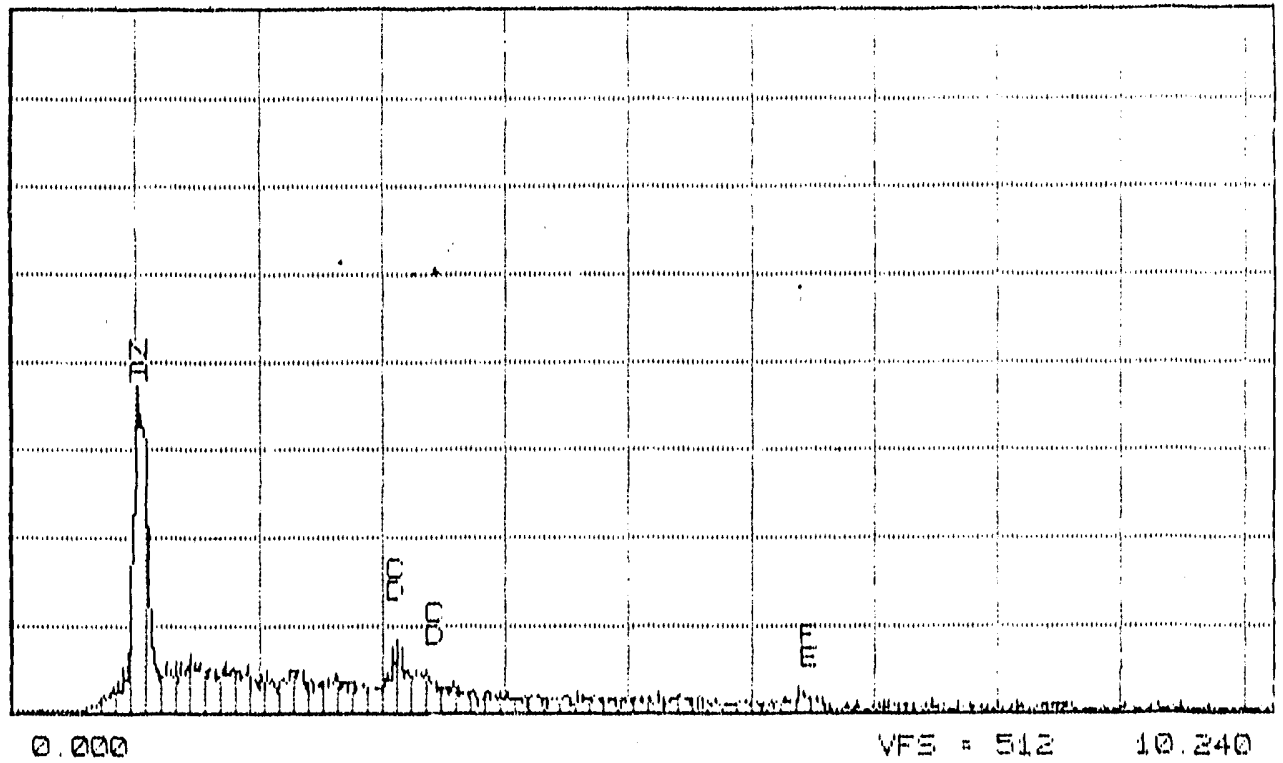

Figure 5-46c Spec.10, Section B, EDS Spectrum for Spot "C" on Figure 4-45b.

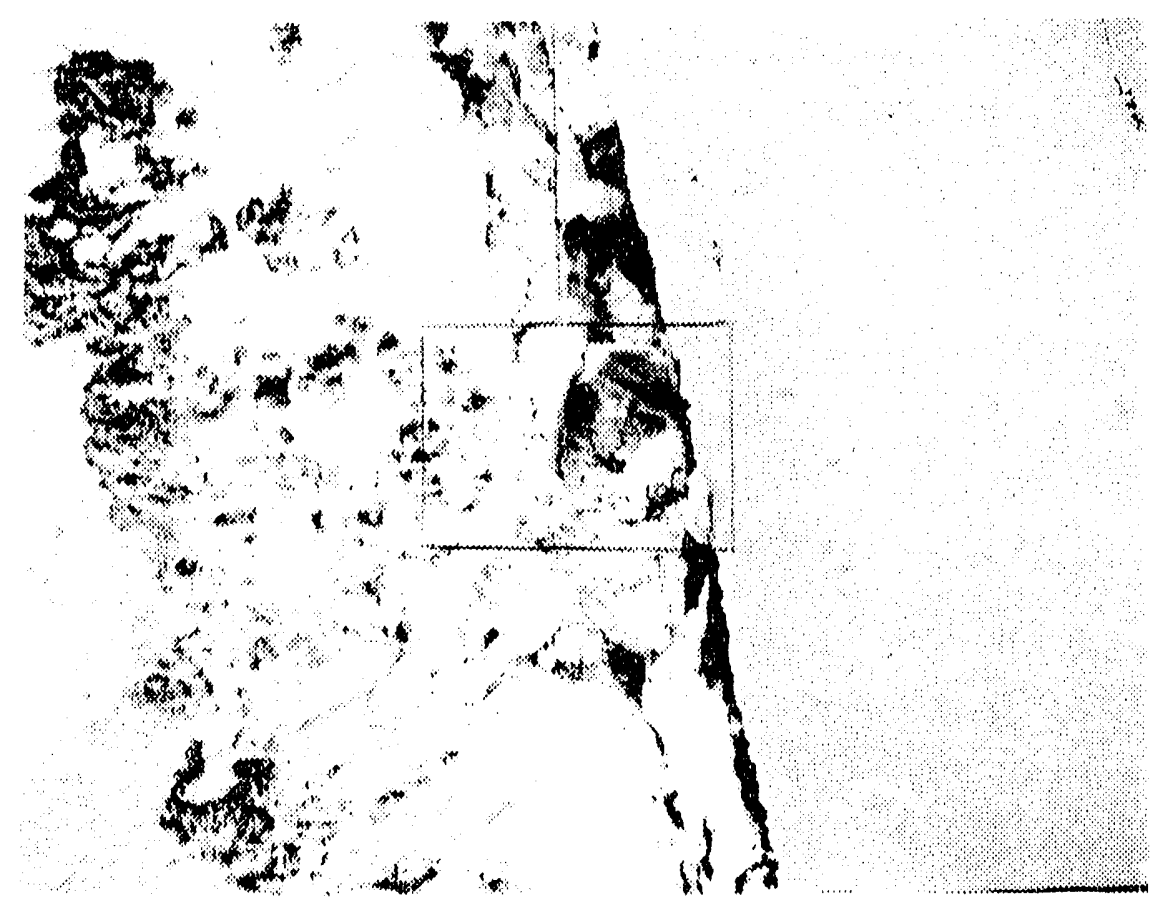

Figure 5-47a Spec,10, Section B, Particle at Inner Cladding Surface (SE, 199x). 


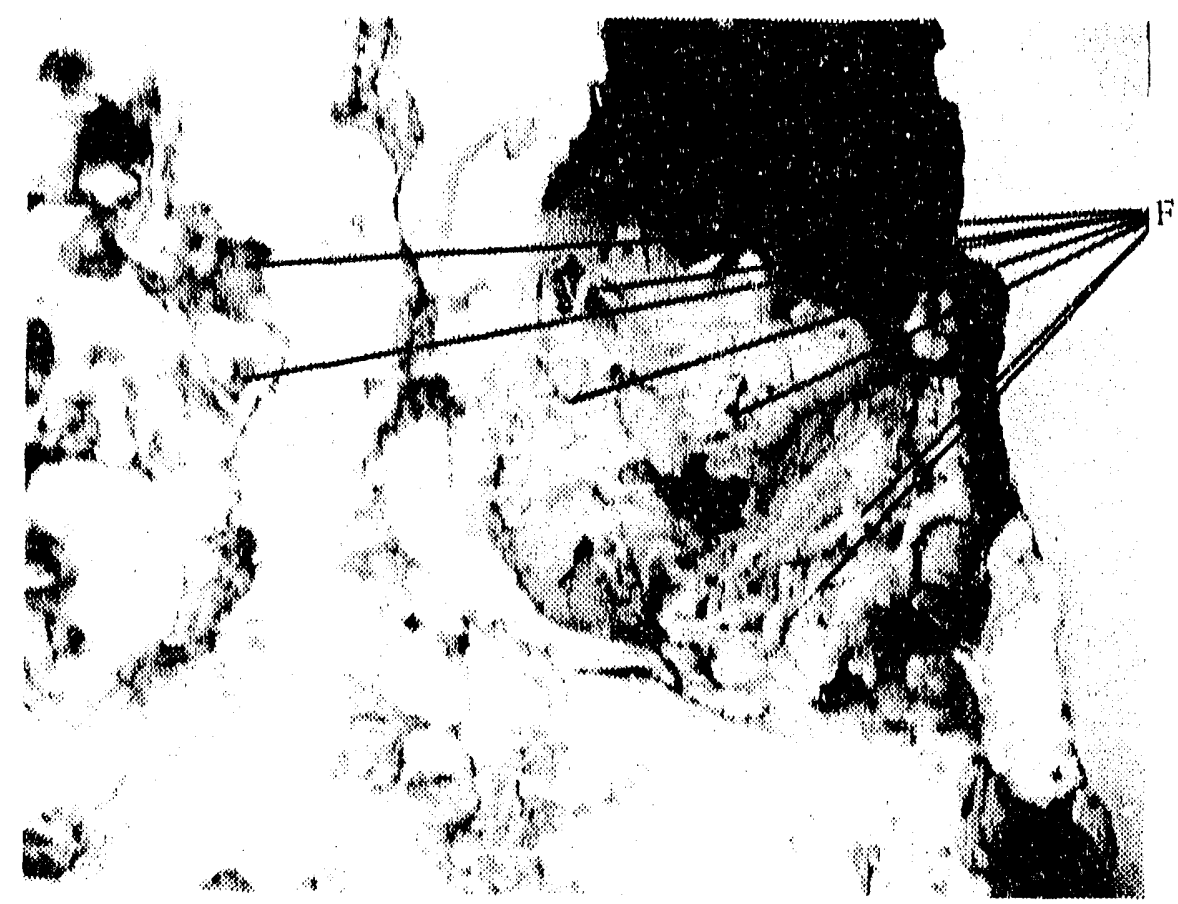

Figure 5-47b Spec.10, Section B, Particle at Inner Cladding Surface (BSE, 750x),

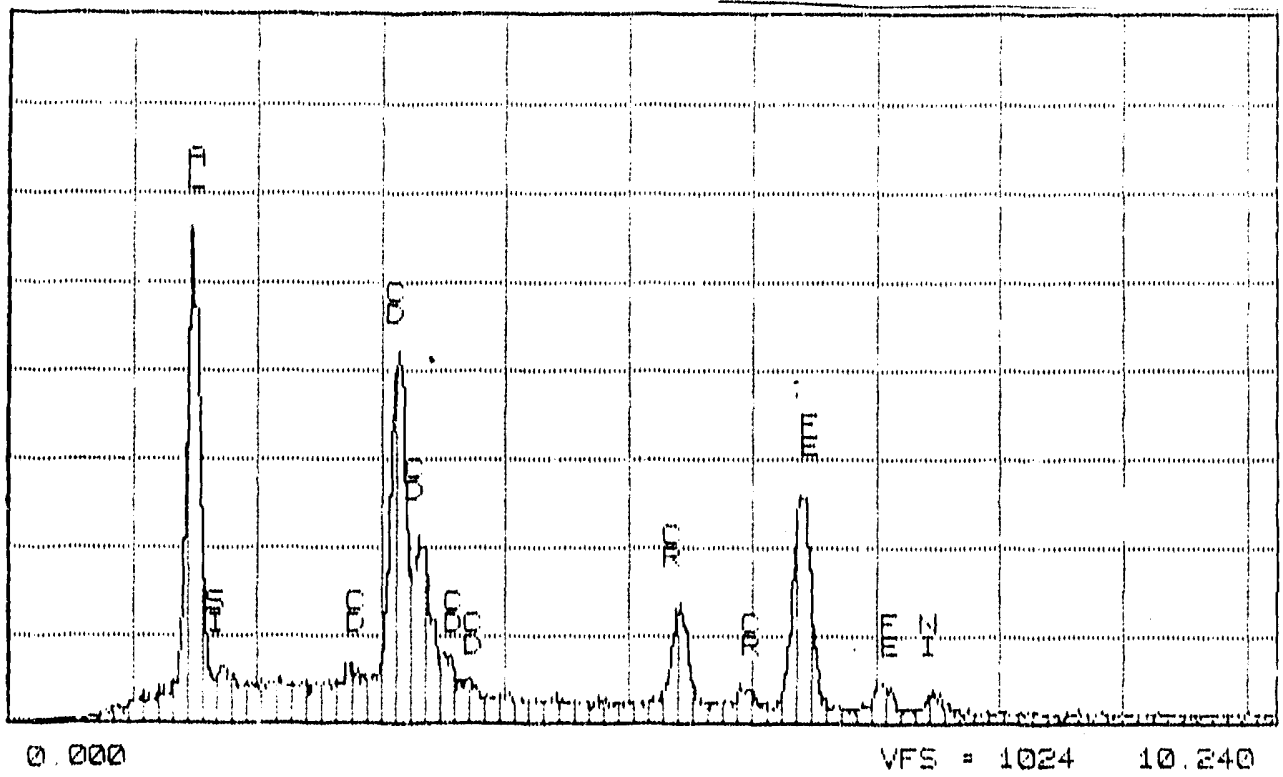

Figure 5-47c Spec.10, Section B, EDS Spectrum for Areas Identified on Figure 5-47b. 
S. S. $3(44$ Claclding

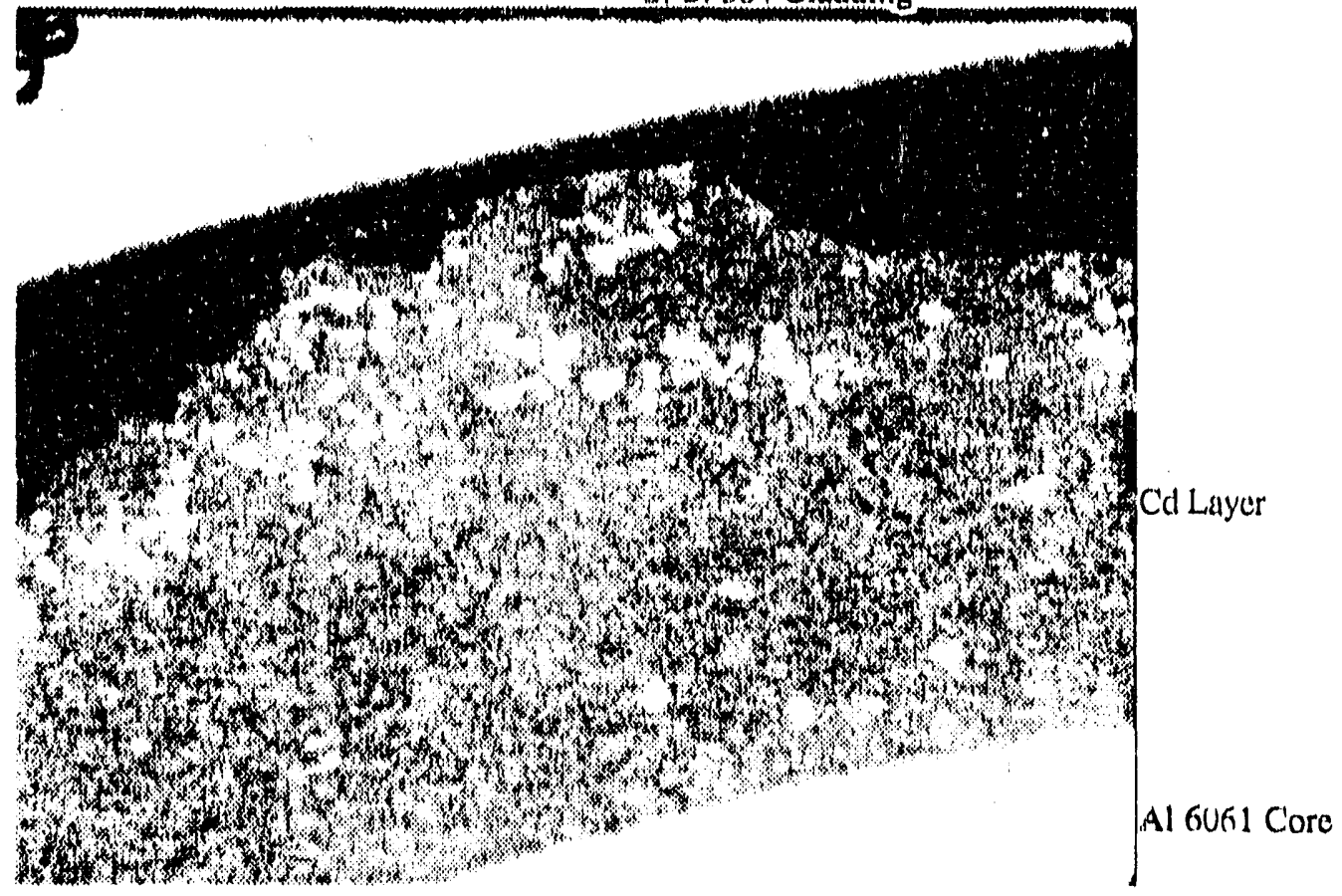

Figure 5-48a Spec.10, Section A, Low-Magnification Optical Micrograph (50x),

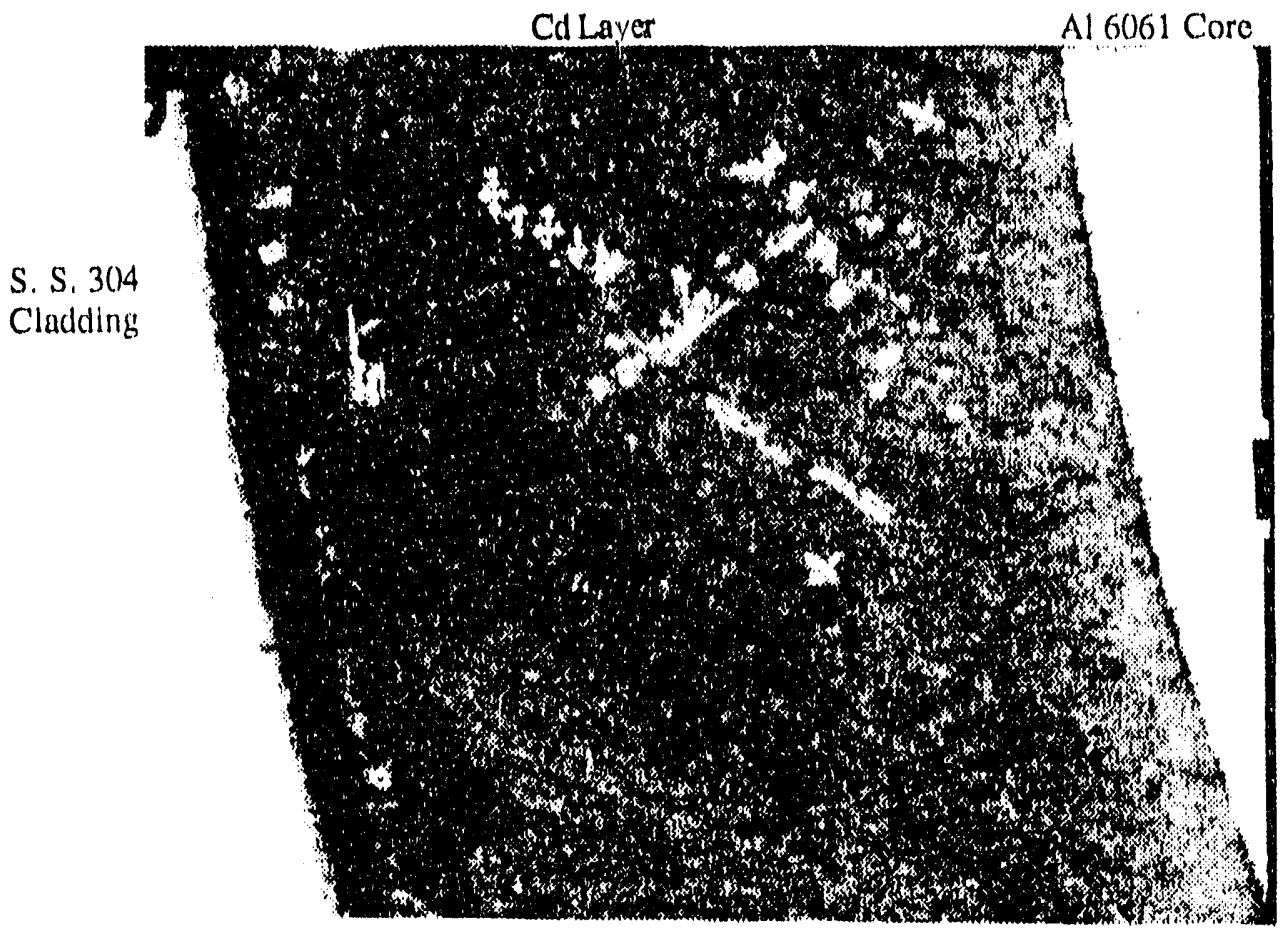

Figure 5-48b Spec.10, Section A, Low-Magnification Optical Micrograph (50x), 


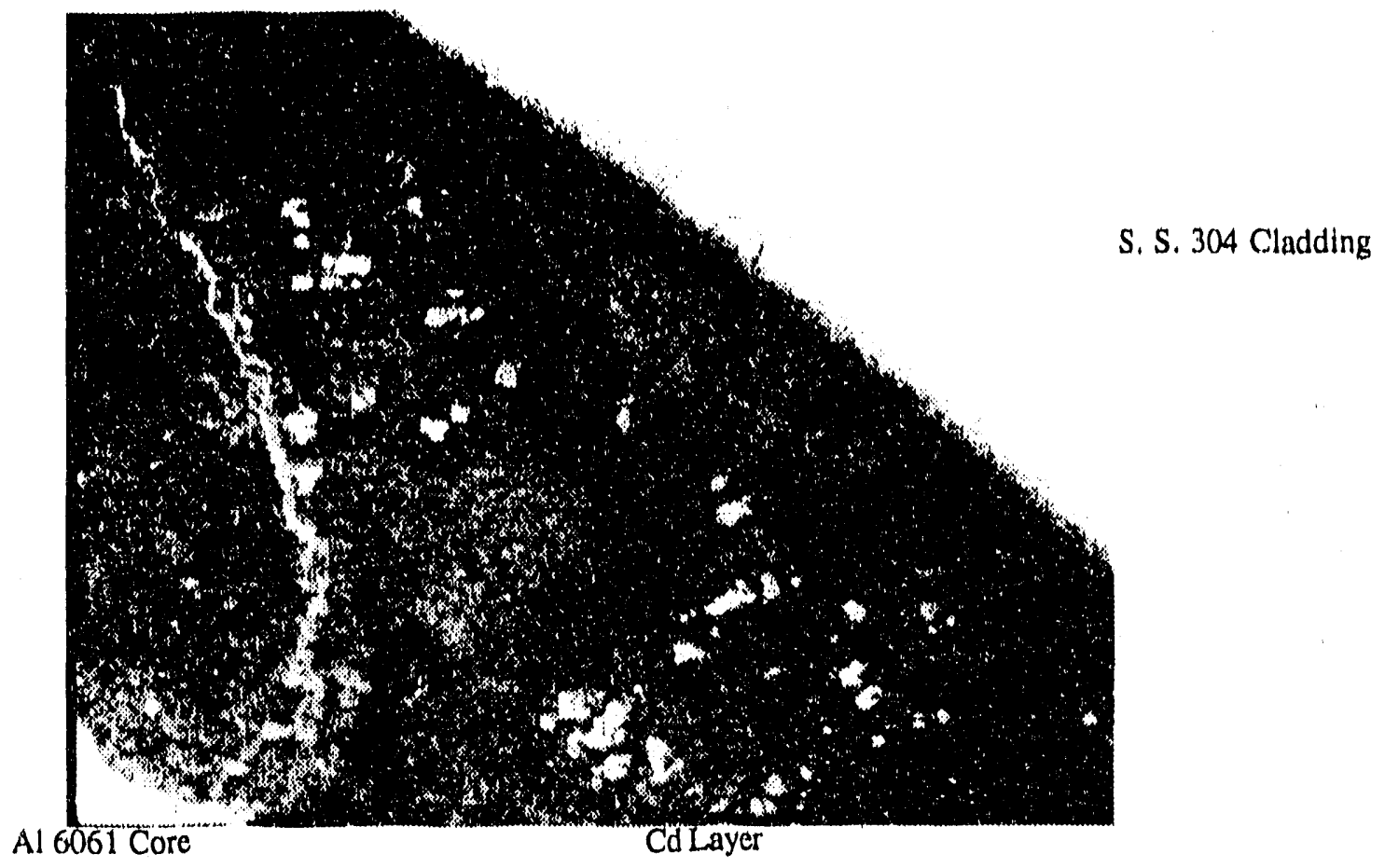

Figure 5-48c Spec.10, Section A, Low-Magnification Optical Micrograph (50x).

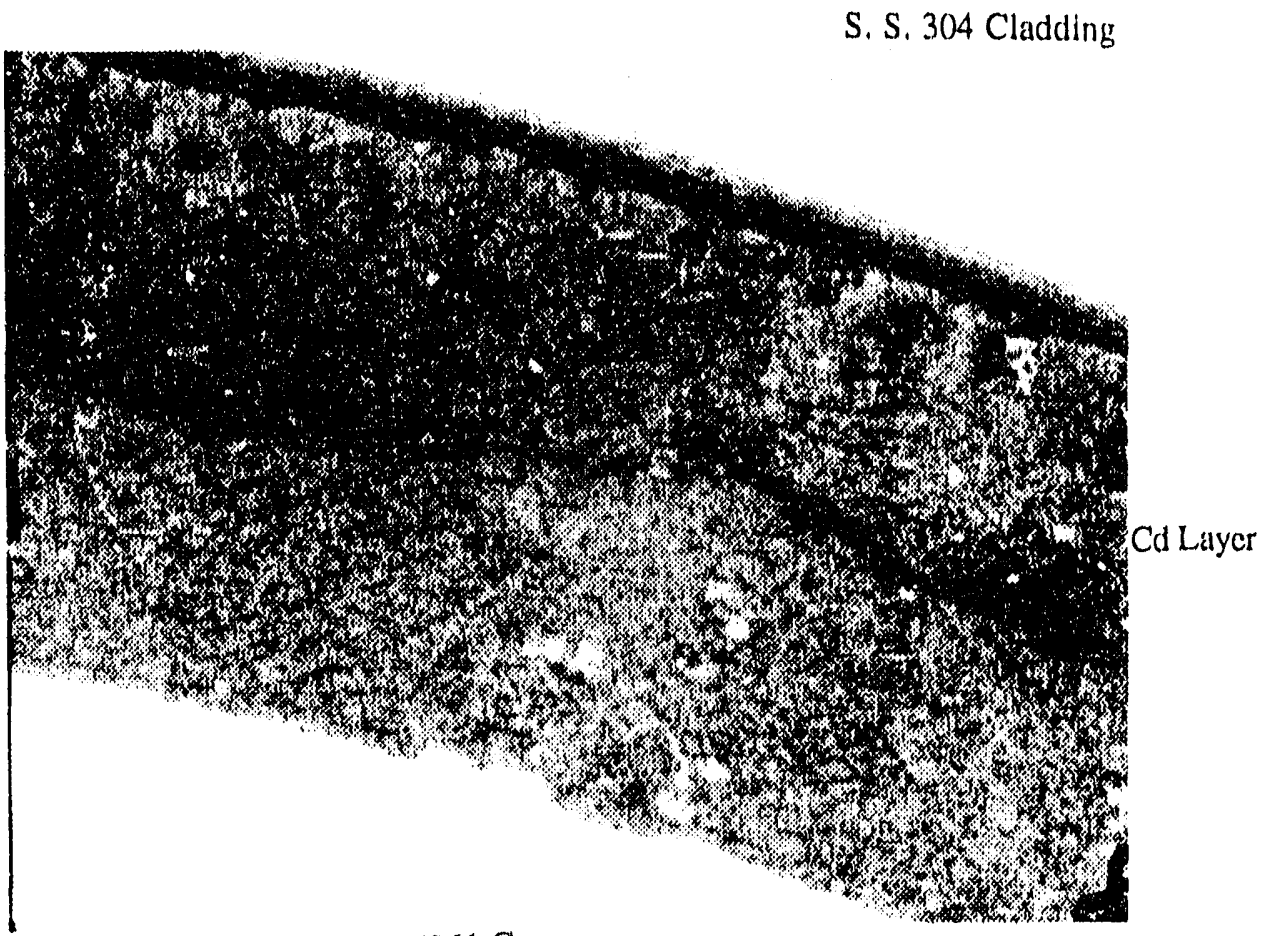

Al 6061 Core

Figıre 5-48d Spec.10, Section A, Low-Magnification Optical Micrograph (50x). 


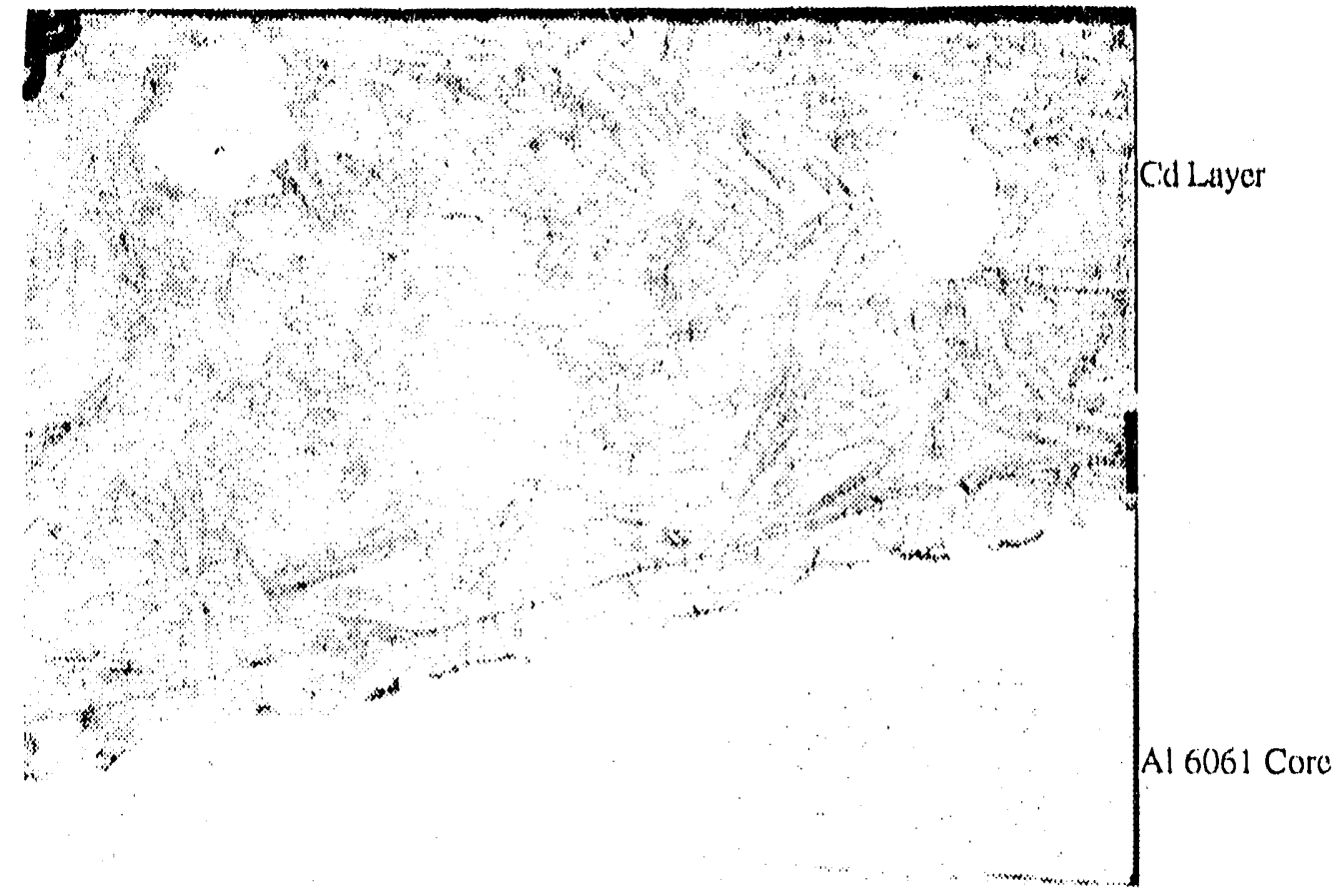

Figure 5-49a Spec.10, Section A, Optical Micrograph of Al-Cd Interface (250x).

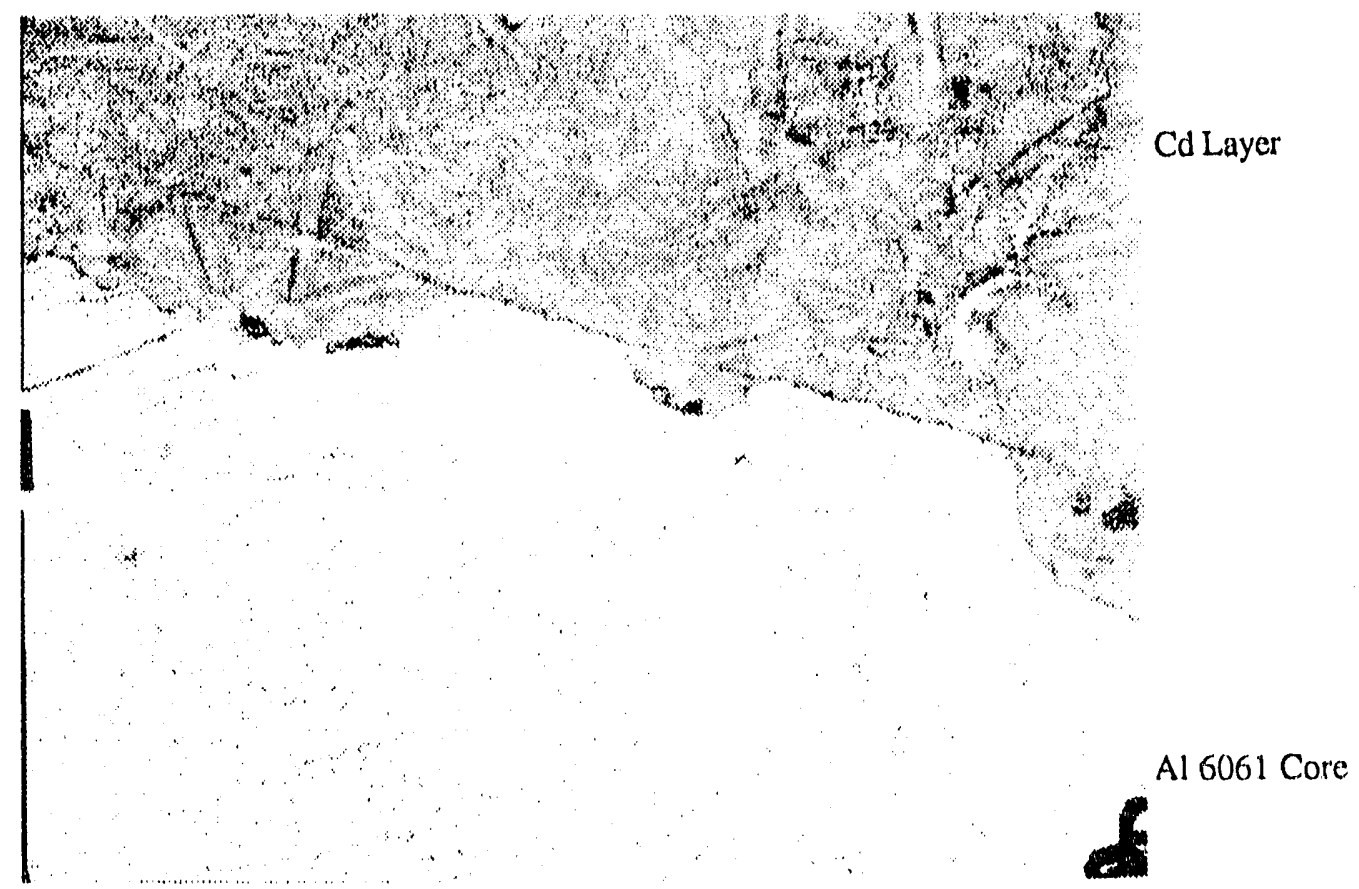

Figure 5-49b Spec.10, Section A, Optical Micrograph of Al-Cd Interface (250x). 


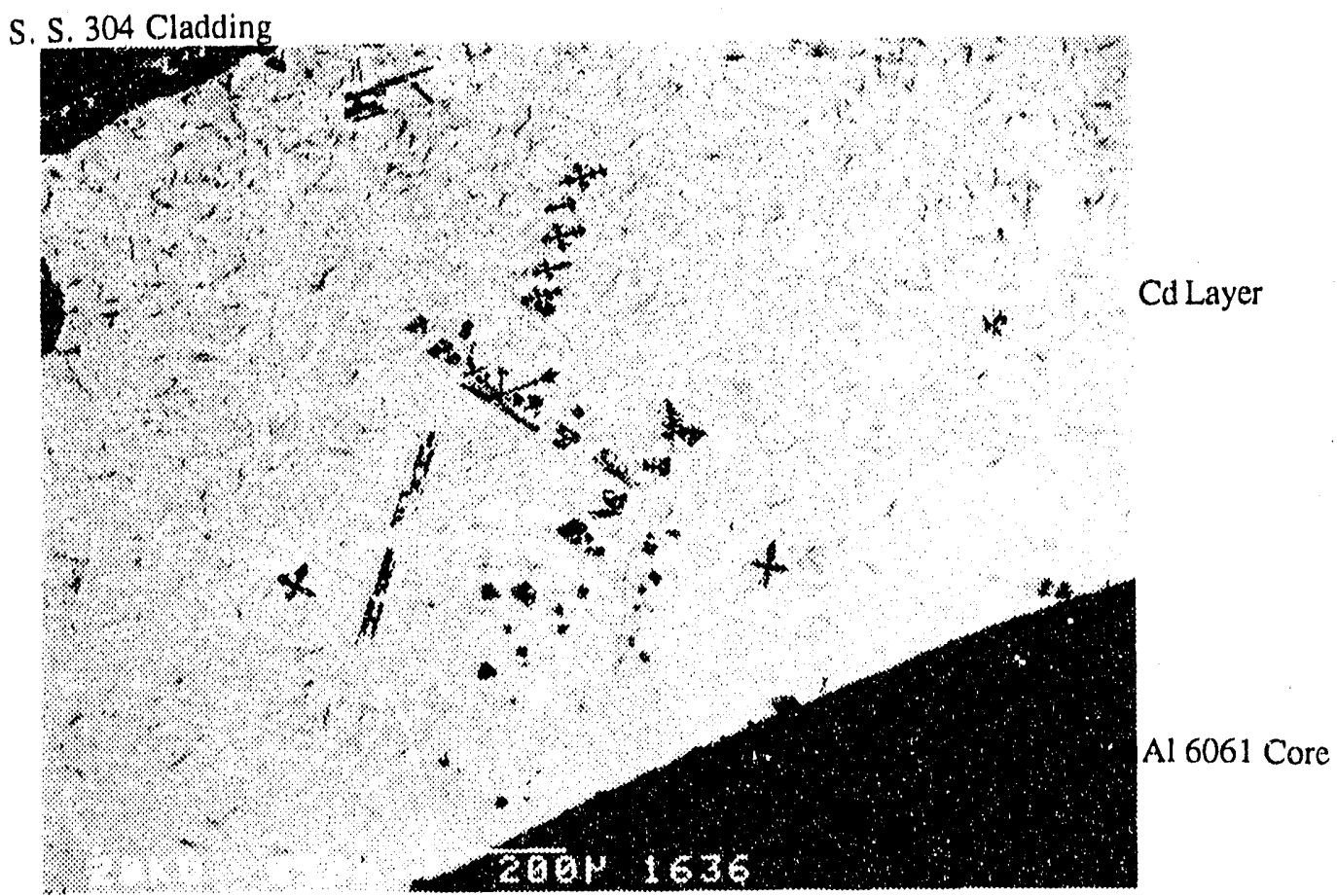

Figure 5-50 Spec.10, Section A, Low-Magnification SEM Micrograph (BSE, 50x). 


\section{Top Half of Specimen}

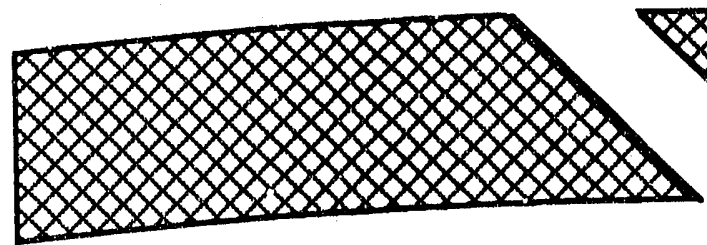

Right Side of Fracture

Left Side of Fracture

\section{Bottom Half of Specimen}
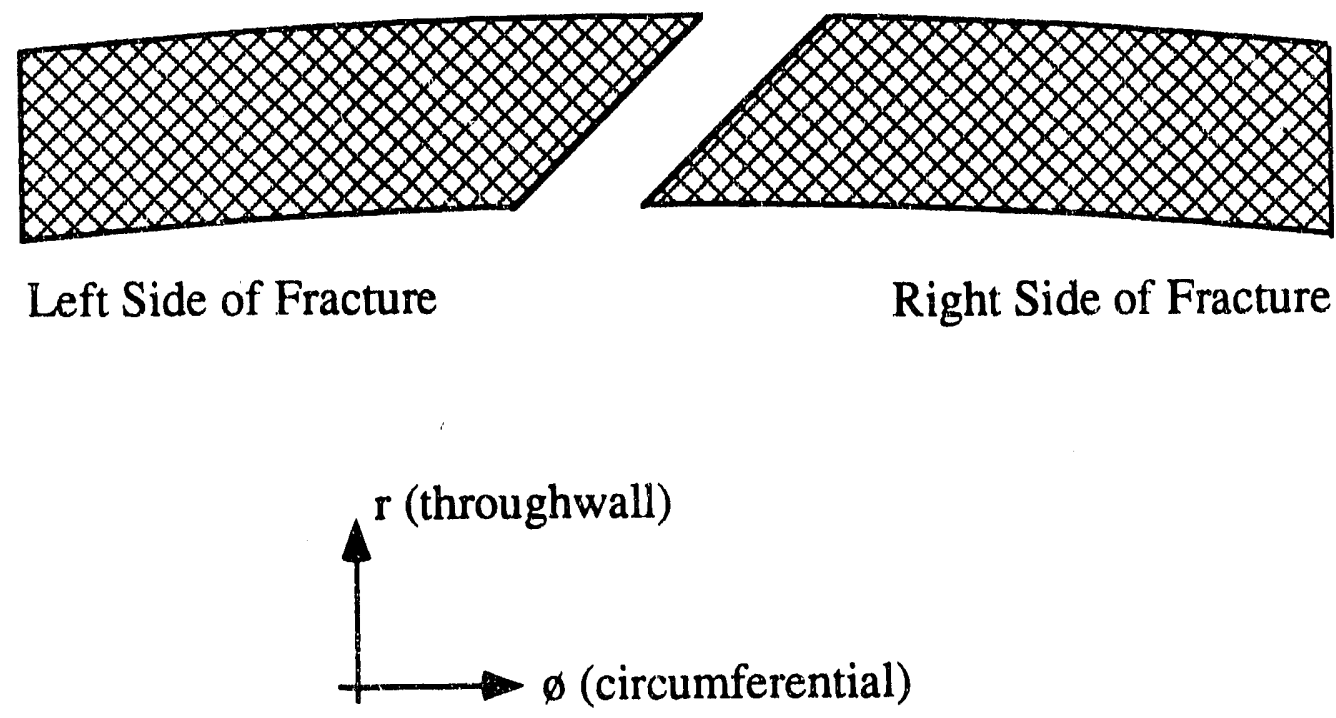

Figure 5-51 Fracture Side Orientations for Specimens 11 and 12. 


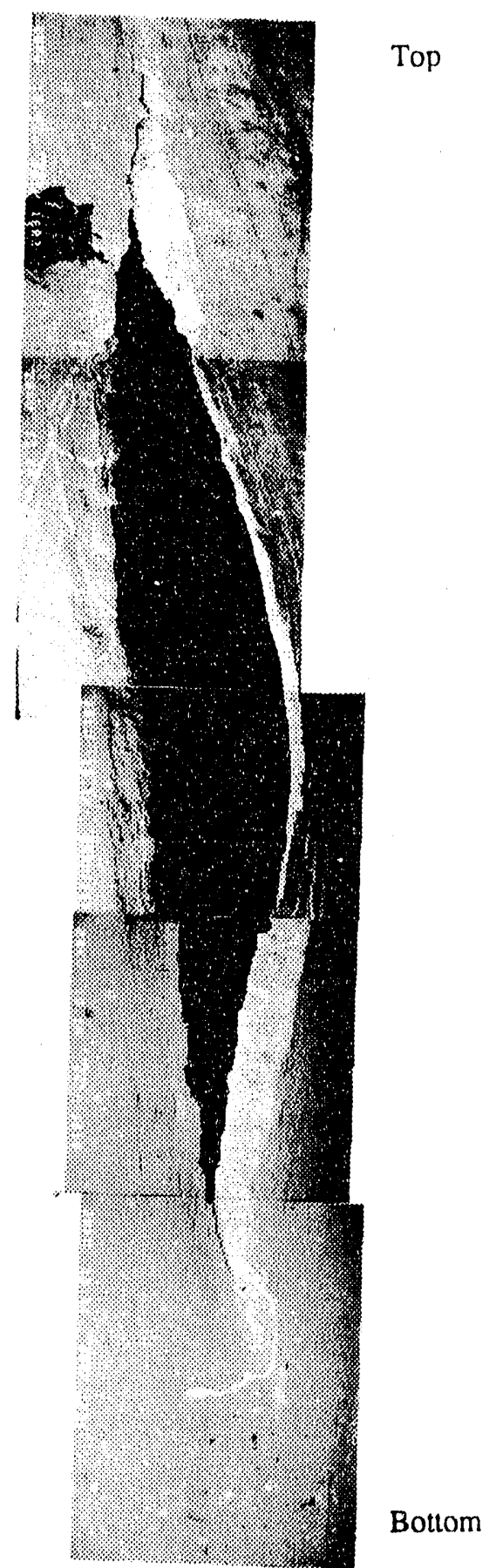

Figure 5-52a Spec.11, Montage of Outer Surface Near Fracture (BSE). 


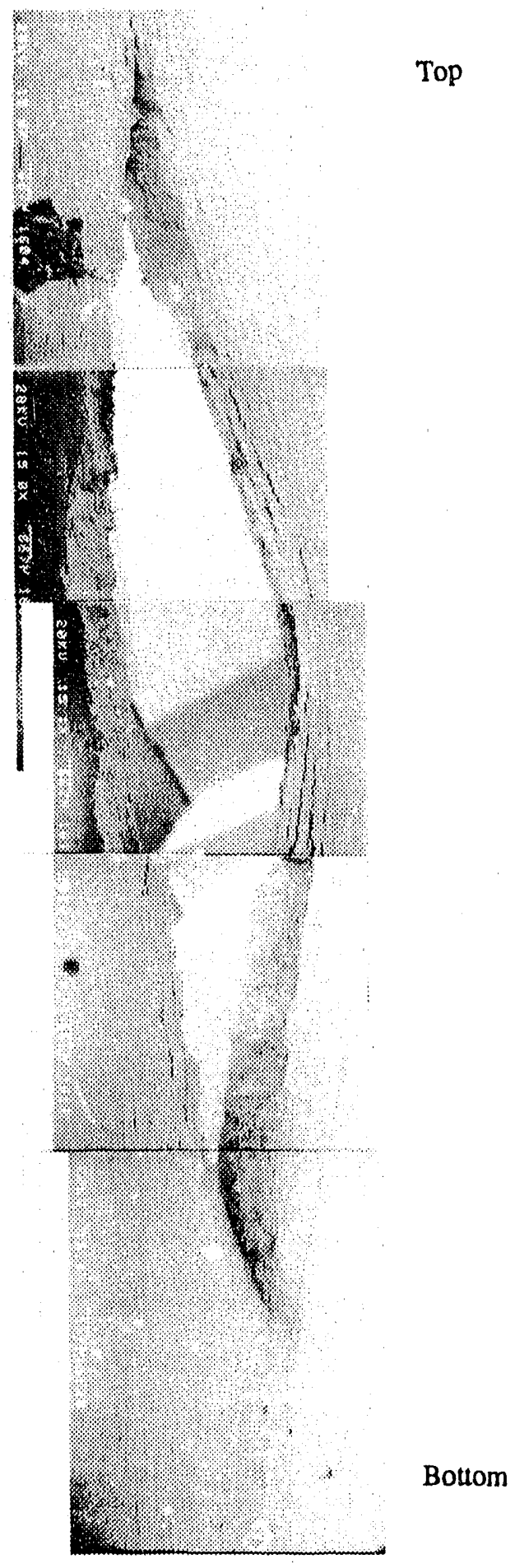

Figure 5-52b Spec.11, Montage of Outer Surface Near Fracture (SE). 
Page 143

WSRC-RP-92-222

January 1992

Task $91-001-1$

Top

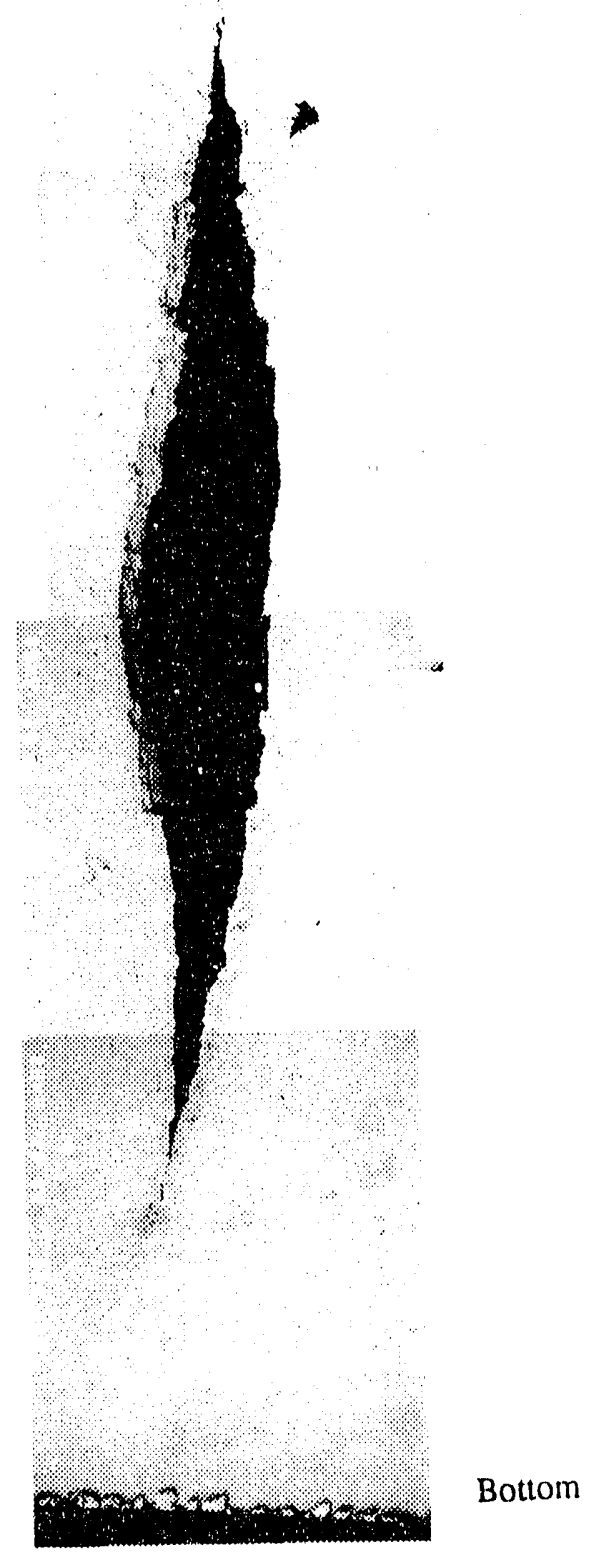

Figure 5-53 Spec.11, Montage of Inner Surface Near Fracture (BSE). 


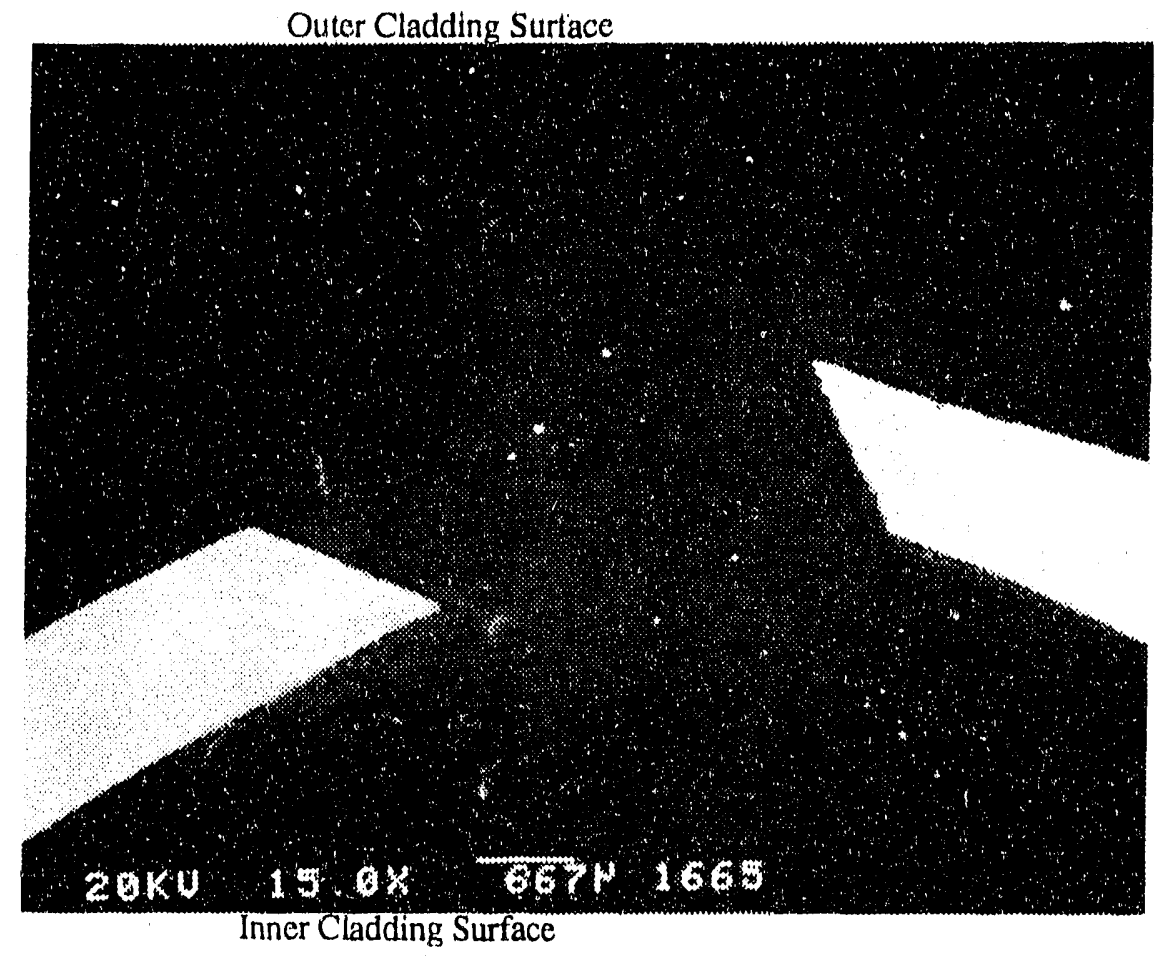

Figure 5-54 Spec.11, 1st Grind, Top Half, Low-Magnification SEM Micrograph (BSE, $15 \mathrm{x})$.

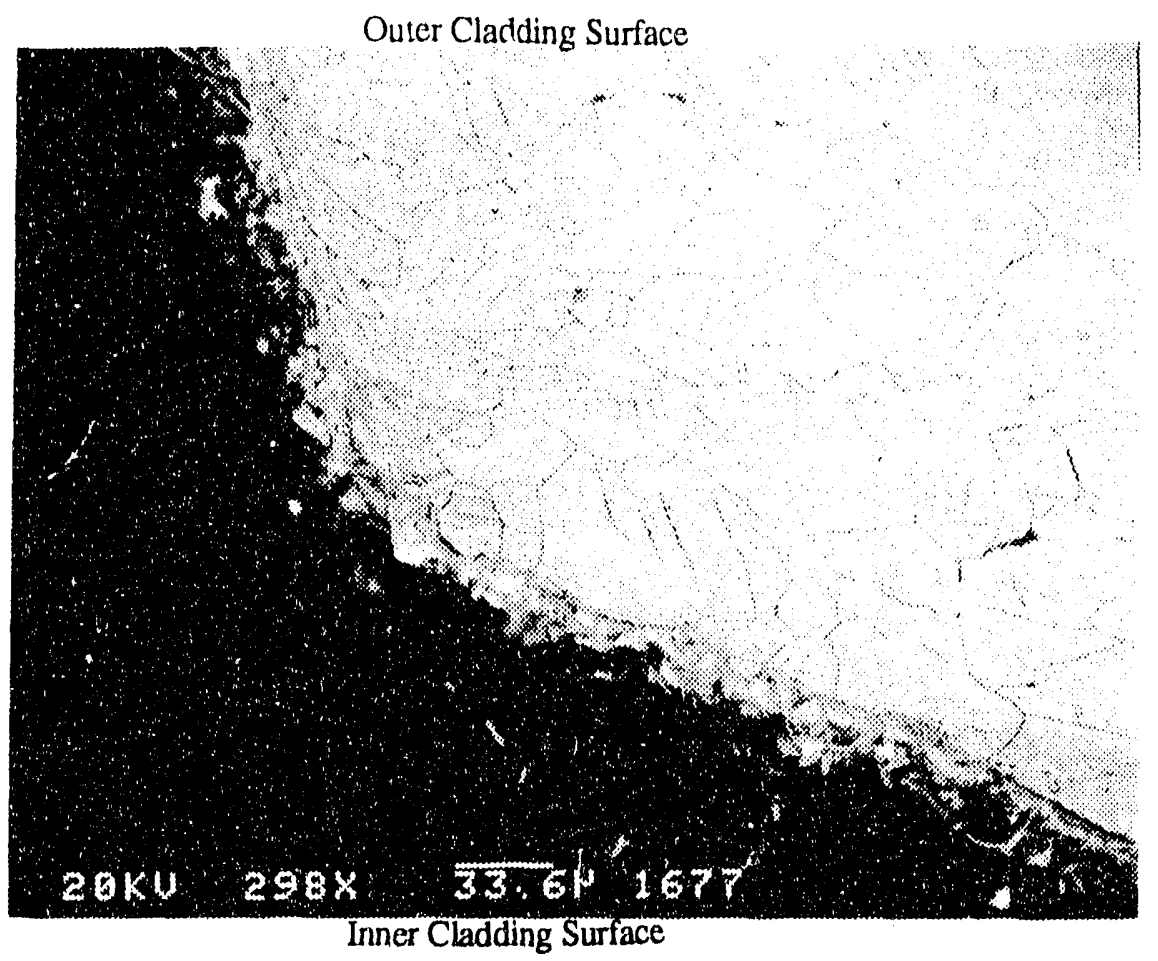

Figure 5-55a Spec.11, 1st Grind, Top Half, Left Side, Fracture Surface at I.D. (BSE, 298x). 


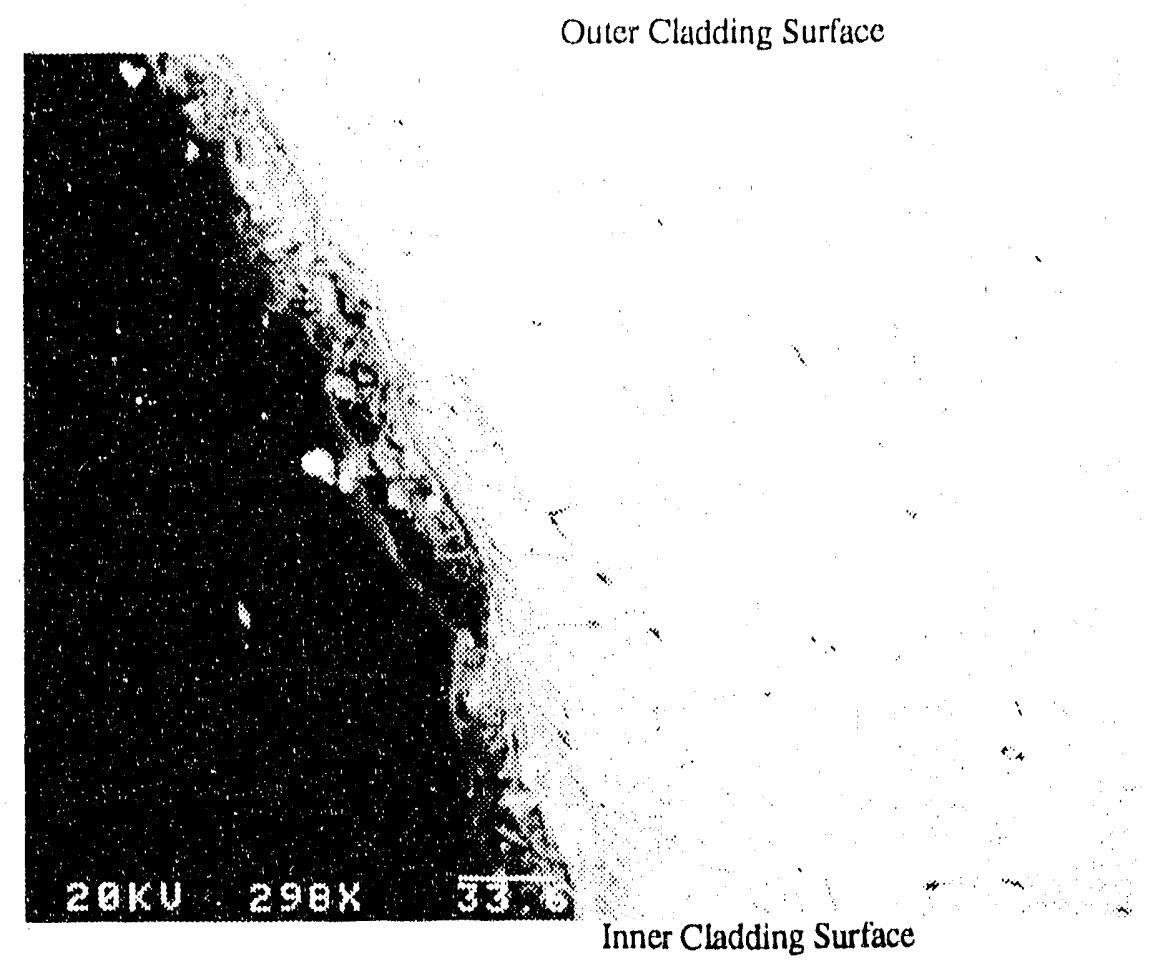

Figure 5-55b Spec.11, 1st Grind, Top Half, Left Side, Near Cladding Midpoint (BSE, 298x).

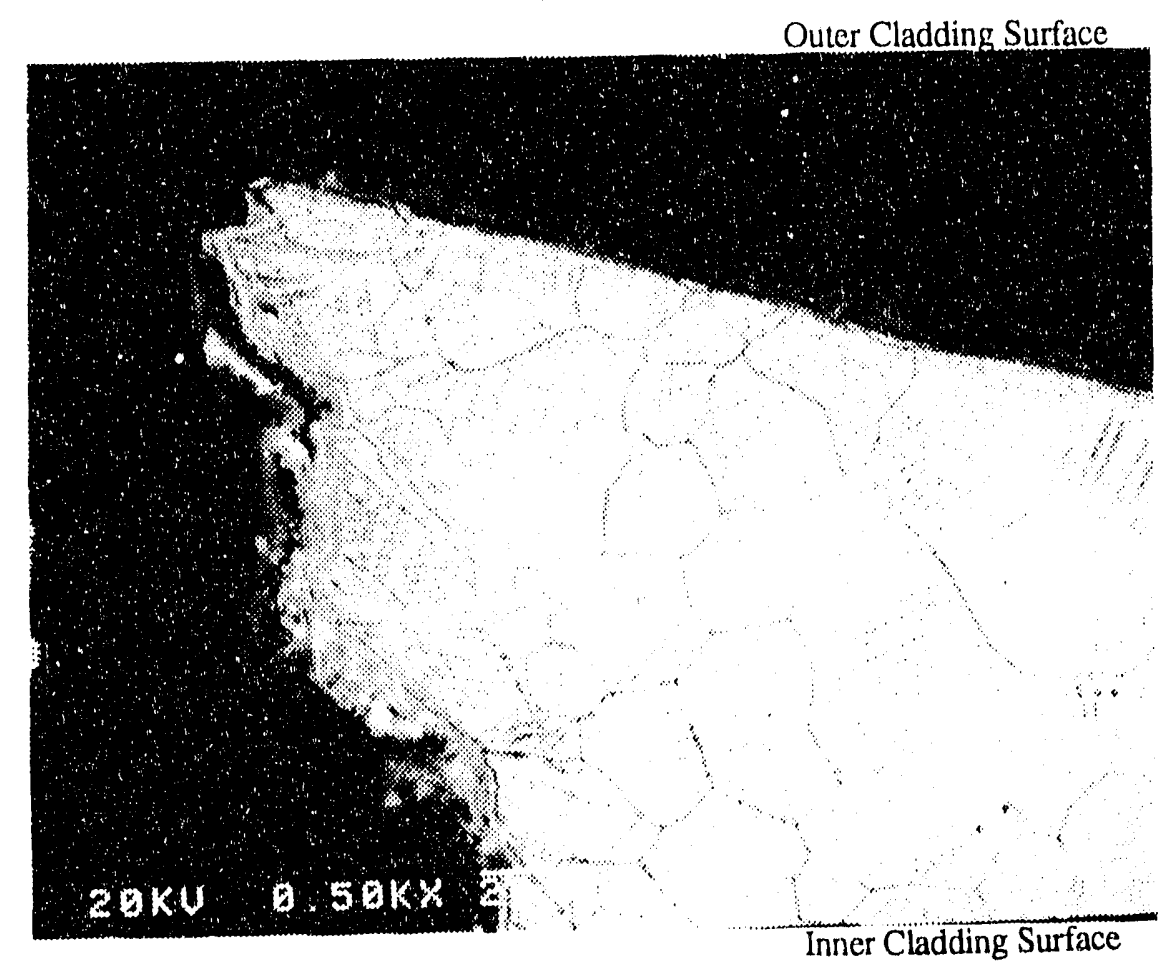

Figure 5-55c Spec.11, 1st Grind, Top Half, Left Side, Fracture Surface at O.D. (BSE, $500 x$ ). 


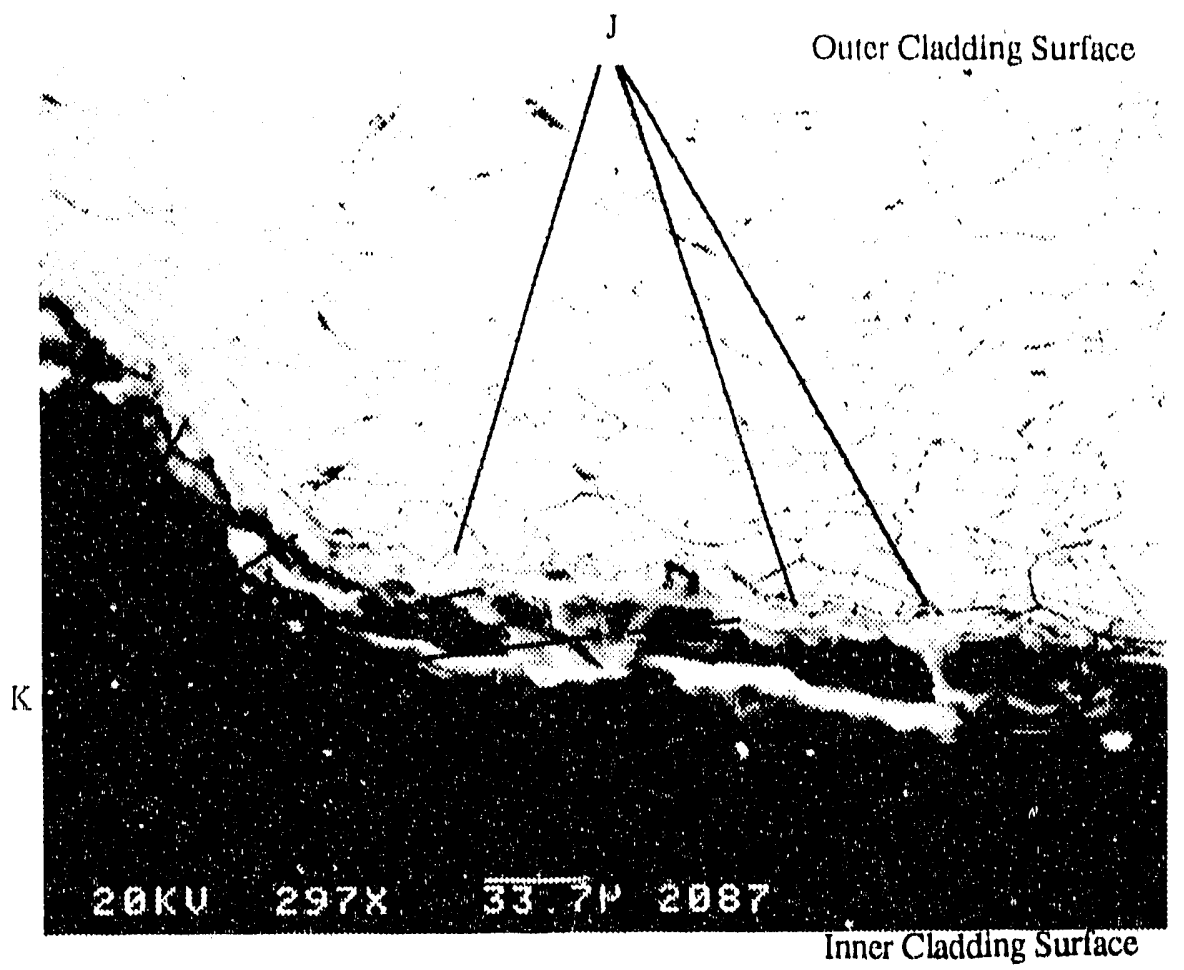

Figure 5-56a Spec.11, 2nd Grind, Top Half, Left Side, Fracture Surface at I.D. (SE, 297x).

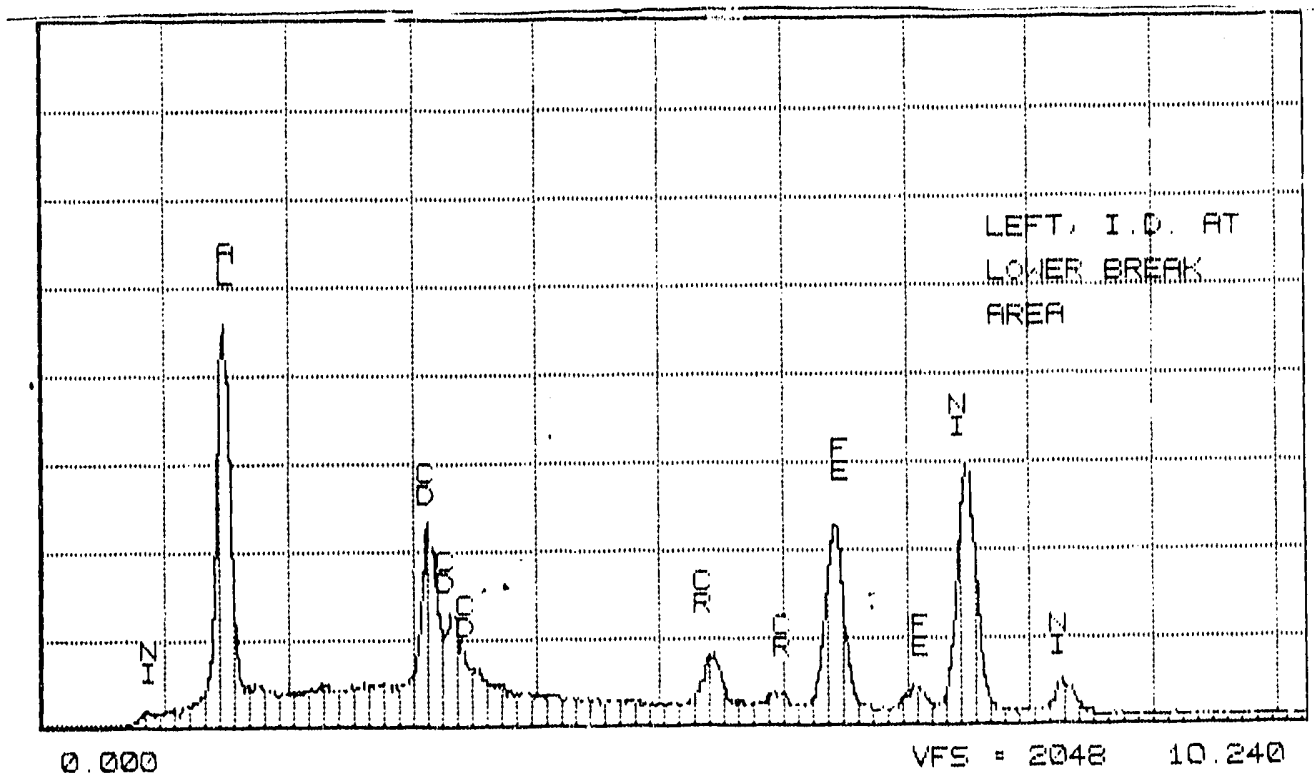

Figure 5-56b Spec.11, 2nd Grind, Top Half, EDS Spectrum for Spot "J" on Figure 5$56 \mathrm{a}$. 


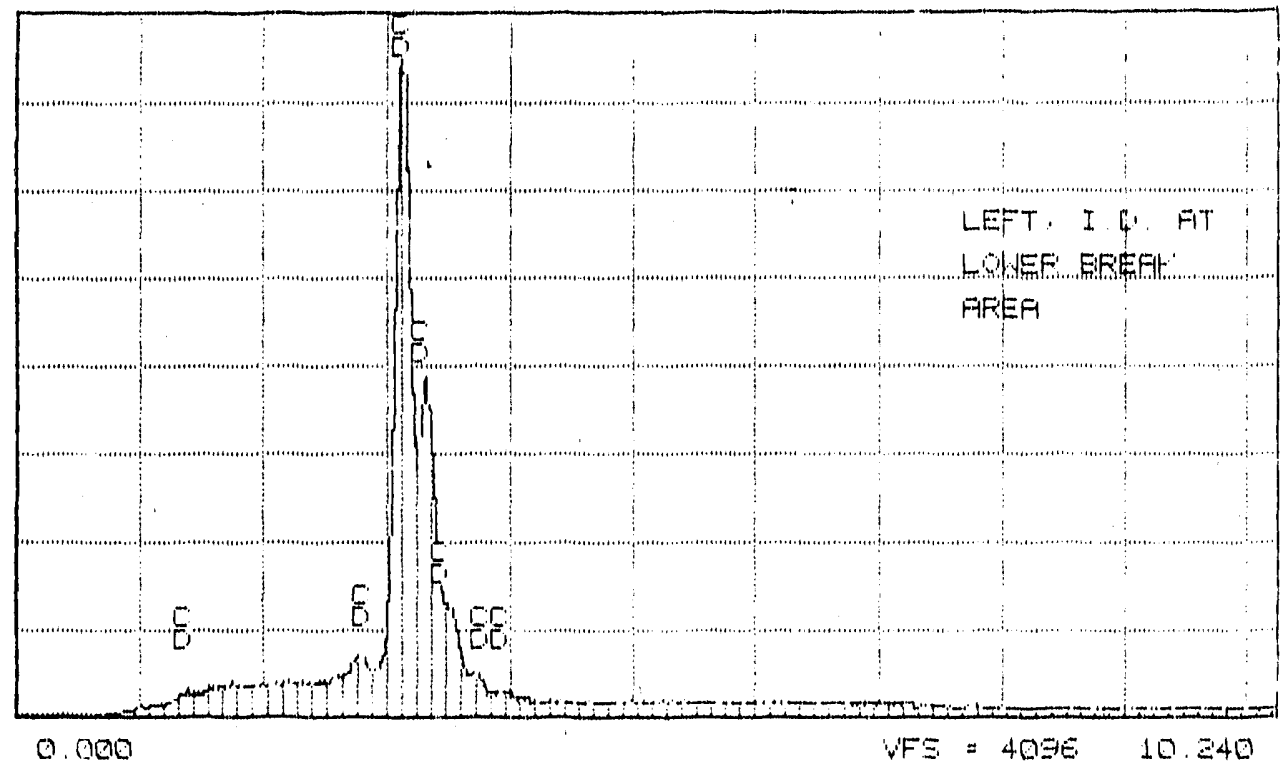

Figure 5-56c Spec.11, 2nd Grind, Top Half, EDS Spectrum for Spot "K" on Figure 5$56 a$.

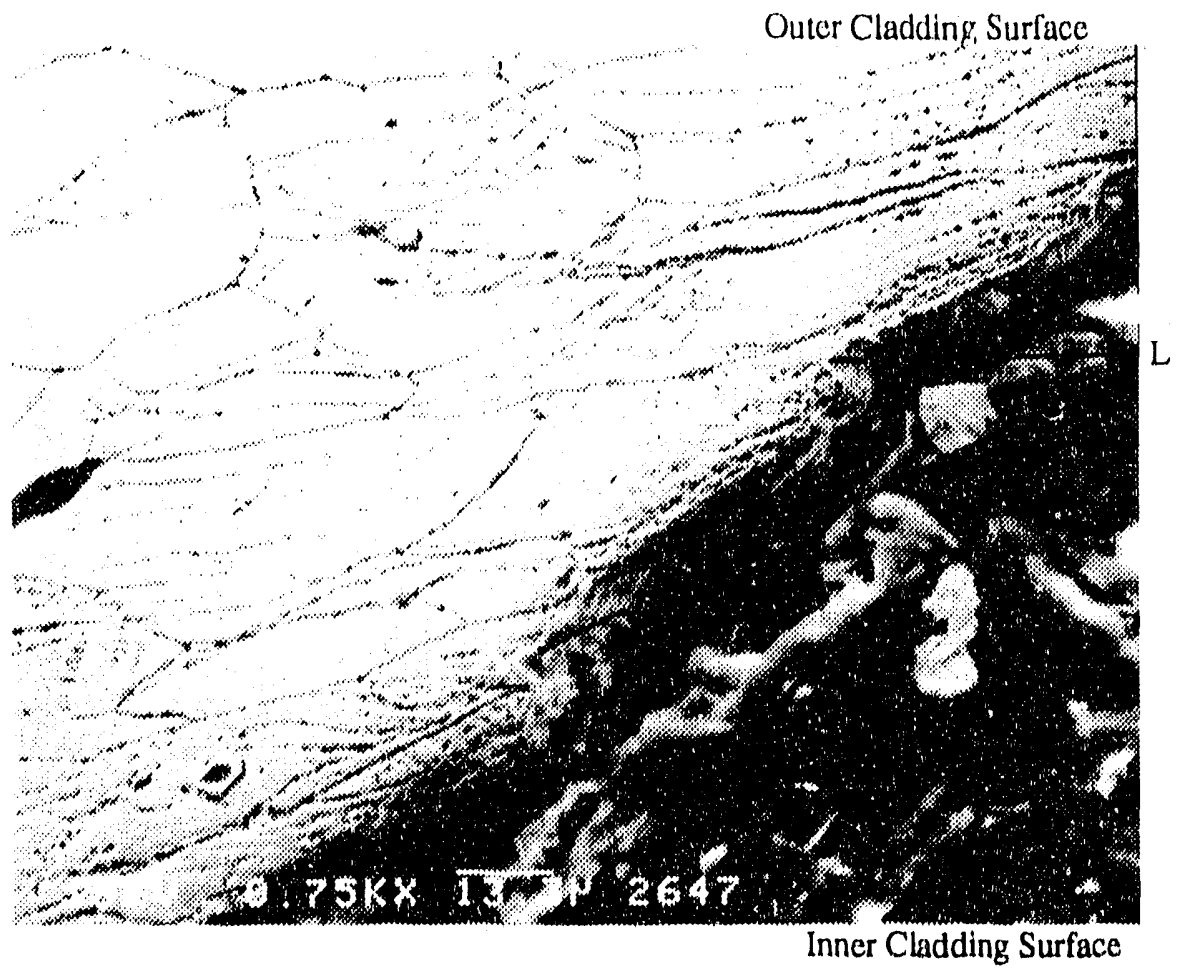

Figure 5-57a Spec. 11, 2nd Grind, Bottom Half, Right Side, Fracture Surface $\approx 3 / 4$ Throughwall (SE, 750x). 


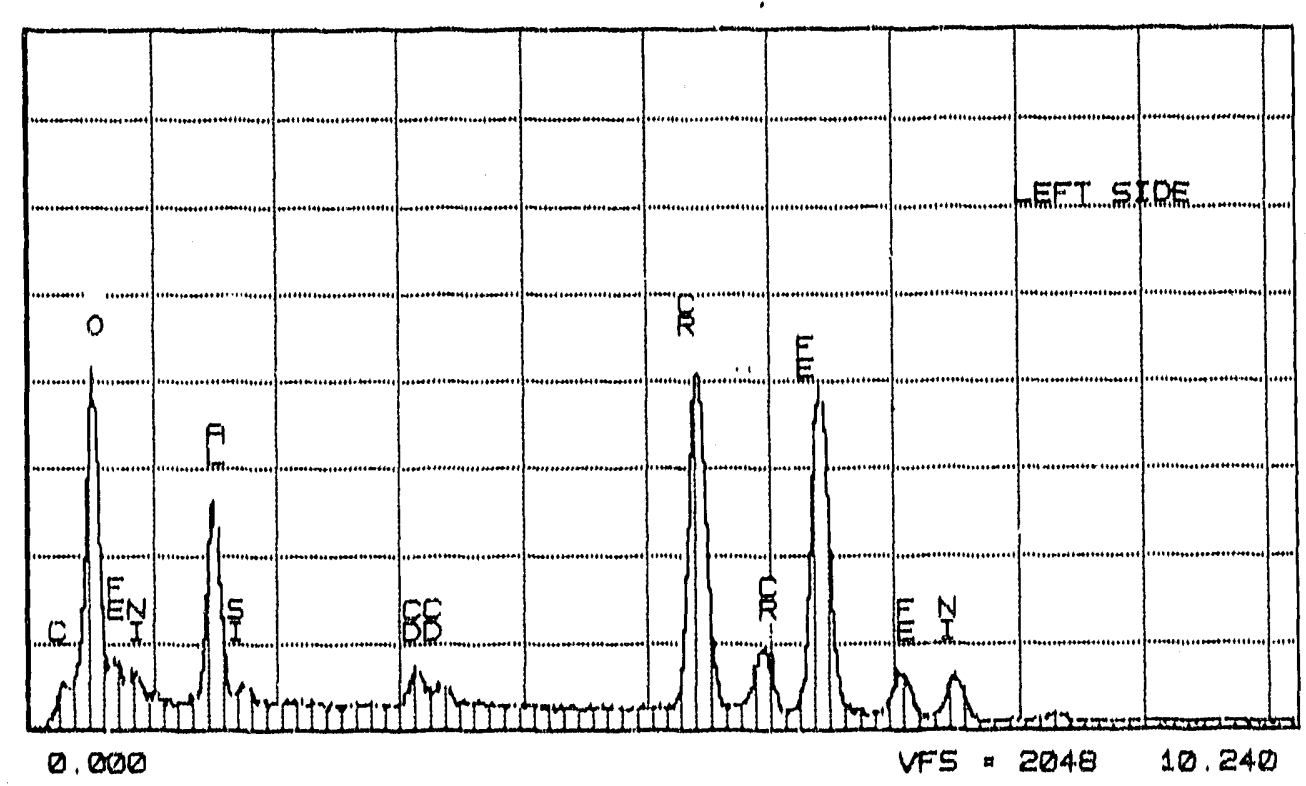

Figure 5-57b Spec.11, 2nd Grind, Bottom Half, EDS Spectrum for Spot "L" on Figure 5-56a. 


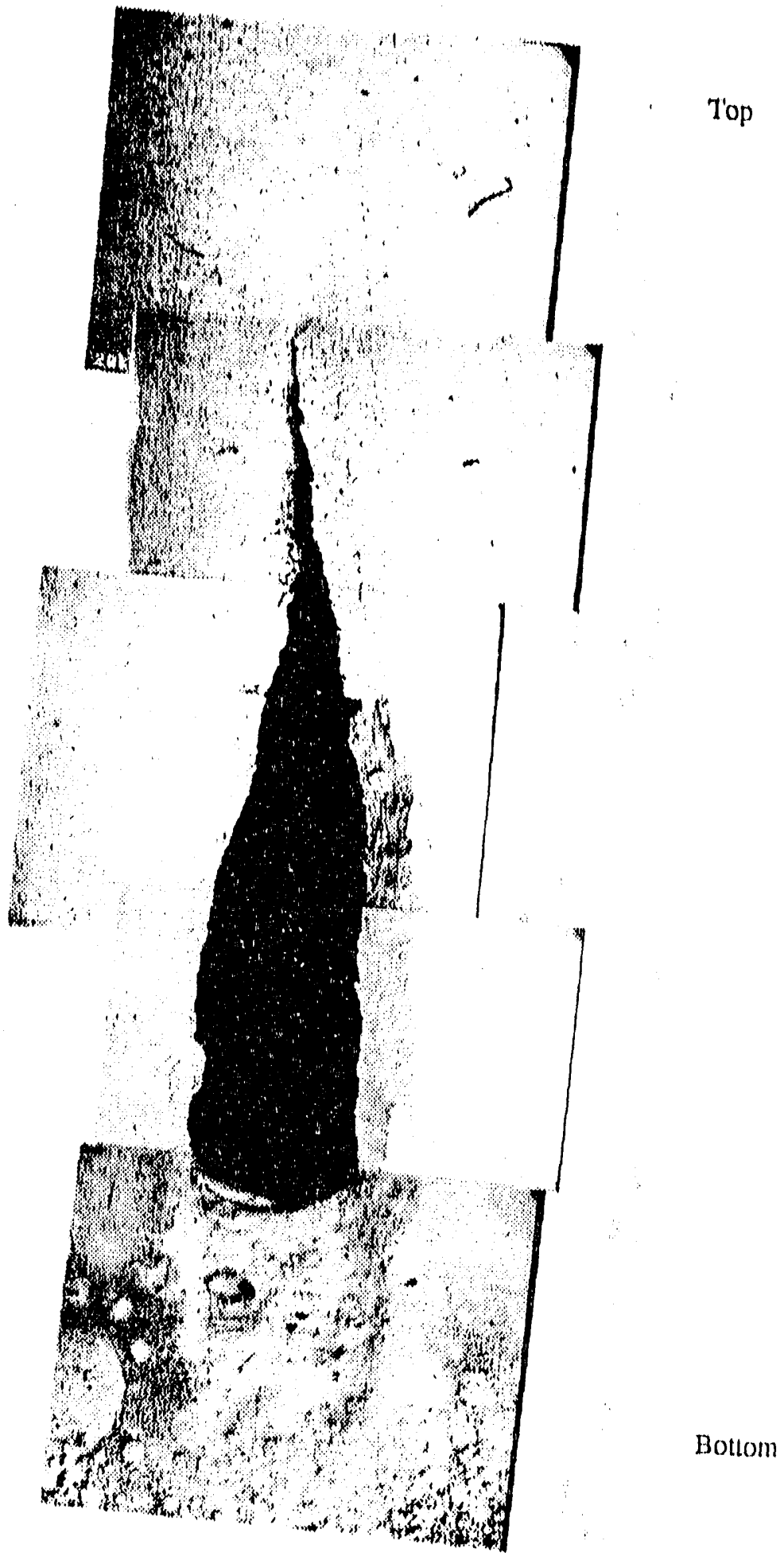

Figure 5-58a Spec.12, Montage of Outer Surface Near Fructure (BSE). 


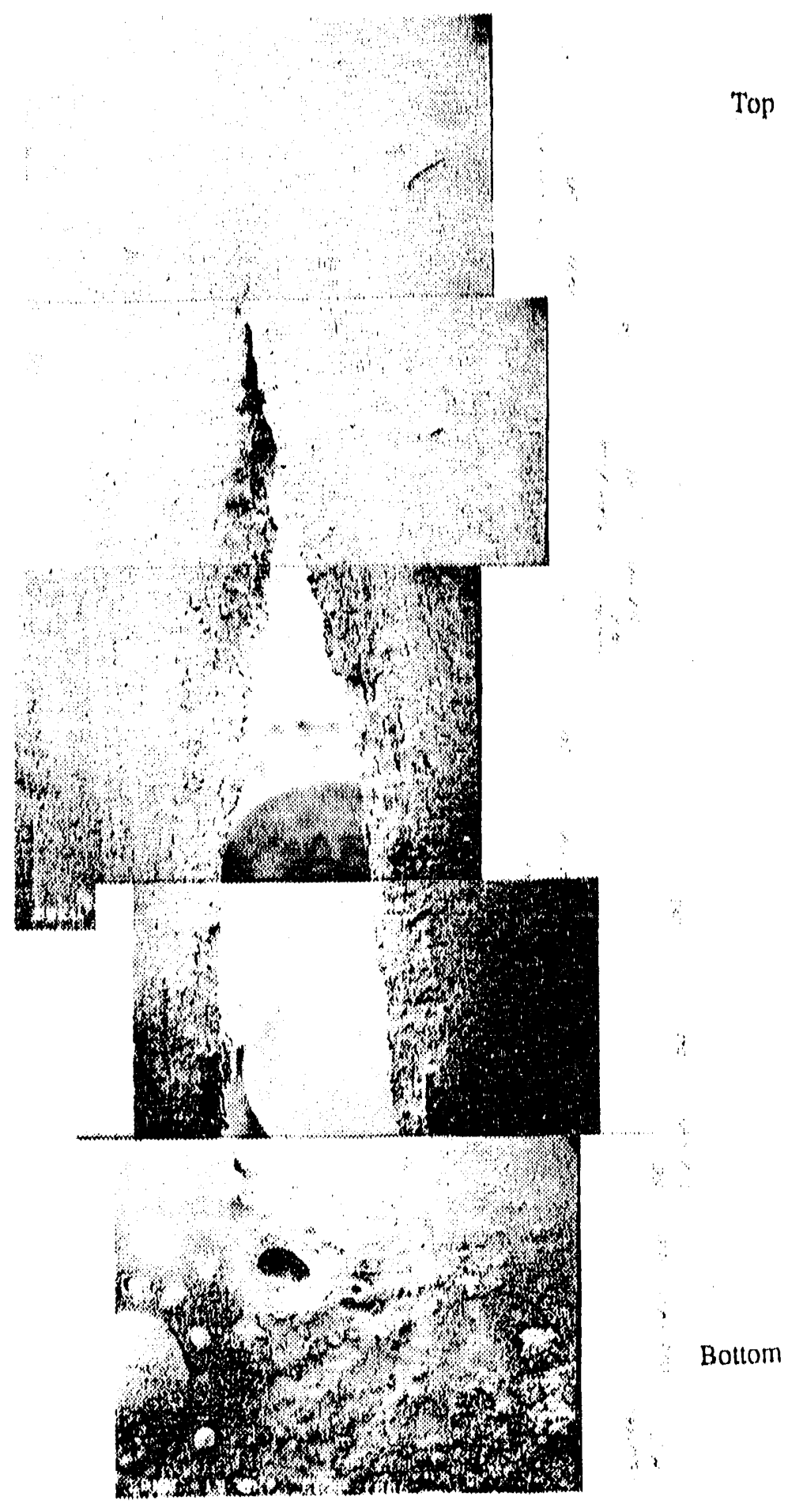

Figure 5-58b Spec.12, Montage of Outer Surface Near Fracture (SE). 


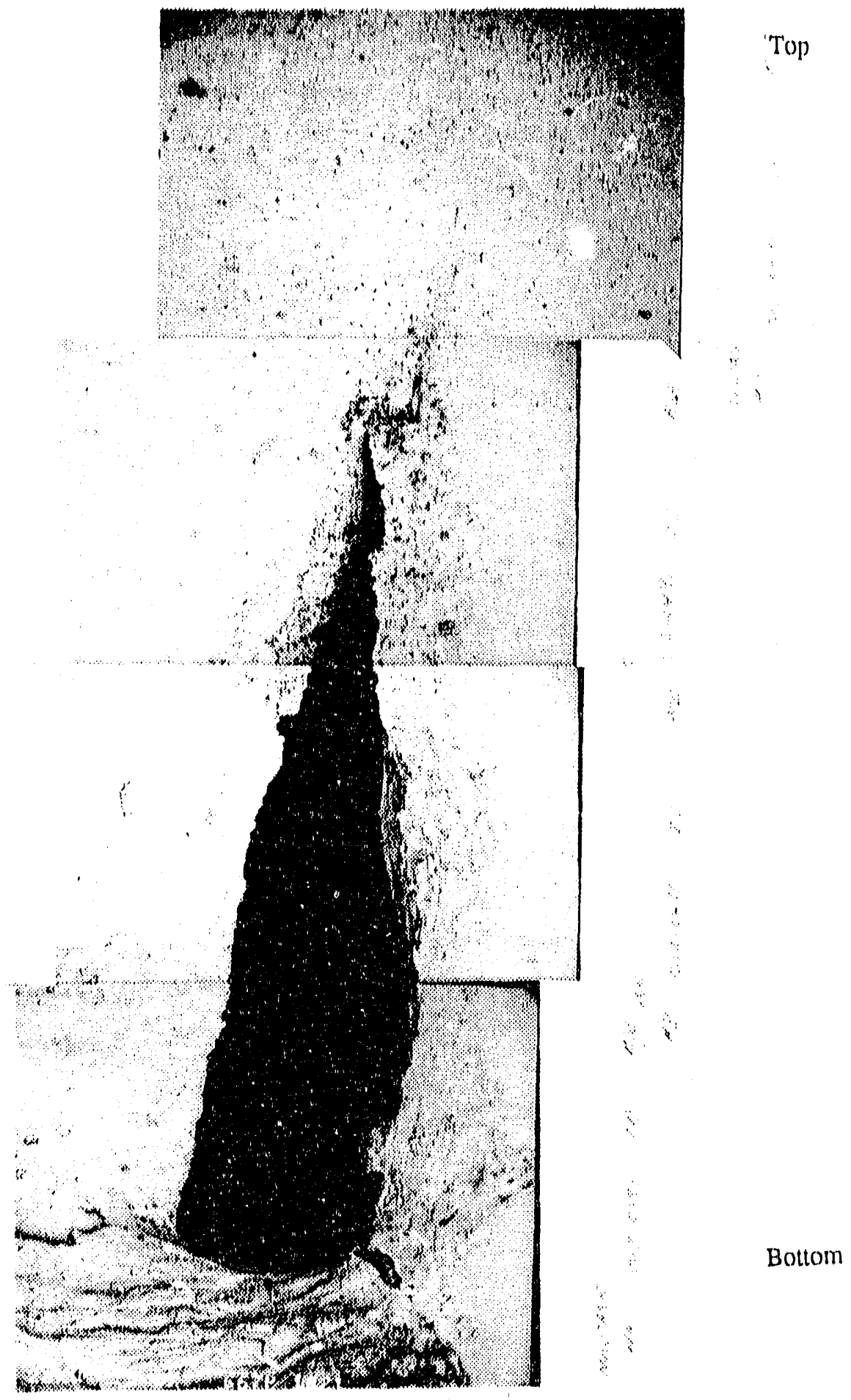

Figure 5-59a Spec.12, Montage of Inner Surface Near Fracture (BSE). 


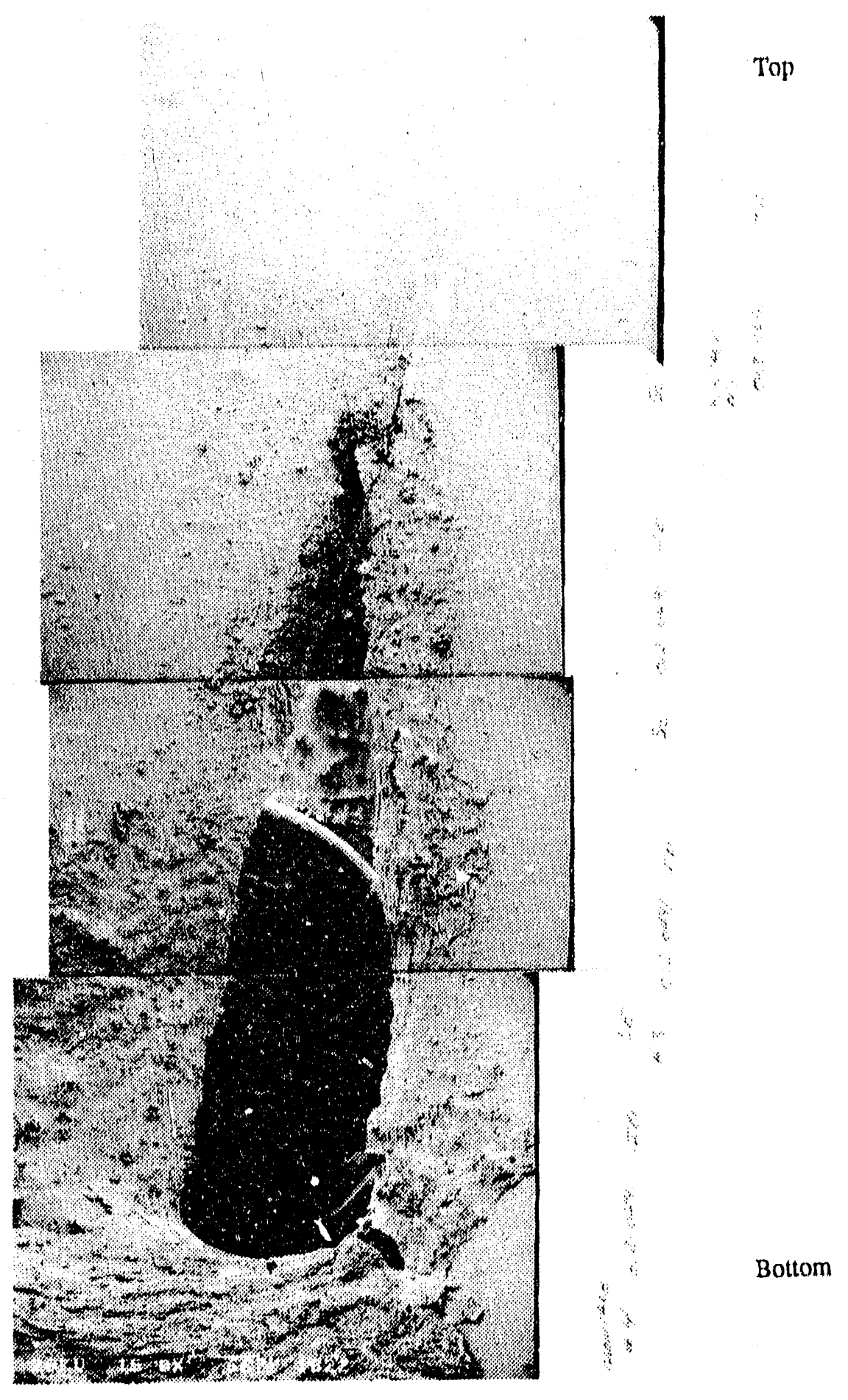

Figure 5-59b Spec.12, Montage of Inner Surface Near Fracture (SE), 


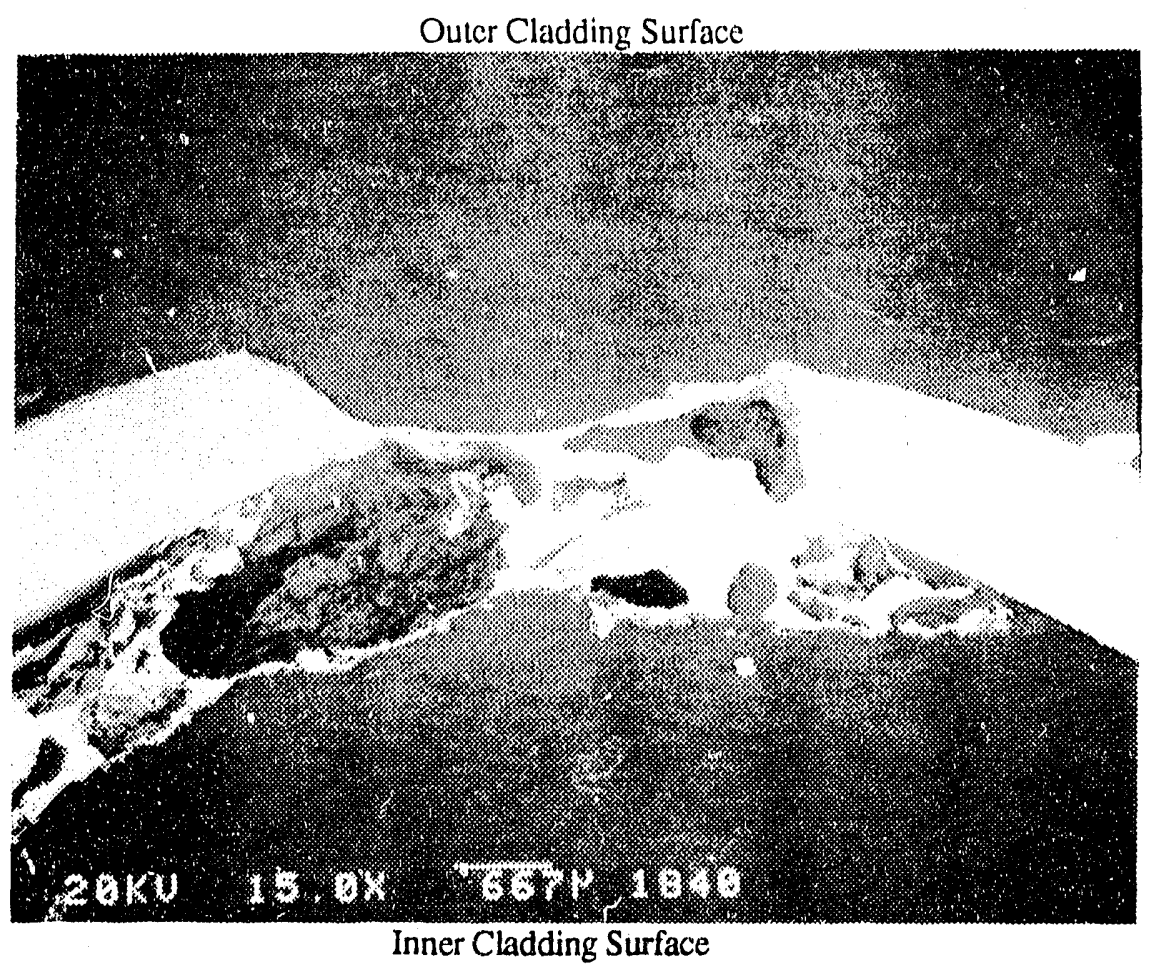

Figure 5-60 Spec.12, 1st Grind, Botiom Half, Low-Magnification SEM Micrograph (BSE, 15x).

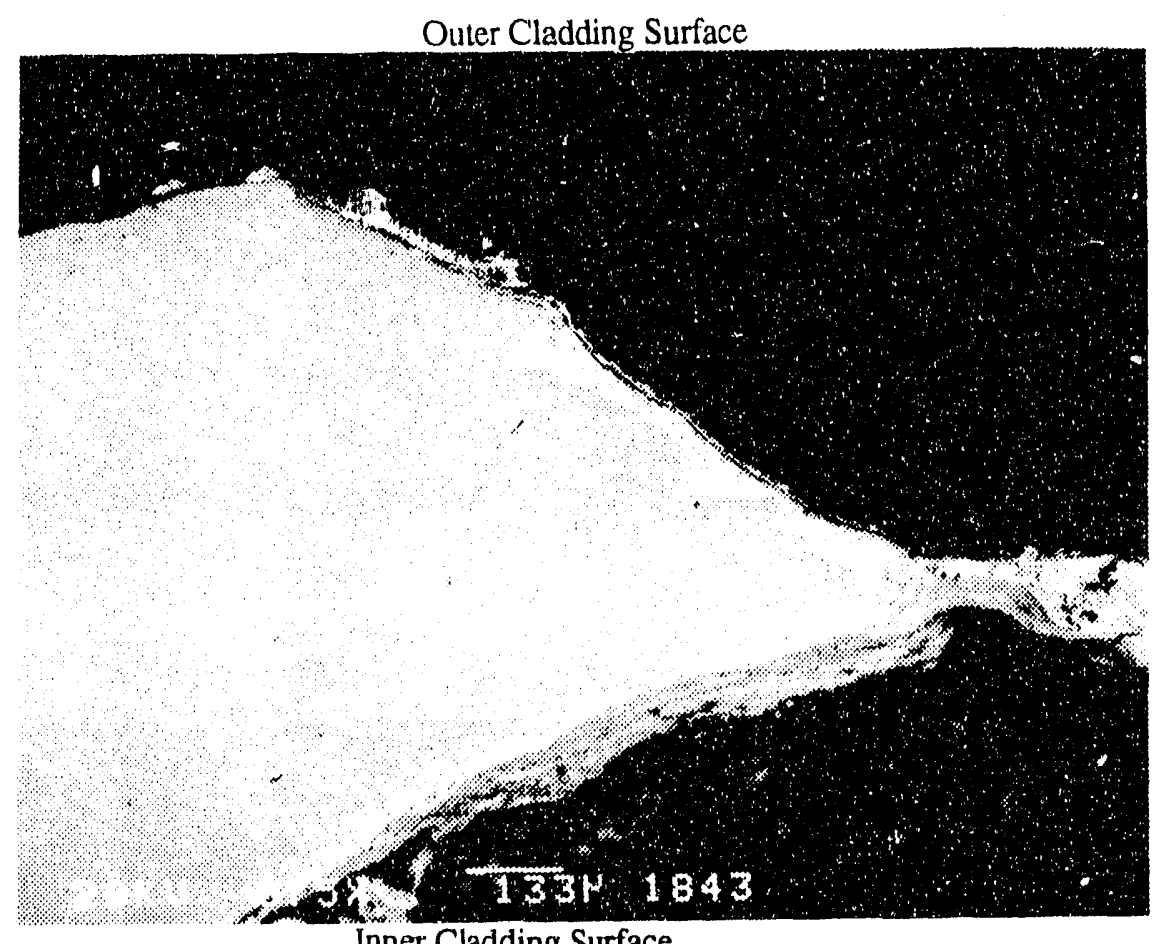

Inner Cladding Surface

Figure 5-61a Spec.12, 1st Grind, Bottom Half, Left Side (BSE, 75x). 


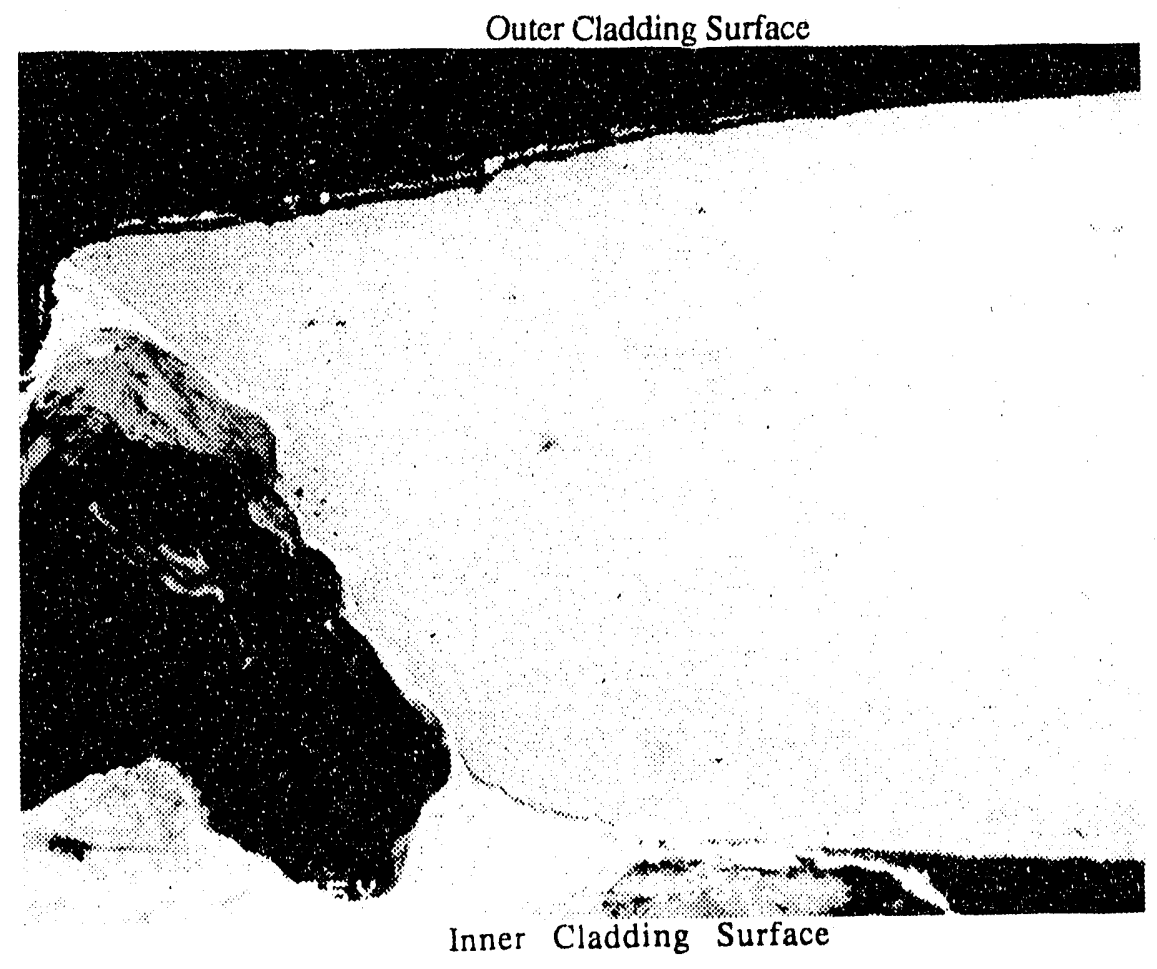

Figure 5-61b Spec.12, 1st Grind, Bottom Half, Right Side (BSE, 75x).

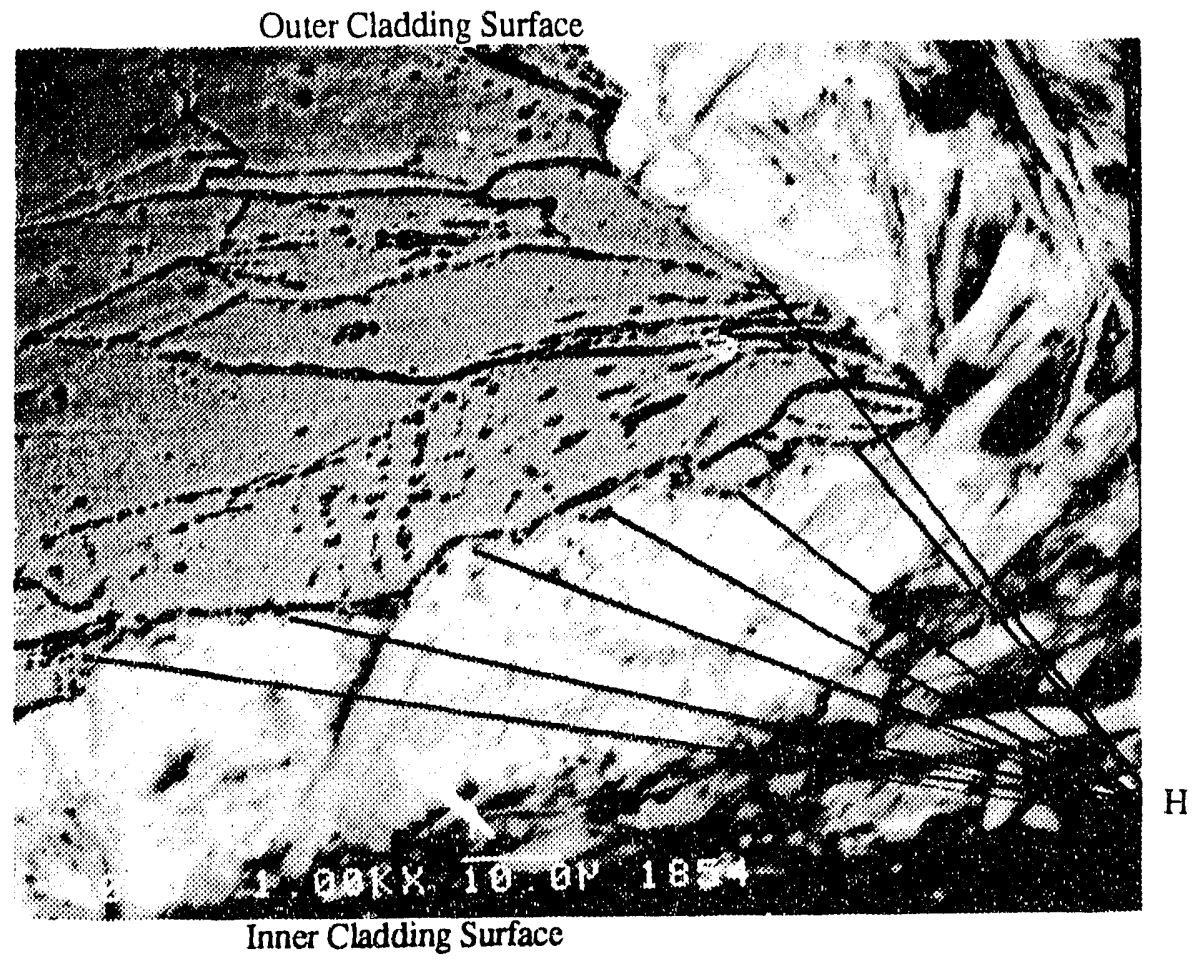

Figure 5-62a Spec.12, 1st Grind, Bottom Half, Left Side, Fracture Surface at I.D. (BSE, $1000 x)$. 


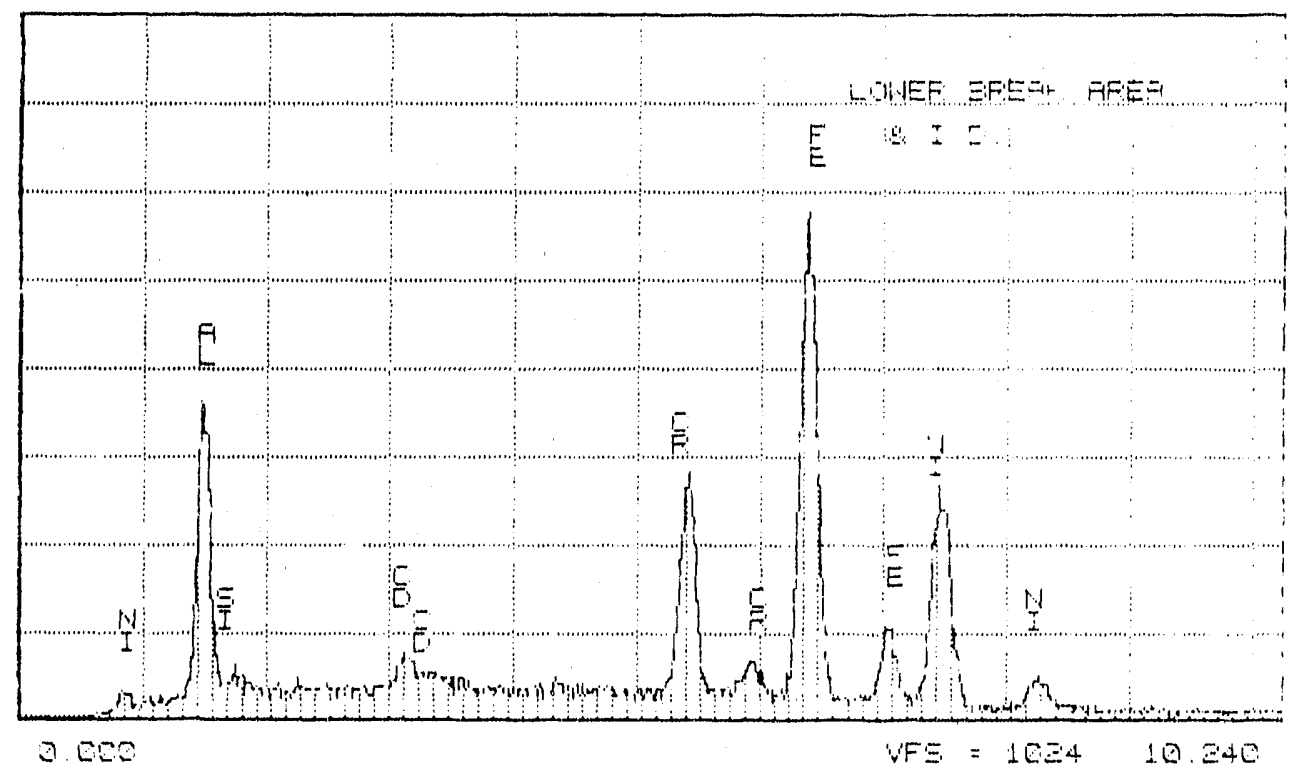

Figure 5-62b Spec.12, 1st Grind, Bottom Half, EDS Spectrum for Spot "H" on Figure 5$62 \mathrm{a}$.

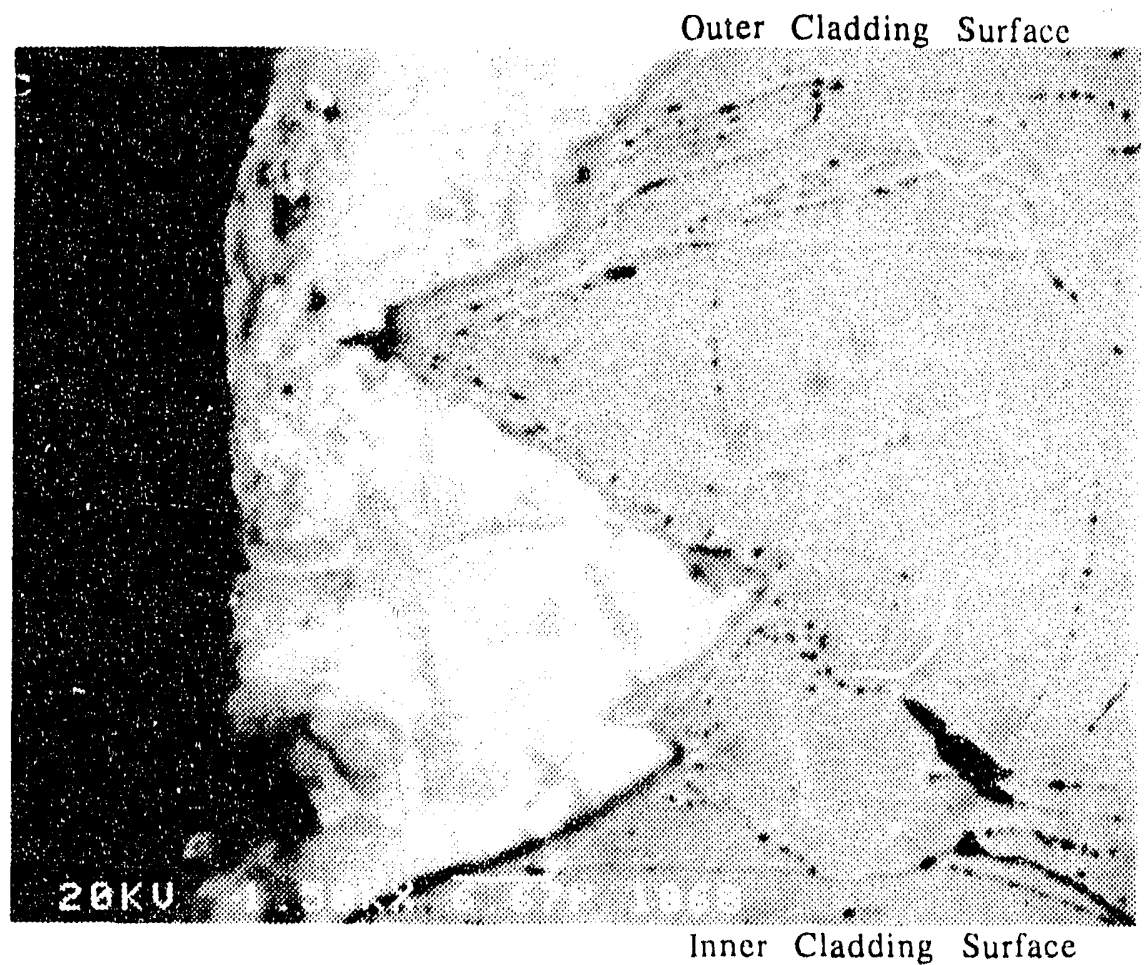

Figure 5-63 Spec.12, 1st Grind, Bottom Half, Right Side, Fracture Surface Near Cladding Midpoint (BSE, 1500x). 


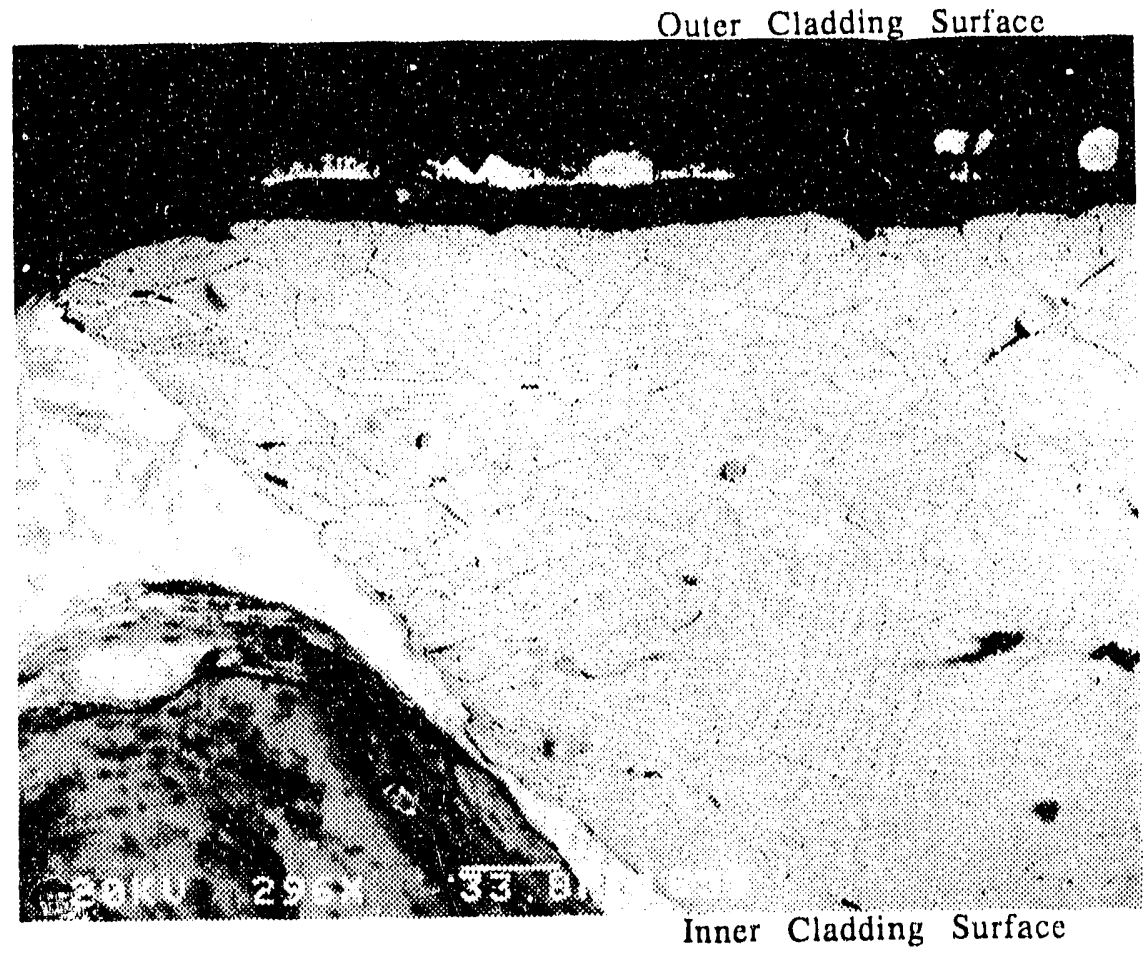

Figure 5-64a Spec. 12, 1st Grind, Bottom Half, Right Side, Fracture Surface at O.D. (BSE, 296x).

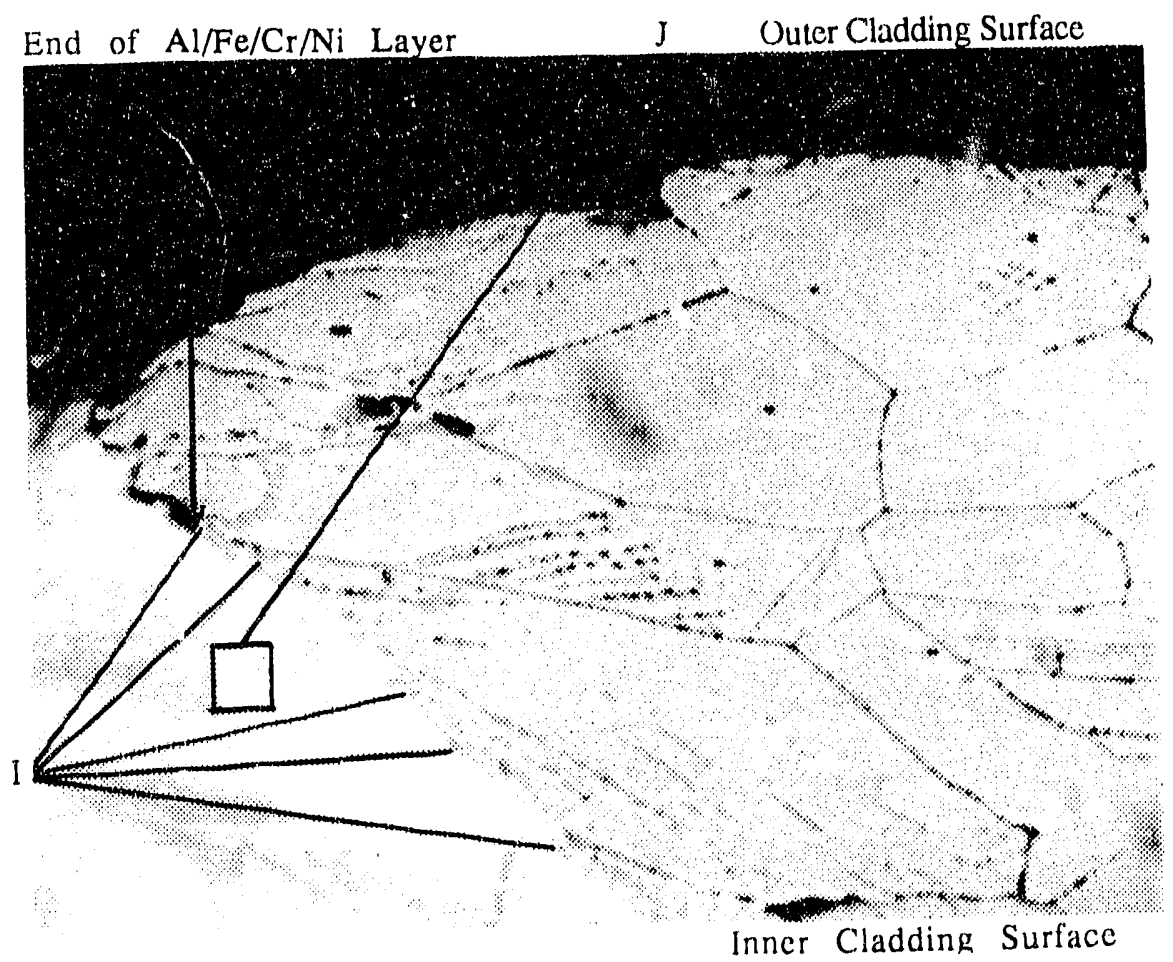

Figure 5-64b Spec.12, 1st Grind, Bottom Half, Right Side, Fracture Surface at O.D. (BSE, 1000x). 


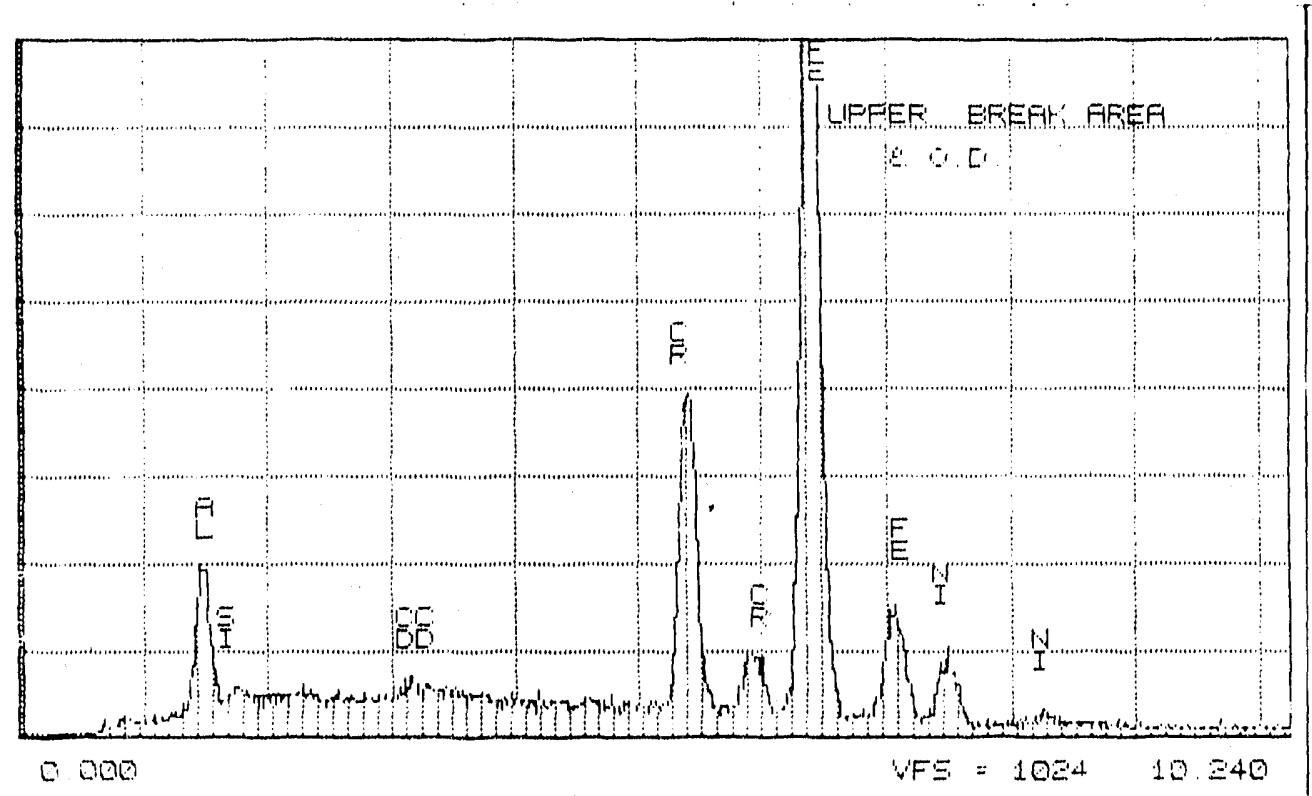

Figure 5-64c Spec.12, 1st Grind, Bottom Half, EDS Spectrum for Spot "I" on Figure 5$64 b$.

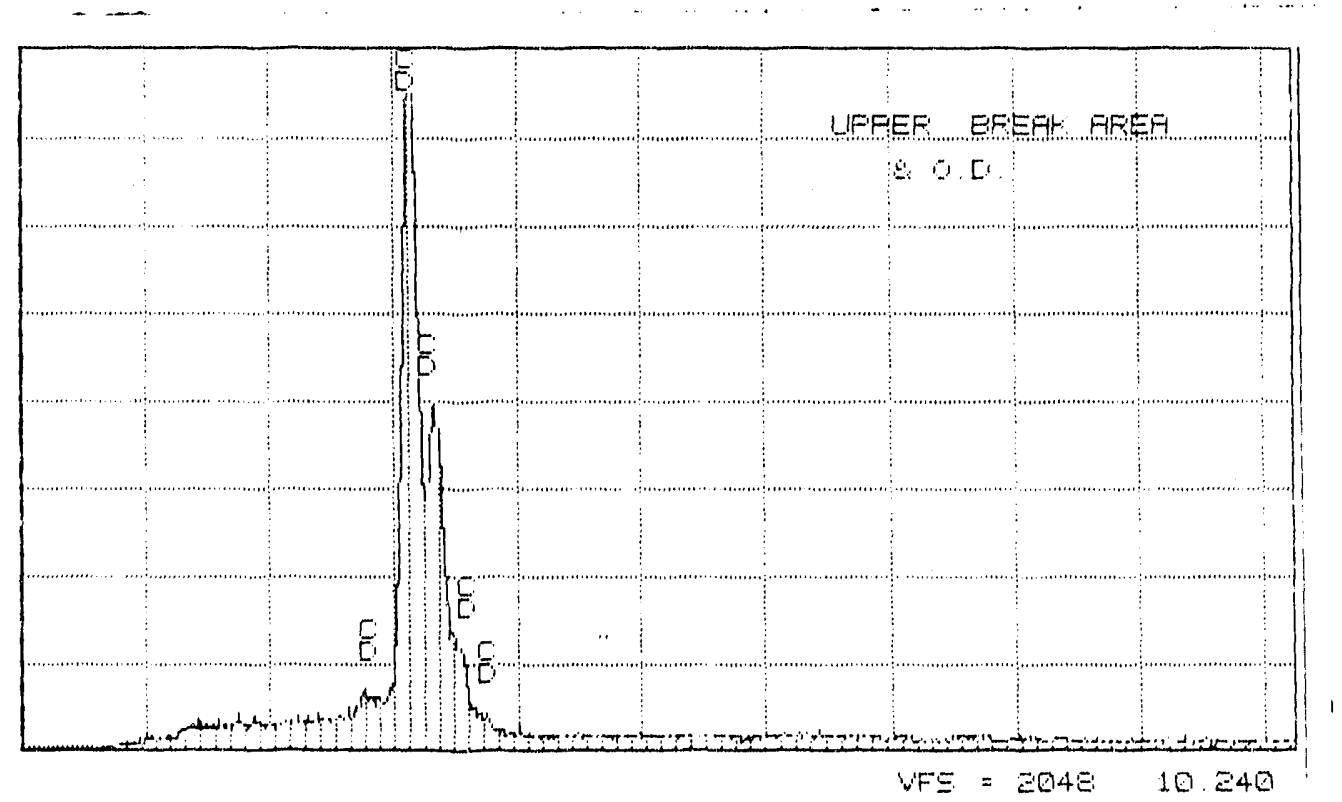

Figure 5-64d Spec.12, 1st Grind, Bottom Half, EDS Spectrum for Spot "J" on Figure 5$64 \mathrm{~b}$. 


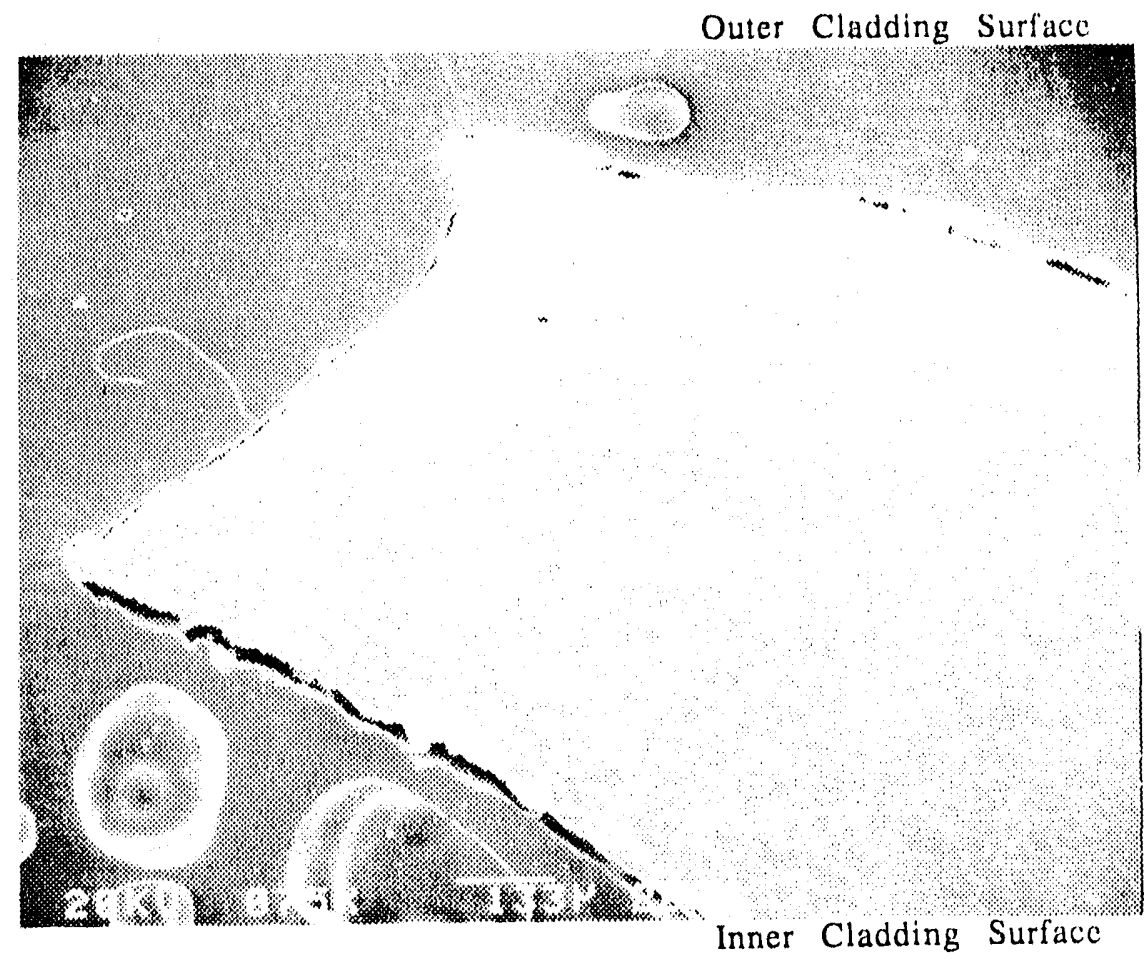

Figure 5-65a Spec.12, 1st Grind, Top Half, Left Side (SE, 75x).

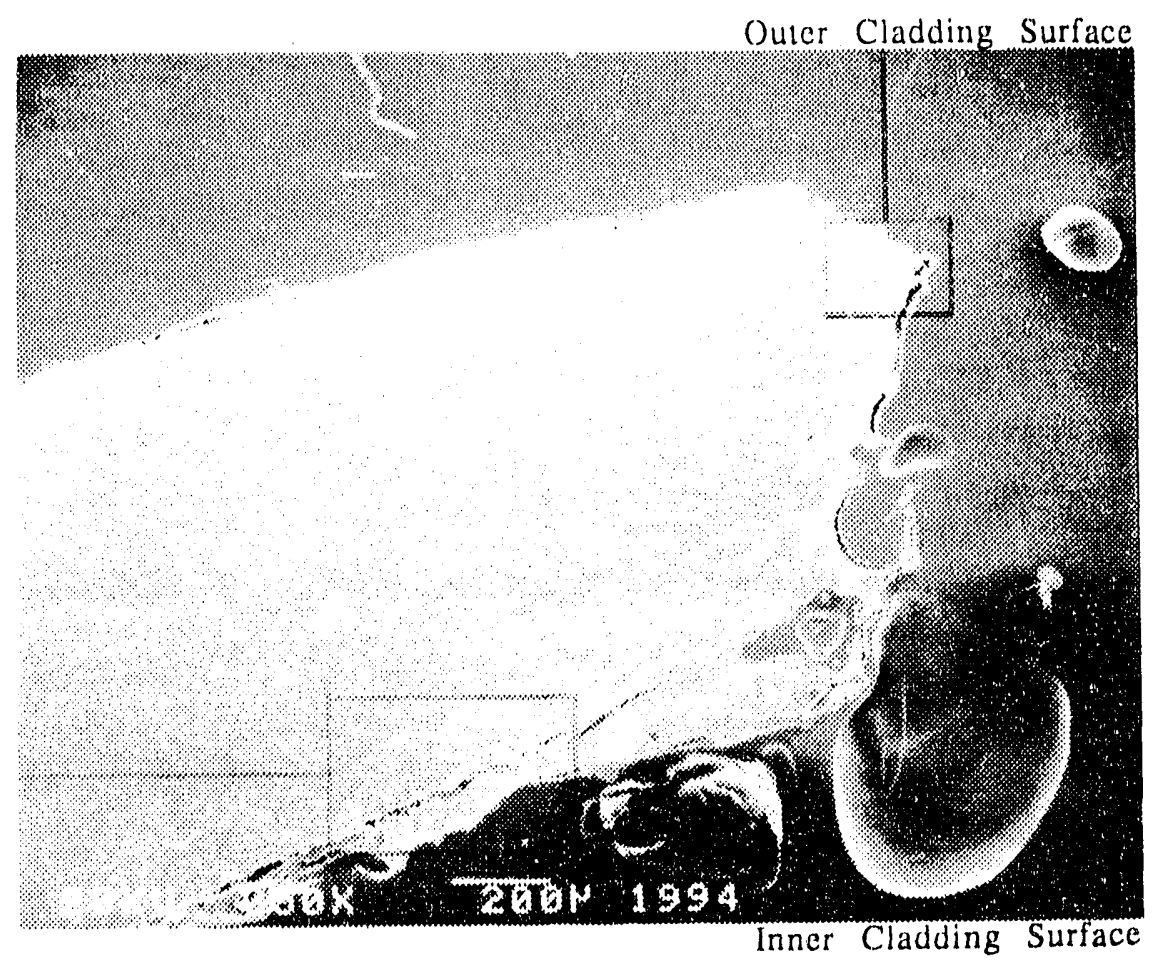

Figure 5-65b Spec.12, 1st Grind, Top Half, Right Side (SE, 50x). 


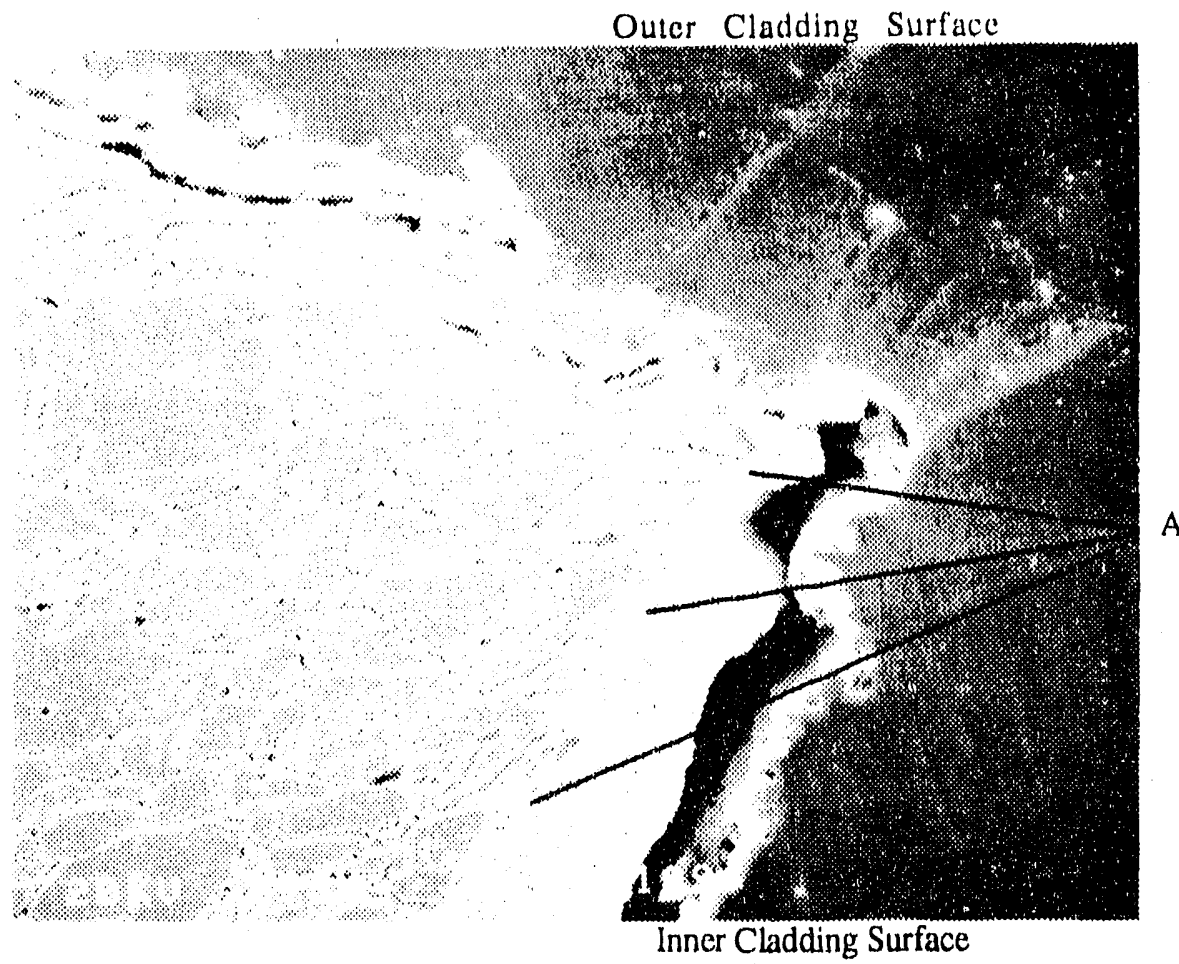

Figure 5-66a Spec.12, 1st Grind, Top Half, Right Side, Fracture Surface near O.D. (SE, $393 x)$.

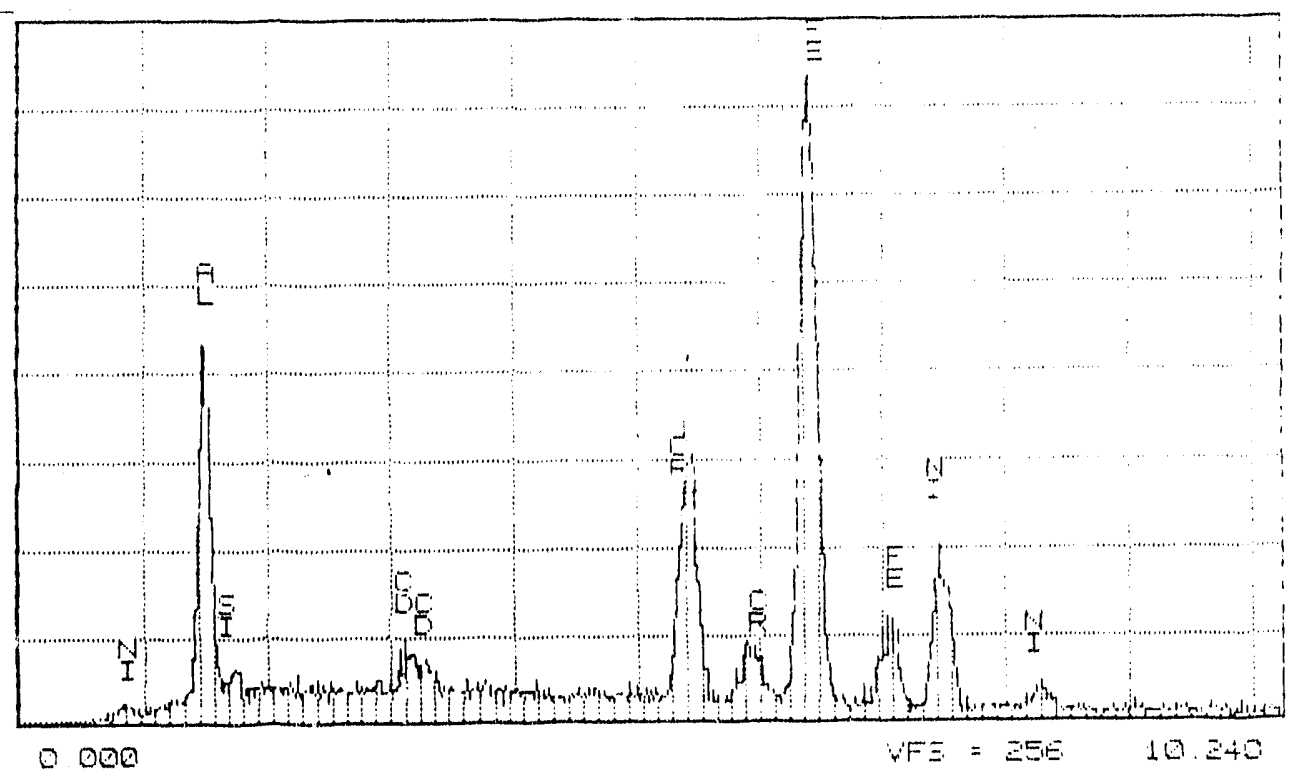

Figure 5-66b Spec.12, 1st Grind, Top Half, EDS Spectrum for Spot "A" on Figure 5$66 \mathrm{a}$. 


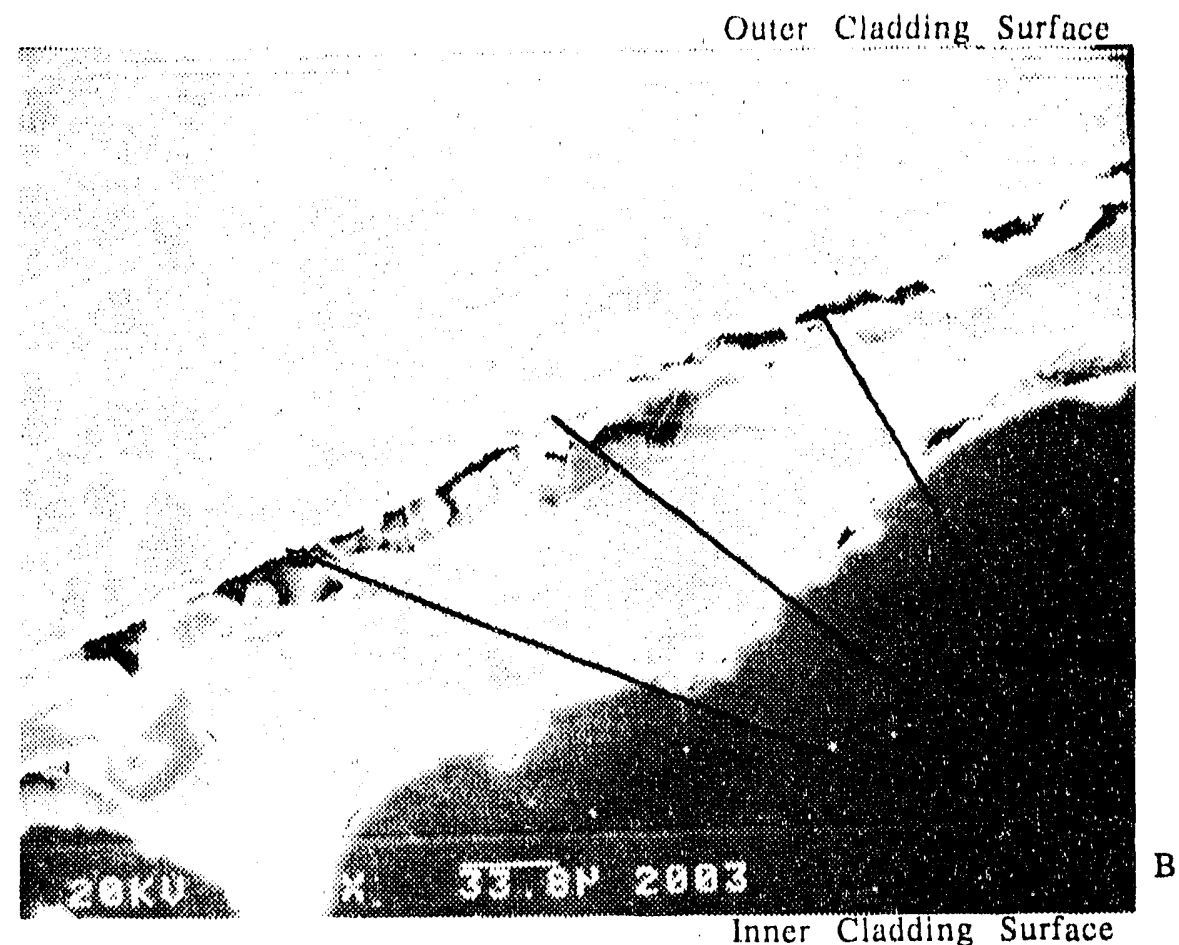

Figure 5-67a Spec.12, 1 st Grind, Top Half, Right Side, Inner Cladding Surface (SE, 296x).

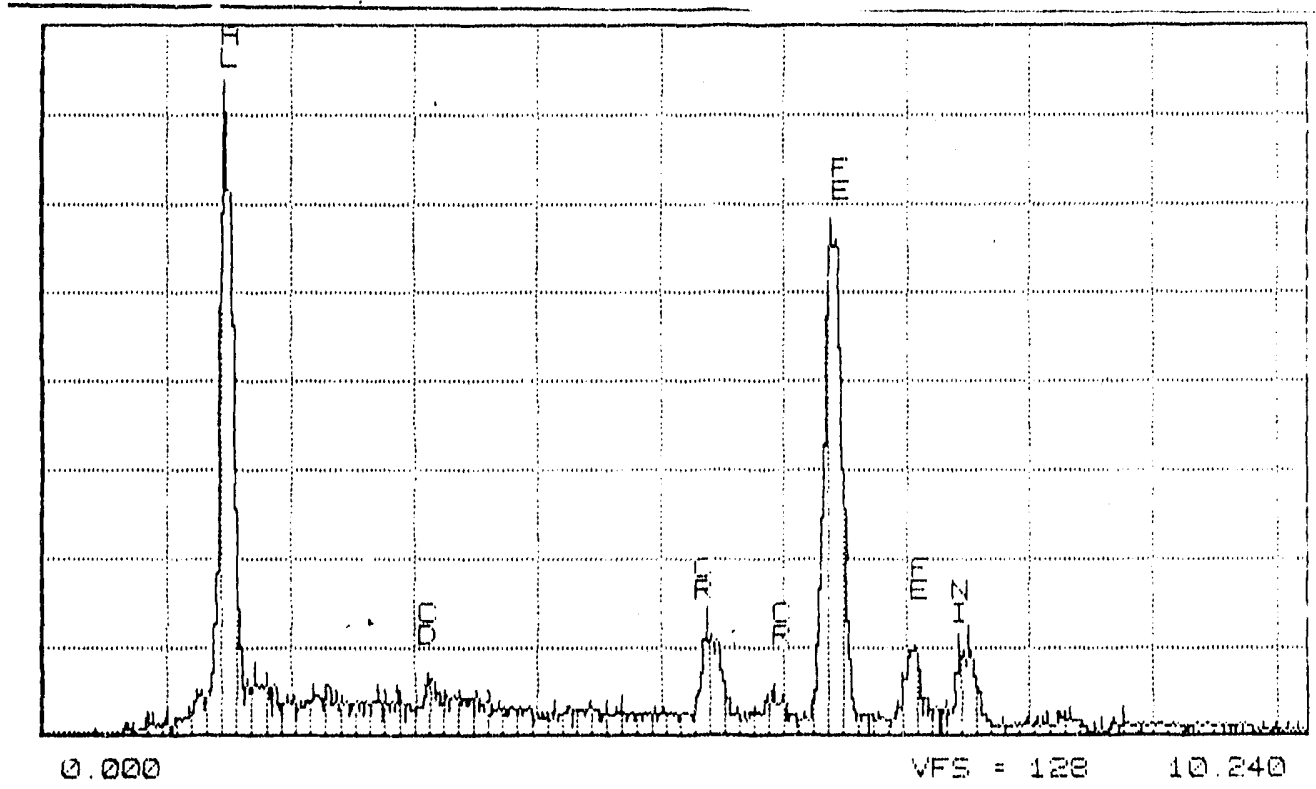

Figure 5-67b Spec.12, 1st Grind, Top Half, EDS Spectrum for Spot "B" on Figure 5$67 a$. 


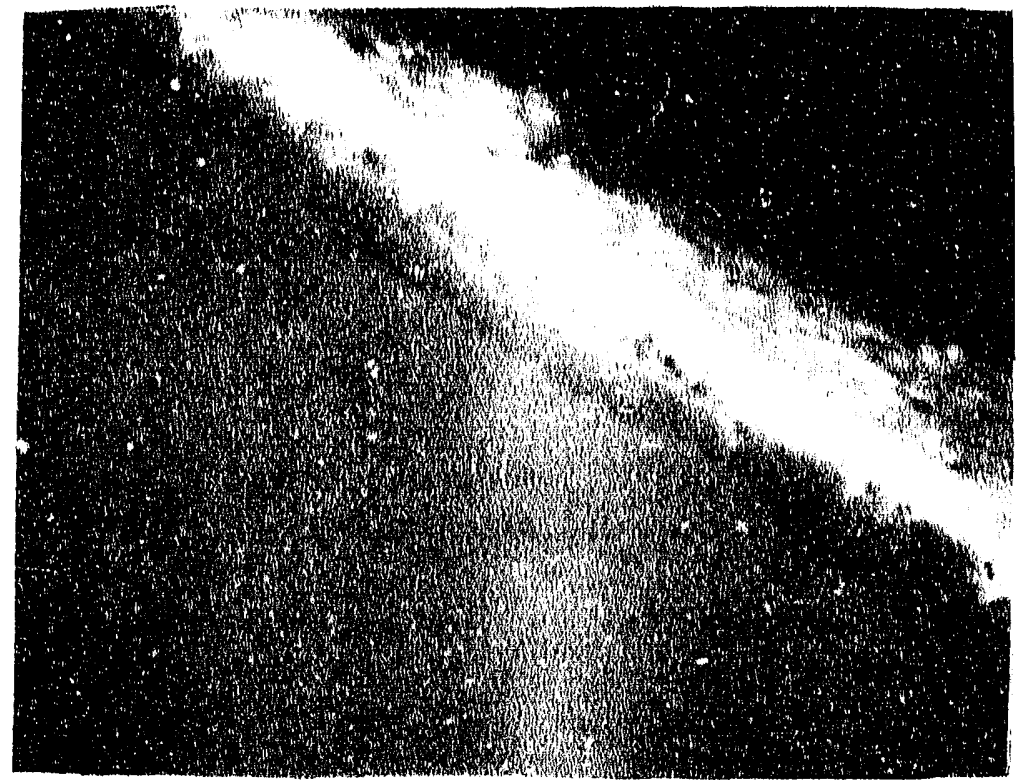

Figure 5-68a Spec.9, 1 st Grind, Bottom Half, Left Side, Cladding I.D., Electron Microprobe Micrograph (BSE).

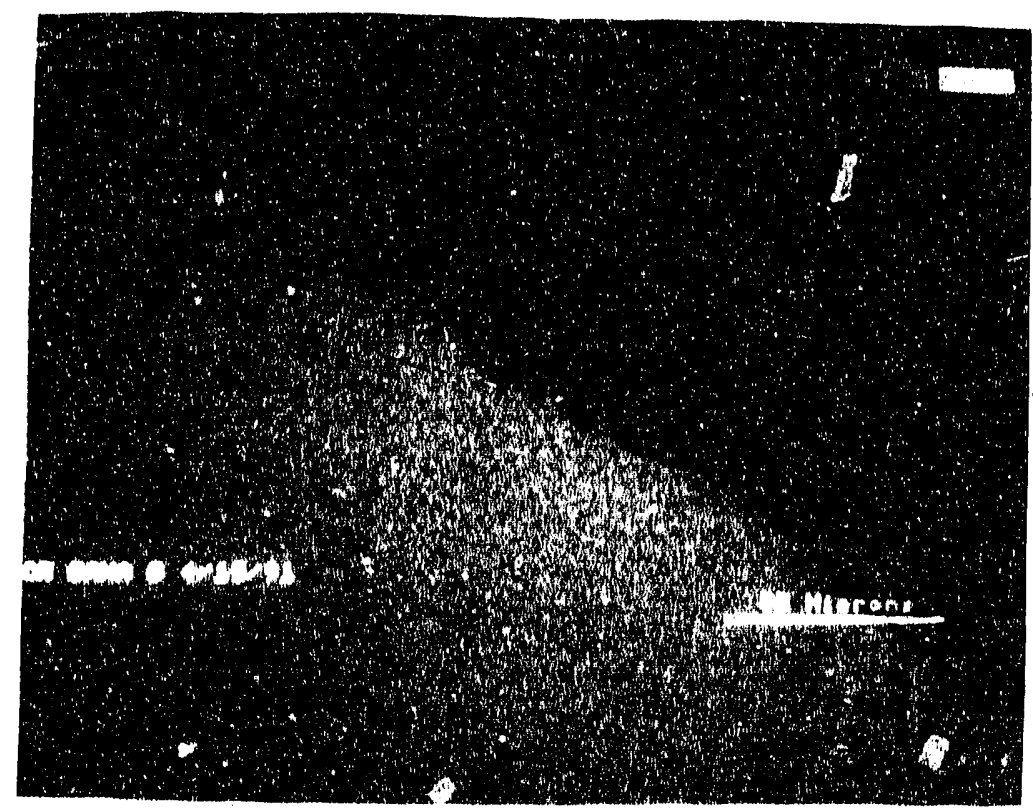

Figure 5-68b Spec.9, 1st Grind, Bottom Half, Left Side, Cladding I.D., Cr x-ray map. 


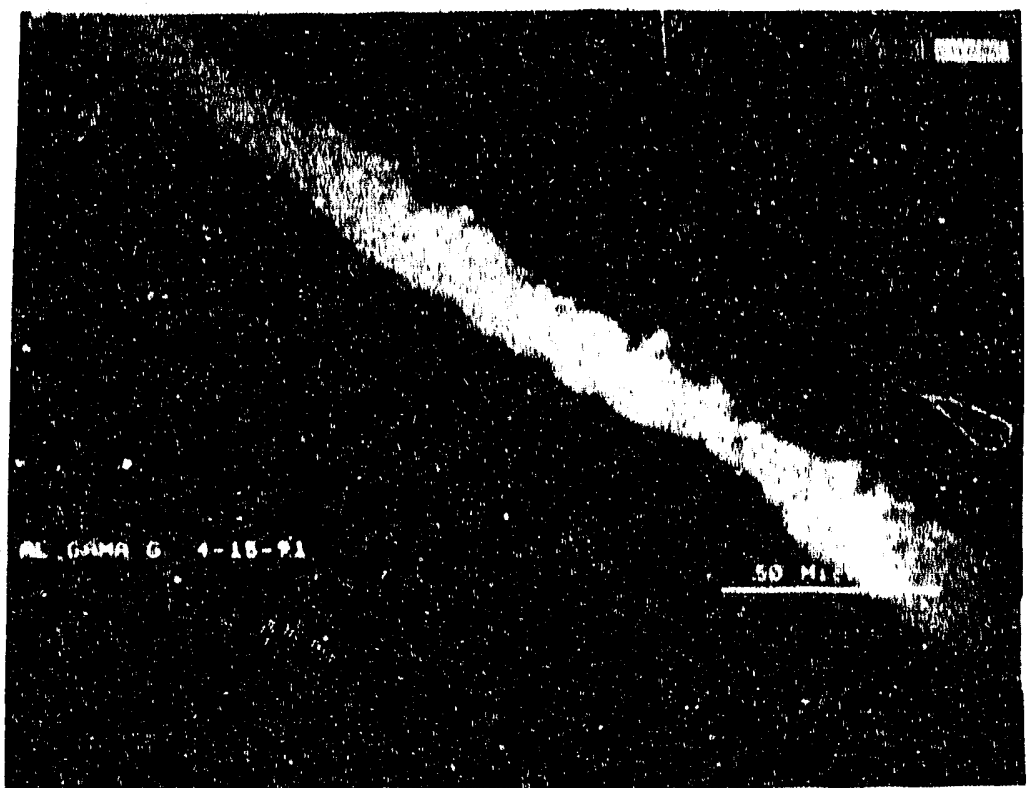

Figure 5-68c Spec.9, 1st Grind, Bottom Half, Left Side, Cladding I.D., Al x-ray map.

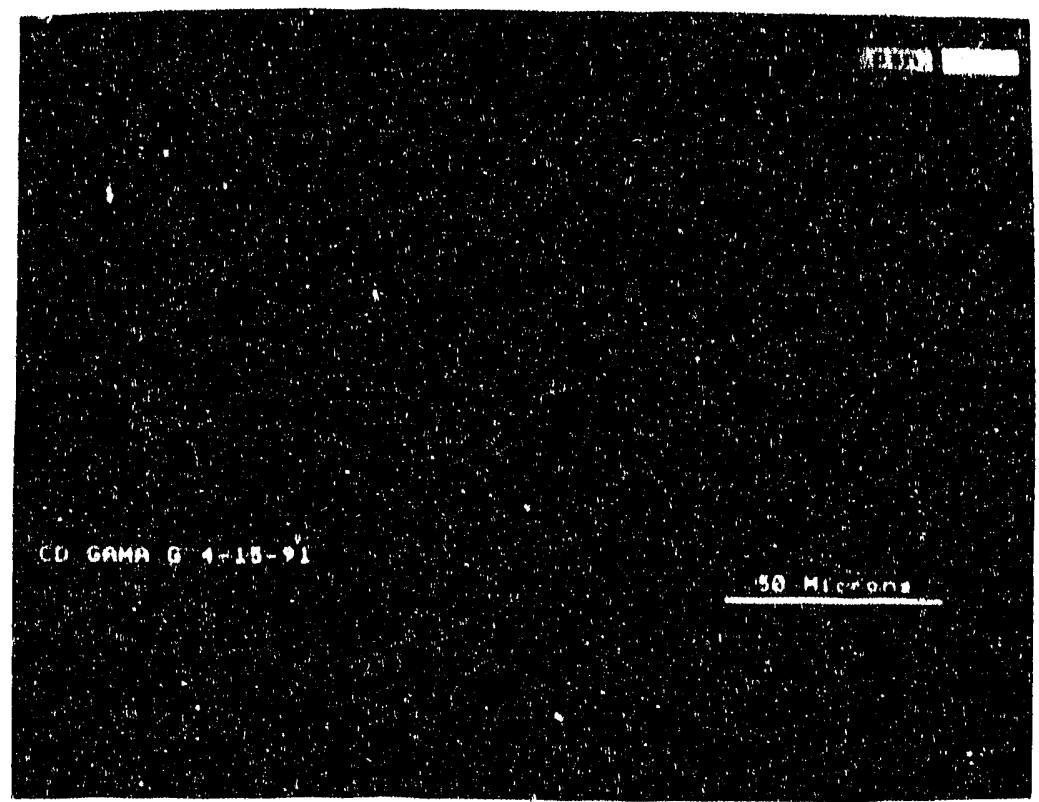

Figure 5.68d Spec.9, Ist Grind, Bottom Half, Left Side, Cladding I.D., Cd x ray map. 


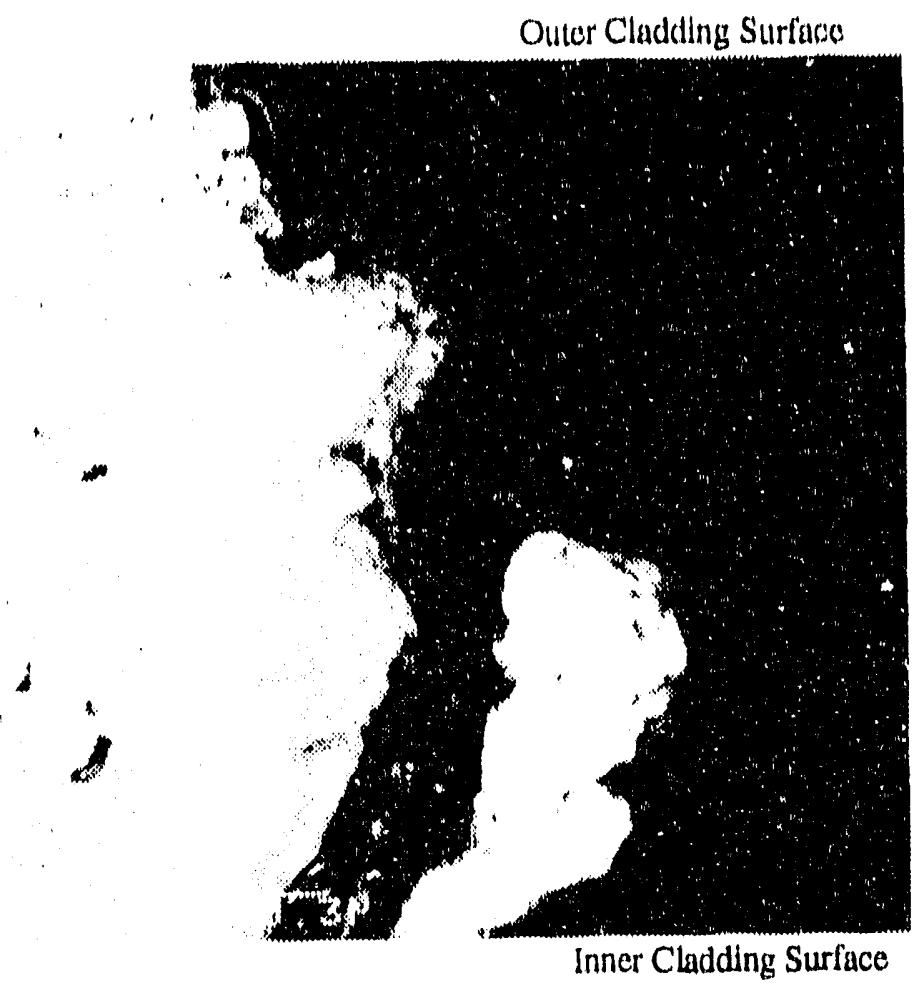

Figure 5-69 Spec.9, 1st Grind, Bottom Half, Left Side, $\approx 1 / 2$ throughwall, SEM Micrograph (BSE, 500x). 


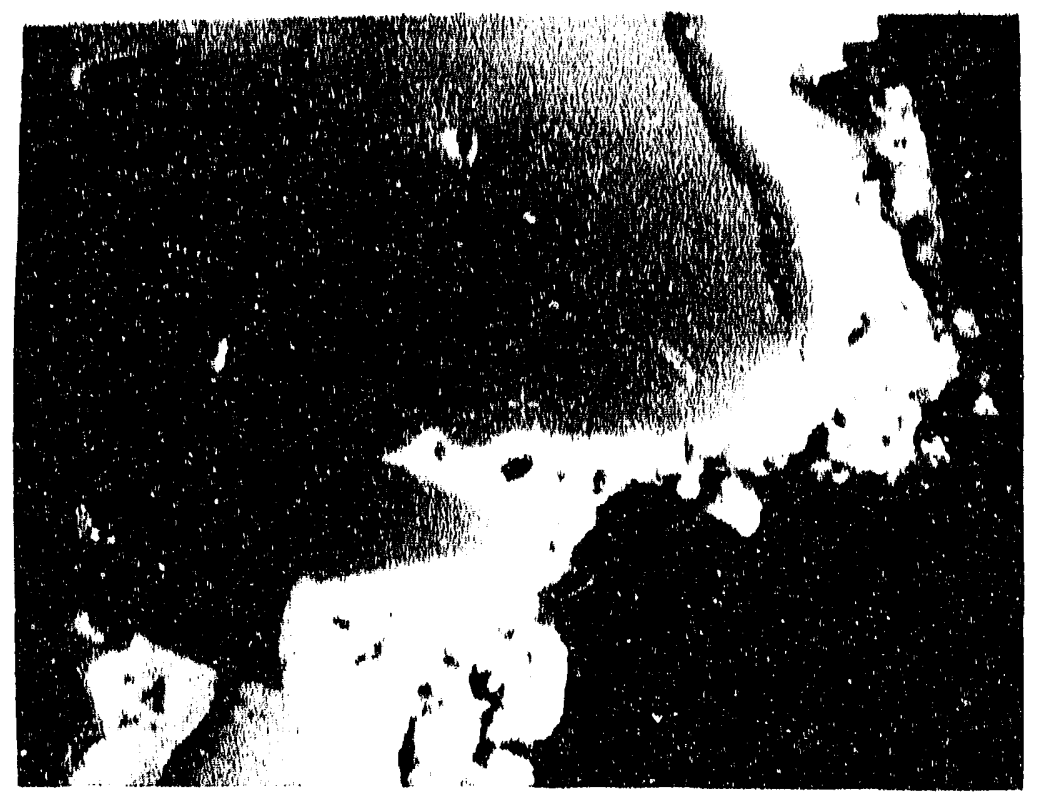

Figure 5-70a Spec,9, Ist Grind, Bottom Half, Left Side, $\approx 1 / 2$ throughwall, Electron Microprobe Micrograph (BSE).

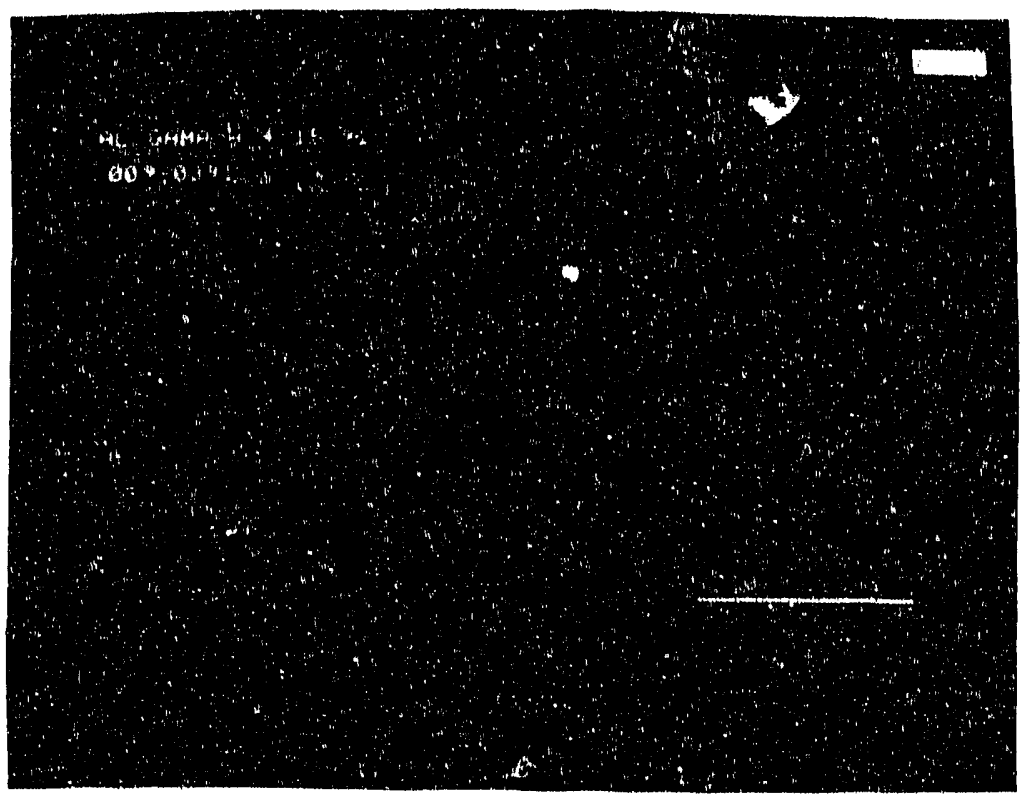

Figure 5-70t Spec.9, 1 st Grind, Bottom Half, Left Side, $\approx 1 / 2$ throughwall, Al $x$-ray map. 


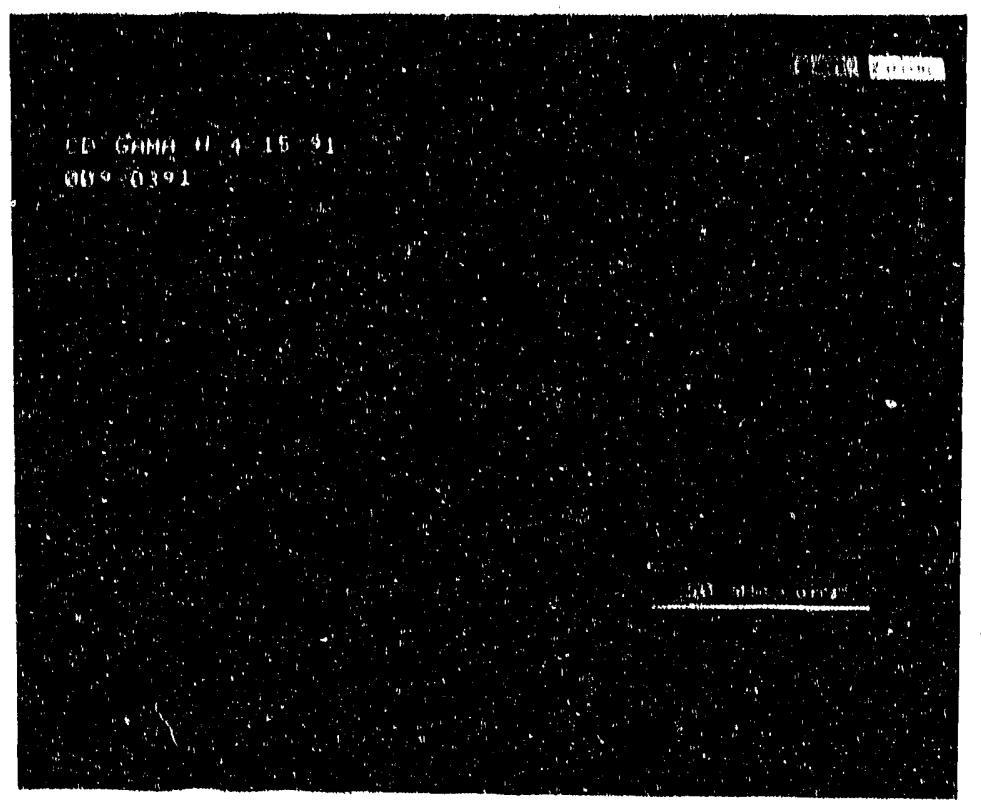

Figure 5-7()c Spec.9, 1 st Grind, Bottom Half, Left Side, $\approx 1 / 2$ throughwall, Cd $x$-ray map.

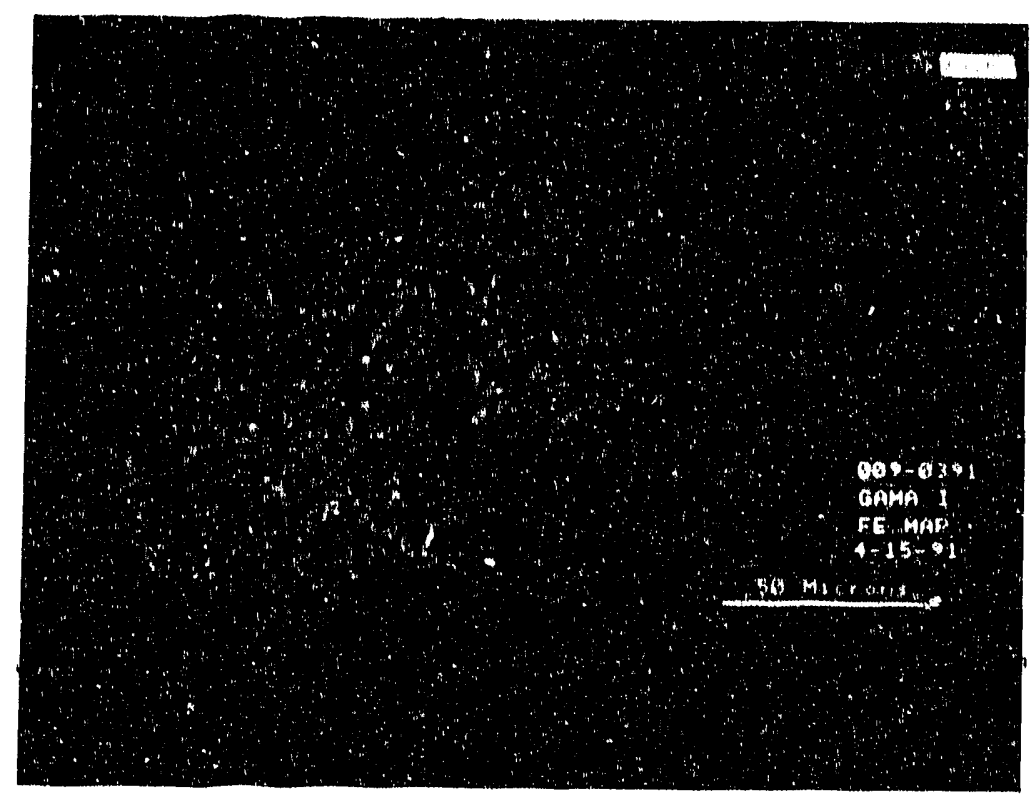

Figure 5-70d Spec.9, 1 st Grind, Bottom Half, Left Side, $=1 / 2$ throughwall, Fe $x$-ray map. 


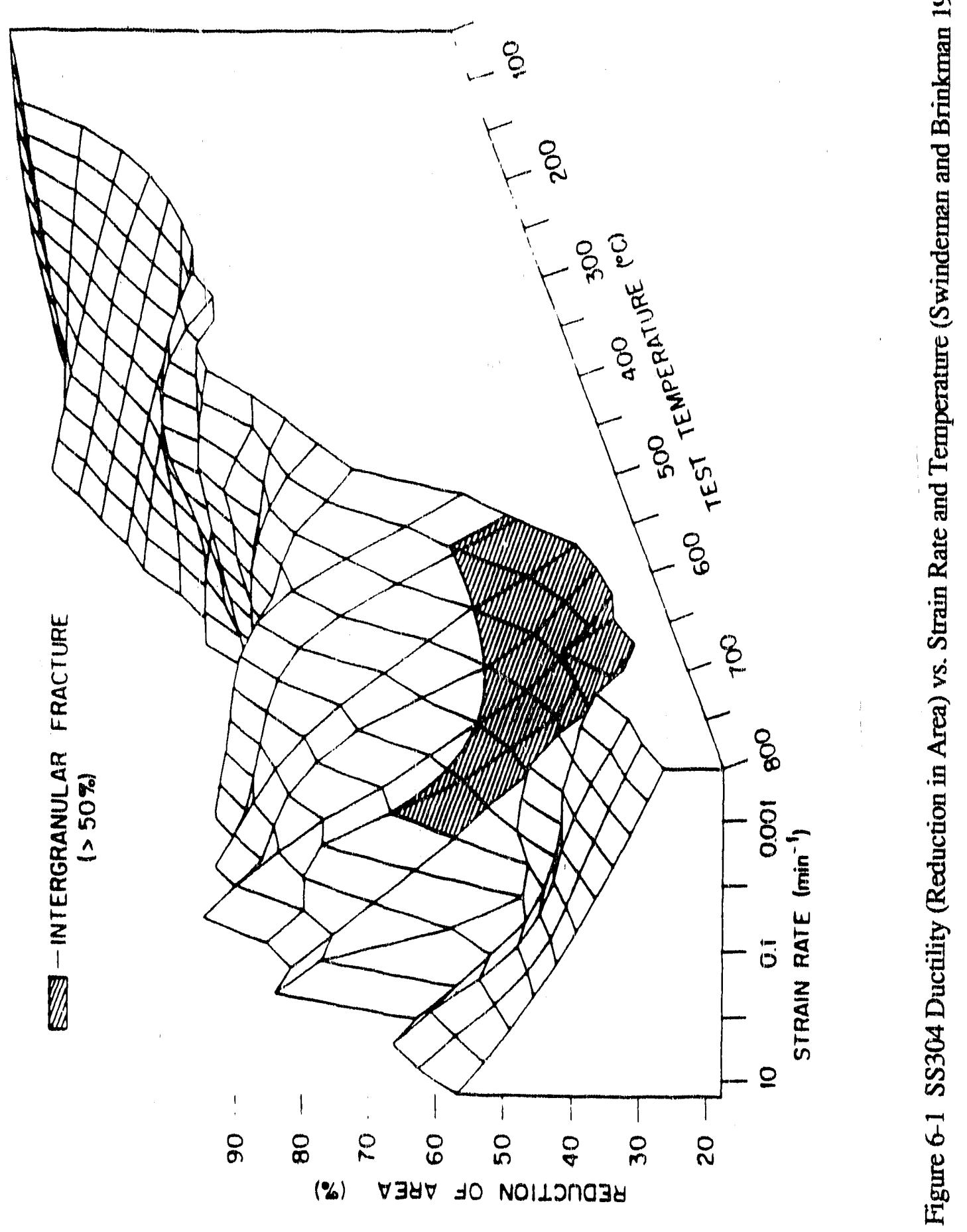



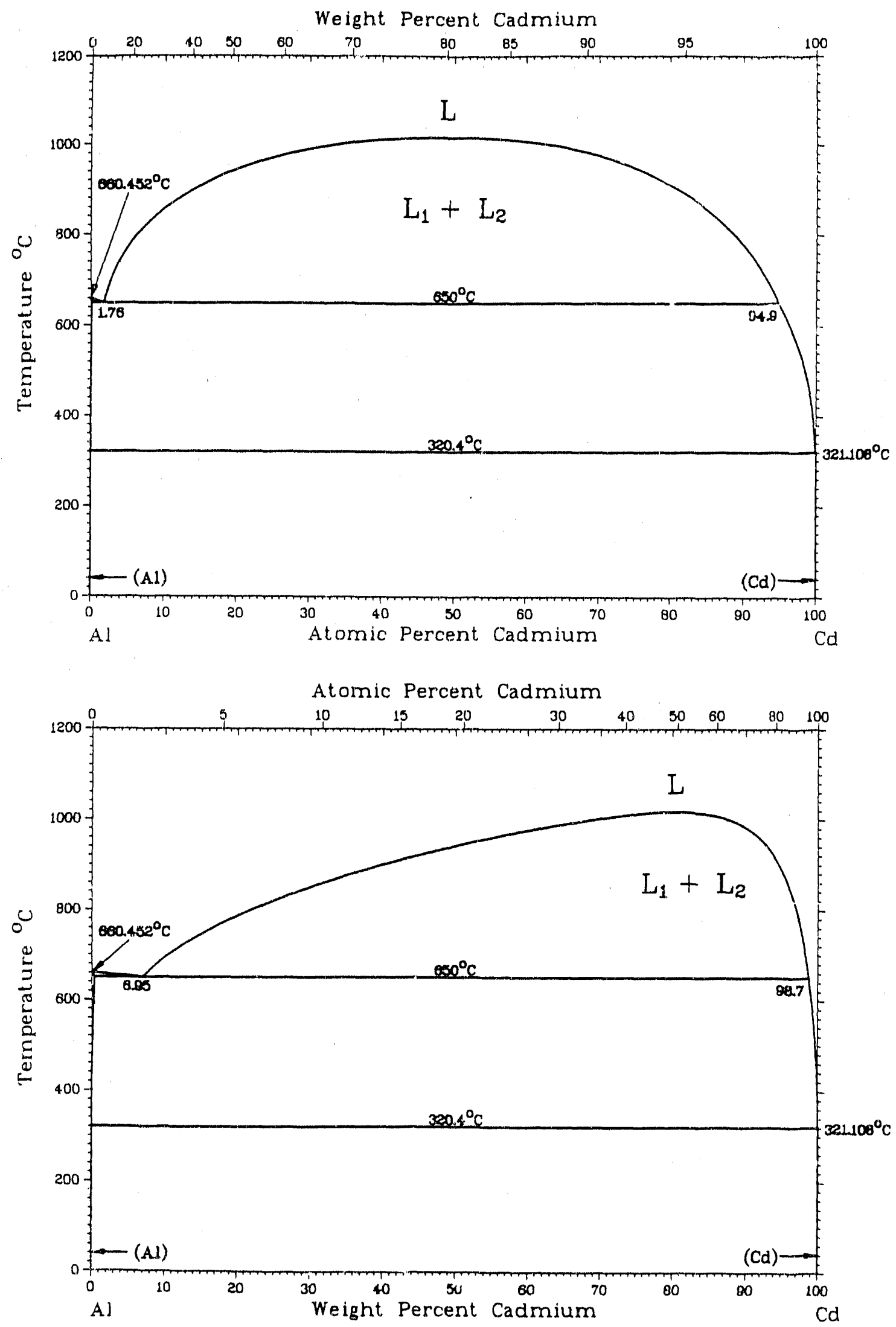

Figure G-2 Al-Cd Phase Diagram (ASM 1990). 


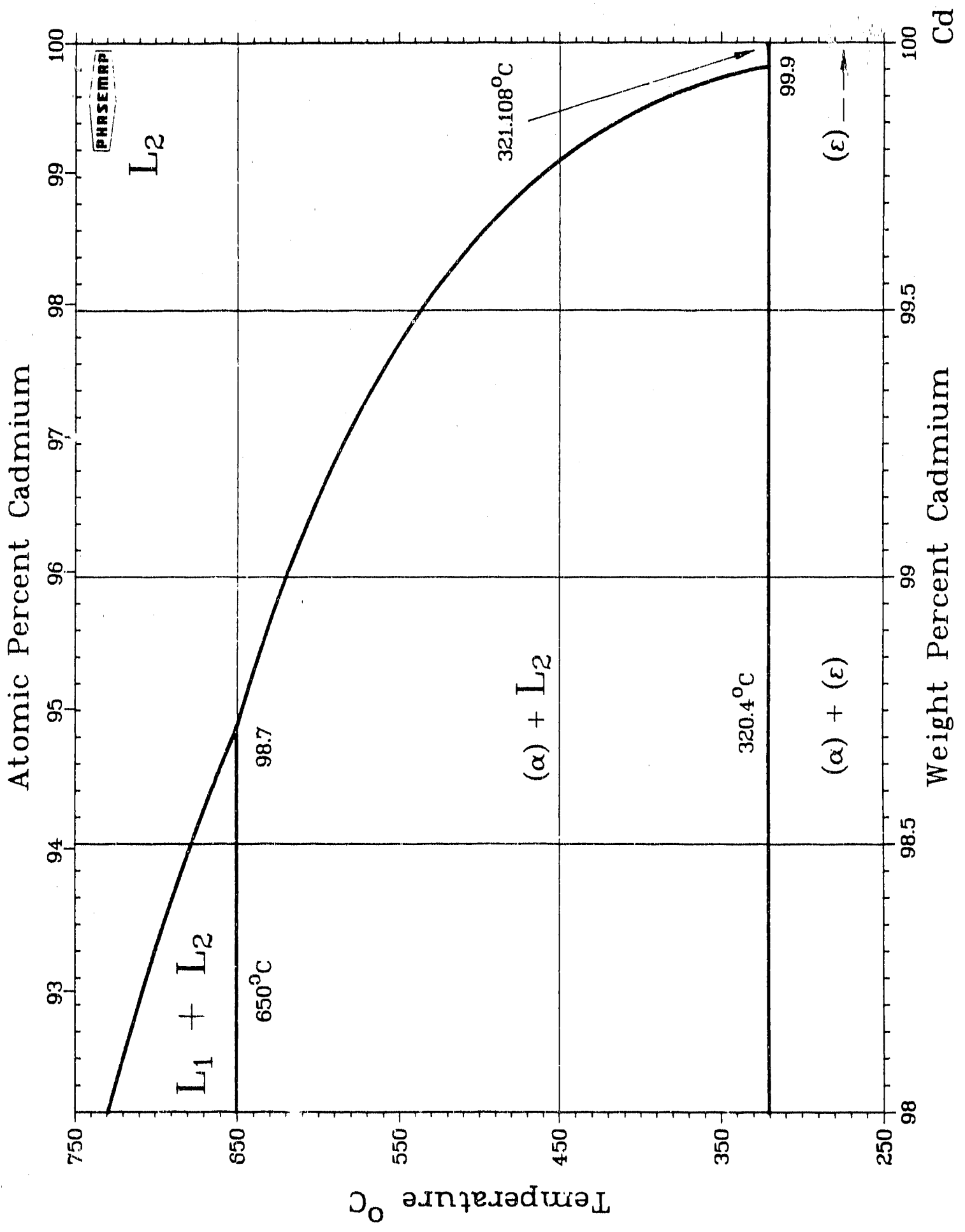

Figure 6-3 Cd-Rich End of Al-Cd Phase Diagram (McAlister 1982). 

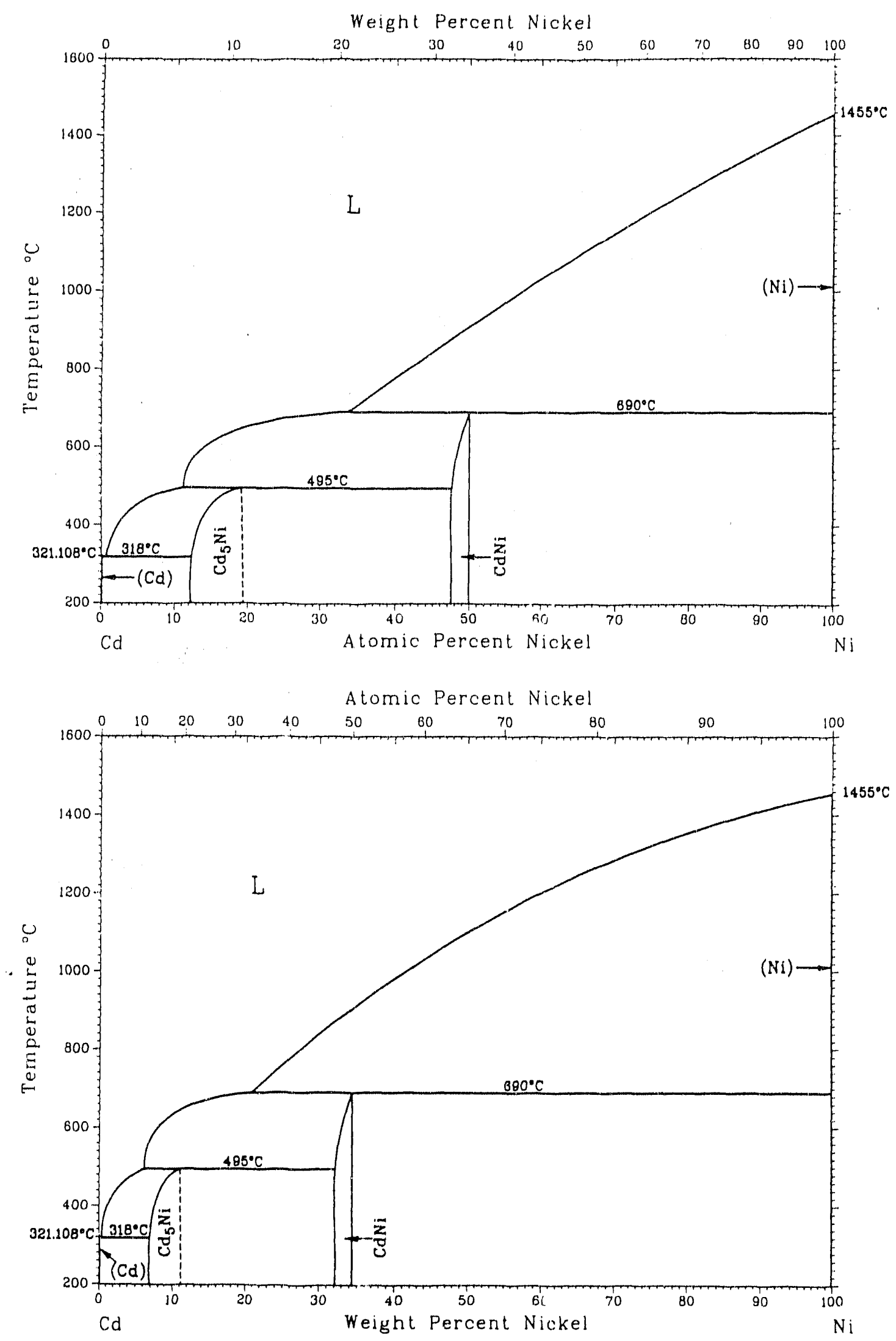

Figure 6-4 Cd-Ni Phase Diagram (ASM 1990). 

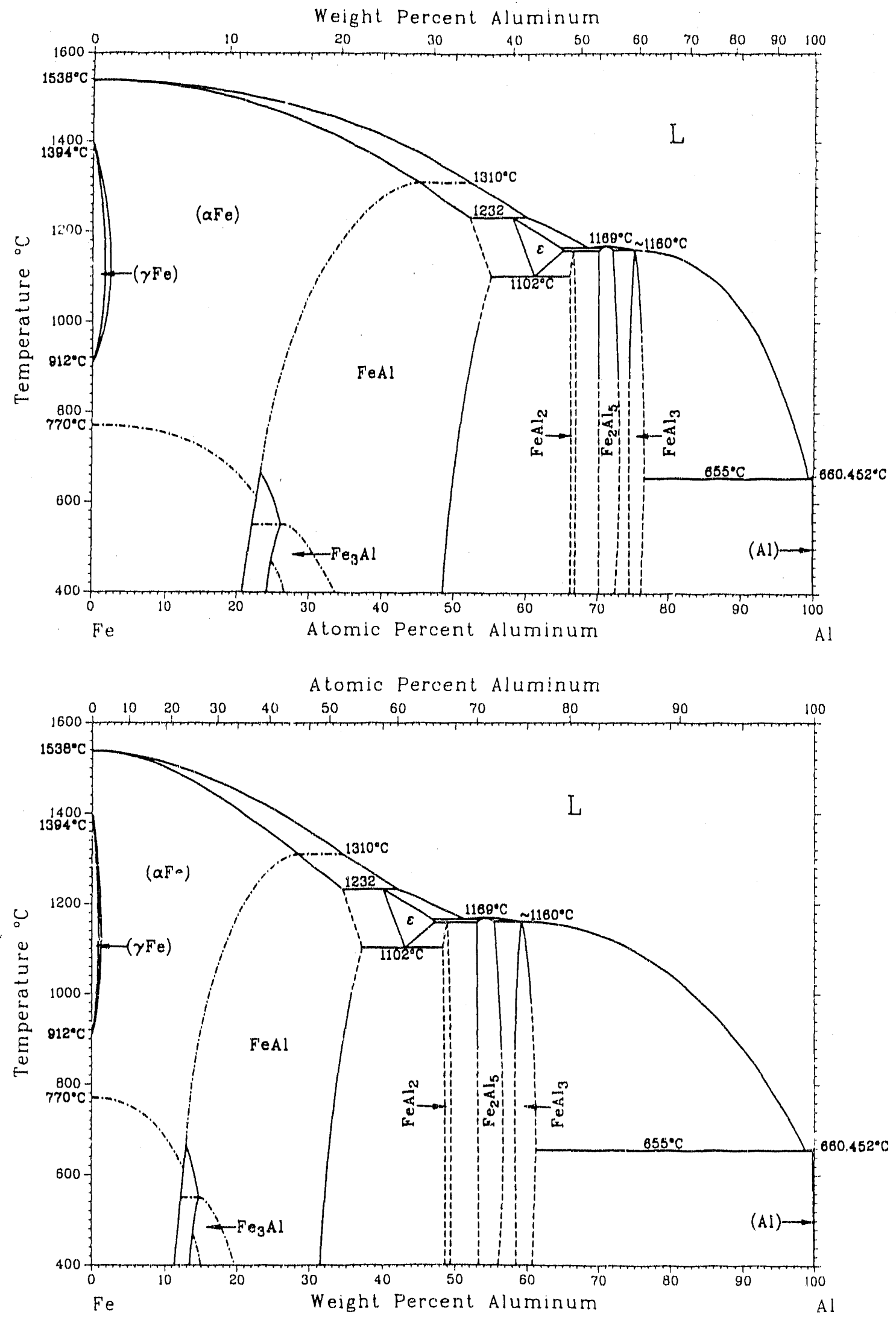

Figure 6-5 Al-Fe Phase Diagram (ASM 1990). 

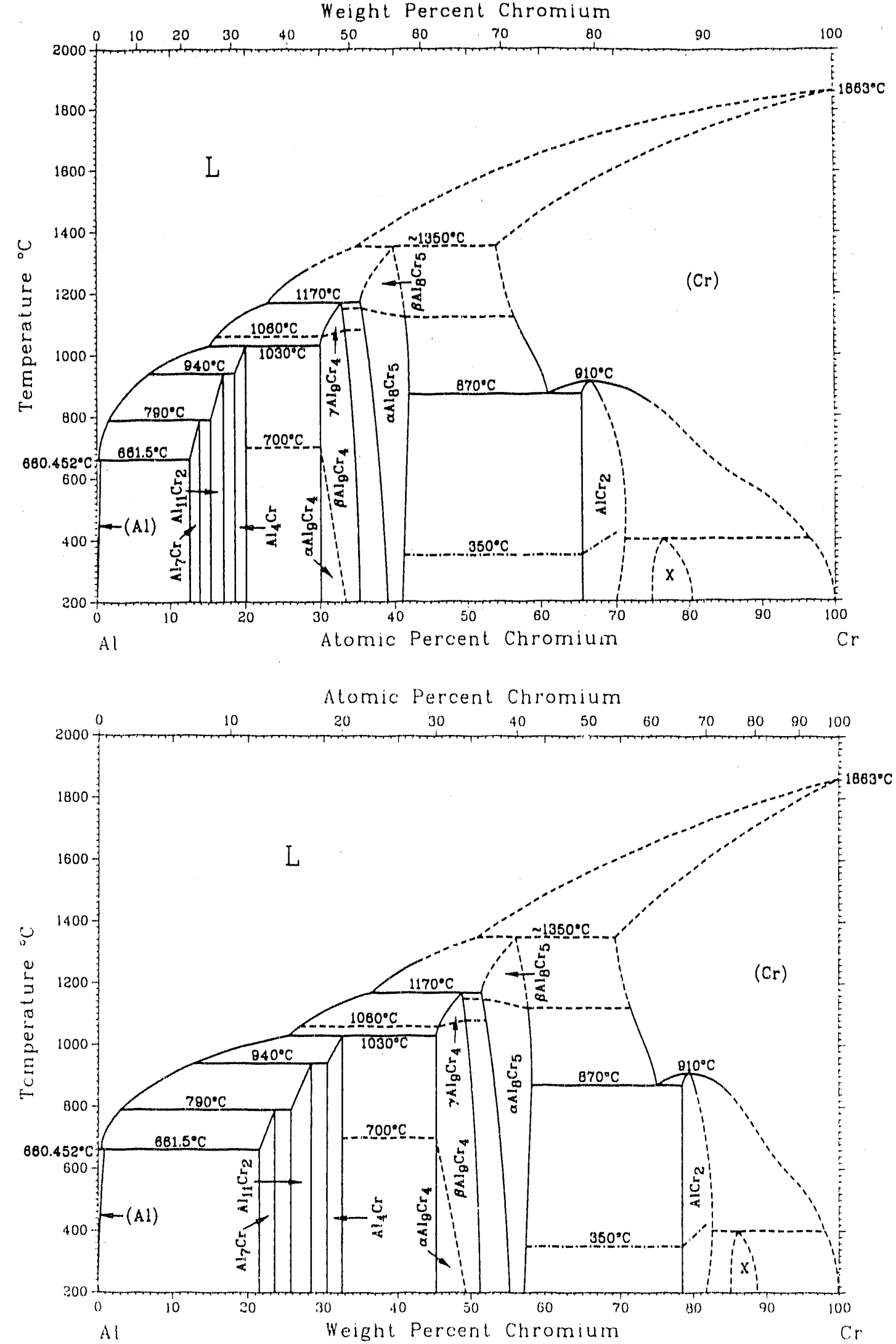

Figure 6-6 Al-Cr Phase Diagram (ASM 1996). 

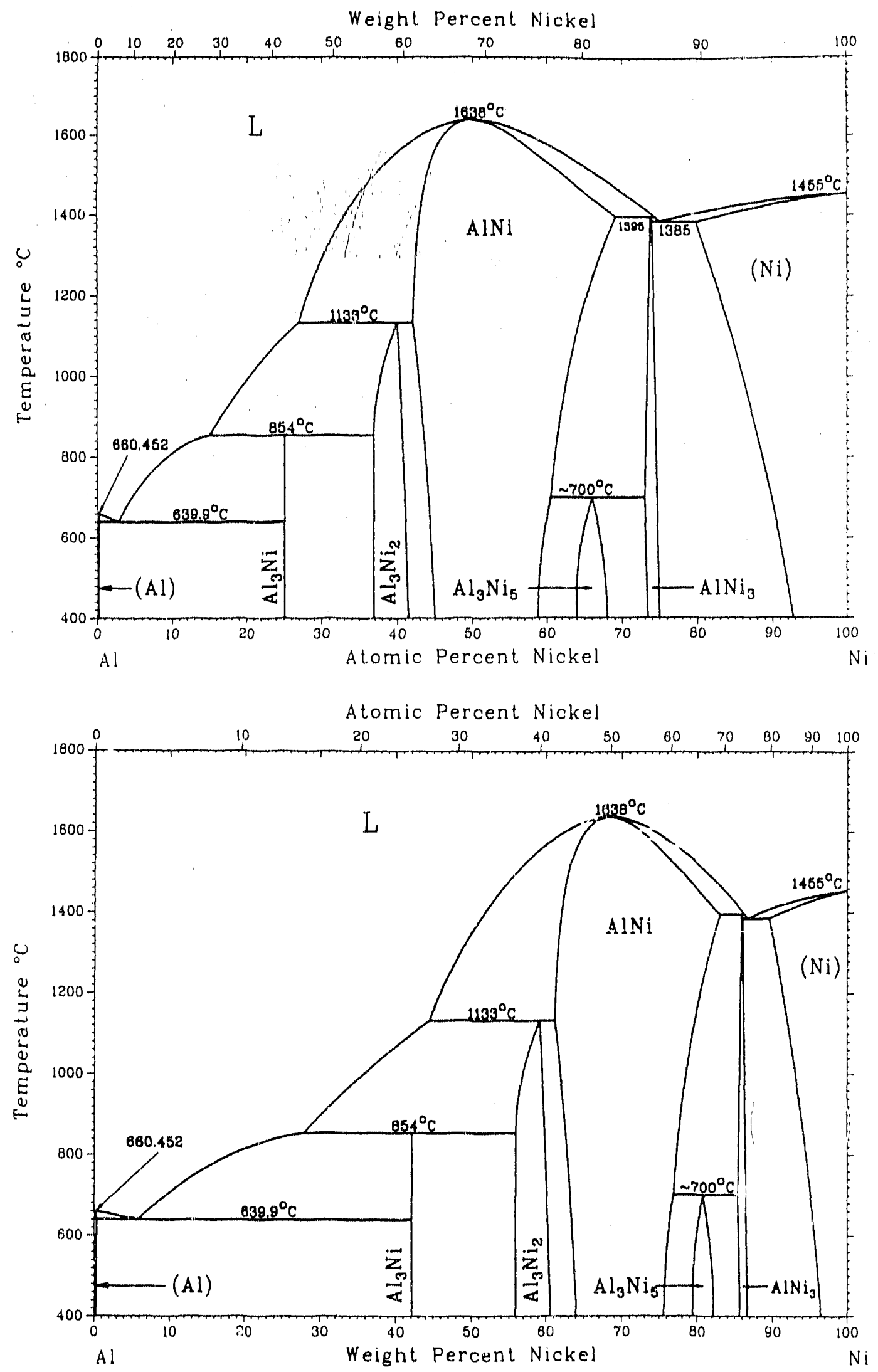

Figure 6-7 Al-Ni Phase Diagram (ASM 1990). 


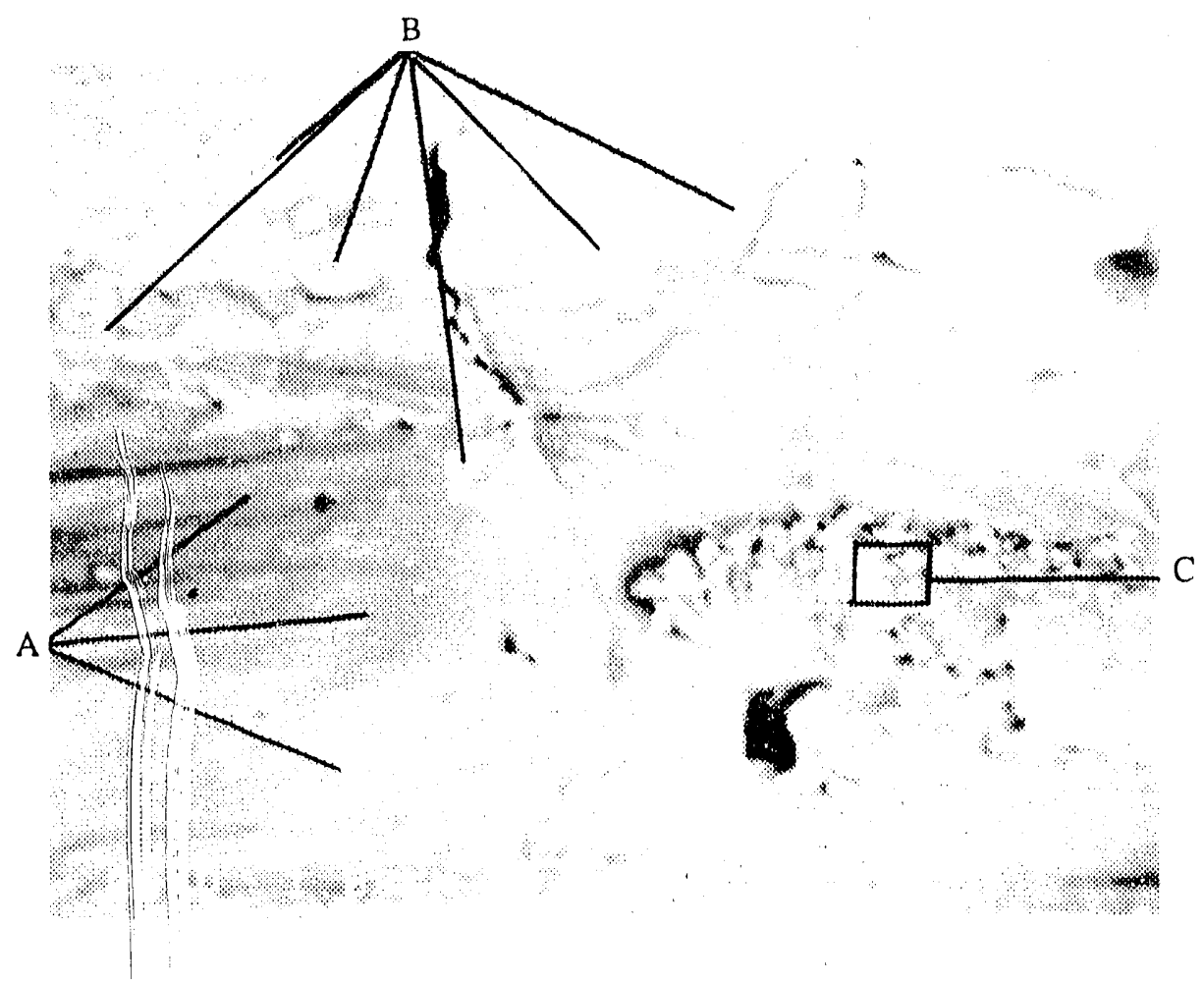

Figure 6-8: EM Micrograph of Al/SS304/Cd DTA Specimen (SE, 1000x).

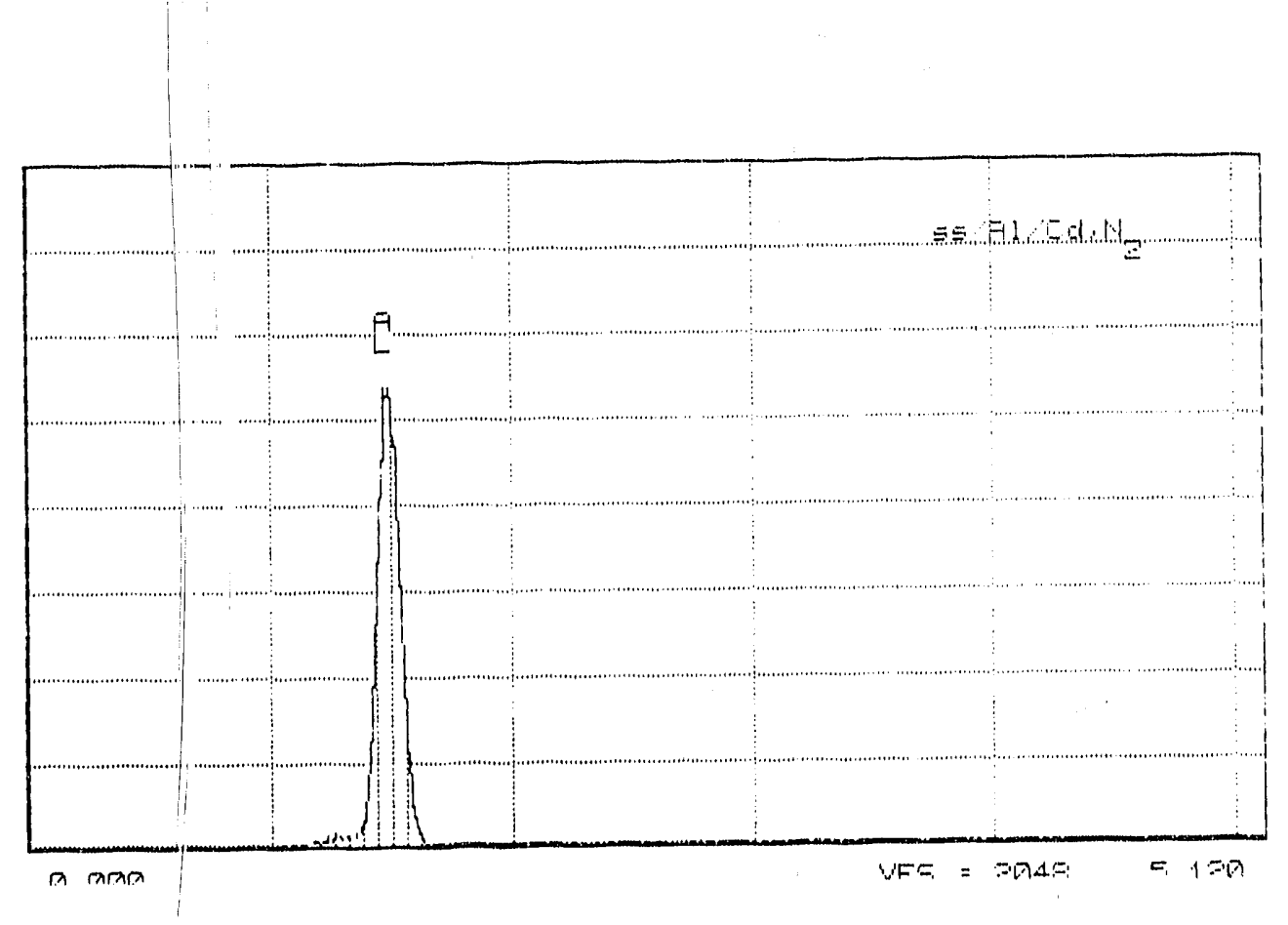

Figure 6-8b Al/SS304/Cd DTA Spec., EDS Spectrum for Spot "A" on Figure 6-8a. 


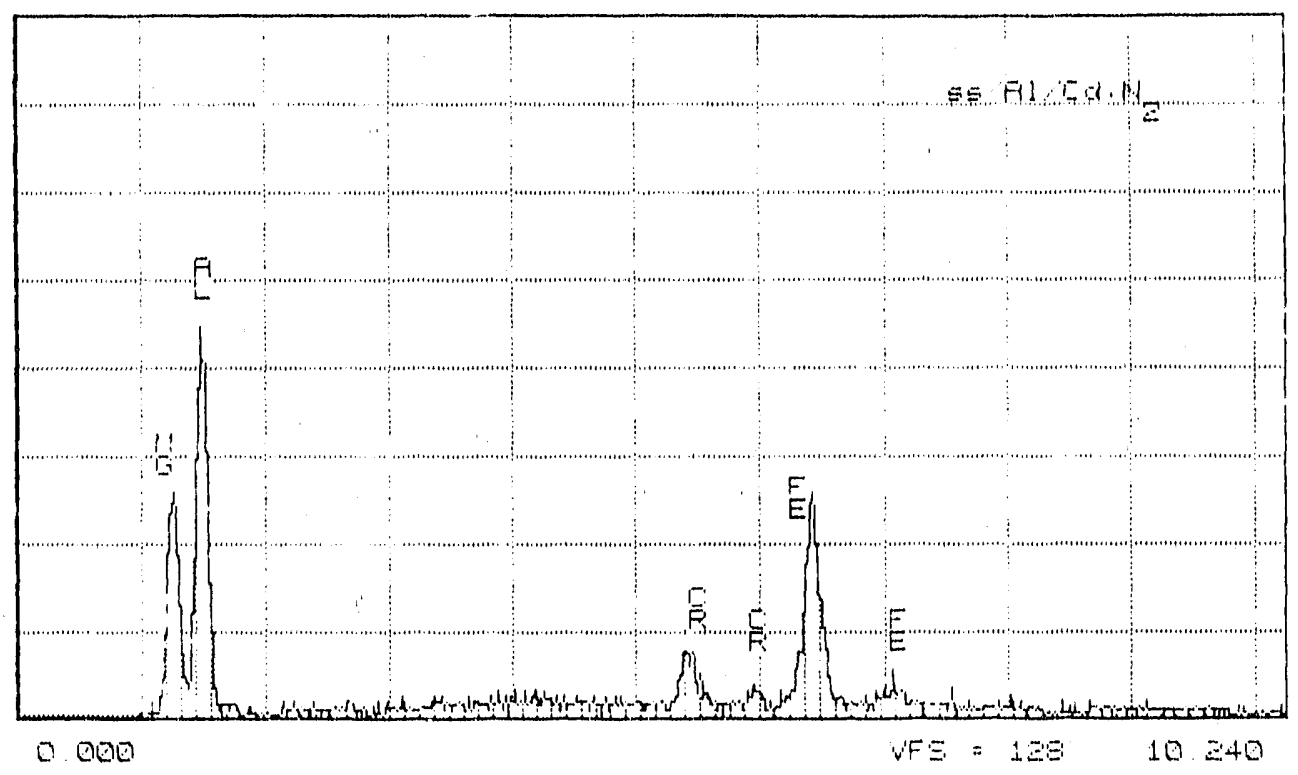

Figure 6-8c Al/SS304/Cd DTA Spec., EDS Spectrum for Spot "B" on Figure 6-8a.

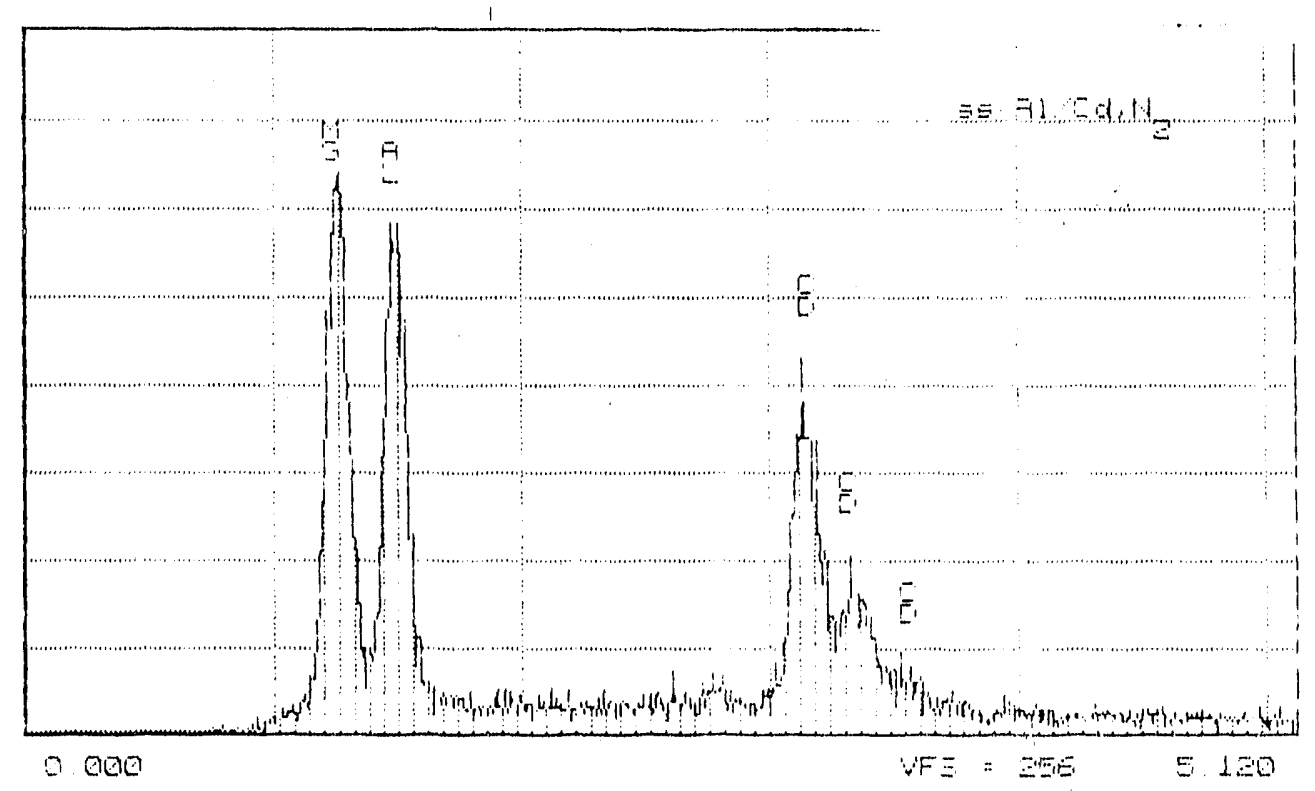

Figure 6-8d Al/SS304/Cd DTA Spec., EDS Spectrum for Spot "C" on Figure 6-8a. 


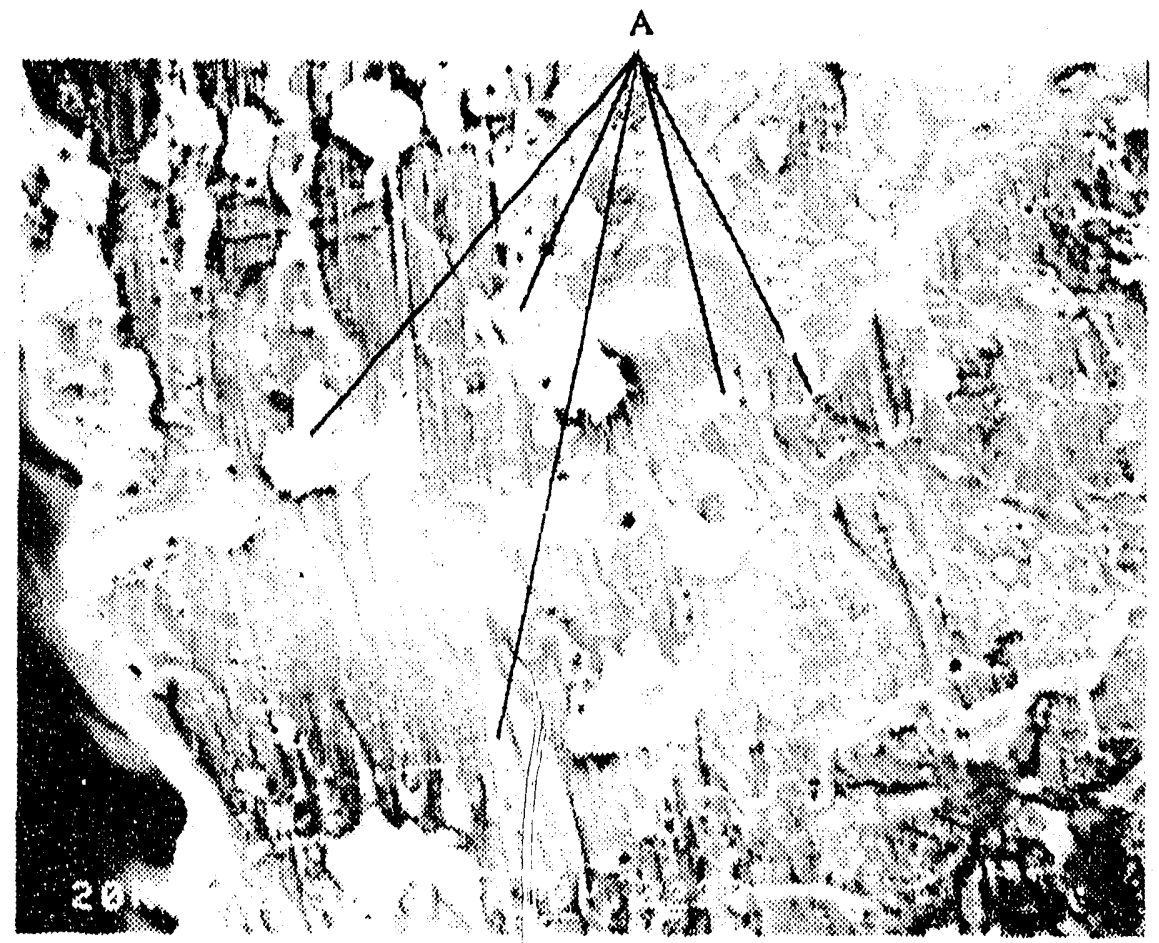

Figure 6-9a SEM Micrograph o Al/Cd DTA Specimen (SE, 500x).

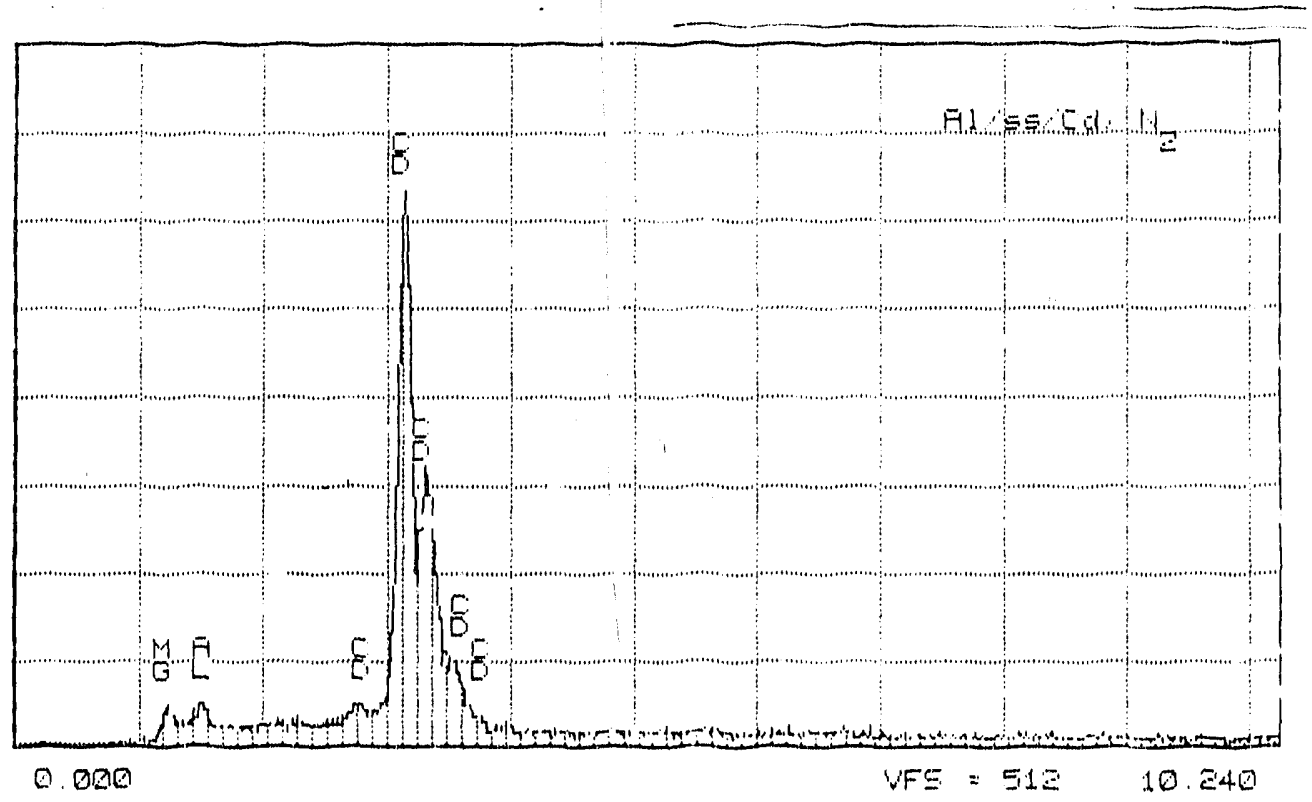

Figure 6-9b Al/Cd DTA Spec., EDS Spectrum for Spot "A" on Figure 6-9a. 


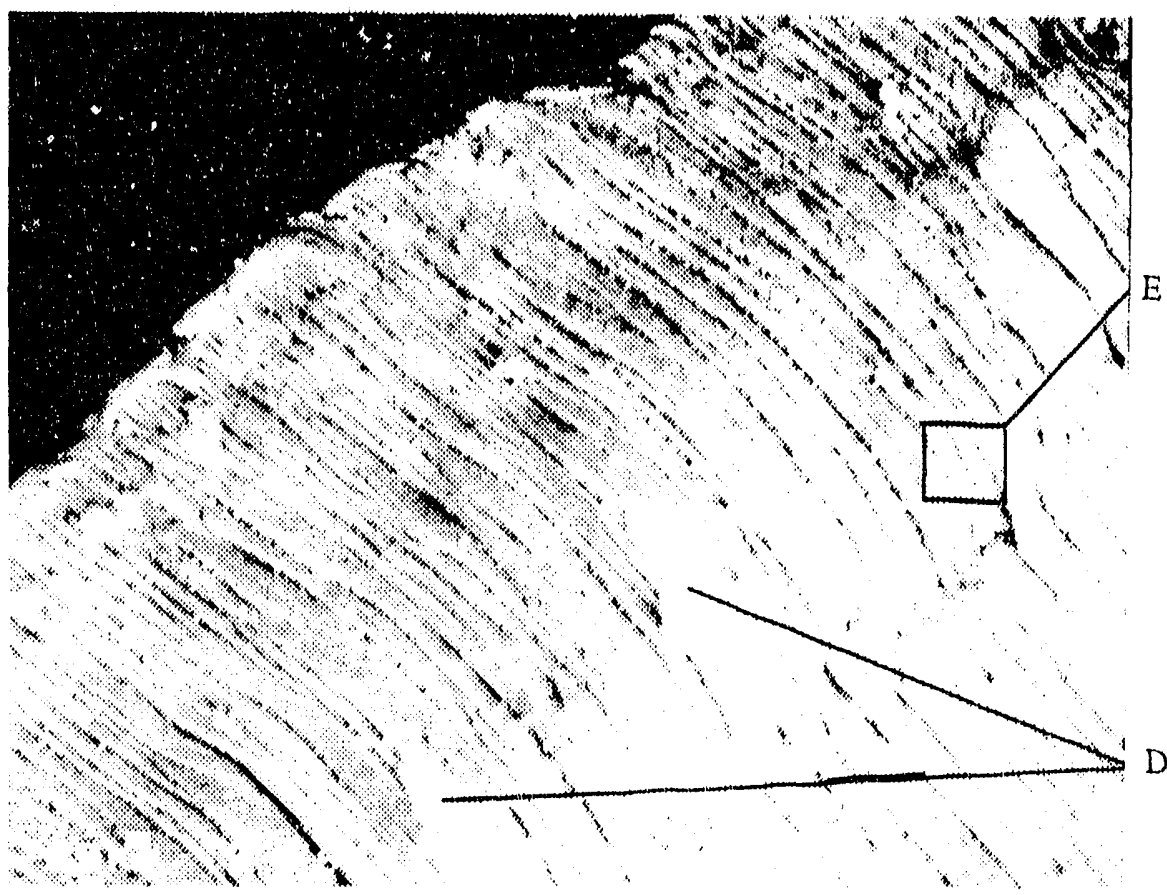

Figure 6-10a SEM Micrograph of SS304/Cd DTA Specimen (BSE, 760x).

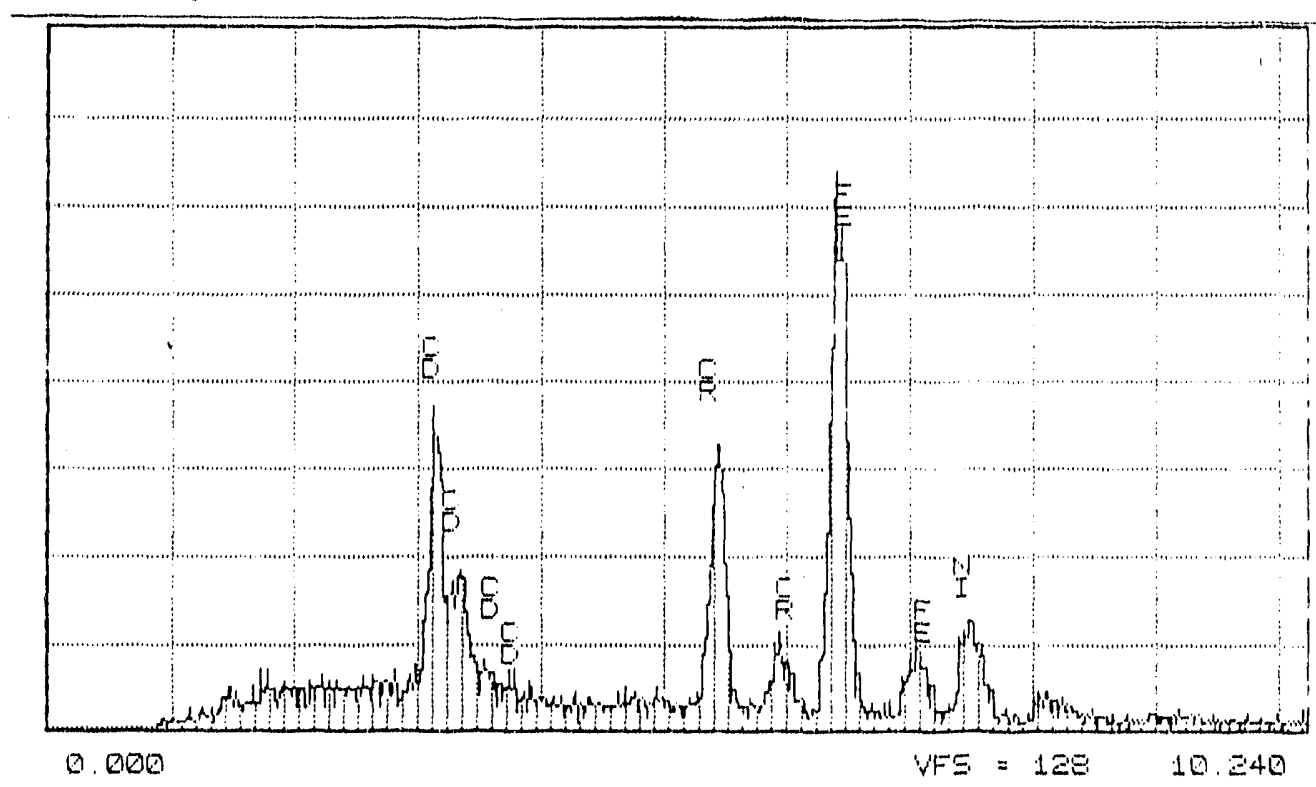

Figure 6-10b SS304/Cd DTA Spec., EDS Spectrum for Spot "D" on Figure 6-10a. 


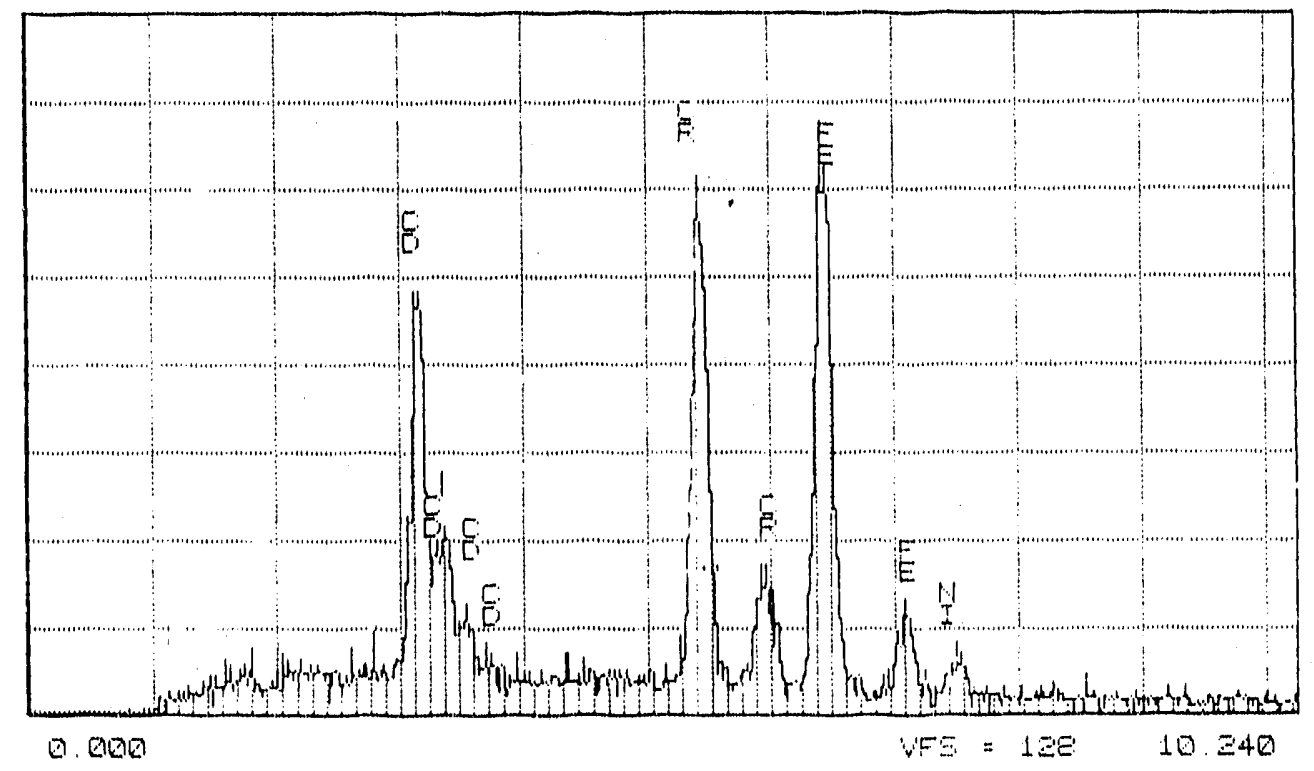

Figure 6-10c SS304/Cd DTA Spec., EDS Spectrum for Spot "E" on Figure 6-10a. 


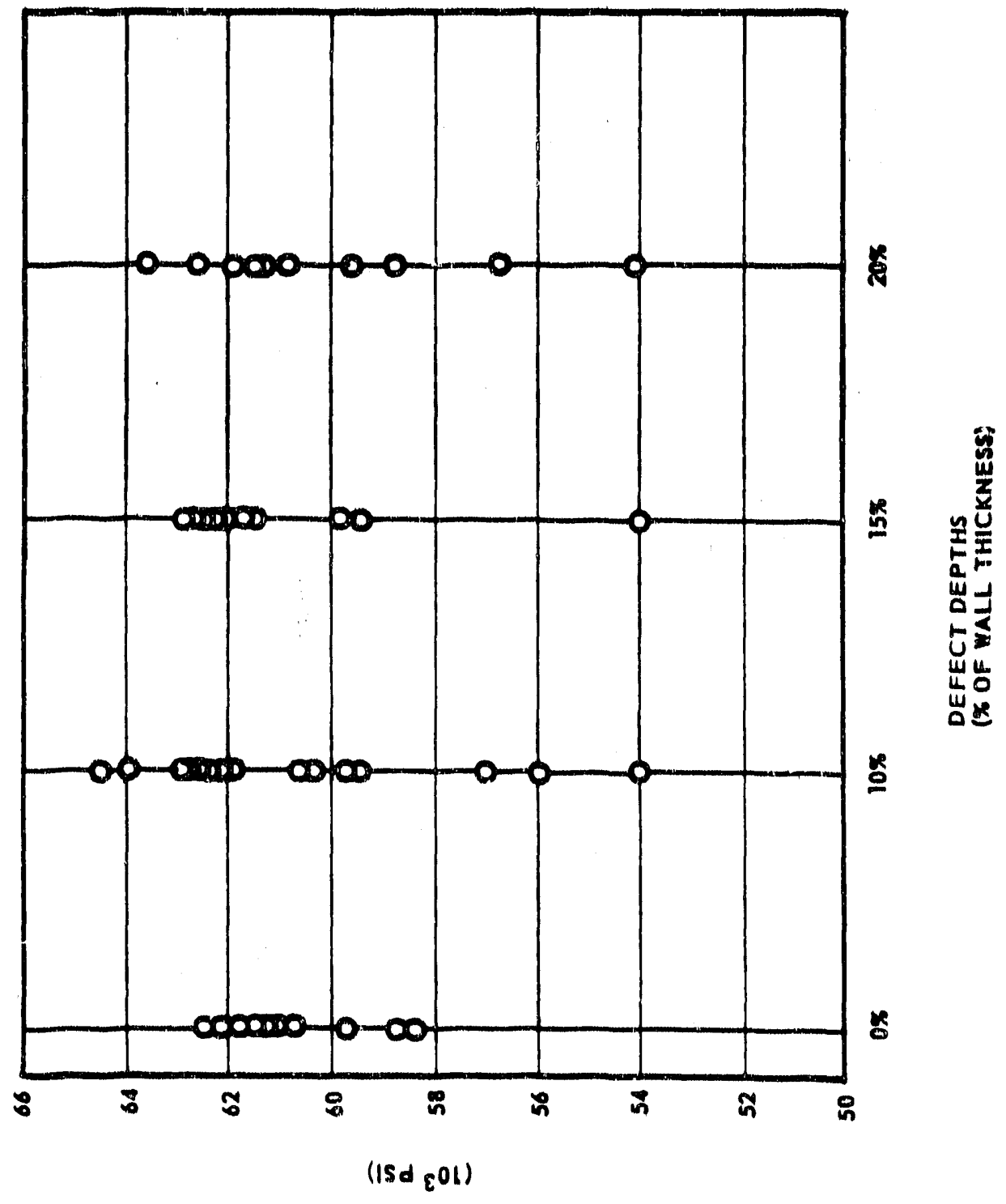

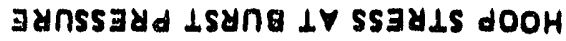

Figure 6-11a Defected SS304 Tube Burst Strength at $677-732^{\circ} \mathrm{C}$ (Kirby 1962). 


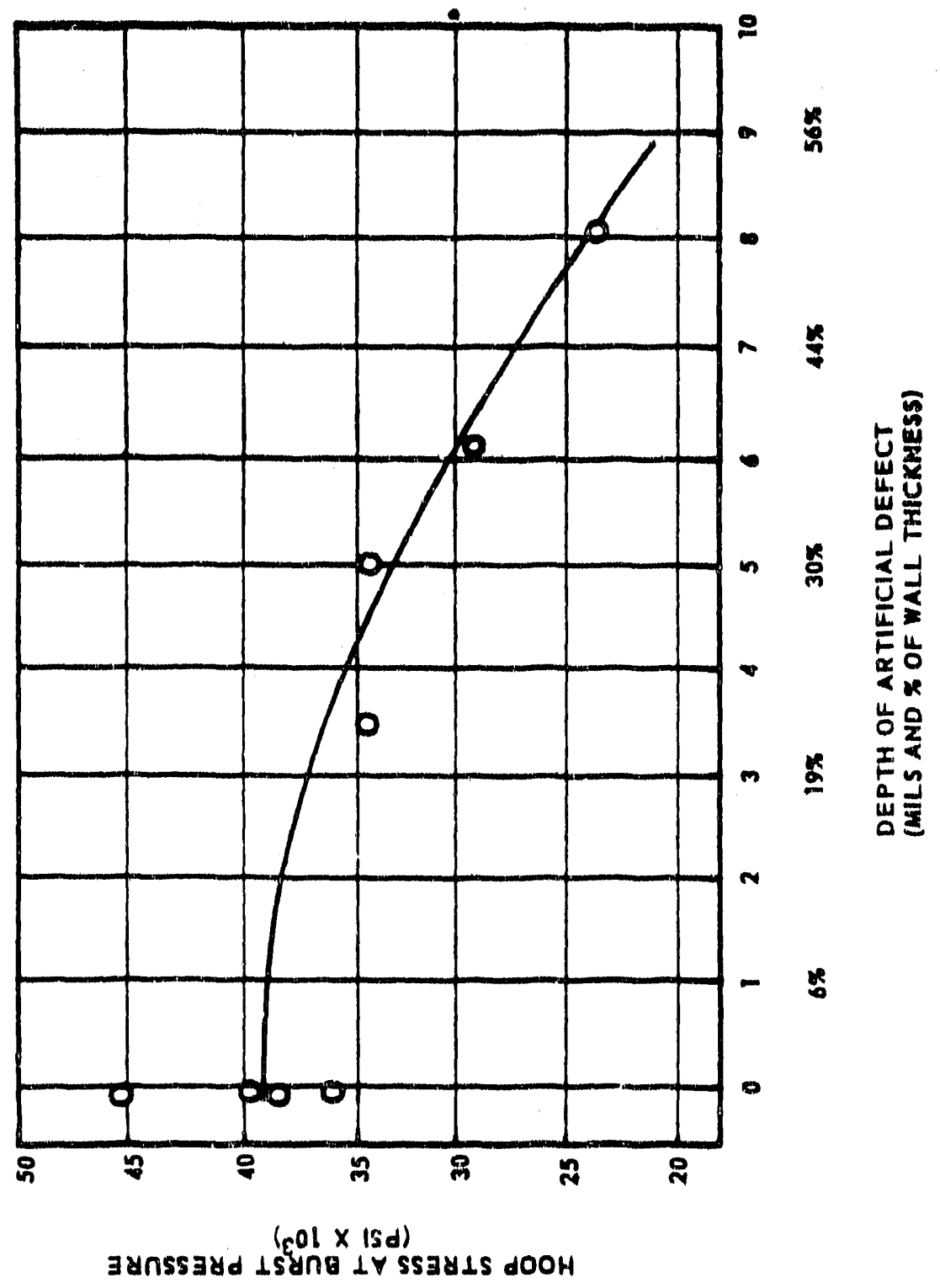

Figure 6-11b Defected SS304 Tube Burst Strength at $677^{\circ} \mathrm{C}$ (Kirby 1962). 


\section{7}

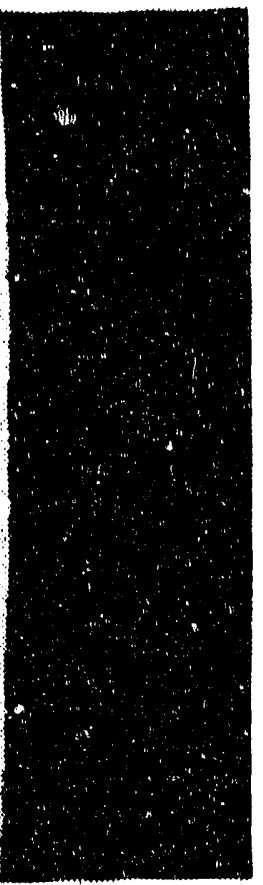

Figure 6-12a Optical Micrograph of U-Bend Specimen No. $5(100 \mathrm{x})$.
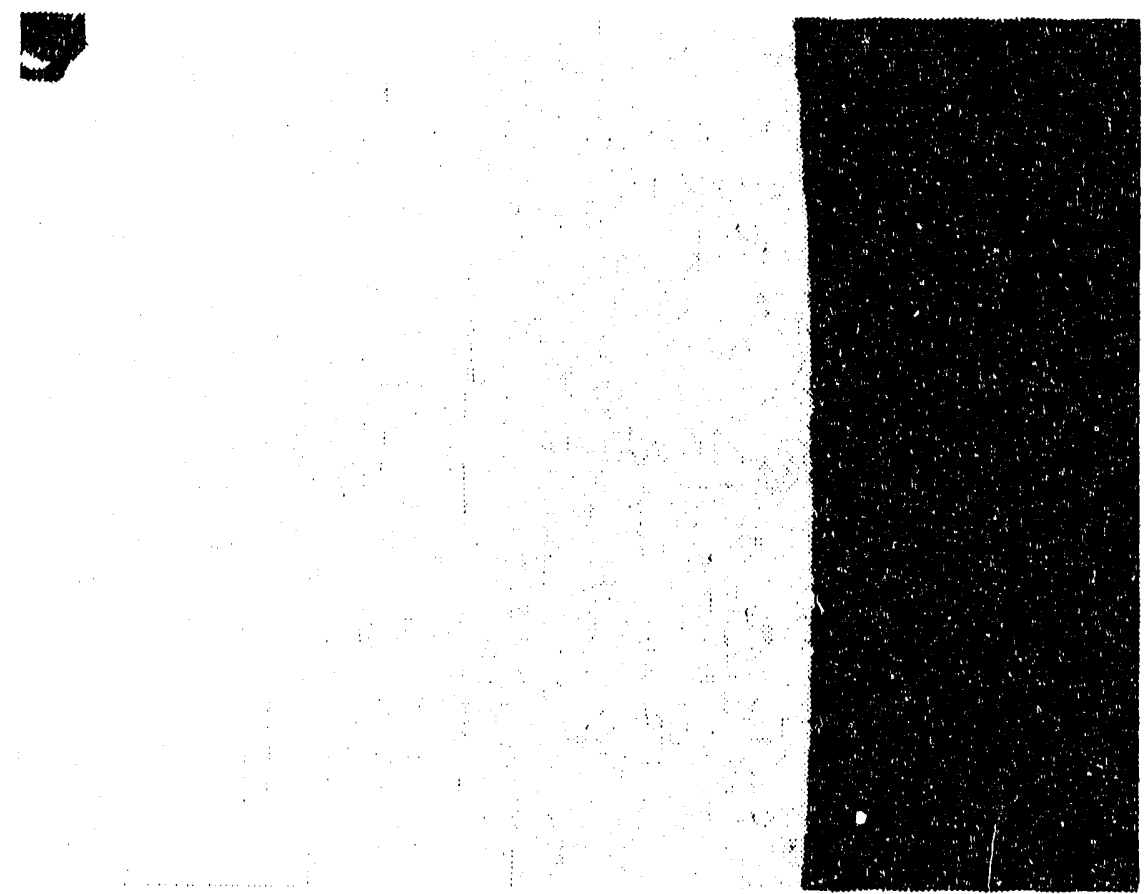

Figure 6-12b Optical Micrograph of U-Bend Specimen No. 6 (100x). 


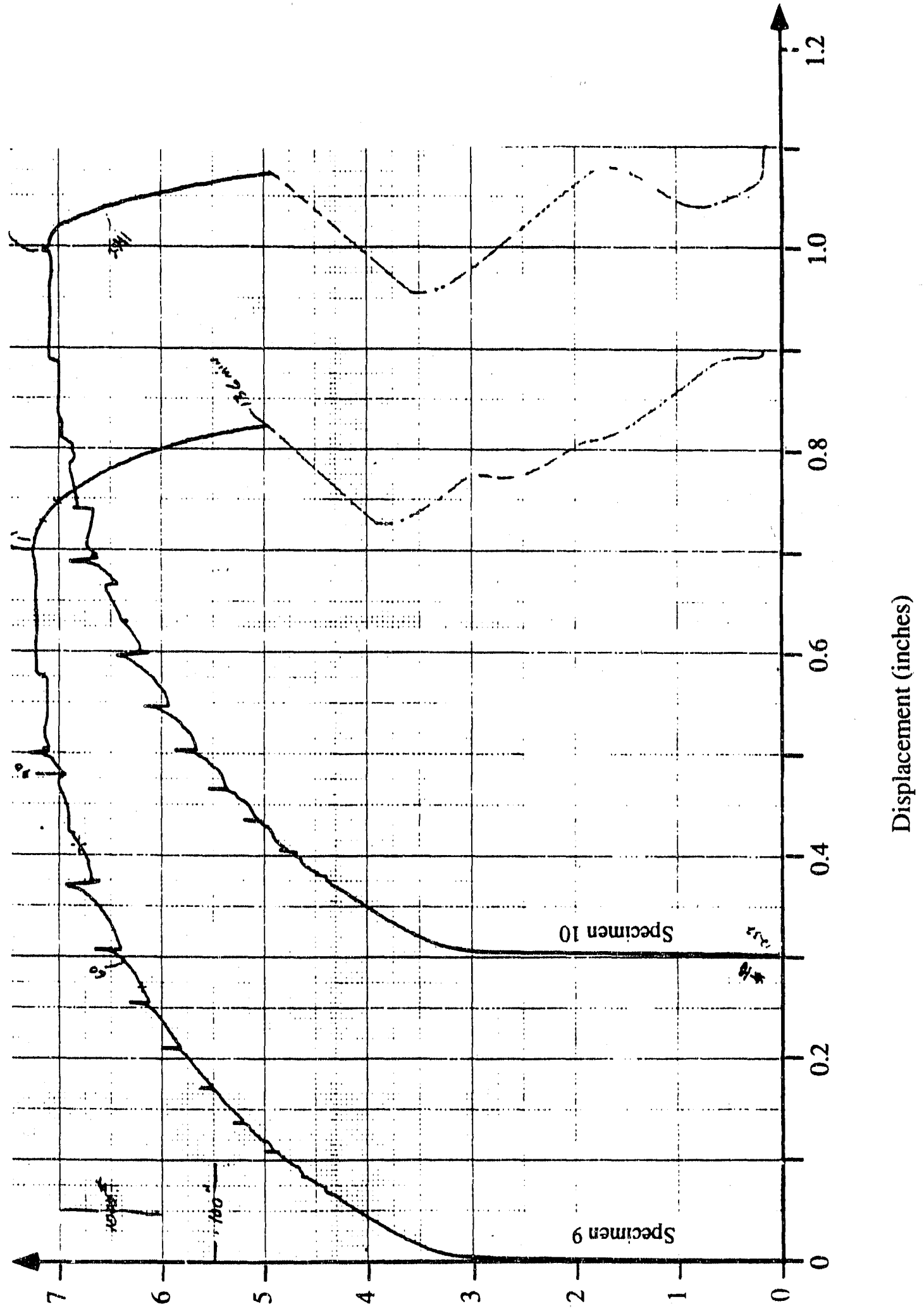

(sdp̣) proT

Figure 7-1a Load Displacement Curve for SS304 Tensile Test at $500^{\circ} \mathrm{C}$ and $3 \times 10^{-3} \mathrm{~min}^{-1}$. 


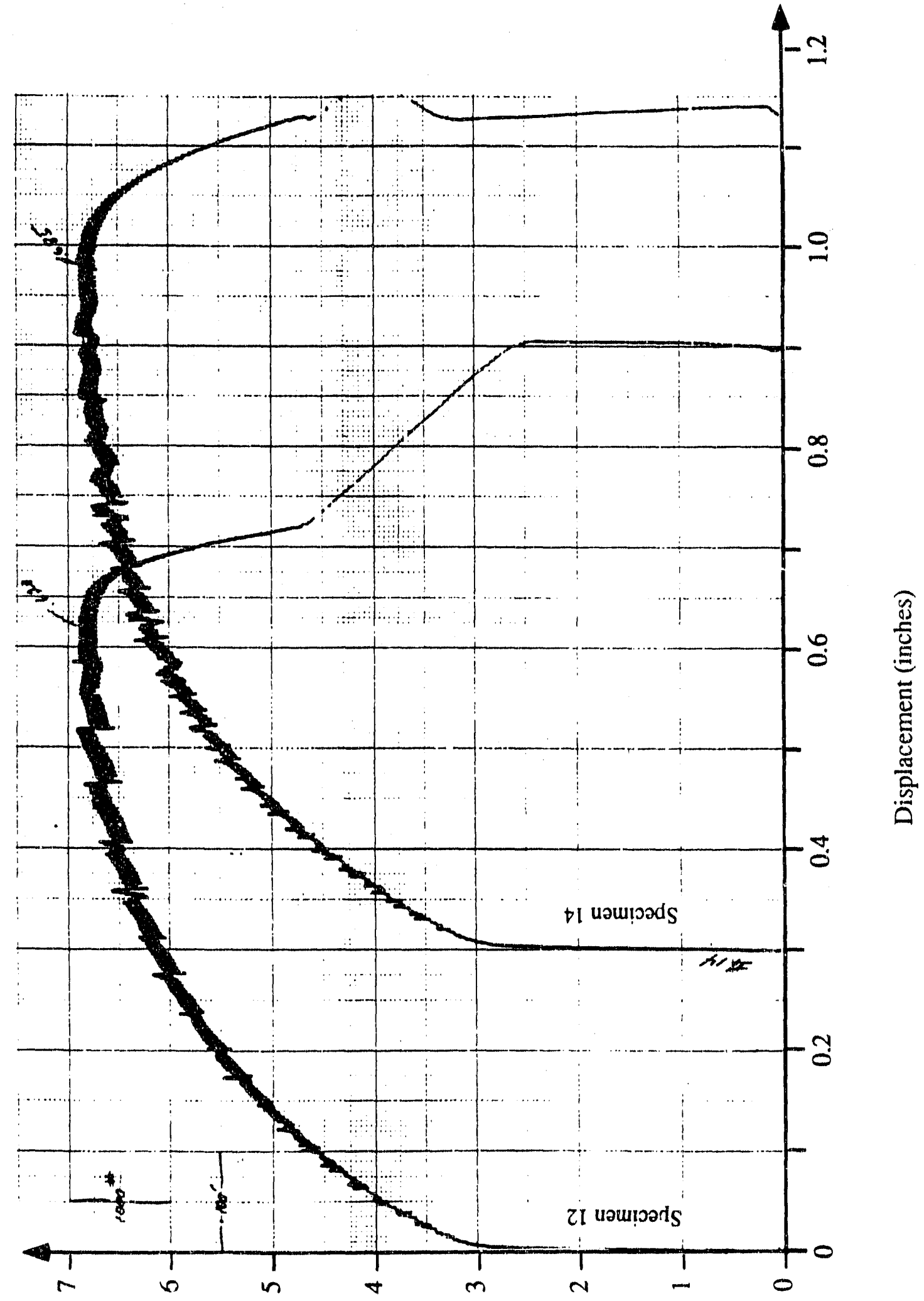

(sdp̣) prot

Figure 7-1b Load Displacement Curve for SS304 Tensile Test at $550^{\circ} \mathrm{C}$ and $3 \times 10^{-3} \mathrm{~min}^{-1}$. 


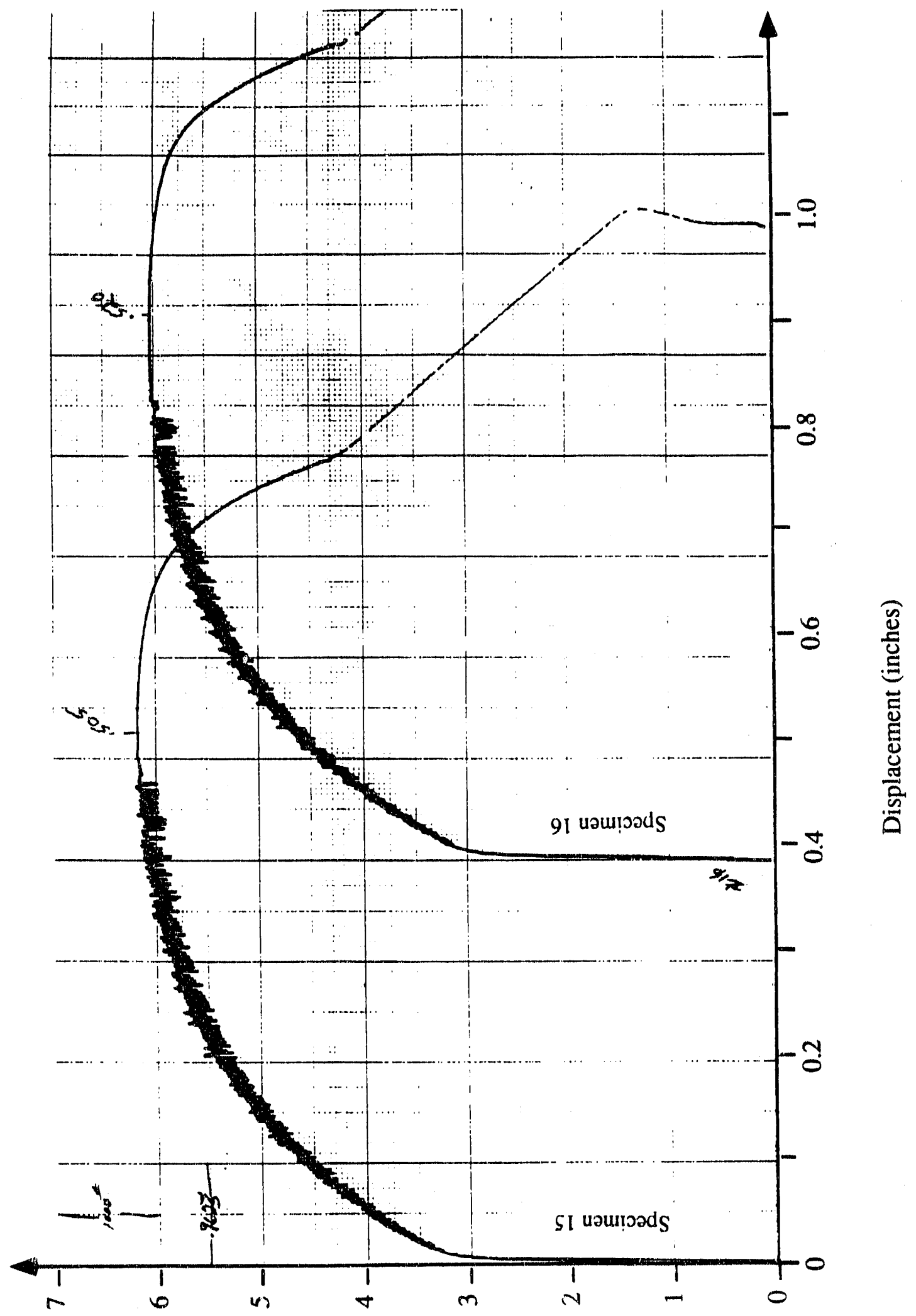

(sdr্) prof

Figure 7-1c Load Displacement Curve for SS304 Tensile Test at $600^{\circ} \mathrm{C}$ and $3 \times 10^{-3} \mathrm{~min}^{-1}$. 

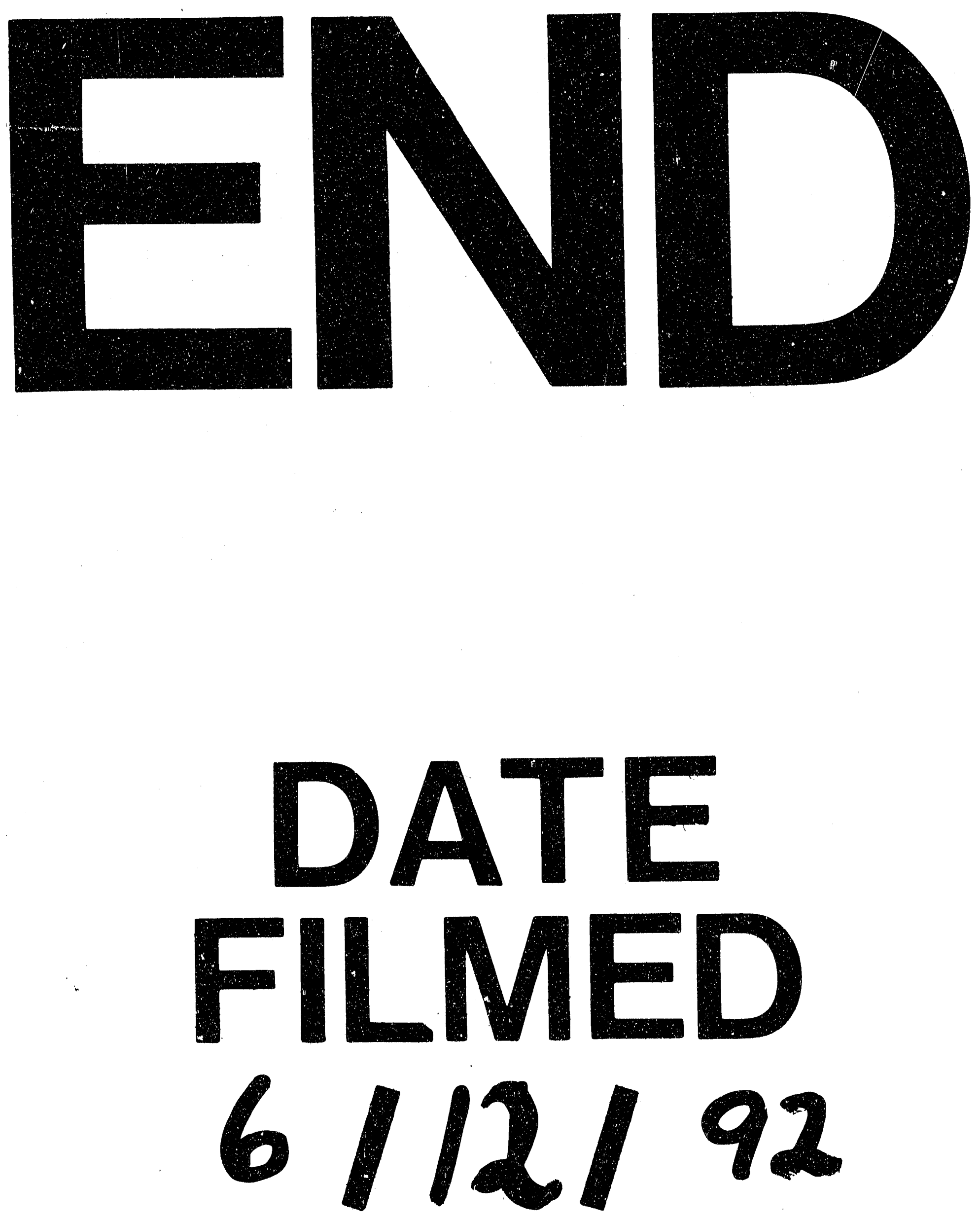

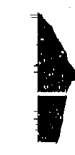


